\title{
Bioreducible Polycationic
}

Gene Vectors

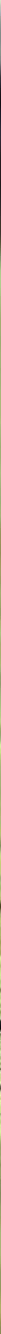




\section{BIOREDUCIBLE POLYCATIONIC GENE VECTORS}

Guoying Si 
Committee

Chairman:

Secretary:

Promotor:

Assistant Promotor:

Members:
Prof. Dr. Ir. J.W.M. Hilgenkamp

Prof. Dr. Ir. J.W.M. Hilgenkamp

Prof. Dr. J.F.J. Engbersen

Dr. J.M.J. Paulusse

Prof. Dr. H.B.J. Karperien

Prof. Dr. Ir. W.E. Hennink

Dr. S. Manohar

Prof. Dr. G. Storm

Prof. Dr. K. Braeckmans

Dr. N. Akeroyd
University of Twente

University of Twente

University of Twente

University of Twente

University of Twente

University of Utrecht

University of Twente

University of Utrecht

University of Ghent

20Med Therapeutics BV

The work presented in this thesis was carried out in the group of Controlled Drug Delivery in the MIRA institute for biomedical engineering and technology medicine in the University of Twente between 2011 and 2015. The research was financially supported by part of NanoNextNL, a micro and nanotechnology innovation consortium of the Government of the Netherlands and 130 partners from academia and industry.

\section{UNIVERSITY OF TWENTE.}

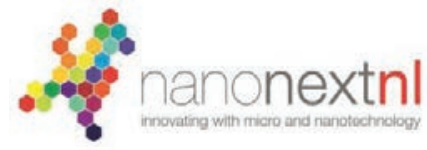

The printing of this thesis was sponsored by the Dutch Society for Biomaterials and Tissue Engineering (NBTE).

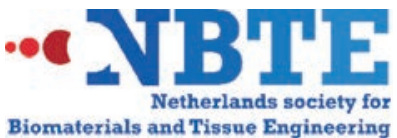

Bioreducible Polycationic Gene Vectors

Guoying Si

$\mathrm{PhD}$ Thesis with references; with summary in English and Dutch

University of Twente, Enschede, the Netherlands, January 2016

Copyright (C) by Guoying Si, 2016. All rights reserved.

Printed by Ipskamp Drukkers B.V., Enschede, the Netherlands

ISBN: 978-90-365-4040-7

DOI: $10.3990 / 1.9789036540407$ 


\section{BIOREDUCIBLE POLYCATIONIC GENE}

\section{VECTORS}

\section{DISSERTATION}

to obtain

the degree of doctor at the University of Twente, on the authority of the rector magnificus, Prof. Dr. H. Brinksma,

on account of the decision of the graduation committee,

to be publicly defended

on Wednesday, January $20^{\text {th }}, 2016$ at $14: 45$

by

\section{Guoying Si}

born on June $28^{\text {th }}, 1986$

in Yancheng, P.R. China 
This dissertation has been approved by:

Promotor:

Prof. Dr. J.F.J. Engbersen

Co-promotor:

Dr. J.M.J. Paulusse 
70 my parents.

my family, and my lover

献给我的父母，

我的家人和我的挚爱 



\section{Table of Contents}

Chapter 1. General Introduction 1

Chapter 2. Bioreducible Polymeric Gene Delivery Systems. 7

Chapter 3. Thiourea Functionalization Enhances Transfection of Bioreducible Poly(amido amine)s as Gene Vectors under Serum Conditions 55

Chapter 4. Effects of Incorporation of Fluoroalkyl Groups in Bioreducible Poly(amido amine)s on Gene Delivery 81

Chapter 5. Poly(amido amine)s/DNA Polyplexes with Incorporated Gold Nanorods as Vectors for Imaging and Gene Delivery 101

Chapter 6. Novel Poly(amino ether)s with Various Disulfide Content as Gene Vectors 125

Chapter 7. Efficient Gene Vectors Based on Bioreducible Poly(amino ether)s with Various Side Groups 145

Chapter 8. Modular Synthesis of Bioreducible Gene Vectors through Polyaddition of $N, N$ '-Dimethylcystamine to Various Diglycidyl Ethers 169

Summary. 191

Samenvatting 195

Acknowledgements 199

Curriculum Vitae .203 

Chapter 1. General Introduction 


\section{BACKGROUND}

Gene delivery is emerging as a promising modality in nanomedicine and precision medicine, and eventually will improve the health and wellbeing of humans. ${ }^{1-5}$ The biologically active genes are exogenous nucleic acids like DNA, messenger RNA (mRNA), small interfering RNA (siRNA), microRNA (miRNA) as well as antisense oligonucleotides. These nucleic acids are relatively large in molecular size, have negative surface charge, and are labile to various enzymes, which necessitates the use of gene vectors to overcome the many hurdles that externally administered genes undergo on their way to the interior of targeting cells. ${ }^{6}$ Viral vectors can be used for this purpose, but despite being efficient in transfection, viral vectors are plagued with various problems related to safety and manufacturing, which renders non-viral vectors as appealing alternatives. ${ }^{3,7}$ Among non-viral vectors, in particular cationic polymers have attracted attention owing to beneficiary features such as synthetic versatility, modification flexibility, absence of immunogenicity, and high loading capacity. ${ }^{8-}$

${ }^{10}$ However, compared to viral vectors, their transfection efficiencies are relatively low, making it appealing to pay efforts in the design and development of novel polymers with both high transfection efficiency and minimal cytotoxicity. ${ }^{4}$

As peptidomimetic polymers, poly(amido amine)s (PAAs) have been intensively studied as non-viral gene vectors, owing to their facile preparation, ease of functionalization, low cytotoxicity, and good water solubility. ${ }^{11,12}$ Protonation of part of the tertiary amino groups in the polymer chain turns these polymers to polycations which readily form complexes (polyplexes) with negatively charged nucleic acids. Repetitive disulfide bonds were successfully incorporated in the PAA main chains to take advantage of the reductive intracellular environment which cleaves the disulfide bonds and releases genetic materials in an active manner. Disulfide-linked PAAs, denoted as bioreducible PAAs, possess high buffer capacity, which facilitates endosomal escape of polyplexes of these PAAs, leading to functional activity of the delivered genes in the cells. ${ }^{13}$ These PAAs have been successfully employed as gene vectors for delivery of DNA, ${ }^{14}$ siRNA, $^{15}$ and proteins ${ }^{16,17}$ in different formulations with outstanding efficiency and excellent cell viability. However, the application of these bioreducible PAAs in vivo is mired by the disturbance of serum on the their polyplex stability. The attachment of hydrophilic poly(ethylene glycol) (PEGylation) to the polymers to form a hydrophilic shell around the polyplexes somehow mitigates the problem, however this approach also results in low cellular uptake and insufficient endosomal escape, both leading to lowered transfection performance. ${ }^{18}$ Thus, it is of great 
interest to improve transfection efficiency of bioreducible PAAs in the presence of serum through other approaches rather than PEGylation. In general, it is of great interest to develop novel bioreducible cationic polymers as gene vectors with efficient transfection and minimal toxicity.

Although the advent and development of nanotechnology have yielded our society with numerous benefits it also has brought some concomitant risks. ${ }^{19,20}$ Therefore as part of this PHD thesis program in the framework of NanoNextNL, all the toxicity assays in this thesis are dedicated to a risk analysis and technology assessment (RATA) analysis.

\section{AIM OF THE STUDY}

The purpose of the study involved in this thesis is dedicated to: (i) improving transfection efficiency of disulfide-linked poly(amido amine)s (SS-PAAs) in the presence of serum through physical and chemical approaches; (ii) developing a novel class of linear bioreducible poly(amino ether)s as efficient polycationic vectors with minimal toxicities and less susceptibility to serum; and (iii) evaluating the in vitro cell viability of polyplexes made of above polymers with DNA in relation to a RATA analysis of novel cationic polymeric vectors.

\section{OUTLINE OF THE THESIS}

The thesis focuses on the optimization and development of bioreducible cationic polymers as efficient and non-toxic gene vectors, as well as performing RATA analysis on the developed polymeric vectors. The outline of the thesis is as follows:

Chapter 2 deals with an overview of current bioreducible polymeric gene delivery systems. Chapter 3 presents thiourea-functionalized SS-PAAs that form stabilized polyplexes through hydrogen bonding between the SS-PAA thiourea groups and the phosphate ester groups of DNA. These polyplexes show improved transfection efficiency under serum-free and serum-present conditions.

Chapter 4 describes the introduction of fluoroalkyl groups onto SS-PAAs by the anhydrideamine reaction. Polyplexes of the fluorinated PAAs are stabilized by increased hydrophobic interactions and exhibited significant higher transfection activity under serum conditions, as compared to their non-fluorinated analogs.

Chapter 5 introduces hybrid polyplexes comprising of SS-PAAs, gold nanorods, and plasmid DNA as a novel type of gene vectors with increased colloidal stability due to gold- 
sulfur interactions. Gold nanorods were first coated with SS-PAAs and subsequently mixed with DNA to form polyplexes with slightly higher positive surface charge compared to normal polyplexes without gold nanorods. Hybrid polyplexes showed higher transfection activity under serum conditions, compared to normal polyplexes.

Chapter 6 introduces a novel class of cationic polymeric gene vectors, the poly(amino ether)s (PAEs) with various amounts of disulfide linkages in the main chain. The PAEs were synthesized by the polyaddition of 4-amino-1-butanol with various ratios of disulfidecontaining and disulfide-free diglycidyl ether. PAEs with higher disulfide content gave higher transfection activity, indicating the favorable effect of the presence of the disulfides in the PAEs-based gene delivery system.

Chapter 7 continues Chapter 6 with the preparation of a series of disulfide-containing PAEs (SS-PAEs) with different side chains by polyaddition of various primary amines to a disulfide-containing diglycidyl ether, and the evaluation of the effect of structural variations on the transfection activity mediated by these SS-PAEs.

Chapter $\mathbf{8}$ describes a promising modular synthesis of SS-PAEs via polyaddition reaction of disulfide-containing bi(secondary)amine with various diglycidyl ethers. The SS-PAEs induce remarkable transfection without cytotoxicity in COS-7 cells, both in serum-free and serum-containing medium, underlining the promising potential of these SS-PAEs vectors for in vivo gene delivery. 


\section{REFERENCES}

(1) Kim, B. Y. S.; Rutka, J. T.; Chan, W. C. W. Nanomedicine. New Engl.J. Med. 2010, $363,2434-2443$.

(2) Collins, F. S.; Varmus, H. A New Initiative on Precision Medicine. New Engl. J. Med. 2015, 372, 793-795.

(3) Yin, H.; Kanasty, R. L.; Eltoukhy, A. A.; Vegas, A. J.; Dorkin, J. R.; Anderson, D. G. Non-viral vectors for gene-based therapy. Nat. Rev. Genet. 2014, 15, 541-555.

(4) Lachelt, U.; Wagner, E. Nucleic Acid Therapeutics Using Polyplexes: A Journey of 50 Years (and Beyond). Chem. Rev. 2015, 115, 11043-11078.

(5) Juliano, R. Nanomedicine: is the wave cresting? Nat. Rev. Drug Discov. 2013, 12, 171-172.

(6) Jones, C. H.; Chen, C. K.; Ravikrishnan, A.; Rane, S.; Pfeifer, B. A. Overcoming Nonviral Gene Delivery Barriers: Perspective and Future. Mol. Pharmaceutics 2013, 10, 4082-4098.

(7) Kay, M. A. State-of-the-art gene-based therapies: the road ahead. Nat. Rev. Genet. 2011, 12, 316-328.

(8) Pack, D. W.; Hoffman, A. S.; Pun, S.; Stayton, P. S. Design and development of polymers for gene delivery. Nat. Rev. Drug Discov. 2005, 4, 581-593.

(9) Miyata, K.; Nishiyama, N.; Kataoka, K. Rational design of smart supramolecular assemblies for gene delivery: chemical challenges in the creation of artificial viruses. Chem. Soc. Rev. 2012, 41, 2562-2574.

(10) Mintzer, M. A.; Simanek, E. E. Nonviral Vectors for Gene Delivery. Chem. Rev. 2009, 109, 259-302.

(11) Lin, C.; Engbersen, J. F. J. The role of the disulfide group in disulfide-based polymeric gene carriers. Expert Opin. Drug Delivery 2009, 6, 421-439.

(12) Ferruti, P. Poly(amidoamine)s: Past, present, and perspectives. J. Polym. Sci., Part A: Polym. Chem. 2013, 51, 2319-2353.

(13) Lin, C.; Zhong, Z.; Lok, M. C.; Jiang, X.; Hennink, W. E.; Feijen, J.; Engbersen, J. F. J. Novel Bioreducible Poly(amido amine)s for Highly Efficient Gene Delivery. Bioconjugate Chem. 2007, 18, 138-145.

(14) Hujaya, S. D.; Marchioli, G.; Roelofs, K.; van Apeldoorn, A. A.; Moroni, L.; Karperien, M.; Paulusse, J. M.; Engbersen, J. F. Poly(amido amine)-based multilayered thin films on 2D and 3D supports for surface-mediated cell transfection. J. Controlled Release 2015, 205, 181-189. 
(15) van der Aa, L. J.; Vader, P.; Storm, G.; Schiffelers, R. M.; Engbersen, J. F. J. Optimization of poly(amido amine)s as vectors for siRNA delivery. J. Controlled Release 2011, 150, 177-186.

(16) Coué, G.; Engbersen, J. F. J. Functionalized linear poly(amidoamine)s are efficient vectors for intracellular protein delivery. J. Controlled Release 2011, 152, 90-98.

(17) Coué, G.; Engbersen, J. F. J. Bioreducible poly(amidoamine)s with charge-reversal properties for intracellular protein delivery. J. Controlled Release 2010, 148, e9-e11.

(18) Hatakeyama, H.; Akita, H.; Harashima, H. A multifunctional envelope type nano device (MEND) for gene delivery to tumours based on the EPR effect: A strategy for overcoming the PEG dilemma. Adv. Drug Deliv. Rev. 2011, 63, 152-160.

(19) Godwin, H.; Nameth, C.; Avery, D.; Bergeson, L. L.; Bernard, D.; Beryt, E.; Boyes, W.; Brown, S.; Clippinger, A. J.; Cohen, Y.; Doa, M.; Hendren, C. O.; Holden, P.; Houck, K.; Kane, A. B.; Klaessig, F.; Kodas, T.; Landsiedel, R.; Lynch, I.; Malloy, T.; Miller, M. B.; Muller, J.; Oberdorster, G.; Petersen, E. J.; Pleus, R. C.; Sayre, P.; Stone, V.; Sullivan, K. M.; Tentschert, J.; Wallis, P.; Nel, A. E. Nanomaterial Categorization for Assessing Risk Potential To Facilitate Regulatory DecisionMaking. ACS Nano 2015, 9, 3409-3417.

(20) Join the dialogue. Nat. Nanotechnol. 2012, 7, 545-545. 


\section{Chapter 2. Bioreducible Polymeric Gene Delivery Systems}

Guoying Si, Jos M.J. Paulusse* and Johan F.J. Engbersen*

Department of Controlled Drug Delivery, MIRA Institute for Biomedical Technology and Technical Medicine, Faculty of Science and Technology, University of Twente, P.O. Box 217, 7500 AE Enschede, The Netherlands

\section{KEYWORDS}

Bioreducible polymers; polycations; polydisulfide; drug delivery; nanomedicine; gene therapy.

This chapter has been in preparation for publication. 


\section{ABSTRACT}

Gene delivery concerns the introduction of exogenous genes into cells through either viralor non-viral gene vectors, and possesses tremendous potential in therapeutic applications. In comparison to their viral counterparts, non-viral vectors bring a number of important advantages, such as decreased cytotoxicity and immunogenicity, ease of preparation and good possibilities for modular functionalization. Among non-viral gene delivery vectors, polycationic materials are the most popular vectors, since they are able to associate genes into nanoscaled polyplexes through electrostatic interactions, and can escort genes to the cells, and eventually release genes into the cytoplasm to target the gene machinery. This however, requires conflicting colloidal stabilities of the polyplexes in the extracellular environment and the intracellular milieu (i.e. highly stable vs labile, respectively). To address this stability paradox, the high redox potential inside cells has been exploited by incorporation of bioreducible disulfide moieties. The polycationic vectors based on disulfide containing polycations are stable outside cells but are rapidly degraded by cleaving of the disulfides in the intracellular milieu. In this chapter, various approaches to introduce bioreducible disulfide groups in polycationic gene delivery carriers and the effect on polyplex properties, transfection efficiency, and cell toxicity will be discussed.

\section{INTRODUCTION}

Nanomedicine tackles human health issues through nanotechnology, and denotes a multidisciplinary field combining chemistry, physics, biology, medicine and engineering. ${ }^{1-}$ ${ }^{5}$ Within nanomedicine, gene delivery has attracted considerable attention owing to its therapeutic potential in treating numerous genetic and acquired diseases, among which cancers, ${ }^{6}$ cystic fibrosis, ${ }^{7}$ Parkinson's disease,${ }^{8}$ immunodeficiency, ${ }^{9}$ chronic granulomatous disorder, ${ }^{10}$ as well as deciphering biological events at a molecular level. ${ }^{11}$ The genes, also referred to as genetic materials, include DNA, ${ }^{12,13}$ messenger RNA (mRNA), ${ }^{14,15}$ small interfering RNA (siRNA), ${ }^{16-19}$ microRNA (miRNA) ${ }^{20,21}$ or antisense oligonucleotides. ${ }^{22,23}$ Efficacious gene delivery relies on efficient and safe vectors that are able to protect the gene from denaturation by a wide variety of enzymes, while facilitating cellular uptake and gene traffic inside the targeted cells. ${ }^{24,25}$ The vectors for delivering genes are categorized into two main types: viral vectors ${ }^{26,27}$ and non-viral vectors. ${ }^{25,28}$ Viral carriers, consisting of retroviruses, adenoviruses, and adeno-associated viruses, are imparted with gene to be delivered and typically display high efficiency in introducing genetic material into host cells. $^{29}$ However, they are plagued with insertional mutagenesis, ${ }^{30}$ immunogenic 
responses, ${ }^{31}$ and toxicity, ${ }^{32}$ all of which severely impede their widespread implementation in real applications. Non-viral carriers present an interesting alternative, ${ }^{33}$ in particular cationic polymers. ${ }^{34-36}$ Cationic polymers are characterized and can be designed by their ease of preparation and functionalization with minimal toxicity and immunogenicity. ${ }^{24}$ Cationic polymeric gene vectors form complexes with genes into so-called polyplexes through electrostatic interactions between the cationic sites in these polymers and the anionic phosphate groups present in genes. ${ }^{37-39}$

The advances in polymer chemistry ${ }^{40}$ and nanotechnology ${ }^{41,42}$ allow for accurate manipulation of polymeric architectures and hence have fueled important progress in nonviral gene delivery. ${ }^{43,44}$ However, cationic polymeric gene delivery systems still need to overcome numerous barriers before becoming a feasible approach in gene delivery. ${ }^{25,45}$ Those barriers include efficient cellular entry to target cells, ${ }^{46}$ endosomal escape, ${ }^{47}$ gene unpacking and subsequent internalization, ${ }^{48}$ and DNA transcription and translation. ${ }^{49}$ Ideally, polyplexes should have prolonged systemic circulation with excellent colloidal stability, avoid reticuloendothelial clearance, possess the ability to extravasate tissues and enter target cells, while circumventing lysosomal degradation, and releasing genes to the sites of interest resulting in gene expression. ${ }^{50}$ Polyplexes should have high stability outside the cells, but should rapidly destabilize to release the gene payload after cellular entry. ${ }^{24}$ These conflicting requirements between extracellular stability and intracellular stability have triggered exploiting the reductive potential across the cell membrane. ${ }^{51-60}$ In secreted proteins, matrix proteins, and cell surface proteins, the cysteine amino acids mainly exist in the intracellular compartments in their (cystine) disulfide form. ${ }^{61}$ Inside the cell, glutathione (GSH) and enzymes from the thioredoxin family collectively generate a reducing cytosol. ${ }^{62}$ Intracellular GSH concentrations are between $1-11 \mathrm{mM}$, which is approximately 100-1000 times higher than extracellular concentrations. ${ }^{59}$ Disulfide bonds are rapidly cleaved in the reducing cytoplasm, but remain intact outside the cell. Disulfide bonds have therefore been deliberately incorporated into polymeric gene vectors to resolve the aforementioned conflicting requirements in the stability of polyplexes. ${ }^{60}$ 


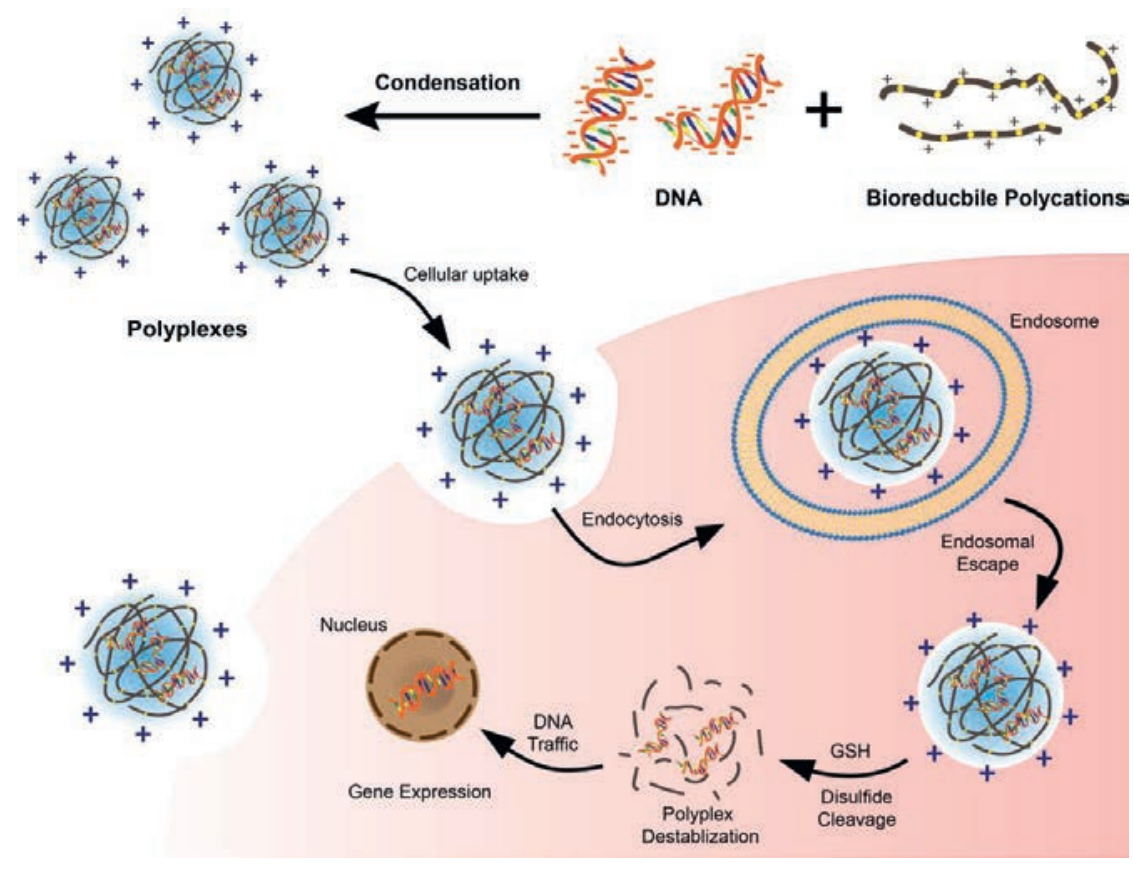

Figure 1. Schematic illustration of DNA delivery via bioreducible polycations as gene vector.

Disulfide-functional cationic polymeric vectors can associate nucleic acids through electrostatic interactions into nanoscaled polyplexes. Cationic polyplexes have affinity for the negatively charged cell membrane and facilitate nucleic acid entry into the cell via endocytosis. After endosomal escape the polyplexes arrive in the reducing environment of the cytosol and dissociate to release nucleic acid after intracellular cleavage of disulfide linkages, resulting in transcription of the gene (Figure 1). Intracellular cleavage of polymers containing disulfide bonds implies reduction of the disulfide bonds into thiol groups, and the vectors are therefore also named bioreducible polymeric vectors. ${ }^{59}$ In this chapter, an overview of bioreducible non-viral gene vectors is presented with a focus on synthetic gene vectors.

\section{POLYETHYLENEIMINE DERIVATIVES}

\section{Various approaches of incorporation disulfide bonds}

Polyethyleneimine (PEI, 1, Figure 2) is one of the most widely used transfection agents, because of a combination of excellent gene binding abilities and good endosomal buffering capacity. ${ }^{63-66}$ However, its full application potential is severely impeded by its intrinsic cytotoxicity. ${ }^{67-70}$ Disulfide bonds have been introduced into PEI to prepare bioreducible gene vectors with efficient transfection ability, but with mitigated cytotoxicity. Branched 
PEI (800 Da) was reacted with bifunctional disulfide-based crosslinkers (i.e. dithiobis(succinimidylpropionate) and dimethyl 3,3'-dithiobispropionimidate) resulting in polymeric vectors (2) which exhibited transfection abilities comparable to PEI (25 kDa) as evaluated in Chinese hamster ovary $(\mathrm{CHO})$ cells with substantially reduced toxicity. ${ }^{71}$ The comparable transfection activity and reduced toxicity is theorized as the polyplexes disassembled due to GSH-induced disulfide cleavage, resulting in free DNA and small polymer fragments that are easily cleared. ${ }^{71}$ Polyplexes based on disulfide-crosslinked PEI and DNA prepared at an N/P ratio of 10 showed improved biocompatibility over nonreducible branched PEI (25 kDa) ${ }^{72}$ Branched PEI $(800 \mathrm{Da})$ was crosslinked via disulfides through either thiolation followed by oxidation $(3)^{73}$ or through Michael addition on cystamine bisacrylamide (CBA) (4). ${ }^{74}$ Compared to PEI $(25 \mathrm{kDa})$, the disulfide-linked branched PEI (800 Da) gave higher transfection activity, lower cytotoxicity, and increased serum-stability as revealed by in vitro experiments. ${ }^{73,74}$ The transfection activity of disulfide-linked branched PEI (1.8 kDa) was further increased through conjugation with the endosomolytic protein listeriolysin $\mathrm{O}$ from the intracellular pathogen Listeria monocytogenes. ${ }^{75}$ Zhong et al. reported the modification of branched PEI (1.8 kDa) with hydrophobic lipoic acids via carbodiimide chemistry (5), to give up to 500-fold increased transfection ability in HeLa and 293T cells as compared to unmodified parent groups, and up to 3-fold as compared to PEI (branched, $25 \mathrm{kDa}$ ). ${ }^{76}$ The same research group later enhanced transfection activity (4-fold) and reduced toxicity of PEI ( $25 \mathrm{kDa})$ by introducing a bioreducible cystamine periphery on the PEI polymer through Michael-type addition (6). ${ }^{77}$ Bae and coworkers thiolated branched PEI (800 Da) with 2-iminothiolane and successively oxidized the thiols to obtain bioreducible PEI as gene vectors with molecular weights ranging from $5-80 \mathrm{kDa}(7)$, while preserving the high buffering capacities of the parent PEI. ${ }^{78}$ The bioreducible gene vectors were demonstrated to display at least 8 times less cytotoxicity than standard PEI (25 kDa). With binding DNA into 100-200 nm-sized polyplexes with cationic surface charge $(+20-35 \mathrm{mV})$, the bioreducible vectors exhibited approximately 1200 to1500-fold and 7-fold higher transfection activities than parent PEI $(800 \mathrm{kDa})$ and standard PEI $(25 \mathrm{kDa})$ respectively as revealed from in vitro transfection experiments. ${ }^{78}$ Branched PEI (1.2 kDa) was successively guanidinylated, thiolated, and oxidized, to afford bioreducible guanidinylated PEI (8) with enhanced cellular uptake, low cytotoxicity, and remarkable transfection activity in human breast cancer cells (MCF-7 and MDA-MB-231) and cervical cancer cells (HeLa). ${ }^{79}$ 
<smiles>[R]OC(C)(C)CCN(CCNC)CCNC</smiles>

1 PEI: นmm<smiles>CCNCC(C)SSC(C)CNC</smiles>

3<smiles>CCNC(=O)CCCCC1CCSS1</smiles><smiles>CCNC(=[NH2+])CCCSSCCCC(=[NH2+])NCC</smiles><smiles>CCCCNC(C)CSSCC(C)NCCCCCCNC(=N)N</smiles>

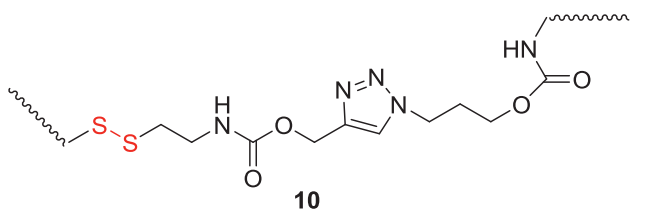<smiles>CCSCCNCCNCCNCCNC(C)(C)C</smiles>

12<smiles>CCCCNC(=O)NCCSSCCNC(=O)OCc1cn(CCCOC(=O)NCC)nn1</smiles>
11<smiles>CCCNC(=O)OCCSSCCOC(=O)NC</smiles>

14<smiles>O=C(CCSSCCC(=O)ON1C(=O)CCC1=O)ON1C(=O)CCC1=O</smiles>

Figure 2. Chemical structures of bioreducible polymeric gene vectors based on polyethyleneimine derivatives.

Goepferich et al. prepared disulfide-linked branched PEI vectors (9) by crosslinking linear PEI (2.6, 3.1, and $4.6 \mathrm{kDa}$ ) with dithiodipropionic acid or cysteine linkers through 
EDC/NHS chemistry. ${ }^{80}$ The reversibly crosslinked vectors degraded under reducing conditions into non-toxic fragments, which ensured their high biocompatibility observed in cell experiments. The bioreducible branched PEI-based vectors gave superior transfection activities with up to $70 \%$ transfection efficiency achieved in HEK cells. ${ }^{80}$ These bioreducible vectors enabled siRNA delivery for the knockdown of EGFP (enhanced green fluorescent protein) expression in CHO-K1 cells. The cellular uptake of siRNA was boosted with increased degree of branching in the vectors. ${ }^{81}$ Also Zhao et al. have used the same chemistry to crosslink branched PEI (800 Da) and used the obtained bioreducible PEI successfully as delivery vector of hTERT (human telomerase reverse transcriptase) siRNA to inhibit the growth of HepG2 xenograft tumor model. ${ }^{82}$

Another approach was followed by Jiang et al. who employed click chemistry to prepare disulfide-crosslinked branched PEI $(1.8 \mathrm{kDa})$ as bioreducible nonviral gene vectors. ${ }^{83,84}$ The branched PEI was first functionalized with approximately four azide pendant groups, which were subsequently reacted with a disulfide-containing dialkyne linker via $\mathrm{CuBr}$ catalyzed click reaction, leading to bioreducible high molecular weight PEI (10). ${ }^{83}$ Transfections carried out on $293 \mathrm{~T}$ and HeLa cells revealed that the bioreducible PEI exhibited superior transfection activity and substantially lower cytotoxicity as compared to conventional branched PEI $(25 \mathrm{kDa})$, both under serum-free and serum-present conditions. ${ }^{83}$ Multi-azido-functional branched PEI (1.8 kDa) was also prepared and reacted with mono-alkyne-terminated PEI with disulfide linkages, to give hyperbranched disulfidecontaining PEI (11) with much lower cytotoxicity and similar transfection efficiency. ${ }^{84}$ Mono alkyne-terminated PEI was grafted to poly(aspartic acid) with various azide pendant groups, forming a bioreducible polymer brush with minimal toxicity and high transfection activity, as demonstrated in $293 \mathrm{~T}$ cells. ${ }^{85}$

\section{Fluorescence measurements to follow intracellular disulfide reduction}

Bioreducible linear PEI (12) with molecular weights ranging from $7.0 \mathrm{kDa}$ to $11.0 \mathrm{kDa}$ was synthesized by oxidative polycondensation of ethylene imine oligomers with two terminal free thiols. ${ }^{86}$ Its transfection activity increased with increasing amine density, approaching that of PEI $(25 \mathrm{kDa})$. The bioreducible linear PEI exhibited low cytotoxicity, owing to the complete intracellular degradation within $3 \mathrm{~h}$, as demonstrated by fluorescence microscopy using probe-probe de-quenching of BODIPY-FL fluorescent dyes. ${ }^{86} \mathrm{Wu}$ et al. labeled linear PEI $(3.0 \mathrm{kDa})$ with Rhodamine $\mathrm{B}$ via a linker that 
contained one free thiol, and applied oxidation to form disulfide linkage between two linear PEI chains. Fluorescence quenching of the Rhodamine B molecules indicated that these were closely coupled. Fluorescence was restored upon disulfide cleavage. Moreover, the plasmid was modified with a Rhodamine B fluorescence resonance energy transfer (FRET) donor of BODIPY. These fluorescent materials possess higher transfection activity and lower toxicity as compared to conventional branched PEI (25 kDa) which was exemplified on HepG2 cells. The analysis of FRET and self-dequenching of the polyplexes unveiled that (i) DNA release from the polyplexes occurred prior to disulfide cleavage; (ii) some polyplexes rapidly escaped the endosome, and (iii) cleavage of disulfides took place inside lysosomes $5 \mathrm{~h}$ after endocytosis. ${ }^{87}$

Qiao and coworkers developed an autofluorescent linker with dual responsiveness towards $\mathrm{pH}$ and GSH that enabled traceable and controlled delivery of nucleic acids. ${ }^{88-90}$ The autofluorescent linker consisted of acetaldehyde-modified-cystine (AC) with one disulfide bond and two Schiff bases, which induce autofluorescence via the $n-\pi *$ transition of their two $\mathrm{C}=\mathrm{N}$ bonds. ${ }^{91-93}$ The $\mathrm{n}-\pi^{*}$ transition is broken upon disulfide reduction in the cytosol and imine bonds are hydrolyzed by the low $\mathrm{pH}$ in late endosomes, leading to different fluorescence intensities for imaging. ${ }^{88}$ Uniform dendrimer-linked amino-functionalized silica nanoparticles with hierarchical pores $\left(\mathrm{HPSNs}-\mathrm{NH}_{2}\right)$ were grafted with non-toxic branched PEI (800 Da) via AC linkers (Figure 3). The traceable gene vectors exhibited strong gene binding ability, negligible cytotoxicity, and transfection efficiency enhancements of $80 \%, 72 \%$, and $56 \%$ in HEK293, HeLa, and CHO cells, respectively, as compared to linear PEI (22 kDa) and Lipofectamine $2000 .{ }^{88}$ Fluorescence of the gene vectors inside the cells increased between 0.5-6 h post-transfection, due to accumulative uptake of the vectors inside cells. However, fluorescence weakened and eventually disappeared $6 \mathrm{~h}$ after transfection. This was ascribed to Schiff base hydrolysis and disulfide cleavage. ${ }^{88}$ The AC linker was subsequently also employed in HPSNs/PEI hybrid vectors ${ }^{90}$ and PEI-based nanogels ${ }^{89}$ to obtain traceable and responsive delivery of siRNA. 


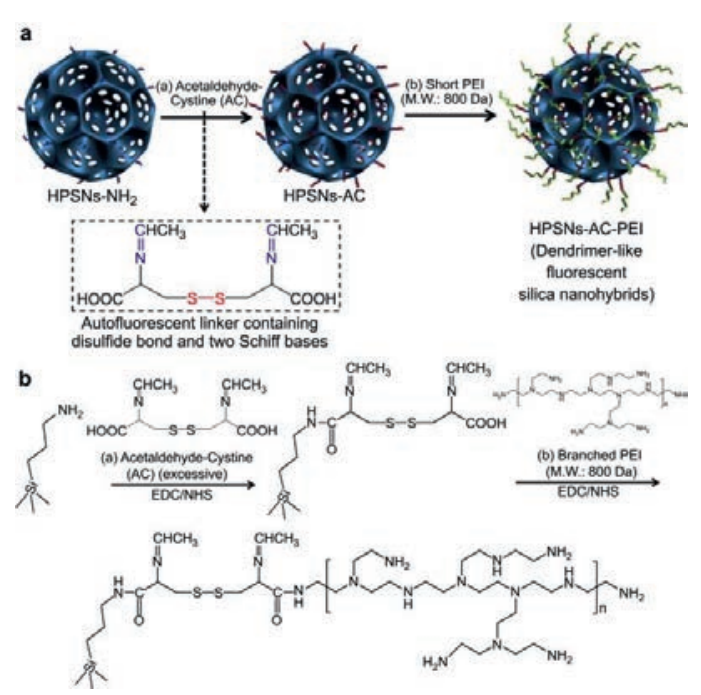

Figure 3. Schematic illustration of GSH- and pH-responsive traceable gene delivery system based on HPSNsAC-PEI (a) and its corresponding synthetic route (b). ${ }^{88}$

\section{Stabilization of polyplexes}

PEI (branched, $25 \mathrm{kDa}$ )/DNA polyplexes were endowed with robust extracellular stability against anionic competition through coating with hydrophilic poly[N-(2hydroxypropyl)methacrylamide] (PHPMA) via disulfide linkages between PHPMA and PEI. DNA was fully released upon treatment with DTT $(20 \mathrm{mM})$ due to disulfide reduction. The resulting polyplexes exhibited up to 100-fold higher transfection efficiencies as compared to polyplexes based on vectors coated with PHPMA through thioethers. ${ }^{94}$ Alternatively, PEI (25 kDa)/DNA polyplexes were stabilized with disulfide-containing dithiobis(succinimidyl propionate) (DSP) as a reversible linker (13). ${ }^{95,96}$ As anticipated, the resulting disulfide-crosslinked polyplexes showed numerous merits in terms of resistance against polyanion exchange and high ionic strength, colloidal stability, and little- to no association with blood proteins and erythrocytes. ${ }^{95}$ The crosslinked polyplexes were efficiently taken up by NIH 3T3 cells and subsequently released DNA through intracellular reduction of the vector. After intravenous administration, transfection dominated in the liver rather than in the lung (undesired), owing to higher blood levels for crosslinked polyplexes resulting from disulfide crosslinking. ${ }^{97}$ In following studies, high molecular weight PEG (30 kDa) was conjugated onto branched PEI (25 kDa) through urea linkages, affording PEG-PEI copolymers. The copolymers efficiently complexated DNA into polyplexes that were further crosslinked by DSP. The resulting polyplexes exhibited 10- 
fold improved transfection activity and substantially reduced hemolytic activity, owing to their significantly prolonged circulation in vivo. ${ }^{96}$ The effect of PEGylation on transfection by bioreducible PEI-based vectors was investigated in detail by Bauhuber et al. on a library of 39 linear PEG-PEI copolymers with either thioether or disulfide linkages. ${ }^{98}$ This study revealed that PEG, rather than PEI, domains dominate the physicochemical properties of polyplexes and small $(<150 \mathrm{~nm})$, nearly neutral polyplexes with favorable stability were formed from copolymers with PEG contents over $50 \%$. Compared to the corresponding parent PEI, PEG-PEI copolymers linked through thioether bonds exhibited substantially reduced transfection activity that was restored upon substituting thioethers with disulfides. ${ }^{98}$ More recently, PEI (25 kDa)/DNA polyplexes were coated with bioreducible PEG-based nanoshells containing CBA. These PEI (25 kDa)/DNA polyplexes exhibited robust colloidal stability against physiological serums and gave boosted in vivo transfection activity as compared to pristine polyplexes. ${ }^{99}$

Guo and Zhou et al. modified the surface of gold nanorods (GNRs) with disulfide-linked short polyethylenimine (DSPEI) to achieve NIR-triggered gene delivery to glioblastoma U87 MG cells (Figure 4). ${ }^{100}$ DSPEI was functionalized with PEG and tagged with RGD targeting ligands to obtain DSPEI-PEG-RGD, which replaced CTAB on the GNR surface (termed as GNR-DSPEI-PEI-RGD). GNR-DSPEI-PEI-RGD is able to condense DNA into complexes, which can be destabilized by addition of DTT and/or applying NIR irradiation. The complexes readily transfect U-87 MG cells with enhanced transfection efficiency under NIR irradiation. The NIR-enhanced transfection is effected by photochemicaltriggered endosomal escape. ${ }^{100}$ After functionalization with RGD targeting ligands, this system successfully enabled delivery of small hairpin (sh)RNA delivery through active targeting, affording efficient gene silencing both in vitro and in vivo. ${ }^{101}$ 


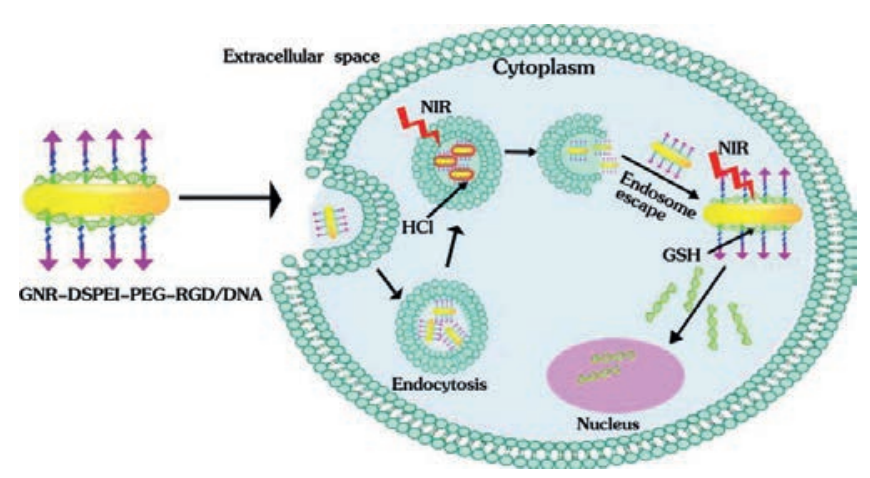

Figure 4. Schematic illustration of NIR-triggered gene delivery carrier based on disulfide-liked PEI. ${ }^{100}$

After intracellular reduction of disulfide-containing polyplexes prepared from PEI, the resulting free thiols exchange with disulfide bonds in proteins through thiol/disulfide exchange or form new disulfides with cysteine residues on proteins via oxidation, which potentially interferes with protein function and normal cellular processes. ${ }^{102,103}$ Dong et al. developed bioreducible PEI-based vectors (14) via crosslinking branched PEI (2 kDa) with a releasable disulfide-carbonate linker. ${ }^{104}$ The cell experiment revealed that the bioreducible gene vectors possessed higher transfection ability and lower cytotoxicity as compared to control groups of PEI $(25 \mathrm{kDa})$ and Lipofectamine 2000. After reductive cleavage of this linker, intramolecular cyclization takes place, leading to cleavage of the carbamate bond with degradation products being 1,3-oxathiolan-2-one rather than free thiols. $^{105,106}$

\section{POLYVINYL DERIVATIVES}

$\operatorname{Poly}(N, N$-dimethylaminoethyl) methacrylate (PDMAEMA, 15, Figure 5) is an interesting class of cationic polymeric vectors with great promise in clinical applications. ${ }^{107,108}$ PDMAEMA can be readily prepared through anionic ${ }^{109}$ and controlled radical polymerization techniques like atom transfer radical polymerization (ATRP) ${ }^{110}$ and reversible addition fragmentation transfer $(\mathrm{RAFT})^{111}$ with tunable molecular weights, welldefined terminal groups, and different macromolecular architectures ranging from block, star, to graft. High molecular weight PDMAEMA has been demonstrated to give high transfection activity, but also displays substantial toxicity. ${ }^{108}$ 
<smiles>CN(C)CCOC(=O)C(CC(C)(C)C)C(C)(C)C</smiles>

15

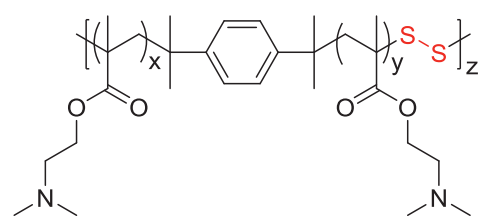

16

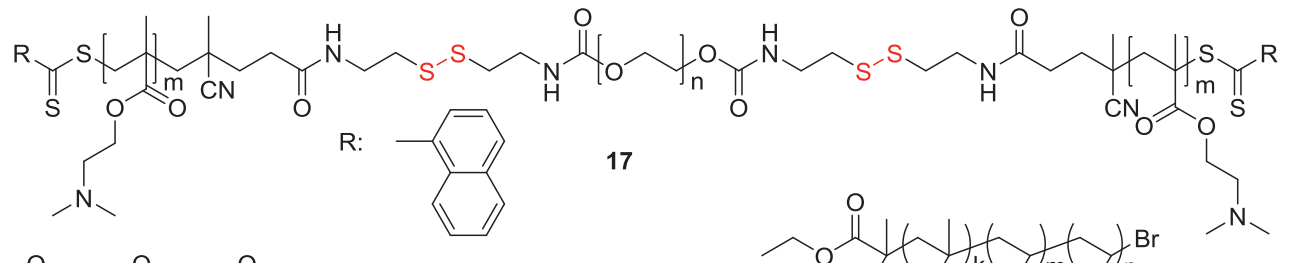<smiles>CCC(=O)N[Y9](CC(=O)NC)(CC(=O)NCC(=O)NCCCNC)C(=O)NCCSS</smiles>

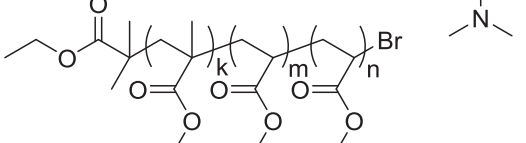

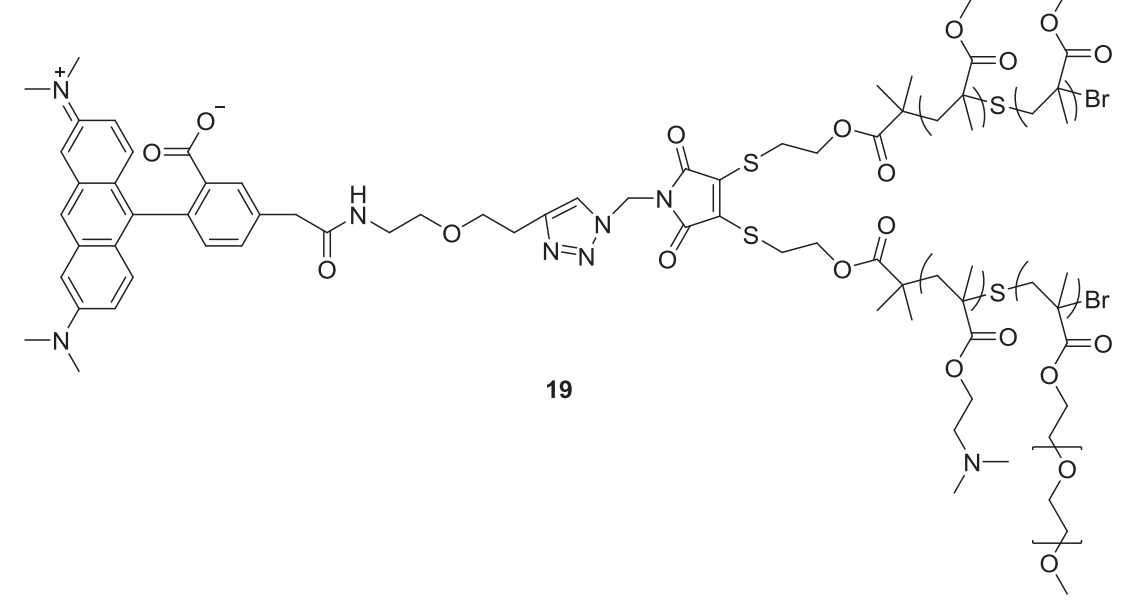

Figure 5. Chemical structures of bioreducible polymeric gene vectors based on polyvinyl derivatives. 
Bioreducible PDMAEMA (16) was first reported by Oupický and coworkers in 2007. ${ }^{112}$ They proposed an elegant approach based on oxidative polycondensation of oligomers with thiol endgroups. ${ }^{112-114}$ A bifunctional chain transfer agent, 1,4-bis(2(thiobenzoylthio)prop-2-yl) benzene (BTBP), was employed in the preparation of PDMAEMA oligomers with thioester endgroups. These thioesters were converted to thiols via aminolysis, affording $\alpha, \omega$-dithiol-terminated PDMAEMA oligomers, which were further polymerized through oxidative polycondensation to obtain disulfide linked high molecular weight PDMAEMA $\left(\mathrm{M}_{\mathrm{n}}=16.7\right.$ and $\left.53 \mathrm{kDa}\right)$. The resulting PDMAEMA exhibited up to 10-fold higher molecular weight, as well as higher polydispersities in comparison to the parent oligomers. The bioreducible PDMAEMA displayed much lower cytotoxicity, but comparable and enhanced transfection ability in a panel of cell lines as compared to non-bioreducible PDMAEMA. ${ }^{112}$

Bioreducible cationic star polymers based on PDMAEMA (sPDMAEMA) were prepared using cystamine bisacrylamides (CBA) as a core, from which PDMAEMA arms were polymerized. ${ }^{115}$ In an approach in which the 'arms' were prepared first, ${ }^{116}$ linear PDMAEMA precursor polymers were synthesized and subsequently crosslinked via CBA, affording bioreducible sPDMAEMA $\left(\mathrm{M}_{\mathrm{n}}=8.3\right.$ and $\left.28.3 \mathrm{kDa}\right)$ with average numbers of arms of 8.2 and 10.7 respectively. The bioreducible sPDMAEMA showed enhanced DNA binding ability, and improved transfection efficiency as compared to its linear precursor. With longer and more arms, sPDMAEMA exhibited decreased cytotoxicity and enhanced transfection activity as compared to standard PEI $(25 \mathrm{kDa}) .{ }^{115}$ Atomic force microscopy (AFM) and time-resolved fluorescence spectroscopy revealed that sPDMAEMA/DNA polyplexes were destabilized by the steric hindrance of the arms, as well as the outward extension of the cationic arms upon decrease in $\mathrm{pH}$ from 7.4 to 5.0, while linear counterparts adopted a more compact polyplex morphology. ${ }^{115}$ Bioreducible sPDMAEMA was further employed as an siRNA vector to knock down genes in mouse calvarial preosteoblast-like cells (MC3T3-E1.4) with excellent cytocompatibility. ${ }^{117}$ Recently, CBAlinked PDMAEMA was applied as capping agent for siRNA-preloaded mesoporous silica nanoparticles (SS-MSN/siRNA) in siRNA delivery with minimal cytotoxicity and gene silencing efficiency comparable to Lipofectamine 2000. ${ }^{118}$ After injected through tail vein into mice, SS-MSN/siRNA efficiently delivered siRNA to HeLa-Luc xenograft tumor which led to tumor growth inhibition. ${ }^{118}$ 
Zhong and coworkers reported bioreducible ABA-type triblock copolymers of PDMAEMA and PEG, linked by disulfides (i.e. PDMAEMA-SS-PEG-SS-PDMAEMA, 17). ${ }^{119}$ The bioreducible triblock copolymer efficiently condensed pDNA into nanoscaled $(<120 \mathrm{~nm})$ polyplexes with surface charges of up to $+6 \mathrm{mV}$. The polyplexes exhibited enhanced resistance against high ionic strength owing to the PEG corona around the polyplexes. pDNA was released from the polyplexes under reductive conditions as revealed by gel electrophoresis experiments. The polyplexes displayed similar cytocompatibility and 28-fold higher transfection activities on COS-7 cells than the nonreducible triblock copolymer. ${ }^{119}$ Low molecular weight PDMAEMA (12.7 kDa) was grafted onto poly(aspartic acid) $(15.8 \mathrm{kDa})$ through disulfide spacers via azide/alkyne click chemistry, forming bioreducible brushed PDMAEMA (18). ${ }^{120}$ Poly(aspartic acid) was functionalized with alkynes via disulfide linkers, and grafted by mono azido-terminated low molecular weight PDMAEMA, leading to polyaspartamide-based brushed PDMAEMAs. The bioreducible brushed PDMAEMAs exhibited much lower cytotoxicity and higher transfection capability on $293 \mathrm{~T}$ cells than standard PEI (25 kDa) or high molecular weight PDMAEMA. ${ }^{120}$ Pun et al. synthesized copolymers of DMAEMA and methoxy oligo(ethylene glycol) methacrylate (OEGMA) from a bifunctional ATRP initiator containing an internal disulfide, and subsequently used dibromomaleimide-alkyne to crosslink the obtained copolymers, affording bioreducible polycations (19) with molecular weights ranging from $15.4 \mathrm{kDa}$ to $35.8 \mathrm{kDa} .{ }^{121}$ The bioreducible polycations exhibited comparable DNA complexation abilities and transfection efficiencies, but substantially lower cytotoxicity as compared to their non-reducible counterparts. Moreover, the alkyne groups in bioreducible polycations enabled azide-alkyne click functionalization with rhodamine fluorophores to investigate intracellular dynamics of the polyplexes, providing possibilities of controlled conjugation of biomolecules such as peptides and antibodies.

Wang et al. applied in situ deactivation enhanced ATRP (DE-ATRP) $)^{122-124}$ to prepare hyperbranched $^{125}$ or knot-shaped ${ }^{126}$ PDMAEMA from DMAEMA and crosslinker bis(2acryloyl)oxyethyl disulfide (BADS) with ethyl 2-bromoisobutyrate as an initiator. The branching degree of hyperbranched PDMAEMA increased upon increasing BADS content. At BADS/initiator ratios above 1, pendent vinyl groups remained intact, providing handles for functionalization with 3-morpholinopropylamine through Michael-type addition. ${ }^{125}$ The resulting hyperbranched PDMAEMA (20) fragmented into smaller parts after $1 \mathrm{~h}$ treatment 
with $20 \mathrm{mM} \mathrm{GSH}$ as revealed by size exclusion chromatography. In vitro experiments on HeLa cells disclosed that the transfection ability of hyperbranched PDMAEMA was higher than that of linear PDMAEMA and increased further with higher branching degrees. The hyperbranched PDMAEMA with the highest branching degree exhibited good preservation of cell viability. ${ }^{125}$ The knot-shaped PDMAEMA with incorporated disulfides was prepared as a 'single knot' that self-assembled into multi-knots, whose residual vinyl moieties were converted to amines through Michael-addition to form bioreducible multiknot PDMAEMA based gene vectors (see Figure 6). ${ }^{126}$ The multi-knot PDMAEMA degraded into smaller fragments with one tenth of the original size through disulfide cleavage under $5 \mathrm{mM}$ GSH. The multi-knot shaped polymeric vectors in particular showed high transfection activity and low cytotoxicity towards skin cells of recessive dystrophic epideromylis bullosa (RDEB), which is superior over PEI (25 kDa) and Lipofectamine 2000. The bioreducible multi-knot vectors possess considerable potential for clinical therapy of RDEB and other wounds. ${ }^{126}$
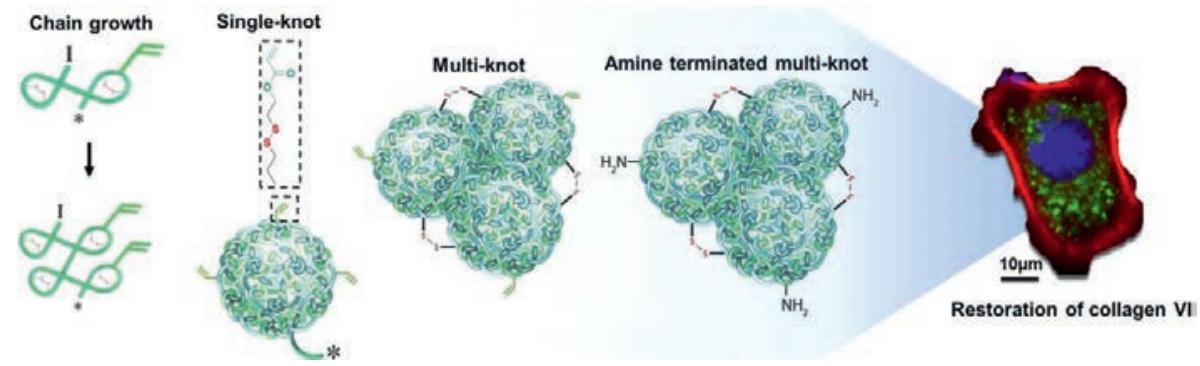

Figure 6. Bioreducible multi-knot PDMAEMA as gene vectors to potentially restore collagen VII expression in skin of recessive dystrophic epideromylis bullosa (RDEB) patients. ${ }^{126}$

Hennink and coworkers developed bioreducible decationized polyplexes with a PEG shell and a DNA-entrapping core of disulfide cross-linked poly(2-hydroxypropyl methacrylamide) (PHPMA) as an interesting gene delivery system. ${ }^{127}$ The cationic block copolymer p(HPMA-DMAE-co-PDETEMA)-b-PEG (HPMA-DMAE: carbonic acid 2dimethylamino-ethyl ester 1-methyl-2-(2-methacryloylamino)-ethyl ester; PDETEMA: $\mathrm{N}$ [2-(2-pyridyldithio)]ethyl methacrylamide) was polymerized through controlled radical polymerization. The obtained cationic block copolymer (abbreviated as pHDP-PEG) complexated DNA into nanosized polyplexes through electrostatic inclusion at $\mathrm{pH} 8.5$, followed by the formation of interchain disulfides with 3,6-dioxa-1,8-octane-dithiol and the removal of DMAE groups through hydrolysis of the carbonate ester bonds at $\mathrm{pH} 7.4$ ( 
Figure 7). The decationized nanoparticles exhibit hydrodynamic sizes of $128 \mathrm{~nm}$, surface charges of $-5 \mathrm{mV}$ and good preservation cell viability in HeLa cells. High transfection activity was only observed through electroporating the nanoparticles into HeLa cells, due to limited cellular uptake of these decationized nanoparticles. After functionalization with folic acid (FA) as a targeting ligand, the decationized polyplexes displayed enhanced delivery of DNA in cell lines that overexpress folate receptors (HeLa and OVCAR-3), ${ }^{128}$ and successfully transported siRNA to human ovarian carcinoma cells. ${ }^{129}$ These decationized polyplexes possess high biocompatibility and excellent colloidal stability in physiological milieu, indicating considerable potential for clinical application. ${ }^{127-130}$

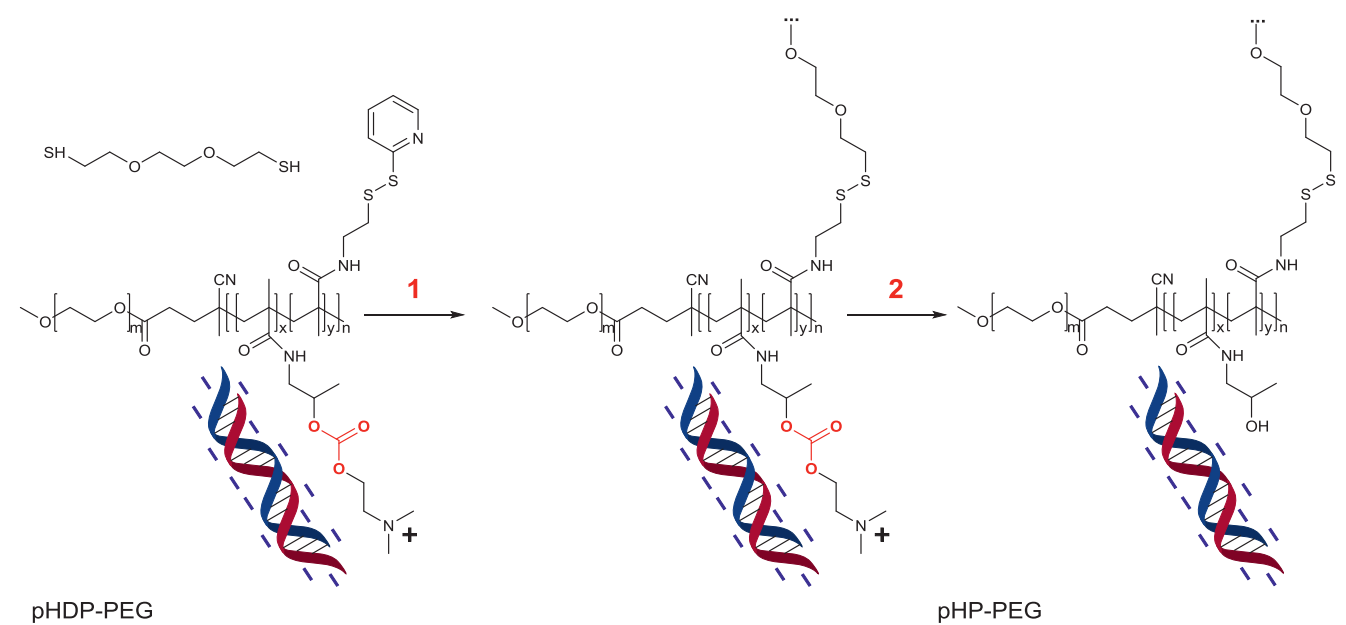

Figure 7. Preparation of decationized polyplexes through DNA condensation, interchain disulfide crosslinking, and polyplex decationization. ${ }^{127}$

\section{SYNTHETIC POLYPEPTIDE DERIVATIVES}

Bioreducible poly(L-Lysine)s (PLLs) (21, Figure 8) with molecular weights of $45 \mathrm{kDa}$ and $187 \mathrm{kDa}$ were prepared by oxidation of the terminal cysteinyl thiols of Cys(Lys) ${ }_{10} \mathrm{Cys}$. The resulting polymers efficiently condensed DNA into polyplexes approximately $65 \mathrm{~nm}$ in size and surface charges of $+30 \mathrm{mV} .{ }^{131}$ The polyplexes were further coated with multivalent reactive copolymers of PHPMA resulting in a slight size increase of $15 \mathrm{~nm}$ and a substantial drop in surface charge down to $-10 \mathrm{mV}$, affording steric stabilization of the polyplexes with high resistance against salt-induced aggregation. However, these laterally stabilized polyplexes exhibited much lower transfection activity in human retinoblast 911 cells compared to non-coated polyplexes. This was attributed to limited cellular uptake and 
insufficient DNA unpacking. ${ }^{131}$ Bioreducible PLLs showed enhanced transfection ability of DNA and mRNA when in the presence of cationic lipids as endosomolytic agents. ${ }^{132}$ Histidine residues were included into bioreducible PLLs with enhanced buffer capacity, giving histidine-rich bioreducible PLLs which achieved efficient cytoplasmic delivery of plasmid DNA, mRNA, and siRNA on a panel of cells. ${ }^{133}$ Bae et al. applied mixtures of PLL and bioreducible PLL at various ratios in the preparation of polyplexes with tunable decomplexation rates, and explored the optimal decomplexation rate for high transfection efficiency. ${ }^{134}$ The monomer sequence in bioreducible histidine-rich PLL copolymers was found to substantially affect their DNA binding ability, buffer capacity and transfection efficiency. Differences in transfection activities of up to 2 orders of magnitude were observed for different monomer sequences. ${ }^{135}$

Cationic block copolymers of PLL with hydrophilic PEG segments are capable to effectively condense nucleic acids into core-shell-type polyplexes with hydrophilic coronas. $^{136-139}$ The micellar polyplexes exhibit remarkable transfection activity in various cell lines, as well as in liver and tumors owing to their excellent colloidal stability and prolonged blood circulation. ${ }^{140}$ PEG-PLL cationic block copolymers, based on PLL segments that were thiolated through $N$-succinimidyl 3-(2-pyridyldithio)propionate (SPDP) spontaneously self-assemble with antisense oligonucleotides (ODN) into polyion complex (PIC) micelles with a disulfide-linked core. ODN was well protected in the micellar core against nuclease, but rapidly liberated upon GSH-induced core dissociation. ${ }^{141}$ The PLL segments were thiolated with either SPDP (22) or Traut's reagent (2-iminothiolane) (23) to vary both the cationic charge density and disulfide cross-linking densities of the PEG-PLL cationic blocks. The thiolated PEG-PLL associated with plasmid DNA into disulfidelinked block-catiomer polyplexes with remarkable stability. Polyplexes from SPDPmodified PEG-PLL exhibited pDNA release in the reducing cytotol and induced ca. 50fold higher transfection in $293 \mathrm{~T}$ cells than that thiolated with Traut's reagent. ${ }^{142}$ Moreover, transfection of disulfide-linked PIC micelles was well maintained during the lyophilization-thawing procedure and did not require any lyoprotectants. ${ }^{142,143}$ After intravenous injection, reversible linked PIC micelles induce uniform gene expression in the liver parenchymal cells in mice. ${ }^{143}$ The disulfide-linked PIC micelles were endowed with $\mathrm{pH}$ responsiveness for enhanced intracellular pDNA delivery ${ }^{144}$ and further employed as efficient vectors for siRNA. ${ }^{145,146}$ PIC micelles were also prepared by spontaneous selfassembly of PEI-PLL thiolated with iminothiolane and siRNA. The resulting PIC micelles 
showed uniform sizes of $60 \mathrm{~nm}$ with spherical shape and possessed high colloidal stability against high ionic strength and enzymes in the extracellular environment, but rapidly disassemble through disulfide cleavage in the cytoplasm with efficient release of siRNA. Substantially higher (100-times) gene silencing in human hepatoma (Huh7) cells was obtained as compared to non-crosslinked PIC micelles. ${ }^{145}$ The disulfide-linked PIC micelles were tagged with cell-targeting cyclic RGD to achieve actively targeted systematic delivery siRNA to experimental cancers ${ }^{147}$ and solid tumors. ${ }^{148}$ Shuai et al. used siRNA loaded PIC micelles made from PLL grafted with linear PEI for the targeted delivery of siRNA in vivo and successfully obtained Skov-3 tumor inhibition in mice. ${ }^{149}$

Cass et al. adopted diisocyanate condensation-induced chain extension to prepare bioreducible polycations as siRNA delivery vectors. ${ }^{150}$ The disulfide-centered PLL oligomers (24) were prepared by ring-opening polymerization of $\varepsilon$-Cbz-L-lysine NCA $(N$ carboxyanhydride) with cystamine as initiator, and subsequently were extended with 1,6hexanediisocyanate and terminated with PEG-amine. After removing the protecting cbzgroups, the resulting bioreducible polymers were obtained with molecular weights ranging from $12 \mathrm{kDa}$ to $23 \mathrm{kDa}$, and exhibiting good complexation of siRNA. The polyplexes had superior knockdown of GFP in CHO cells as compared to Lipofectamine 2000, with a knock down up to $50 \%$ of GFP expression. ${ }^{150}$

PIC micelles were also prepared analogously using nucleic acids and PEG-based block catiomers prepared from other materials. Polyaspartamide was flanked with $\mathrm{N}$-(2aminoethyl)-2-aminoethyl group, leading to cationic segments (P[Asp(DET)]) with high buffer capacity. ${ }^{151}$ Block copolymers of PEG-P[Asp(DET)] were developed as efficient and safe gene vectors. Disulfide linkage was employed to link two polymer blocks, affording PEG-SS-P[Asp(DET)] (25) that associated with pDNA into PIC micelles. The PIC micelles exhibited up to 3 orders of magnitude higher transfection activity and faster initiation of gene expression than those without disulfide linkages, owing to improved endosomal escape via PEG detachment in the endosome. ${ }^{152}$ Shuai et al. prepared a GSH and $\mathrm{pH}$-induced intracellular delivery system based on a triblock copolymer of PEG, 2mercaptoethylamine (MEA)-grafted aspartamide (P[Asp(MEA)]), and 2(diisopropylamino)ethylamine (DIP)-grafted polyaspartamide (P[Asp(DIP)]) (26). The triblock copolymer self-assembles into micelles with a disulfide-crosslinked interlayer and $\mathrm{P}[\mathrm{Asp}(\mathrm{DIP})]$ as the core. ${ }^{153}$ The micelles were subsequently applied as vector for long- 
circulating and tumor-targeted siRNA delivery, ${ }^{154}$ and co-delivery of siRNA and DOX for synergistic cancer therapy in vivo. ${ }^{155}$<smiles>CNC(CCCCN)C(C)=O</smiles>

21<smiles>CNC(CCCC[NH-])C(=O)NC(CCCCNC(=O)CCS)C(=O)NCCOC</smiles><smiles>CNC(CCCCC[NH3+])C(=O)NC(CCCCNC(C)CCCS)C(=O)NCCOC</smiles>

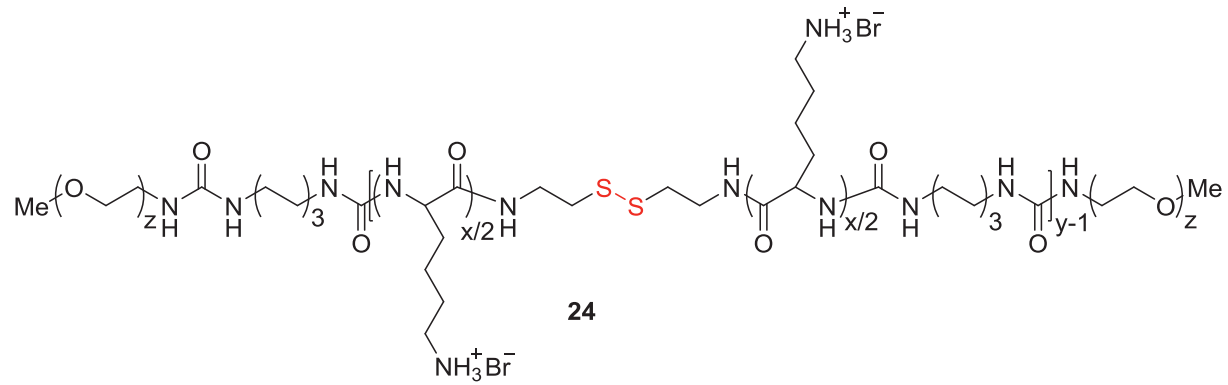<smiles>CCOCC(C)(C)SSCCNC(=O)C(CC(=O)NCCNCCN)NC(=O)CC(NC(=O)CNCCN)C(=O)NCCNCCN</smiles><smiles>[R7]N(CCC(=O)OC)CCC(=O)OCC</smiles>

27<smiles>CCSSCCN(CCC(=O)OC)CCC(=O)O[R](C)(C)C</smiles><smiles>CC(C)OCC(C)(C)NC(=O)C(CC(=O)NCCS)NC(C)(C)CC(NC(=O)Cn1cc(CNC(=O)C(CC(=O)NCCN(C(C)C)C(C)C)C(=O)NCCS)nn1)NC(C)(C)CC(=O)NC(=O)CNCCN(C(C)C)C(C)C</smiles>

Figure 8. Chemical structures of bioreducible polymeric gene vectors based on synthetic polypeptides and poly(amino ester)s derivatives. 


\section{POLY(AMINO ESTER)S DERIVATIVES}

Poly(amino ester)s (27, Figure 8) are a class of biodegradable cationic polymers intensively explored by Langer and coworkers ${ }^{156}$ for non-viral gene delivery in the past decade. ${ }^{157-160}$ A large library of structurally diverse polymers was readily screened through high-throughput processes ${ }^{161,162}$ to identify optimal structures that result in efficient gene delivery to a myriad of cell lines in vitro. Also poly(amino ester)s were efficiently for gene delivery in the vitreous of eyes and tumors in vivo. ${ }^{163,164}$ Bioreducible poly(amino ester)s (28) were first prepared through Michael addition between diacrylate monomers with 2(pyridyldithio)-ethylamine (PDA). ${ }^{165}$ The pendent pyridyldithio groups were readily reacted with thiol-containing moieties, such as mercaptoethylamine (MEA) and RGDC peptide. The obtained derivatives exhibited strong DNA binding ability that was substantially diminished in $10 \mathrm{mM}$ GSH. The transfection experiments in human hepatocellular carcinoma cells illustrated the derivatives induced transfection efficiency comparable to standard PEI (25 kDa), however with much lower cellular toxicity. ${ }^{165}$

Cystamine-terminated poly(amino ester)s were found to be efficient vectors in the knockdown of genes for enhanced osteogenic differentiation in human mesenchymal stem cells (up to $91 \%$ ). ${ }^{166}$ Kozielski et al. designed bioreducible poly(amino ester)s as efficient and safe siRNA vehicles for nearly full knockdown of fluorescent marker genes in human glioblastoma cells. ${ }^{167,168}$ The bioreducible cationic polymer was prepared by Michael-type polymerization of 4-amino-1-butanol with mixtures of 2,2'-disulfanediylbis(ethane-2,1-diyl) diacrylate and hexane-1,6-diyl diacrylate, followed by end-capping with 1-(3aminopropyl)-4-methylpiperazine (Figure 9). The obtained cationic polymers selfassembled with siRNA to $100 \mathrm{~nm}$ sized polyplexes, and actively liberated siRNA from polyplexes through reductive cleavage of disulfides in the cytosol to induce gene silencing. Gene silencing experiments in primary human glioblastoma (GBM 319) cells expressing GFP $\left(\mathrm{GFP}^{+}\right.$GBM 319) demonstrated gene silencing efficiency up to $91 \%$ without significant cytotoxicity $(6 \pm 12 \%)$ compared to $40 \%$ knockdown induced by Lipofectamine 2000 based polyplexes at $20 \mathrm{nM}$ siRNA dosing. The gene silencing was more effective in GBM 319 cells (up to 97\%) than in human fetal neural progenitor cells (fNPC 34s, up to $27 \%$ ), identifying cancer specificity of the polyplexes prepared from these poly(amino ester)s. ${ }^{168}$ 


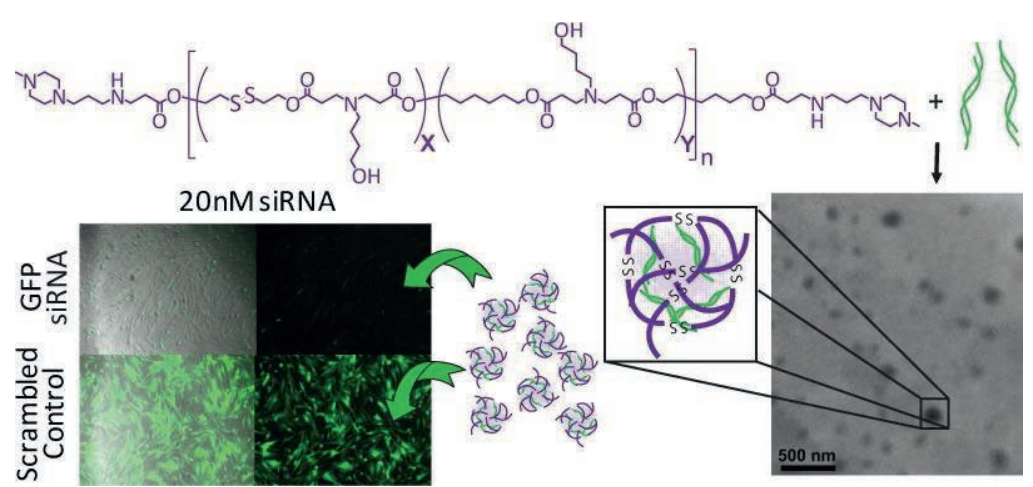

Figure 9. Cytoplasmic gene silencing in human brain cancer cells enabled by siRNA with vectors of bioreducible cationic poly(amino ester)s. ${ }^{168}$

\section{POLY(AMIDO AMINE) DERIVATIVES}

Poly(amido amine)s (PAAs) are peptidomimetic polymers which have attracted considerable attention in drug and gene delivery, as well as tissue engineering, owing to their excellent water solubility, low toxicity, high biocompatibility, and synthetic versatility. PAAs are easily prepared via Michael-type polyaddition of various primary or secondary amines to bisacrylamide monomers under mild reaction conditions, to give PAAs with broad functionality in both the main polymer chain, as well as in the side groups. ${ }^{169,170}$

Engbersen's group developed bioreducible PAAs with disulfides in the main chain (SSPAAs) as non-viral gene vectors. The SS-PAAs were prepared via Michael addition of 1(2-aminoethyl)piperazine (AEP) to bisacrylamide mixtures with various amounts of disulfide-containing bisacrylamide (CBA) (Figure 10A). In vitro experiments on COS-7 cells revealed that SS-PAAs exhibit higher levels of gene expression and reduced cytotoxicity as compared to PAAs without disulfides, owing to their high DNA binding ability, buffer capacity, and excellent biocompatibility. ${ }^{171}$ Later, various pendant groups were incorporated into SS-PAAs to tune their DNA complexation ability, buffer capacity, and transfection activity (Figure 10A). ${ }^{172}$ The amine moieties in the side groups of SSPAAs afford stronger DNA binding ability and determine buffer capacity of the polymers. SS-PAAs with histamine (HIS), 5-amino-1-pentanol (APOL), and 4-amino-1-butanol (ABOL) moieties exhibit enhanced transfection activities without imposing any cytotoxicity to COS-7 cells, as compared to standard PEI (25 kDa), demonstrating that the side groups have strong influence on the transfection performance. ${ }^{172,173}$ Oligoamines with 
varying amine content and alkyl spacer length were incorporated into SS-PAAs as side groups through protective-group chemistry, and were shown to significantly improve buffer capacity, DNA complexation ability, transgene potency, and cytotoxicity of the resulting polymers (Figure 10A). ${ }^{174}$ SS-PAAs with oligoamine pendant groups were later used as vectors of Fas siRNA to suppress Fas expression in human mesenchymal stem cells (hMSCs) and therefore inhibit hypoxia-induced apoptosis in the enlarged hMSC spheroids, suggesting therapeutic potential in ischemic disease. ${ }^{175}$ Oupický and coworkers incorporated macrocyclic amines into SS-PAAs through Michael-type addition and prepared plasmid DNA delivery systems with PEI imaging modularity ${ }^{176}$ and CXCR4 antagonism. ${ }^{177}$ 


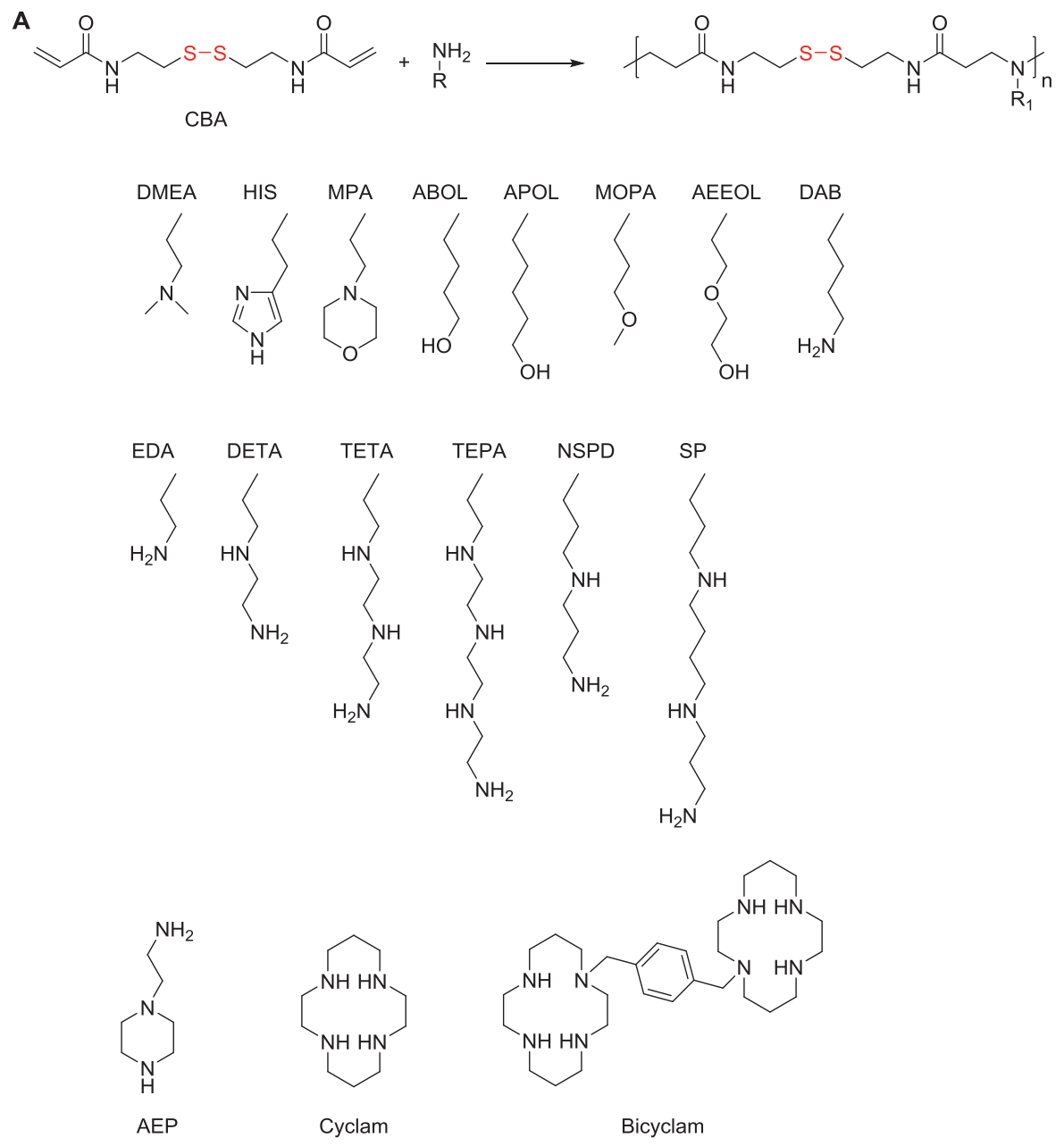

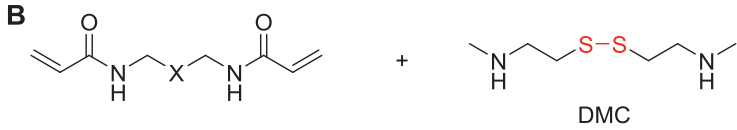

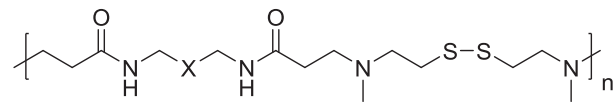

Figure 10. Chemical structures of bioreducible poly(amido amine)s (SS-PAAs) with different pendant groups (A) and alternative synthetic approach through polymerizing $N, N$ '-dimethylcystamine (DMC) as amine monomers to various bisacrylamide monomers (B).

SS-PAAs with pendant primary amine groups (pCBA-DAB) (Figure 10A) afford diverse functionalization opportunities, excellent DNA binding capacity, but also exhibit high 
toxicities associated with excess cationic charges. After modification with hydrophobic moieties via benzoylation and acetylation, the modified SS-PAAs exhibit less cytotoxicity and higher transfection activities on COS-7 cells due to the resulting polyplexes displaying hydrophobic stabilization and improved endosomolytic properties. ${ }^{178}$ In continued optimization, through polymerization of amine mixtures comprising of ABOL and defined functionalized amine monomers, SS-PAAs were successfully synthesized as vectors combining attributes of enhanced transfection performance and minimal toxicity through introduction of boronic acid groups, ${ }^{179,180}$ nicotinamide groups, ${ }^{181,182}$ as well as chargereversal groups. ${ }^{183}$ An alternative modular synthesis of SS-PAAs was developed through polymerization of $N, N^{\prime}$-dimethylcystamine (DMC) with various bisacrylamide monomers (Figure 10B). The resulting SS-PAAs displayed high buffer capacity owing to the somewhat lower basicity of the tertiary nitrogens of DMC induced by the closer proximity of the disulfide moiety, and exhibit improved transfection without noticeable toxicity. ${ }^{184}$

Kim et al. together with Engbersen et al. developed branched bioreducible peptidomimetic polymers, coined poly(amido ethylenimine)s (SS-PAEI), through Michael type polyaddition between $\mathrm{CBA}$ and three ethylene amine monomers, i.e. ethylenediamine (EDA), diethylenetriamine (DETA), and triethylenetetramine (TETA) (Figure 11A). ${ }^{185}$ All three SS-PAEIs associated with DNA into sub-200 nm and positively charged polyplexes, which induced approximately 20-fold higher transfection efficiencies in comparison to standard PEI (25 kDa) as revealed in mouse embryonic fibroblast cells (NIH3T3), primary bovine aortic endothelial cells (BAEC), and rat aortic smooth muscle cells (A7R5). ${ }^{185}$ One of these three polymers, poly(amido ethylenimine) (SS-PAED), was applied as vector to deliver RTP-VEGF in a rabbit myocardial infarct model with significant VEGF expression, indicating the potential to promote neo-vascular formation and improve tissue function in ischemic myocardium. ${ }^{186}$ Transfection efficiency of SS-PAEI was affected by serum proteins, though still significantly higher than standard PEI (25 kDa). ${ }^{185}$ PEG (2 kDa) was grafted to SS-PAEI prepared from TETA and CBA (SS-PAEI-g-PEG) to minimize interactions with serum protein and to improve carrier effectiveness under serum conditions. ${ }^{187}$ The polycation-PEG ratio was readily tuned by mixing different quantities of SS-PAEI and SS-PAEI-g-PEG (i.e. 50/50 and 90/10). When no more than 10\% SS-PAEIg-PEG was used, up to $70 \%$ DNA was protected from serum nuclease degradation over $6 \mathrm{~h}$. Increasing SS-PAEI-g-PEG volume to $50 \%$ and $100 \%$ resulted in reductions in DNA protection against serum protein. Polyplexes prepared with $10 \%$ SS-PAEI-g-PEG exhibited 
significantly enhanced transfection in vitro than SS-PAEI under serum conditions. ${ }^{187}$ Continued as in vivo study in a murine adenocarcinoma model, it was found that polyplexes prepared with $25 \%$ SS-PAEI-g-PEG exhibited the smallest size and lowest surface charges, resulting in their predominant accumulation in the liver and to a lesser degree in the spleen. ${ }^{188}$ Liu et al. developed hyperbranched SS-PAAs with tertiary amino cores through Michael addition between CBA and AEP as efficient gene vectors. ${ }^{189}$ The hyperbranched SS-PAAs exhibited higher transfection efficiency compared with linear counterparts, as revealed in a study of Engbersen et al. together with Ferruti et al. ${ }^{190}$ Hyperbranched SS-PAAs prepared through reaction between $\mathrm{CBA}$ and $\mathrm{N}, \mathrm{N}$ dimethyldipropylenetriamine effectively condensed DNA into polyplexes that were further crosslinked through disulfide exchange induced during 15 min incubation at $50{ }^{\circ} \mathrm{C}$. The cross-linked polyplexes showed enhanced colloidal stability under physiological conditions, and induced enhanced transfection efficiency in vitro and in vivo compared with noncrosslinked groups. ${ }^{191}$

A

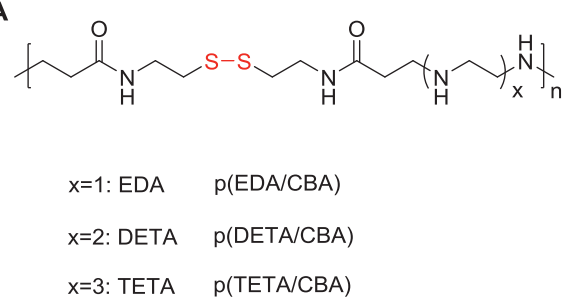

B

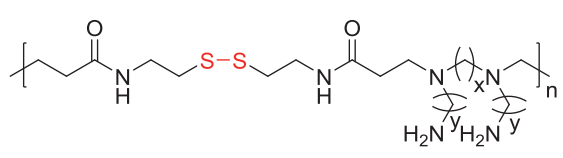

$x=2, y=2$ : TETA $\quad p(C B A-T E T A)$

$x=3, y=2:$ AEPD $\quad p(C B A-A E P D)$

$x=2, y=3$ : APED $\quad p(C B A-A P E D)$

$x=3, y=3:$ APPD $\quad p(C B A-A P P D)$

$x=4, y=3$ : TETA $\quad p(C B A-S P)$

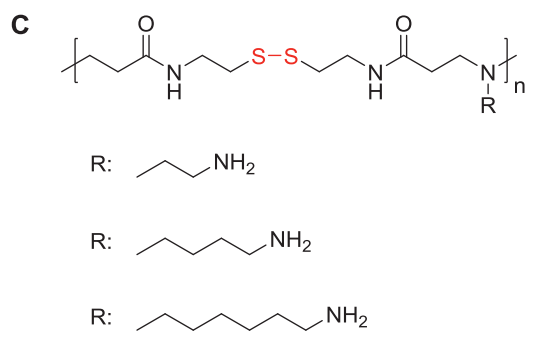

$R: \sim_{\mathrm{O}}^{\mathrm{N}} \prod_{\mathrm{GBP}}^{\mathrm{NH}_{2}}$

R: ح-

Figure 11. Chemical structures of bioreducible PAAs: A, poly(amido ethylenimine) (SS-PAEI); B and C, poly(disulfide amine)s (PDAs).

A series of bioreducible PAAs coined poly(disulfide amine)s (PDAs) by Kim et al. ${ }^{192}$ were prepared by polyaddition of CBA with oligoamine monomers, yielding polymers with different lengths of polymethylene spacer in the main chain and the side chain (Figure 
11B). Polymers with longer propylene pendant spacers (i.e., poly(CBA-SP), poly(CBAAPPD), and ploy(CBA-APED)) induced higher transgene activity than their counterparts (i.e., poly(CBA-AEPD), poly(CBA-TETA)) with shorter ethylene pendant spacers. Poly(CBA-SP), poly(CBA-APPD), poly(CBA-APED) with increasing main chain spacers achieved similar transfection efficiencies, implying a smaller effect of polymer main chain length on transfection efficiency. ${ }^{192}$ Moreover, transfection results of the employed polymers varied for different cell lines, with poly(CBA-SP) inducing highest transfection in the $\mathrm{C} 2 \mathrm{C} 12$ cell line, and poly(CBA-APED) delivering the highest transfection in the HeLa cell line. The longer, more hydrophobic alkyl side chains and more flexible backbones of these polymers improved the buffering capacity, protonation degree of tertiary amine groups, basicity and charge density of the polymers, and therefore elevated the gene transfection efficiency. ${ }^{192}$

Another type of bioreducible PAAs was prepared via Michael addition between CBA and three $N$-Boc protected diamines ( $N$-Boc-1,2-diaminoethane, $N$-Boc-1,4-diaminobutane, and $N$-Boc-1,6-diaminohexane) followed by $N$-Boc removal (Figure 11C). The side-chain spacer length substantially influenced transfection induced by polyplexes prepared from these polymers. Cell experiments revealed that poly(CBA-DAH) with a hexamethylene pendant spacer induced comparable or higher transfection efficiency in vitro compared to standard PEI (25 kDa). ${ }^{193}$ After modification with prostaglandin $\mathrm{E}_{2}\left(\mathrm{PGE}_{2}\right)$, Fas siRNA was formulated and transported by poly(CBA-DAH) to rat cardiomyocytes (H9C2 cells) through $\mathrm{PGE}_{2}$ receptor-mediated endocytosis, affording enhanced Fas gene silencing and substantial inhibition of cardiomyocyte apoptosis without inducing interferon- $\alpha$ in peripheral blood mononuclear cells. ${ }^{194}$

Taking advantage of their excellent cell-penetrating abilities, ${ }^{195-198}$ arginine and guanidine groups have been merged into bioreducible polymers to achieve enhanced transfection activity. Arginine-grafted p(CBA-DAH) (ABP) was prepared with a molecular weight of $4.5 \mathrm{kDa} .{ }^{199}$ Cell experiments in mammalian cells revealed that ABP had no significant cytotoxicity and substantially enhanced transfection efficiency as compared to $\mathrm{p}(\mathrm{CBA}-$ $\mathrm{DAH})$ and standard PEI (25 kDa). The remarkable increase in transfection of ABP was not only contributed to its high cellular penetrating ability, but mediated by other factors as well, such as good nuclear localization ability. ${ }^{199}$ The arginine moieties in ABP were later found to directly penetrate the endosome membrane, which facilitated endosomal escape of 
the polyplexes. ${ }^{200} \mathrm{ABP}$ polymer was used in gene delivery of plasmid human EPP (phEPO) for prolonged and controlled release of erythropoietin (EPO). ${ }^{201}$ After transfection mediated by ABP polymer, long-term EPO expression stimulated hematopoietic progenitor cells and hence inhibited cardiomyocyte apoptosis in vitro. ${ }^{201}$ After systemic injection, the $\mathrm{ABP} / \mathrm{phEPO}$ complexes induced higher hematocrit levels over $60 \mathrm{~d}$ together with enhanced reticulocytosis and boosted EOP protein expression, due to the distinct temporal and spatial distribution of complexes. During the experiment period, the innate immune response (IL-6) was not significantly activated, in contrast to controls treated with standard PEI (25 kDa). ${ }^{202}$ Guanidinylated bioreducible polymer (GBP) was obtained by converting amine groups in $\mathrm{p}(\mathrm{CBA}-\mathrm{DAH})$ into guanidine groups with $1 H$-pyrazole-1-carboxamidine. This polymer exhibited 8-fold higher transfection activity than the precursor polymer, owing to higher cellular uptake efficiency (up to 96\%) and excellent nuclear localization ability contributed by the guanidine groups. ${ }^{203}$

PAAs with much higher molecular weight than those prepared through conventional Michael-type addition have been prepared through polycondensation between disulfidecontaining di- $p$-nitrophenyl esters and primary diamines (Figure 12) ${ }^{204}$ The cationic PAAs with disulfide and 1,4-bis(3-aminopropyl)piperazine (BAP) moieties gave comparable or higher transfection activities as observed for PEI (25 kDa) and Lipofectamine 2000, owing to their distinct properties including high buffering capacity, strong gene binding ability, and intracellular gene release ability. Intravenous administration of the bioreducible polyplexes induced higher transgene expression in mouse liver, than linear PEI (22 kDa).
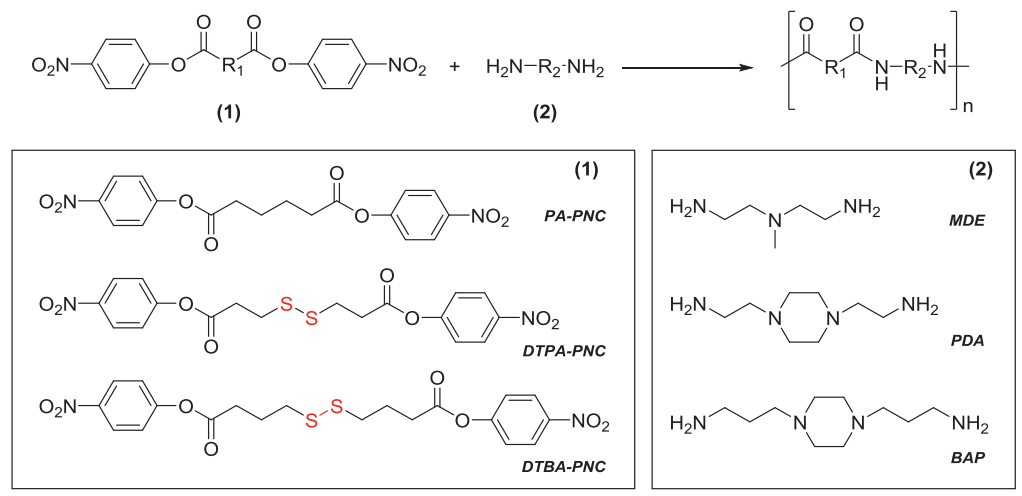

Figure 12. Synthesis of linear poly(amido amine)s via polycondensation between di-p-nitrophenyl esters and primary diamines. ${ }^{204}$ 


\section{CONCLUSION AND PERSPECTIVES}

Bioreducible disulfide bonds have been incorporated into polycationic materials by various synthetic approaches, providing favorable features to gene delivery carriers. In particular, the introduction of reducibility in the polymers allows polyplexes that are stable in the extracellular environment and dissemble in the intracellular compartment, leading to gene unpacking in an active manner. Moreover, usually colloidal stability of the polyplexes is enhanced by the introduction of disulfide bonds due to enhanced flexibility of the polymer chains by their free rotation around S-S bonds. Encouraging advances in bioreducible gene delivery carriers have been achieved both in vitro and in vivo. Nevertheless, the transfection efficiencies mediated by bioreducible polycationic vectors are still far from optimal, and potential toxicity of polymer fragments can be a risk. In addition, as common for cationic polyplexes, the transfection performance is still susceptible to serum proteins, leading to the formation of larger aggregates through non-specific interactions with proteins, and eventually diminishing transfection efficiency. Introduction of hydrophilic PEG chains to the polymers improves the circulation times of the polyplexes, however, often at the cost of transfection efficiency. Therefore, development of novel bioreducible polycationic vectors with minimized toxicity and improved transfection, even in the presence of serum, is of key importance to bring non-viral gene therapy further to the clinic. 


\section{REFERENCES}

(1) Kim, B. Y. S.; Rutka, J. T.; Chan, W. C. W. Nanomedicine. New Engl. J. Med. 2010, 363, 2434-2443.

(2) Ho, D. A. Fighting Cancer with Nanomedicine. Scientist 2014, 28, $26-27$.

(3) Liu, Y. F.; Wang, H. F. Nanomedicine - Nanotechnology tackles tumours. Nat. Nanotechnol. 2007, 2, 20-21.

(4) Brown, P. D.; Patel, P. R. Nanomedicine: a pharma perspective. Wiley Interdiscip. Rev.-Nanomed. Nanobiotechnol. 2015, 7, 125-130.

(5) Heath, J. R.; Davis, M. E.; Hood, L. Nanomedicine Targets CANCER. Sci. Am. 2009, 300, 44-51.

(6) El-Aneed, A. An overview of current delivery systems in cancer gene therapy. $J$. Controlled Release 2004, 94, 1-14.

(7) Clark, K. L.; Hughes, S. A.; Bulsara, P.; Coates, J.; Moores, K.; Parry, J.; Carr, M.; Mayer, R. J.; Wilson, P.; Gruenloh, C.; Levin, D.; Darton, J.; Weber, W.-M.; Sobczak, K.; Gill, D. R.; Hyde, S. C.; Davies, L. A.; Pringle, I. A.; Sumner-Jones, S. G.; Jadhav, V.; Jamison, S.; Strapps, W. R.; Pickering, V.; Edbrooke, M. R. Pharmacological Characterization of a Novel ENaC[alpha] siRNA (GSK2225745) With Potential for the Treatment of Cystic Fibrosis. Mol. Ther. Nucleic Acids 2013, 2, e65.

(8) Kaplitt, M. G.; Feigin, A.; Tang, C.; Fitzsimons, H. L.; Mattis, P.; Lawlor, P. A.; Bland, R. J.; Young, D.; Strybing, K.; Eidelberg, D.; During, M. J. Safety and tolerability of gene therapy with an adeno-associated virus (AAV) borne GAD gene for Parkinson's disease: an open label, phase I trial. The Lancet, 369, 20972105.

(9) Cavazzana-Calvo, M.; Hacein-Bey, S.; De Saint Basile, G.; Gross, F.; Yvon, E.; Nusbaum, P.; Selz, F.; Hue, C.; Certain, S.; Casanova, J. L.; Bousso, P.; Le Deist, F.; Fischer, A. Gene therapy of human severe combined immunodeficiency (SCID)-X1 disease. Science 2000, 288, 669-672.

(10) Grez, M.; Reichenbach, J.; Schwable, J.; Seger, R.; Dinauer, M. C.; Thrasher, A. J. Gene Therapy of Chronic Granulomatous Disease: The Engraftment Dilemma. Mol. Ther. 2011, 19, 28-35.

(11) Yin, H.; Kanasty, R. L.; Eltoukhy, A. A.; Vegas, A. J.; Dorkin, J. R.; Anderson, D. G. Non-viral vectors for gene-based therapy. Nat. Rev. Genet. 2014, 15, 541-555. 
(12) Scholz, C.; Wagner, E. Therapeutic plasmid DNA versus siRNA delivery: Common and different tasks for synthetic carriers. J. Controlled Release 2012, $161,554-565$.

(13) Mastrobattista, E.; Hennink, W. E. Polymers for Gene Delivery Charged for Success. Nat. Mater. 2012, 11, 10-12.

(14) Wang, Y.; Su, H.-h.; Yang, Y.; Hu, Y.; Zhang, L.; Blancafort, P.; Huang, L. Systemic Delivery of Modified mRNA Encoding Herpes Simplex Virus 1 Thymidine Kinase for Targeted Cancer Gene Therapy. Mol. Ther. 2013, 21, 358367.

(15) Su, X.; Fricke, J.; Kavanagh, D. G.; Irvine, D. J. In Vitro and in Vivo mRNA Delivery Using Lipid-Enveloped pH-Responsive Polymer Nanoparticles. Mol. Pharmaceutics 2011, 8, 774-787.

(16) Vader, P.; van der Aa, L.; Engbersen, J. J.; Storm, G.; Schiffelers, R. DisulfideBased Poly(amido amine)s for siRNA Delivery: Effects of Structure on siRNA Complexation, Cellular Uptake, Gene Silencing and Toxicity. Pharm. Res. 2011, $28,1013-1022$

(17) Whitehead, K. A.; Langer, R.; Anderson, D. G. Knocking down barriers: advances in siRNA delivery. Nat. Rev. Drug Discov. 2009, 8, 129-138.

(18) Dahlman, J. E.; Barnes, C.; Khan, O. F.; Thiriot, A.; Jhunjunwala, S.; Shaw, T. E.; Xing, Y. P.; Sager, H. B.; Sahay, G.; Speciner, L.; Bader, A.; Bogorad, R. L.; Yin, H.; Racie, T.; Dong, Y. Z.; Jiang, S.; Seedorf, D.; Dave, A.; Sandhu, K. S.; Webber, M. J.; Novobrantseva, T.; Ruda, V. M.; Lytton-Jean, A. K. R.; Levins, C. G.; Kalish, B.; Mudge, D. K.; Perez, M.; Abezgauz, L.; Dutta, P.; Smith, L.; Charisse, K.; Kieran, M. W.; Fitzgerald, K.; Nahrendorf, M.; Danino, D.; Tuder, R. M.; von Andrian, U. H.; Akinc, A.; Panigrahy, D.; Schroeder, A.; Koteliansky, V.; Langer, R.; Anderson, D. G. In vivo endothelial siRNA delivery using polymeric nanoparticles with low molecular weight. Nat. Nanotechnol. 2014, 9, 648-655.

(19) Kanasty, R.; Dorkin, J. R.; Vegas, A.; Anderson, D. Delivery materials for siRNA therapeutics. Nat. Mater. 2013, 12, 967-977.

(20) Liu, C.; Wen, J.; Meng, Y.; Zhang, K.; Zhu, J.; Ren, Y.; Qian, X.; Yuan, X.; Lu, Y.; Kang, C. Efficient Delivery of Therapeutic miRNA Nanocapsules for Tumor Suppression. Adv. Mater. 2015, 27, 292-297.

(21) Zhang, Y.; Wang, Z.; Gemeinhart, R. A. Progress in microRNA delivery. $J$. Controlled Release 2013, 172, 962-974. 
(22) Evers, M. M.; Toonen, L. J. A.; van Roon-Mom, W. M. C. Antisense oligonucleotides in therapy for neurodegenerative disorders. Adv. Drug Deliv. Rev. 2015, 87, 90-103.

(23) Juliano, R.; Alam, M. R.; Dixit, V.; Kang, H. Mechanisms and strategies for effective delivery of antisense and siRNA oligonucleotides. Nucleic Acids Res. 2008, 36, 4158-4171.

(24) Pack, D. W.; Hoffman, A. S.; Pun, S.; Stayton, P. S. Design and development of polymers for gene delivery. Nat. Rev. Drug Discov. 2005, 4, 581-593.

(25) Miyata, K.; Nishiyama, N.; Kataoka, K. Rational design of smart supramolecular assemblies for gene delivery: chemical challenges in the creation of artificial viruses. Chem. Soc. Rev. 2012, 41, 2562-2574.

(26) Thomas, C. E.; Ehrhardt, A.; Kay, M. A. Progress and problems with the use of viral vectors for gene therapy. Nat. Rev. Genet. 2003, 4, 346-358.

(27) Giacca, M.; Zacchigna, S. Virus-mediated gene delivery for human gene therapy. J. Controlled Release 2012, 161, 377-388.

(28) Mintzer, M. A.; Simanek, E. E. Nonviral Vectors for Gene Delivery. Chem. Rev. 2009, 109, 259-302.

(29) Croyle, M. A.; Cheng, X.; Wilson, J. M. Development of formulations that enhance physical stability of viral vectors for gene therapy. Gene Ther. 2001, 8, 1281-1290.

(30) Daniel, R.; Smith, J. A. Integration site selection by retroviral vectors: Molecular mechanism and clinical consequences. Hum. Gene. Ther. 2008, 19, 557-568.

(31) Lowenstein, P. R.; Mandel, R. J.; Xiong, W. D.; Kroeger, K.; Castro, M. G. Immune responses to adenovirus and adeno-associated vectors used for gene therapy of brain diseases: The role of immunological synapses in understanding the cell biology of neuroimmune interactions. Curr. Gene Ther. 2007, 7, 347-360.

(32) Rothe, M.; Modlich, U.; Schambach, A. Biosafety Challenges for Use of Lentiviral Vectors in Gene Therapy. Curr. Gene Ther. 2013, 13, 453-468.

(33) Seow, Y.; Wood, M. J. Biological Gene Delivery Vehicles: Beyond Viral Vectors. Mol. Ther. 2009, 17, 767-777.

(34) De Smedt, S. C.; Demeester, J.; Hennink, W. E. Cationic polymer based gene delivery systems. Pharm. Res. 2000, 17, 113-126.

(35) Jeong, J. H.; Kim, S. W.; Park, T. G. Molecular design of functional polymers for gene therapy. Prog. Polym. Sci. 2007, 32, 1239-1274. 
(36) Nguyen, D. N.; Green, J. J.; Chan, J. M.; Langer, R.; Anderson, D. G. Polymeric Materials for Gene Delivery and DNA Vaccination. Adv. Mater. 2009, 21, 847867.

(37) Bloomfield, V. A. DNA condensation by multivalent cations. Biopolymers 1997, 44, 269-282.

(38) Meneksedag-Erol, D.; Tang, T.; Uludağ, H. Molecular modeling of polynucleotide complexes. Biomaterials 2014, 35, 7068-7076.

(39) Schaaf, P.; Schlenoff, J. B. Saloplastics: processing compact polyelectrolyte complexes. Adv. Mater. 2015, 27, 2420-2432.

(40) Matyjaszewski, K.; Tsarevsky, N. V. Nanostructured functional materials prepared by atom transfer radical polymerization. Nat. Chem. 2009, 1, 276-288.

(41) Farokhzad, O. C.; Langer, R. Impact of Nanotechnology on Drug Delivery. Acs Nano 2009, 3, 16-20.

(42) Park, K. Facing the Truth about Nanotechnology in Drug Delivery. ACS Nano 2013, 7, 7442-7447.

(43) Chu, D. S. H.; Schellinger, J. G.; Shi, J. L.; Convertine, A. J.; Stayton, P. S.; Pun, S. H. Application of Living Free Radical Polymerization for Nucleic Acid Delivery. Acc. Chem. Res. 2012, 45, 1089-1099.

(44) Ahmed, M.; Narain, R. Progress of RAFT based polymers in gene delivery. Prog. Polym. Sci. 2013, 38, 767-790.

(45) Jones, C. H.; Chen, C. K.; Ravikrishnan, A.; Rane, S.; Pfeifer, B. A. Overcoming Nonviral Gene Delivery Barriers: Perspective and Future. Mol. Pharmaceutics 2013, 10, 4082-4098.

(46) Rejman, J.; Bragonzi, A.; Conese, M. Role of Clathrin- and Caveolae-Mediated Endocytosis in Gene Transfer Mediated by Lipo- and Polyplexes. Mol. Ther. 2005, $12,468-474$.

(47) Wagner, E. Effects of membrane-active agents in gene delivery. J. Controlled Release 1998, 53, 155-158.

(48) Schaffer, D. V.; Fidelman, N. A.; Dan, N.; Lauffenburger, D. A. Vector unpacking as a potential barrier for receptor-mediated polyplex gene delivery. Biotechnol. Bioeng. 2000, 67, 598-606.

(49) Luo, D.; Saltzman, W. M. Synthetic DNA delivery systems. Nat. Biotech. 2000, $18,33-37$. 
(50) Draghici, B.; Ilies, M. A. Synthetic Nucleic Acid Delivery Systems: Present and Perspectives. J. Med. Chem. 2015, 58, 4091-4130.

(51) Oupicky, D.; Li, J. Bioreducible polycations in nucleic acid delivery: past, present, and future trends. Macromol. Biosci. 2014, 14, 908-922.

(52) Lee, Y. S.; Kim, S. W. Bioreducible polymers for therapeutic gene delivery. $J$. Controlled Release 2014, 190, 424-439.

(53) Klein, P. M.; Wagner, E. Bioreducible polycations as shuttles for therapeutic nucleic acid and protein transfection. Antioxid. Redox Signal. 2014, 21, 804-817.

(54) Gongora-Benitez, M.; Tulla-Puche, J.; Albericio, F. Multifaceted Roles of Disulfide Bonds. Peptides as Therapeutics. Chem. Rev. 2014, 114, 901-926.

(55) Lee, M. H.; Yang, Z.; Lim, C. W.; Lee, Y. H.; Dongbang, S.; Kang, C.; Kim, J. S. Disulfide-Cleavage-Triggered Chemosensors and Their Biological Applications. Chem. Rev. 2013, 113, 5071-5109.

(56) Cheng, R.; Feng, F.; Meng, F. H.; Deng, C.; Feijen, J.; Zhong, Z. Y. Glutathioneresponsive nano-vehicles as a promising platform for targeted intracellular drug and gene delivery. J. Controlled Release 2011, 152, 2-12.

(57) Meng, F. H.; Hennink, W. E.; Zhong, Z. Reduction-sensitive polymers and bioconjugates for biomedical applications. Biomaterials 2009, 30, 2180-2198.

(58) Bauhuber, S.; Hozsa, C.; Breunig, M.; Gopferich, A. Delivery of Nucleic Acids via Disulfide-Based Carrier Systems. Adv. Mater. 2009, 21, 3286-3306.

(59) Schafer, F. Q.; Buettner, G. R. Redox environment of the cell as viewed through the redox state of the glutathione disulfide/glutathione couple. Free Radical Bio. Med. 2001, 30, 1191-1212.

(60) Lin, C.; Engbersen, J. F. J. The role of the disulfide group in disulfide-based polymeric gene carriers. Expert Opin. Drug Delivery 2009, 6, 421-439.

(61) Fass, D. Disulfide Bonding in Protein Biophysics. Annual Review of Biophysics 2012, 41, 63-79.

(62) Holmgren, A.; Bjornstedt, M.: [21] Thioredoxin and thioredoxin reductase. In Methods in Enzymology; Lester, P., Ed.; Academic Press, 1995; Vol. Volume 252; pp 199-208.

(63) Boussif, O.; Lezoualc'h, F.; Zanta, M. A.; Mergny, M. D.; Scherman, D.; Demeneix, B.; Behr, J. P. A versatile vector for gene and oligonucleotide transfer into cells in culture and in vivo: polyethylenimine. Proc. Natl. Acad. Sci. U.S.A. 1995, 92, 7297-7301. 
(64) Bolcato-Bellemin, A.-L.; Bonnet, M.-E.; Creusat, G.; Erbacher, P.; Behr, J.-P. Sticky overhangs enhance siRNA-mediated gene silencing. Proc. Natl. Acad. Sci. U.S.A. 2007, 104, 16050-16055.

(65) Zou, S.-M.; Erbacher, P.; Remy, J.-S.; Behr, J.-P. Systemic linear polyethylenimine (L-PEI)-mediated gene delivery in the mouse. J. Gene Med. 2000, 2, 128-134.

(66) Behr, J.-P. Synthetic Gene Transfer Vectors II: Back to the Future. Acc. Chem. Res. 2012, 45, 980-984.

(67) Chollet, P.; Favrot, M. C.; Hurbin, A.; Coll, J.-L. Side-effects of a systemic injection of linear polyethylenimine-DNA complexes. J. Gene Med. 2002, 4, 8491.

(68) Moghimi, S. M.; Symonds, P.; Murray, J. C.; Hunter, A. C.; Debska, G.; Szewczyk, A. A two-stage poly(ethylenimine)-mediated cytotoxicity: implications for gene transfer/therapy. Mol. Ther. 2005, 11, 990-995.

(69) Grandinetti, G.; Ingle, N. P.; Reineke, T. M. Interaction of Poly(ethylenimine)DNA Polyplexes with Mitochondria: Implications for a Mechanism of Cytotoxicity. Mol. Pharmaceutics 2011, 8, 1709-1719.

(70) Merkel, O. M.; Urbanics, R.; Bedőcs, P.; Rozsnyay, Z.; Rosivall, L.; Toth, M.; Kissel, T.; Szebeni, J. In vitro and in vivo complement activation and related anaphylactic effects associated with polyethylenimine and polyethylenimine-graftpoly(ethylene glycol) block copolymers. Biomaterials 2011, 32, 4936-4942.

(71) Gosselin, M. A.; Guo, W.; Lee, R. J. Efficient Gene Transfer Using Reversibly Cross-Linked Low Molecular Weight Polyethylenimine. Bioconjugate Chem. 2001, 12, 989-994.

(72) Wang, Y.; Chen, P.; Shen, J. The development and characterization of a glutathione-sensitive cross-linked polyethylenimine gene vector. Biomaterials 2006, 27, 5292-5298.

(73) Peng, Q.; Zhong, Z.; Zhuo, R. Disulfide Cross-Linked Polyethylenimines (PEI) Prepared via Thiolation of Low Molecular Weight PEI as Highly Efficient Gene Vectors. Bioconjugate Chem. 2008, 19, 499-506.

(74) Sun, Y.-X.; Zeng, X.; Meng, Q.-F.; Zhang, X.-Z.; Cheng, S.-X.; Zhuo, R.-X. The influence of RGD addition on the gene transfer characteristics of disulfidecontaining polyethyleneimine/DNA complexes. Biomaterials 2008, 29, 4356-4365. 
(75) Choi, S.; Lee, K.-D. Enhanced gene delivery using disulfide-crosslinked low molecular weight polyethylenimine with listeriolysin o-polyethylenimine disulfide conjugate. J. Controlled Release 2008, 131, 70-76.

(76) Zheng, M.; Zhong, Y.; Meng, F.; Peng, R.; Zhong, Z. Lipoic Acid Modified Low Molecular Weight Polyethylenimine Mediates Nontoxic and Highly Potent in Vitro Gene Transfection. Mol. Pharmaceutics 2011, 8, 2434-2443.

(77) Wang, Y.; Zheng, M.; Meng, F.; Zhang, J.; Peng, R.; Zhong, Z. Branched Polyethylenimine Derivatives with Reductively Cleavable Periphery for Safe and Efficient In Vitro Gene Transfer. Biomacromolecules 2011, 12, 1032-1040.

(78) Kang, H. C.; Kang, H.-J.; Bae, Y. H. A reducible polycationic gene vector derived from thiolated low molecular weight branched polyethyleneimine linked by 2 iminothiolane. Biomaterials 2011, 32, 1193-1203.

(79) Lee, D.; Lee, Y. M.; Jeong, C.; Lee, J.; Kim, W. J. Bioreducible Guanidinylated Polyethylenimine for Efficient Gene Delivery. ChemMedChem 2014, 9, 27182724.

(80) Breunig, M.; Lungwitz, U.; Liebl, R.; Goepferich, A. Breaking up the correlation between efficacy and toxicity for nonviral gene delivery. Proc. Natl. Acad. Sci. U.S.A. 2007, 104, 14454-14459.

(81) Breunig, M.; Hozsa, C.; Lungwitz, U.; Watanabe, K.; Umeda, I.; Kato, H.; Goepferich, A. Mechanistic investigation of poly(ethylene imine)-based siRNA delivery: Disulfide bonds boost intracellular release of the cargo. J. Controlled Release 2008, 130, 57-63.

(82) Xia, W.; Wang, P.; Lin, C.; Li, Z.; Gao, X.; Wang, G.; Zhao, X. Bioreducible polyethylenimine-delivered siRNA targeting human telomerase reverse transcriptase inhibits HepG2 cell growth in vitro and in vivo. J. Controlled Release 2012, 157, 427-436.

(83) Liu, J.; Jiang, X.; Xu, L.; Wang, X.; Hennink, W. E.; Zhuo, R. Novel ReductionResponsive Cross-Linked Polyethylenimine Derivatives by Click Chemistry for Nonviral Gene Delivery. Bioconjugate Chem. 2010, 21, 1827-1835.

(84) Jiang, X.; Liu, J.; Xu, L.; Zhuo, R. Disulfide-Containing Hyperbranched Polyethylenimine Derivatives via Click Chemistry for Nonviral Gene Delivery. Macromolecular Chemistry and Physics 2011, 212, 64-71. 
(85) Zhang, G.; Liu, J.; Yang, Q.; Zhuo, R.; Jiang, X. Disulfide-Containing Brushed Polyethylenimine Derivative Synthesized by Click Chemistry for Nonviral Gene Delivery. Bioconjugate Chem. 2012, 23, 1290-1299.

(86) Lee, Y.; Mo, H.; Koo, H.; Park, J.-Y.; Cho, M. Y.; Jin, G.-w.; Park, J.-S. Visualization of the Degradation of a Disulfide Polymer, Linear Poly(ethylenimine sulfide), for Gene Delivery. Bioconjugate Chem. 2007, 18, 13-18.

(87) Ma, Y.; Wu, C. Revisiting the complexation between DNA and polyethylenimine - when and where -S-S- linked PEI is cleaved inside the cell. J. Mater. Chem. B 2014, 2, 3282-3291.

(88) Du, X.; Shi, B.; Tang, Y.; Dai, S.; Qiao, S. Z. Label-free dendrimer-like silica nanohybrids for traceable and controlled gene delivery. Biomaterials 2014, 35, $5580-5590$.

(89) Shi, B.; Zhang, H.; Qiao, S. Z.; Bi, J.; Dai, S. Intracellular MicroenvironmentResponsive Label-Free Autofluorescent Nanogels for Traceable Gene Delivery. Adv. Healthcare Mater. 2014, 3, 1839-1848.

(90) Du, X.; Xiong, L.; Dai, S.; Kleitz, F.; Qiao, S. Z. Intracellular MicroenvironmentResponsive Dendrimer-Like Mesoporous Nanohybrids for Traceable, Effective, and Safe Gene Delivery. Adv. Funct. Mater. 2014, 24, 7627-7637.

(91) Yang, Y.; Jia, Y.; Gao, L.; Fei, J.; Dai, L.; Zhao, J.; Li, J. Fabrication of autofluorescent protein coated mesoporous silica nanoparticles for biological application. Chem. Commun. 2011, 47, 12167-12169.

(92) Wei, W.; Wang, L. Y.; Yuan, L.; Wei, Q.; Yang, X. D.; Su, Z. G.; Ma, G. H. Preparation and Application of Novel Microspheres Possessing Autofluorescent Properties. Adv. Funct. Mater. 2007, 17, 3153-3158.

(93) Jia, Y.; Fei, J.; Cui, Y.; Yang, Y.; Gao, L.; Li, J. pH-responsive polysaccharide microcapsules through covalent bonding assembly. Chem. Commun. 2011, 47, $1175-1177$

(94) Carlisle, R. C.; Etrych, T.; Briggs, S. S.; Preece, J. A.; Ulbrich, K.; Seymour, L. W. Polymer-coated polyethylenimine/DNA complexes designed for triggered activation by intracellular reduction. J. Gene Med. 2004, 6, 337-344.

(95) Neu, M.; Sitterberg, J.; Bakowsky, U.; Kissel, T. Stabilized Nanocarriers for Plasmids Based Upon Cross-linked Poly(ethylene imine). Biomacromolecules 2006, 7, 3428-3438. 
(96) Neu, M.; Germershaus, O.; Mao, S.; Voigt, K.-H.; Behe, M.; Kissel, T. Crosslinked nanocarriers based upon poly(ethylene imine) for systemic plasmid delivery: In vitro characterization and in vivo studies in mice. J. Controlled Release 2007, 118, 370-380.

(97) Neu, M.; Germershaus, O.; Behe, M.; Kissel, T. Bioreversibly crosslinked polyplexes of PEI and high molecular weight PEG show extended circulation times in vivo. J. Controlled Release 2007, 124, 69-80.

(98) Bauhuber, S.; Liebl, R.; Tomasetti, L.; Rachel, R.; Goepferich, A.; Breunig, M. A library of strictly linear poly(ethylene glycol)-poly(ethylene imine) diblock copolymers to perform structure-function relationship of non-viral gene carriers. $J$. Controlled Release 2012, 162, 446-455.

(99) Piao, J.-G.; Ding, S.-G.; Yang, L.; Hong, C.-Y.; You, Y.-Z. Bioreducible CrossLinked Nanoshell Enhances Gene Transfection of Polycation/DNA Polyplex in Vivo. Biomacromolecules 2014, 15, 2907-2913.

(100) Wang, F. H.; Shen, Y. Y.; Zhang, W. J.; Li, M.; Wang, Y.; Zhou, D. J.; Guo, S. R. Efficient, dual-stimuli responsive cytosolic gene delivery using a RGD modified disulfide-linked polyethylenimine functionalized gold nanorod. J Control Release 2014, 196, 37-51.

(101) Wang, F.; Zhang, W.; Shen, Y.; Huang, Q.; Zhou, D.; Guo, S. Efficient RNA delivery by integrin-targeted glutathione responsive polyethyleneimine capped gold nanorods. Acta Biomater. 2015, 23, 136-146.

(102) Kruusma, J.; Benham, A. M.; Williams, J. A. G.; Kataky, R. An introduction to thiol redox proteins in the endoplasmic reticulum and a review of current electrochemical methods of detection of thiols. Analyst 2006, 131, 459-473.

(103) Butera, D.; Cook, K. M.; Chiu, J.; Wong, J. W. H.; Hogg, P. J.: Control of blood proteins by functional disulfide bonds, 2014; Vol. 123.

(104) Feng, L.; Xie, A.; Hu, X.; Liu, Y.; Zhang, J.; Li, S.; Dong, W. A releasable disulfide carbonate linker for polyethyleneimine (PEI)-based gene vectors. New J Chem 2014, 38, 5207-5214.

(105) Lee, M. H.; Kim, J. Y.; Han, J. H.; Bhuniya, S.; Sessler, J. L.; Kang, C.; Kim, J. S. Direct Fluorescence Monitoring of the Delivery and Cellular Uptake of a CancerTargeted RGD Peptide-Appended Naphthalimide Theragnostic Prodrug. J. Am. Chem. Soc. 2012, 134, 12668-12674. 
(106) Lee, M. H.; Han, J. H.; Kwon, P.-S.; Bhuniya, S.; Kim, J. Y.; Sessler, J. L.; Kang, C.; Kim, J. S. Hepatocyte-Targeting Single Galactose-Appended Naphthalimide: A Tool for Intracellular Thiol Imaging in Vivo. J. Am. Chem. Soc. 2012, 134, 1316-1322.

(107) Cherng, J.-Y.; van de Wetering, P.; Talsma, H.; Crommelin, D. A.; Hennink, W. Effect of Size and Serum Proteins on Transfection Efficiency of Poly ((2dimethylamino)ethyl Methacrylate)-Plasmid Nanoparticles. Pharm. Res. 1996, 13, 1038-1042.

(108) Agarwal, S.; Zhang, Y.; Maji, S.; Greiner, A. PDMAEMA based gene delivery materials. Mater. Today 2012, 15, 388-393.

(109) Rungsardthong, U.; Deshpande, M.; Bailey, L.; Vamvakaki, M.; Armes, S. P.; Garnett, M. C.; Stolnik, S. Copolymers of amine methacrylate with poly(ethylene glycol) as vectors for gene therapy. J. Controlled Release 2001, 73, 359-380.

(110) Plamper, F. A.; Schmalz, A.; Penott-Chang, E.; Drechsler, M.; Jusufi, A.; Ballauff, M.; Müller, A. H. E. Synthesis and Characterization of Star-Shaped Poly(N,Ndimethylaminoethyl methacrylate) and Its Quaternized Ammonium Salts. Macromolecules 2007, 40, 5689-5697.

(111) Sahnoun, M.; Charreyre, M.-T.; Veron, L.; Delair, T.; D'Agosto, F. Synthetic and characterization aspects of dimethylaminoethyl methacrylate reversible addition fragmentation chain transfer (RAFT) polymerization. J. Polym. Sci., Part A: Polym. Chem. 2005, 43, 3551-3565.

(112) You, Y.-Z.; Manickam, D. S.; Zhou, Q.-H.; Oupický, D. Reducible poly(2dimethylaminoethyl methacrylate): Synthesis, cytotoxicity, and gene delivery activity. J. Controlled Release 2007, 122, 217-225.

(113) You, Y.-Z.; Zhou, Q.-H.; Manickam, D. S.; Wan, L.; Mao, G.-Z.; Oupický, D. Dually Responsive Multiblock Copolymers via Reversible Addition-Fragmentation Chain Transfer Polymerization: Synthesis of Temperature- and Redox-Responsive Copolymers of Poly(N-isopropylacrylamide) and Poly(2-(dimethylamino)ethyl methacrylate). Macromolecules 2007, 40, 86178624.

(114) You, Y.-Z.; Manickam, D. S.; Zhou, Q.-H.; Oupický, D. A Versatile Approach to Reducible Vinyl Polymers via Oxidation of Telechelic Polymers Prepared by Reversible Addition Fragmentation Chain Transfer Polymerization. Biomacromolecules 2007, 8, 2038-2044. 
(115) Dai, F.; Sun, P.; Liu, Y.; Liu, W. Redox-cleavable star cationic PDMAEMA by arm-first approach of ATRP as a nonviral vector for gene delivery. Biomaterials 2010, 31, 559-569.

(116) Gao, H.; Matyjaszewski, K. Arm-First Method As a Simple and General Method for Synthesis of Miktoarm Star Copolymers. J. Am. Chem. Soc. 2007, 129, 1182811834.

(117) Cho, H. Y.; Srinivasan, A.; Hong, J.; Hsu, E.; Liu, S.; Shrivats, A.; Kwak, D.; Bohaty, A. K.; Paik, H.-j.; Hollinger, J. O.; Matyjaszewski, K. Synthesis of Biocompatible PEG-Based Star Polymers with Cationic and Degradable Core for siRNA Delivery. Biomacromolecules 2011, 12, 3478-3486.

(118) Lin, D.; Cheng, Q.; Jiang, Q.; Huang, Y.; Yang, Z.; Han, S.; Zhao, Y.; Guo, S.; Liang, Z.; Dong, A. Intracellular cleavable poly(2-dimethylaminoethyl methacrylate) functionalized mesoporous silica nanoparticles for efficient siRNA delivery in vitro and in vivo. Nanoscale 2013, 5, 4291-4301.

(119) Zhu, C.; Zheng, M.; Meng, F.; Mickler, F. M.; Ruthardt, N.; Zhu, X.; Zhong, Z. Reversibly Shielded DNA Polyplexes Based on Bioreducible PDMAEMA-SSPEG-SS-PDMAEMA Triblock Copolymers Mediate Markedly Enhanced Nonviral Gene Transfection. Biomacromolecules 2012, 13, 769-778.

(120) Liu, J.; Xu, Y.; Yang, Q.; Li, C.; Hennink, W. E.; Zhuo, R.; Jiang, X. Reduction biodegradable brushed PDMAEMA derivatives synthesized by atom transfer radical polymerization and click chemistry for gene delivery. Acta Biomater. 2013, 9, 7758-7766.

(121) Tan, J.-K. Y.; Choi, J. L.; Wei, H.; Schellinger, J. G.; Pun, S. H. Reducible, dibromomaleimide-linked polymers for gene delivery. Biomater. Sci. 2015, 3, 112-120.

(122) Zheng, Y.; Cao, H.; Newland, B.; Dong, Y.; Pandit, A.; Wang, W. 3D Single Cyclized Polymer Chain Structure from Controlled Polymerization of Multi-Vinyl Monomers: Beyond Flory-Stockmayer Theory. J. Am. Chem. Soc. 2011, 133, 13130-13137.

(123) Newland, B.; Zheng, Y.; Jin, Y.; Abu-Rub, M.; Cao, H.; Wang, W.; Pandit, A. Single Cyclized Molecule Versus Single Branched Molecule: A Simple and Efficient 3D "Knot" Polymer Structure for Nonviral Gene Delivery. J. Am. Chem. Soc. 2012, 134, 4782-4789. 
(124) Zhao, T.; Zheng, Y.; Poly, J.; Wang, W. Controlled multi-vinyl monomer homopolymerization through vinyl oligomer combination as a universal approach to hyperbranched architectures. Nat. Commun. 2013, 4, 1873.

(125) Zhao, T.; Zhang, H.; Newland, B.; Aied, A.; Zhou, D.; Wang, W. Significance of Branching for Transfection: Synthesis of Highly Branched Degradable Functional Poly(dimethylaminoethyl methacrylate) by Vinyl Oligomer Combination. Angew . Chem., Int. Ed. 2014, 53, 6095-6100.

(126) Aied, A.; Zheng, Y.; Newland, B.; Wang, W. Beyond Branching: Multiknot Structured Polymer for Gene Delivery. Biomacromolecules 2014, 15, 4520-4527.

(127) Novo, L.; van Gaal, E. V. B.; Mastrobattista, E.; van Nostrum, C. F.; Hennink, W. E. Decationized crosslinked polyplexes for redox-triggered gene delivery. $J$. Controlled Release 2013, 169, 246-256.

(128) Novo, L.; Mastrobattista, E.; van Nostrum, C. F.; Hennink, W. E. Targeted Decationized Polyplexes for Cell Specific Gene Delivery. Bioconjugate Chem. 2014, 25, 802-812.

(129) Novo, L.; Takeda, K. M.; Petteta, T.; Dakwar, G. R.; van den Dikkenberg, J. B.; Remaut, K.; Braeckmans, K.; van Nostrum, C. F.; Mastrobattista, E.; Hennink, W. E. Targeted Decationized Polyplexes for siRNA Delivery. Mol. Pharmaceutics 2015, 12, 150-161.

(130) Novo, L.; Rizzo, L. Y.; Golombek, S. K.; Dakwar, G. R.; Lou, B.; Remaut, K.; Mastrobattista, E.; van Nostrum, C. F.; Jahnen-Dechent, W.; Kiessling, F.; Braeckmans, K.; Lammers, T.; Hennink, W. E. Decationized polyplexes as stable and safe carrier systems for improved biodistribution in systemic gene therapy. $J$. Controlled Release 2014, 195, 162-175.

(131) Oupický, D.; Parker, A. L.; Seymour, L. W. Laterally Stabilized Complexes of DNA with Linear Reducible Polycations: Strategy for Triggered Intracellular Activation of DNA Delivery Vectors. J. Am. Chem. Soc. 2002, 124, 8-9.

(132) Read, M. L.; Bremner, K. H.; Oupický, D.; Green, N. K.; Searle, P. F.; Seymour, L. W. Vectors based on reducible polycations facilitate intracellular release of nucleic acids. J. Gene Med. 2003, 5, 232-245.

(133) Read, M. L.; Singh, S.; Ahmed, Z.; Stevenson, M.; Briggs, S. S.; Oupicky, D.; Barrett, L. B.; Spice, R.; Kendall, M.; Berry, M.; Preece, J. A.; Logan, A.; Seymour, L. W. A versatile reducible polycation-based system for efficient delivery of a broad range of nucleic acids. Nucleic Acids Res. 2005, 33, e86. 
(134) Hwang, H. S.; Kang, H. C.; Bae, Y. H. Bioreducible Polymers As a Determining Factor for Polyplex Decomplexation Rate and Transfection. Biomacromolecules 2013, 14, 548-556.

(135) Zhou, J.; Li, Y.; Dong, H.; Yuan, H.; Ren, T.; Li, Y. Effect of monomer sequence of poly(histidine/lysine) catiomers on gene packing capacity and delivery efficiency. RSC Adv. 2015, 5, 14138-14146.

(136) Kakizawa, Y.; Kataoka, K. Block copolymer micelles for delivery of gene and related compounds. Adv. Drug Delivery Rev. 2002, 54, 203-222.

(137) Harada, A.; Kataoka, K. Formation of Polyion Complex Micelles in an Aqueous Milieu from a Pair of Oppositely-Charged Block Copolymers with Poly(ethylene glycol) Segments. Macromolecules 1995, 28, 5294-5299.

(138) Katayose, S.; Kataoka, K. Water-Soluble Polyion Complex Associates of DNA and Poly(ethylene glycol)-Poly(l-lysine) Block Copolymer. Bioconjugate Chem. 1997, 8, 702-707.

(139) Harada, A.; Kataoka, K. Chain Length Recognition: Core-Shell Supramolecular Assembly from Oppositely Charged Block Copolymers. Science 1999, 283, 65-67.

(140) CabralH; MatsumotoY; MizunoK; ChenQ; MurakamiM; KimuraM; TeradaY; Kano, M. R.; MiyazonoK; UesakaM; NishiyamaN; KataokaK. Accumulation of sub-100 nm polymeric micelles in poorly permeable tumours depends on size. Nat. Nanotechnol. 2011, 6, 815-823.

(141) Kakizawa, Y.; Harada, A.; Kataoka, K. Glutathione-Sensitive Stabilization of Block Copolymer Micelles Composed of Antisense DNA and Thiolated Poly(ethylene glycol)-block-poly(l-lysine): A Potential Carrier for Systemic Delivery of Antisense DNA. Biomacromolecules 2001, 2, 491-497.

(142) Miyata, K.; Kakizawa, Y.; Nishiyama, N.; Harada, A.; Yamasaki, Y.; Koyama, H.; Kataoka, K. Block Catiomer Polyplexes with Regulated Densities of Charge and Disulfide Cross-Linking Directed To Enhance Gene Expression. J. Am. Chem. Soc. 2004, 126, 2355-2361.

(143) Miyata, K.; Kakizawa, Y.; Nishiyama, N.; Yamasaki, Y.; Watanabe, T.; Kohara, M.; Kataoka, K. Freeze-dried formulations for in vivo gene delivery of PEGylated polyplex micelles with disulfide crosslinked cores to the liver. J. Controlled Release 2005, 109, 15-23.

(144) Sanjoh, M.; Miyata, K.; Christie, R. J.; Ishii, T.; Maeda, Y.; Pittella, F.; Hiki, S.; Nishiyama, N.; Kataoka, K. Dual Environment-Responsive Polyplex Carriers for 
Enhanced Intracellular Delivery of Plasmid DNA. Biomacromolecules 2012, 13, 3641-3649.

(145) Matsumoto, S.; Christie, R. J.; Nishiyama, N.; Miyata, K.; Ishii, A.; Oba, M.; Koyama, H.; Yamasaki, Y.; Kataoka, K. Environment-Responsive Block Copolymer Micelles with a Disulfide Cross-Linked Core for Enhanced siRNA Delivery. Biomacromolecules 2009, 10, 119-127.

(146) Christie, R. J.; Miyata, K.; Matsumoto, Y.; Nomoto, T.; Menasco, D.; Lai, T. C.; Pennisi, M.; Osada, K.; Fukushima, S.; Nishiyama, N.; Yamasaki, Y.; Kataoka, K. Effect of Polymer Structure on Micelles Formed between siRNA and Cationic Block Copolymer Comprising Thiols and Amidines. Biomacromolecules 2011, 12 , 3174-3185.

(147) Christie, R. J.; Matsumoto, Y.; Miyata, K.; Nomoto, T.; Fukushima, S.; Osada, K.; Halnaut, J.; Pittella, F.; Kim, H. J.; Nishiyama, N.; Kataoka, K. Targeted Polymeric Micelles for siRNA Treatment of Experimental Cancer by Intravenous Injection. ACS Nano 2012, 6, 5174-5189.

(148) Oe, Y.; Christie, R. J.; Naito, M.; Low, S. A.; Fukushima, S.; Toh, K.; Miura, Y.; Matsumoto, Y.; Nishiyama, N.; Miyata, K.; Kataoka, K. Actively-targeted polyion complex micelles stabilized by cholesterol and disulfide cross-linking for systemic delivery of siRNA to solid tumors. Biomaterials 2014, 35, 7887-7895.

(149) Li, J.; Cheng, D.; Yin, T.; Chen, W.; Lin, Y.; Chen, J.; Li, R.; Shuai, X. Copolymer of poly(ethylene glycol) and poly(l-lysine) grafting polyethylenimine through a reducible disulfide linkage for siRNA delivery. Nanoscale 2014, 6, 1732-1740.

(150) Cass, P.; Knower, W.; Hinton, T.; Shi, S.; Grusche, F.; Tizard, M.; Gunatillake, P. Synthesis and evaluation of degradable polyurea block copolymers as siRNA delivery agents. Acta Biomater. 2013, 9, 8299-8307.

(151) Kanayama, N.; Fukushima, S.; Nishiyama, N.; Itaka, K.; Jang, W.-D.; Miyata, K.; Yamasaki, Y.; Chung, U.-i.; Kataoka, K. A PEG-Based Biocompatible Block Catiomer with High Buffering Capacity for the Construction of Polyplex Micelles Showing Efficient Gene Transfer toward Primary Cells. ChemMedChem 2006, 1, 439-444.

(152) Takae, S.; Miyata, K.; Oba, M.; Ishii, T.; Nishiyama, N.; Itaka, K.; Yamasaki, Y.; Koyama, H.; Kataoka, K. PEG-Detachable Polyplex Micelles Based on Disulfide- 
Linked Block Catiomers as Bioresponsive Nonviral Gene Vectors. J. Am. Chem. Soc. 2008, 130, 6001-6009.

(153) Dai, J.; Lin, S.; Cheng, D.; Zou, S.; Shuai, X. Interlayer-Crosslinked Micelle with Partially Hydrated Core Showing Reduction and $\mathrm{pH}$ Dual Sensitivity for Pinpointed Intracellular Drug Release. Angew. Chem., Int. Ed. 2011, 50, 94049408.

(154) Li, J.; Yu, X.; Wang, Y.; Yuan, Y.; Xiao, H.; Cheng, D.; Shuai, X. A Reduction and $\mathrm{pH}$ Dual-Sensitive Polymeric Vector for Long-Circulating and TumorTargeted siRNA Delivery. Adv. Mater. 2014, 26, 8217-8224.

(155) Chen, W.; Yuan, Y.; Cheng, D.; Chen, J.; Wang, L.; Shuai, X. Co-Delivery of Doxorubicin and siRNA with Reduction and $\mathrm{pH}$ Dually Sensitive Nanocarrier for Synergistic Cancer Therapy. Small 2014, 10, 2678-2687.

(156) Lynn, D. M.; Langer, R. Degradable Poly( $\beta$-amino esters): Synthesis, Characterization, and Self-Assembly with Plasmid DNA. J. Am. Chem. Soc. 2000, 122, 10761-10768.

(157) Keeney, M.; Ong, S.-G.; Padilla, A.; Yao, Z.; Goodman, S.; Wu, J. C.; Yang, F. Development of Poly( $\beta$-amino ester)-Based Biodegradable Nanoparticles for Nonviral Delivery of Minicircle DNA. ACS Nano 2013, 7, 7241-7250.

(158) Cutlar, L.; Zhou, D.; Gao, Y.; Zhao, T.; Greiser, U.; Wang, W.; Wang, W. Highly Branched Poly( $\beta$-Amino Esters): Synthesis and Application in Gene Delivery. Biomacromolecules 2015, 16, 2609-2617.

(159) Mastorakos, P.; da Silva, A. L.; Chisholm, J.; Song, E.; Choi, W. K.; Boyle, M. P.; Morales, M. M.; Hanes, J.; Suk, J. S. Highly compacted biodegradable DNA nanoparticles capable of overcoming the mucus barrier for inhaled lung gene therapy. Proc. Natl. Acad. Sci. U.S.A. 2015, 112, 8720-8725.

(160) Deng, X.; Zheng, N.; Song, Z.; Yin, L.; Cheng, J. Trigger-responsive, fastdegradable poly( $\beta$-amino ester)s for enhanced DNA unpackaging and reduced toxicity. Biomaterials 2014, 35, 5006-5015.

(161) Anderson, D. G.; Lynn, D. M.; Langer, R. Semi-Automated Synthesis and Screening of a Large Library of Degradable Cationic Polymers for Gene Delivery. Angew. Chem. Int. Ed. 2003, 42, 3153-3158.

(162) Lynn, D. M.; Anderson, D. G.; Putnam, D.; Langer, R. Accelerated discovery of synthetic transfection vectors: parallel synthesis and screening of a degradable polymer library. J. Am. Chem. Soc. 2001, 123, 8155-5156. 
(163) Sunshine, J. C.; Sunshine, S. B.; Bhutto, I.; Handa, J. T.; Green, J. J. Poly( $\beta$-amino ester)-nanoparticle mediated transfection of retinal pigment epithelial cells in vitro and in vivo. Plos One 2012, 7, e37543.

(164) Huang, Y.-H.; Zugates, G. T.; Peng, W.; Holtz, D.; Dunton, C.; Green, J. J.; Hossain, N.; Chernick, M. R.; Padera, R. F.; Langer, R.; Anderson, D. G.; Sawicki, J. A. Nanoparticle-Delivered Suicide Gene Therapy Effectively Reduces Ovarian Tumor Burden in Mice. Cancer Res. 2009, 69, 6184-6191.

(165) Zugates, G. T.; Anderson, D. G.; Little, S. R.; Lawhorn, I. E. B.; Langer, R. Synthesis of Poly( $\beta$-amino ester)s with Thiol-Reactive Side Chains for DNA Delivery. J. Am. Chem. Soc. 2006, 128, 12726-12734.

(166) Tzeng, S. Y.; Hung, B. P.; Grayson, W. L.; Green, J. J. Cystamine-terminated poly(beta-amino ester)s for siRNA delivery to human mesenchymal stem cells and enhancement of osteogenic differentiation. Biomaterials 2012, 33, 8142-8151.

(167) Kozielski, K. L.; Tzeng, S. Y.; Green, J. J. A bioreducible linear poly $(\beta$-amino ester) for siRNA delivery. Chem. Commun. 2013, 49, 5319-5321.

(168) Kozielski, K. L.; Tzeng, S. Y.; Hurtado De Mendoza, B. A.; Green, J. J. Bioreducible Cationic Polymer-Based Nanoparticles for Efficient and Environmentally Triggered Cytoplasmic siRNA Delivery to Primary Human Brain Cancer Cells. ACS Nano 2014, 8, 3232-3241.

(169) Ferruti, P.; Marchisio, M. A.; Duncan, R. Poly(amido-amine)s: Biomedical applications. Macromol. Rapid Comm. 2002, 23, 332-355.

(170) Ferruti, P. Poly(amidoamine)s: Past, present, and perspectives. J. Polym. Sci., Part A: Polym. Chem. 2013, 51, 2319-2353.

(171) Lin, C.; Zhong, Z.; Lok, M. C.; Jiang, X.; Hennink, W. E.; Feijen, J.; Engbersen, J. F. J. Linear poly(amido amine)s with secondary and tertiary amino groups and variable amounts of disulfide linkages: Synthesis and in vitro gene transfer properties. J. Controlled Release 2006, 116, 130-137.

(172) Lin, C.; Zhong, Z.; Lok, M. C.; Jiang, X.; Hennink, W. E.; Feijen, J.; Engbersen, J. F. J. Novel Bioreducible Poly(amido amine)s for Highly Efficient Gene Delivery. Bioconjugate Chem. 2007, 18, 138-145.

(173) Lin, C.; Engbersen, J. F. J. Effect of chemical functionalities in poly(amido amine)s for non-viral gene transfection. J. Controlled Release 2008, 132, 267-272.

(174) Lin, C.; Blaauboer, C.-J.; Timoneda, M. M.; Lok, M. C.; van Steenbergen, M.; Hennink, W. E.; Zhong, Z.; Feijen, J.; Engbersen, J. F. J. Bioreducible poly(amido 
amine)s with oligoamine side chains: Synthesis, characterization, and structural effects on gene delivery. J. Controlled Release 2008, 126, 166-174.

(175) Shim, M. S.; Bhang, S. H.; Yoon, K.; Choi, K.; Xia, Y. A Bioreducible Polymer for Efficient Delivery of Fas-Silencing siRNA into Stem Cell Spheroids and Enhanced Therapeutic Angiogenesis. Angew. Chem., Int. Ed. 2012, 51, 1189911903.

(176) Li, J.; Zhu, Y.; Hazeldine, S. T.; Firestine, S. M.; Oupický, D. Cyclam-Based Polymeric Copper Chelators for Gene Delivery and Potential PET Imaging. Biomacromolecules 2012, 13, 3220-3227.

(177) Li, J.; Zhu, Y.; Hazeldine, S. T.; Li, C.; Oupický, D. Dual-Function CXCR4 Antagonist Polyplexes To Deliver Gene Therapy and Inhibit Cancer Cell Invasion. Angew. Chem., Int. Ed. 2012, 51, 8740-8743.

(178) Piest, M.; Engbersen, J. F. J. Effects of charge density and hydrophobicity of poly(amido amine)s for non-viral gene delivery. J. Controlled Release 2010, 148, 83-90.

(179) Piest, M.; Engbersen, J. F. J. Role of boronic acid moieties in poly(amido amine)s for gene delivery. J. Controlled Release 2011, 155, 331-340.

(180) Piest, M.; Ankoné, M.; Engbersen, J. F. J. Carbohydrate-interactive pDNA and siRNA gene vectors based on boronic acid functionalized poly(amido amine)s. $J$. Controlled Release 2013, 169, 266-275.

(181) Mateos-Timoneda, M. A.; Lok, M. C.; Hennink, W. E.; Feijen, J.; Engbersen, J. F. J. Poly(amido amine)s as Gene Delivery Vectors: Effects of Quaternary Nicotinamide Moieties in the Side Chains. ChemMedChem 2008, 3, 478-486.

(182) van der Aa, L. J.; Vader, P.; Storm, G.; Schiffelers, R. M.; Engbersen, J. F. J. Intercalating quaternary nicotinamide-based poly(amido amine)s for gene delivery. J. Controlled Release 2014, 195, 11-20.

(183) Coué, G.; Freese, C.; Unger, R. E.; James Kirkpatrick, C.; Engbersen, J. F. J. Bioresponsive poly(amidoamine)s designed for intracellular protein delivery. Acta Biomater. 2013, 9, 6062-6074.

(184) Piest, M.; Lin, C.; Mateos-Timoneda, M. A.; Lok, M. C.; Hennink, W. E.; Feijen, J.; Engbersen, J. F. J. Novel poly(amido amine)s with bioreducible disulfide linkages in their diamino-units: Structure effects and in vitro gene transfer properties. J. Controlled Release 2008, 130, 38-45. 
(185) Christensen, L. V.; Chang, C.-W.; Kim, W. J.; Kim, S. W.; Zhong, Z.; Lin, C.; Engbersen, J. F. J.; Feijen, J. Reducible Poly(amido ethylenimine)s Designed for Triggered Intracellular Gene Delivery. Bioconjugate Chem. 2006, 17, 1233-1240.

(186) Christensen, L. V.; Chang, C.-W.; Yockman, J. W.; Conners, R.; Jackson, H.; Zhong, Z.; Feijen, J.; Bull, D. A.; Kim, S. W. Reducible poly(amido ethylenediamine) for hypoxia-inducible VEGF delivery. J. Controlled Release 2007, 118, 254-261.

(187) Brumbach, J. H.; Lin, C.; Yockman, J.; Kim, W. J.; Blevins, K. S.; Engbersen, J. F. J.; Feijen, J.; Kim, S. W. Mixtures of Poly(triethylenetetramine/cystamine bisacrylamide) and Poly(triethylenetetramine/cystamine bisacrylamide)-gpoly(ethylene glycol) for Improved Gene Delivery. Bioconjugate Chem. 2010, 21, $1753-1761$.

(188) Brumbach, J. H.; Lee, Y. W.; Kim, S. W.; Yockman, J. W. Functional properties and biodistribution of poly(triethylenetetramine/cystamine bisacrylamide) and poly(triethylenetetramine/cystamine bisacrylamide)- poly(ethylene glycol) mixtures formed with nucleic acid. J. Controlled Release 2012, 159, 111-119.

(189) Ping, Y.; Wu, D.; Kumar, J. N.; Cheng, W.; Lay, C. L.; Liu, Y. Redox-Responsive Hyperbranched Poly(amido amine)s with Tertiary Amino Cores for Gene Delivery. Biomacromolecules 2013, 14, 2083-2094.

(190) Martello, F.; Piest, M.; Engbersen, J. F. J.; Ferruti, P. Effects of branched or linear architecture of bioreducible poly(amido amine)s on their in vitro gene delivery properties. J. Controlled Release 2012, 164, 372-379.

(191) Piao, J.-G.; Yan, J.-J.; Wang, M.-Z.; Wu, D.-C.; You, Y.-Z. A new method to cross-link a polyplex for enhancing in vivo stability and transfection efficiency. Biomater. Sci. 2014, 2, 390-398.

(192) Ou, M.; Xu, R.; Kim, S. H.; Bull, D. A.; Kim, S. W. A family of bioreducible poly(disulfide amine)s for gene delivery. Biomaterials 2009, 30, 5804-5814.

(193) Ou, M.; Wang, X.-L.; Xu, R.; Chang, C.-W.; Bull, D. A.; Kim, S. W. Novel Biodegradable Poly(disulfide amine)s for Gene Delivery with High Efficiency and Low Cytotoxicity. Bioconjugate Chem. 2008, 19, 626-633.

(194) Kim, S. H.; Jeong, J. H.; Ou, M.; Yockman, J. W.; Kim, S. W.; Bull, D. A. Cardiomyocyte-targeted siRNA delivery by prostaglandin E2-Fas siRNA polyplexes formulated with reducible poly(amido amine) for preventing cardiomyocyte apoptosis. Biomaterials 2008, 29, 4439-4446. 
(195) Futaki, S. Membrane-permeable arginine-rich peptides and the translocation mechanisms. Adv. Drug Delivery Rev. 2005, 57, 547-558.

(196) Zorko, M.; Langel, Ü. Cell-penetrating peptides: mechanism and kinetics of cargo delivery. Adv. Drug Delivery Rev. 2005, 57, 529-545.

(197) Nakase, I.; Takeuchi, T.; Tanaka, G.; Futaki, S. Methodological and cellular aspects that govern the internalization mechanisms of arginine-rich cellpenetrating peptides. Adv. Drug Delivery Rev. 2008, 60, 598-607.

(198) Wender, P. A.; Galliher, W. C.; Goun, E. A.; Jones, L. R.; Pillow, T. H. The design of guanidinium-rich transporters and their internalization mechanisms. $A d v$. Drug Delivery Rev. 2008, 60, 452-472.

(199) Kim, T.-i.; Ou, M.; Lee, M.; Kim, S. W. Arginine-grafted bioreducible poly(disulfide amine) for gene delivery systems. Biomaterials 2009, 30, 658-664.

(200) Kim, T.-i.; Rothmund, T.; Kissel, T.; Kim, S. W. Bioreducible polymers with cell penetrating and endosome buffering functionality for gene delivery systems. $J$. Controlled Release 2011, 152, 110-119.

(201) Nam, H. Y.; Lee, Y.; Lee, M.; Shin, S. K.; Kim, T.-i.; Kim, S. W.; Bull, D. A. Erythropoietin gene delivery using an arginine-grafted bioreducible polymer system. J. Controlled Release 2012, 157, 437-444.

(202) Lee, Y.; Nam, H. Y.; Kim, J.; Lee, M.; Yockman, J. W.; Shin, S. K.; Kim, S. W. Human Erythropoietin Gene Delivery Using an Arginine-grafted Bioreducible Polymer System. Mol. Ther. 2012, 20, 1360-1366.

(203) Kim, T.-i.; Lee, M.; Kim, S. W. A guanidinylated bioreducible polymer with high nuclear localization ability for gene delivery systems. Biomaterials 2010, 31, 1798-1804.

(204) Zhang, C.; Jin, R.; Zhao, P.; Lin, C. A family of cationic polyamides for in vitro and in vivo gene transfection. Acta Biomater. 2015, 22, 120-130. 



\section{Chapter 3. Thiourea Functionalization Enhances Transfection of Bioreducible Poly(amido amine)s as Gene Vectors under Serum Conditions}

Guoying Si, Jos M.J. Paulusse* and Johan F.J. Engbersen*

Department of Controlled Drug Delivery, MIRA Institute for Biomedical Technology and Technical Medicine, Faculty of Science and Technology, University of Twente, P.O. Box 217, 7500 AE Enschede, The Netherlands

KEYWORDS

Gene delivery; thiourea; hydrogen bonding; bioreducible; serum-tolerance.

This chapter has been submitted for publication. 


\section{ABSTRACT}

Successful gene therapy relies on gene delivery vectors with high transfection efficiency and minimal toxicity. Bioreducible poly(amido amine)s (PAAs) with disulfide linkages along the backbone and varying amounts of thiourea moieties in the side-chains were prepared via Michael-type polyaddition of 1-(4-aminobutyl)-3-(pyridin-3-yl)thiourea (PTBA) to $N, N^{\prime}$-cystamine bisacrylamide (CBA). The thiourea-containing PAAs are able to bind plasmid DNA into nanosized polyplexes with positive surface charge as characterized by dynamic light scattering (DLS) and zeta-potential measurements. The plasmid DNA is liberated from the polyplexes in reducing environment, as is shown by gel electrophoresis after treatment with the reducing agent dithiothreitol (DTT). Polyplexes of thiourea-functionalized PAAs show markedly higher transfection efficiencies on COS-7 cells compared to polyplexes of the frequently applied PEI (branched, $25 \mathrm{kDa}$ ) and the PAA analog obtained by polyaddition of 1-amino-4-butanol (ABOL) to CBA, pABOL, at their optimal conditions. The high transfection capacity of the thiourea-functionalized PAAs remains largely unaffected in the presence of $10 \%$ serum, while those of PEI and pABOL drops strongly under these conditions. The results demonstrate that thiourea functionalization of PAAs is a promising approach to obtain gene vectors with enhanced transfection, minimal toxicity, and good serum tolerance.

\section{INTRODUCTION}

Cationic polymers emerge as appealing materials in non-viral gene delivery vectors owing to their remarkable advantages over viral vectors. ${ }^{1-4}$ These advantages range from versatility in synthesis, ${ }^{5-7}$ absence of immunogenicity, ${ }^{2}$ and high flexibility in functionalization. Functionalities that can be incorporated involve ligands for targeted gene delivery, ${ }^{8-11}$ imaging moieties for tracking gene biodistribution, ${ }^{12-15}$ as well as therapeutic motifs for synergistic therapy. ${ }^{16-19}$ The positive charges along the chains of cationic polymers are able to condense negatively charged DNA through multivalent electrostatic interactions into nanosized polyplexes with polymeric cationic corona. ${ }^{20-23}$ To overcome the numerous barriers along the delivery route, ${ }^{24,25}$ increased colloidal stability of polyplexes is desirable and may be achieved by incorporating alternative interaction forces such as hydrophobic interactions ${ }^{26,27}$ and hydrogen bonding, ${ }^{28-30}$ as well as tertiary components as either physical ${ }^{31}$ or chemical cross-linker. ${ }^{32}$ 
Recently, hydrogen bonding interactions have attracted considerable attention in the construction of non-viral gene delivery vectors, ${ }^{28,29,33-37}$ as well as in the preparation of dynamic biomedical materials. ${ }^{38-43}$ In this respect, thiourea groups are of particular interest since they are strong hydrogen bond donors and have the interesting ability to interact with phosphate groups of DNA. ${ }^{44-48}$ Liposomes endowed with thiourea groups were applied as non-viral gene vectors with comparable transfection efficiencies, though reduced cytotoxicity, as compared with their cationic liposome analogues. ${ }^{36,48}$ Modification of amino groups present in aminoalkyl poly(methacrylate) $\mathrm{s}^{49}$ and poly(ethylenimine) $(\mathrm{PEI})^{50}$ by reaction with isothiocyanate to introduce thiourea functionalities, resulted in derivatives with efficient plasmid DNA delivery. In addition, reliable siRNA delivery, both in vitro and in vivo, was achieved by post-modification of $25 \mathrm{kDa}$ PEI (branched) with thiourea groups. ${ }^{51,52}$ However, although the above described gene vectors illustrate the favorable effect of thiourea functionalization, they have some inherent disadvantages. Liposomes have limited transfection efficacy due to poor stability and rapid clearance, ${ }^{53}$ and may induce inflammatory or anti-inflammatory responses. ${ }^{54}$ The non-degradability of PEI and poly(methacrylate) impose high potential toxicity to cells and tissues. ${ }^{55}$ These problematic issues of liposomes, PEI, and poly(methacrylate) severely restrict their wide deployment in clinical applications.

Peptidomimetic poly(amido amine)s (PAAs) are biodegradable, biocompatible, and nontoxic, rendering PAAs excellent materials for gene delivery. ${ }^{56}$ Especially when disulfide linkages are incorporated in the PAA backbone the PAAs take advantage of the difference in intra- and extracellular redox potential, resulting in efficient intracellular delivery of plasmid DNA, ${ }^{56-60}$ siRNA $^{61}$ and even proteins. ${ }^{62}$ PAAs are synthesized by Michael addition of amines to bisacrylamides under very mild conditions. ${ }^{63}$ The resulting tertiary amines in the polymer backbone are prone to protonation in the neutral and endosomal $\mathrm{pH}$ range, endowing PAAs with overall positive charge and excellent water solubility. ${ }^{63}$ However, PAAs bear moderate DNA binding ability and significantly susceptibility to serum protein interference, ${ }^{64-66}$ making it interesting to introduce functionalities which increases their DNA binding ability and resistance to serum interference.

In this chapter, we describe incorporation of thiourea moieties into disulfide-linked PAAs to increase polyplex stability and resulting transfection efficiency through hydrogen bonding between thiourea and phosphate groups in DNA (Scheme 1). Thiourea-functional 
PAAs were prepared through stepwise polymerization of thiourea-containing amines with CBA. The obtained polymers were characterized in detail, their ability to form stable polyplexes was evaluated, and cytotoxicity and transfection efficiency to COS-7 cells were evaluated under both serum-free and serum conditions. The transfection efficiency of leading candidates were qualitatively screened by fluorescence images and further quantitatively evaluated by flow cytometry.

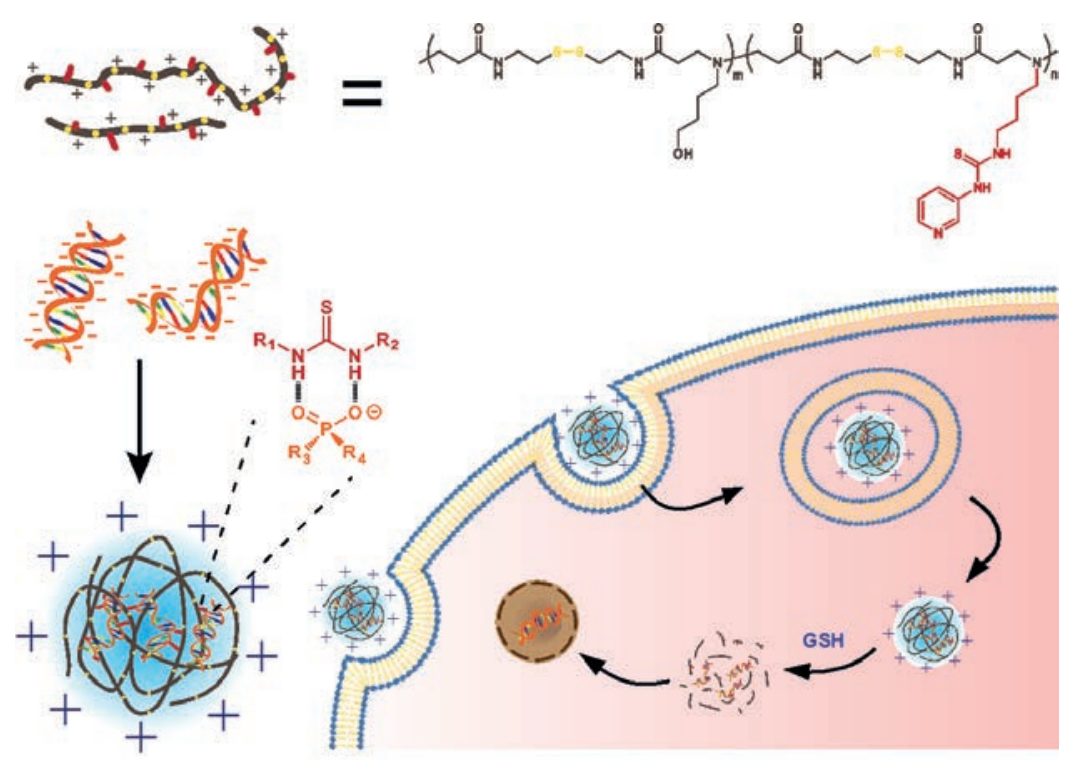

Scheme 1. Schematic representation of thiourea-functionalized disulfide-linked poly(amido amine)s for enhanced polyplex stability through hydrogen binding between thiourea and phosphate in DNA.

\section{EXPERIMENTAL PROCEDURES}

\section{Materials and Methods}

All monomers, 4-amino-1-butanol (ABOL, Sigma-Aldrich), N, N’-cystaminebisacrylamide (CBA, Polysciences), 3-pyridyl isothiocyanate (PyNCS, $95.0 \%$, Acros), dithiothreitol (DTT, $\geq 99.5 \%$, Sigma-Aldrich) and $N$-Boc-1,4-butanediamine (Boc-DAB, Sigma-Aldrich) were purchased in the highest purity and used without further purification. HEPES sodium salt and $\mathrm{LiCl}$ were purchased in the highest purity from Sigma-Aldrich. All water used in the described experiments was treated by a Milli-Q Gradient System (Millipore, Bedford, MA). Plasmid DNA, plasmid pCMV-GFP was purchased from Plasmid Factory (Bielefeld, Germany). Branched polyethylenimine (PEI, $\left.\mathrm{M}_{\mathrm{w}} 25 \mathrm{kDa}\right)$ was purchased from SigmaAldrich. 
Monomers and polymers were characterized by NMR spectroscopy on a Bruker $400 \mathrm{MHz}$ spectrometer in deuterated solvent. Molecular weights were determined by gel permeation chromatography (GPC) relative to PEG standards, using a Waters Alliance 2695 separation module equipped with a PL-aquagel-OH 8 micron Mixed-M column $(300$ x $7.5 \mathrm{~mm})$ with $\mathrm{N}, \mathrm{N}$-dimethylformamide (DMF) containing $\mathrm{LiCl}(50 \mathrm{mM})$ as eluent at $35^{\circ} \mathrm{C}$.

\section{Synthesis of 1-(4-aminobutyl)-3-(pyridin-3-yl)thiourea (PTBA, monomer 1)}

To a solution of $\mathrm{N}$-Boc-1,4-butanediamine (2.63 g, $14.0 \mathrm{mmol}, 1.0 \mathrm{eq}$.) in methanol (50 $\mathrm{mL}), 3$-pyridyl isothiocyanate (2.00 g, $14.0 \mathrm{mmol}, 1.0$ eq.) was added slowly. After stirring at ambient temperature for $16 \mathrm{~h}$, the obtained mixture was condensed under reduced pressure. The solids were dissolved in a mixture of methanol and dichloromethane $(1 / 1$, $\mathrm{v} / \mathrm{v}, 80 \mathrm{~mL}$ ) and hydrochloric acid (g) was led through the solution for $30 \mathrm{~min}$. The obtained white solid was filtered off, washed with dichloromethane, and finally dried at 40 ${ }^{\circ} \mathrm{C}$ in a vacuum oven overnight to yield the hydrochloric acid salt as a white powder $(3.30$ g, 88.1\%). $\quad{ }^{1} \mathrm{H} \quad \mathrm{NMR} \quad\left(\mathrm{DMSO}_{6}, \quad 400 \quad \mathrm{MHz}\right): \quad \delta \quad 1.62 \quad(\mathrm{~d}, \quad 4 \mathrm{H}$, $\mathrm{NHCSNHCH}_{2} \mathrm{CH}_{2} \mathrm{CH}_{2} \mathrm{CH}_{2} \mathrm{NH}_{2}$ ), 2.80 (d, 2H, $\mathrm{NHCSNHCH}_{2} \mathrm{CH}_{2} \mathrm{CH}_{2} \mathrm{CH}_{2} \mathrm{NH}_{2}$ ), 3.51 (d, $2 \mathrm{H}, \mathrm{NHCSNHCH} \mathrm{CH}_{2} \mathrm{CH}_{2} \mathrm{CH}_{2} \mathrm{NH}_{2}$ ), 7.93 (m, 1H, CHNCHCHCH-pyridyl ring), 8.54 (m, $2 \mathrm{H}, \mathrm{CHNCHCHCH}$-pyridyl ring), 9.06 (t, 1H, $\mathrm{NHCSNHCH}_{2} \mathrm{CH}_{2} \mathrm{CH}_{2} \mathrm{CH}_{2} \mathrm{NH}_{2}$ ), 9.40 (d, $1 \mathrm{H}, \mathrm{CHNCHCHCH}$-pyridyl ring), $11.48\left(\mathrm{~s}, 1 \mathrm{H}, \mathrm{NHCSNHCH}_{2} \mathrm{CH}_{2} \mathrm{CH}_{2} \mathrm{CH}_{2} \mathrm{NH}_{2}\right) .{ }^{13} \mathrm{C}$ NMR (DMSO-D, 400 MHz): $\delta$ 24.48, 25.24, 38.43, 43.16, 126.75, 133.62, 135.65, 136.26, $139.80,180.57$.

\section{Synthesis of polymers of $\mathrm{p}\left(\mathrm{ABOL} / \mathrm{PTBA}_{n}\right)$}

In a typical experiment (i.e., synthesis of $\left.\mathrm{p}\left(\mathrm{ABOL}_{72} / \mathrm{PTBA}_{28}\right)\right), \quad N, \quad N^{\prime}-$ cystaminebisacrylamide (0.520 g, $2.00 \mathrm{mmol})$, 4-amino-1-butanol (0.156 g, $1.75 \mathrm{mmol}), 1$ (4-aminobutyl)-3-(pyridin-3-yl)thiourea (75 mg, $0.25 \mathrm{mmol})$, and triethylamine $(0.140 \mathrm{~mL}$, $1.00 \mathrm{mmol})$ were dissolved in a mixture of methanol and water $(3 / 1, \mathrm{v} / \mathrm{v}, 1.5 \mathrm{~mL})$. After 8 $\mathrm{d}$ stirring at $50{ }^{\circ} \mathrm{C}$, the resulting viscous mixture was charged with additional 4-amino-1butanol (16 mg, $0.18 \mathrm{mmol}), 1$-(4-aminobutyl)-3-(pyridin-3-yl)thiourea (9.0 mg, 0.030 mmol) and triethylamine $(0.017 \mathrm{~mL}, 0.12 \mathrm{mmol})$ to terminate the polymerization. After stirring at $50{ }^{\circ} \mathrm{C}$ for another $2 \mathrm{~d}$, the mixture was diluted in water, acidified with aqueous hydrochloric acid (4.0 M) to $\mathrm{pH} 4$, and dialyzed with $1000 \mathrm{Da}$ MWCO membrane against water overnight. After lyophilization, the polymer $\mathrm{p}\left(\mathrm{ABOL}_{72} / \mathrm{PTBA}_{28}\right)$ was obtained as an amorphous solid. Other polymers were prepared analogously with varying ratios of 4- 
amino-1-butanol (ABOL) and 1-(4-aminobutyl)-3-(pyridin-3-yl)thiourea (PTBA), namely $0 / 100,50 / 50,87.5 / 12.5$, and 100/0.

$\mathrm{P}\left(\mathrm{ABOL}_{0} / \mathrm{PTBA}_{100}\right): 0.267 \mathrm{~g}, 36.4 \%$ yield. ${ }^{1} \mathrm{H}$ NMR ( $\left.\mathrm{D}_{2} \mathrm{O}, 400 \mathrm{MHz}\right): \delta 1.67-1.76(\mathrm{~m}, 4 \mathrm{H}$, $\mathrm{RNCH}_{2} \mathrm{CH}_{2} \mathrm{CH}_{2} \mathrm{CH}_{2} \mathrm{NHCSNH}$ ), 2.68-2.78 (m, 8H, $2 \times \mathrm{NHCOCH}_{2}+2 \times \mathrm{SSCH}_{2} \mathrm{CH}_{2}$ ), 3.17-3.58 (m, $12 \mathrm{H}, \mathrm{RNCH}_{2} \mathrm{CH}_{2} \mathrm{CH}_{2} \mathrm{CH}_{2} \mathrm{NHCSNH}+\mathrm{RNCH}_{2} \mathrm{CH}_{2} \mathrm{CH}_{2} \mathrm{CH}_{2} \mathrm{NHCSNH}_{+}$ $\mathrm{CH}_{2} \mathrm{CH}_{2} \mathrm{NCH}_{2} \mathrm{CH}_{2}+2$ x $\mathrm{SSCH}_{2} \mathrm{CH}_{2}$ ), 7.46 (1 $\mathrm{H}$, pyridyl ring), 7.81 (1H, pyridyl ring), $8.36(1 \mathrm{H}$, pyridyl ring), and $8.46(1 \mathrm{H}$, pyridyl ring $)$.

P(ABOL50/PTBA50): 0.400 g, $53.4 \%$ yield. ${ }^{1} \mathrm{H}$ NMR (D $\left.2 \mathrm{O}, 400 \mathrm{MHz}\right): \delta 1.60-1.79(\mathrm{~m}, 4 \mathrm{H}$, $\left.\mathrm{RNCH}_{2} \mathrm{CH}_{2} \mathrm{CH}_{2} \mathrm{CH}_{2} \mathrm{NHCSNH} / \mathrm{RNCH}_{2} \mathrm{CH}_{2} \mathrm{CH}_{2} \mathrm{CH}_{2} \mathrm{OH}\right), \quad 2.62-2.78 \quad(\mathrm{~m}, \quad 8 \mathrm{H}, \quad 2 \quad \mathrm{x}$ $\left.\mathrm{NHCOCH}_{2}+2 \times \mathrm{SSCH}_{2} \mathrm{CH}_{2}\right), 3.07-3.61\left(\mathrm{~m}, 12 \mathrm{H}, \mathrm{RNCH}_{2} \mathrm{CH}_{2} \mathrm{CH}_{2} \mathrm{CH}_{2} \mathrm{NHCSNH}_{+}\right.$ $\mathrm{RNCH}_{2} \mathrm{CH}_{2} \mathrm{CH}_{2} \mathrm{CH}_{2} \mathrm{NHCSNH}_{2} \mathrm{RNCH}_{2} \mathrm{CH}_{2} \mathrm{CH}_{2} \mathrm{CH}_{2} \mathrm{OH}+\mathrm{CH}_{2} \mathrm{CH}_{2} \mathrm{NCH}_{2} \mathrm{CH}_{2}+2 \mathrm{x}$ $\left.\mathrm{SSCH}_{2} \mathrm{CH}_{2}+\mathrm{RNCH}_{2} \mathrm{CH}_{2} \mathrm{CH}_{2} \mathrm{CH}_{2} \mathrm{OH}\right), 7.49$ (1 $\mathrm{H}$, pyridyl ring), 7.83 (1 $\mathrm{H}$, pyridyl ring), $8.39(1 \mathrm{H}$, pyridyl ring), and $8.49(1 \mathrm{H}$, pyridyl ring).

$\mathrm{P}\left(\mathrm{ABOL}_{72} / \mathrm{PTBA}_{28}\right): 0.363 \mathrm{~g}, 45.4 \%$ yield. ${ }^{1} \mathrm{H}$ NMR ( $\left.{ }_{2} \mathrm{O}, 400 \mathrm{MHz}\right): 1.60-1.79$ (m, 4H, $\left.\mathrm{RNCH}_{2} \mathrm{CH}_{2} \mathrm{CH}_{2} \mathrm{CH}_{2} \mathrm{NHCSNH} / \mathrm{RNCH}_{2} \mathrm{CH}_{2} \mathrm{CH}_{2} \mathrm{CH}_{2} \mathrm{OH}\right), \quad 2.62-2.78 \quad(\mathrm{~m}, \quad 8 \mathrm{H}, \quad 2 \quad \mathrm{x}$ $\left.\mathrm{NHCOCH}_{2}+2 \times \mathrm{SSCH}_{2} \mathrm{CH}_{2}\right), 3.07-3.61\left(\mathrm{~m}, 12 \mathrm{H}, \mathrm{RNCH}_{2} \mathrm{CH}_{2} \mathrm{CH}_{2} \mathrm{CH}_{2} \mathrm{NHCSNH}+\right.$ $\mathrm{RNCH}_{2} \mathrm{CH}_{2} \mathrm{CH}_{2} \mathrm{CH}_{2} \mathrm{NHCSNH} / \mathrm{RNCH}_{2} \mathrm{CH}_{2} \mathrm{CH}_{2} \mathrm{CH}_{2} \mathrm{OH}+\mathrm{CH}_{2} \mathrm{CH}_{2} \mathrm{NCH}_{2} \mathrm{CH}_{2}+2 \mathrm{x}$ $\mathrm{SSCH}_{2} \mathrm{CH}_{2}+\mathrm{RNCH}_{2} \mathrm{CH}_{2} \mathrm{CH}_{2} \mathrm{CH}_{2} \mathrm{OH}$ ), 7.49 (1 $\mathrm{H}$, pyridyl ring), 7.83 (1 $\mathrm{H}$, pyridyl ring), $8.39(1 \mathrm{H}$, pyridyl ring), and $8.49(1 \mathrm{H}$, pyridyl ring $)$.

P(ABOL $\left.90 / \mathrm{PTBA}_{10}\right): 0.363$ g, $45.4 \%$ yield. ${ }^{1} \mathrm{H}$ NMR ( $\left.\mathrm{D}_{2} \mathrm{O}, 400 \mathrm{MHz}\right): 1.60-1.79(4 \mathrm{H}$, $\mathrm{RNCH}_{2} \mathrm{CH}_{2} \mathrm{CH}_{2} \mathrm{CH}_{2} \mathrm{NHCSNH}_{2} \mathrm{RNCH}_{2} \mathrm{CH}_{2} \mathrm{CH}_{2} \mathrm{CH}_{2} \mathrm{OH}$ ), 2.62-2.78 (8H, 2 x NHCOCH${ }_{2}+$ $\left.2 \mathrm{x} \quad \mathrm{SSCH}_{2} \mathrm{CH}_{2}\right), \quad 3.07-3.61 \quad\left(12 \mathrm{H}, \quad \mathrm{RNCH}_{2} \mathrm{CH}_{2} \mathrm{CH}_{2} \mathrm{CH}_{2} \mathrm{NHCSNH}_{+}\right.$ $\mathrm{RNCH}_{2} \mathrm{CH}_{2} \mathrm{CH}_{2} \mathrm{CH}_{2} \mathrm{NHCSNH} / \mathrm{RNCH}_{2} \mathrm{CH}_{2} \mathrm{CH}_{2} \mathrm{CH}_{2} \mathrm{OH}+\mathrm{CH}_{2} \mathrm{CH}_{2} \mathrm{NCH}_{2} \mathrm{CH}_{2}+2 \mathrm{x}$ $\left.\mathrm{SSCH}_{2} \mathrm{CH}_{2}+\mathrm{RNCH}_{2} \mathrm{CH}_{2} \mathrm{CH}_{2} \mathrm{CH}_{2} \mathrm{OH}\right), 7.49$ (1 $\mathrm{H}$, pyridyl ring), 7.83 (1 $\mathrm{H}$, pyridyl ring), $8.39(1 \mathrm{H}$, pyridyl ring), and $8.49(1 \mathrm{H}$, pyridyl ring).

$\mathrm{P}\left(\mathrm{ABOL}_{100} / \mathrm{PTBA}_{0}\right): 0.320 \mathrm{~g}, 40.4 \%$ yield. ${ }^{1} \mathrm{H}$ NMR $\left(\mathrm{D}_{2} \mathrm{O}, 400 \mathrm{MHz}\right): \delta 1.33(\mathrm{~s}, 9 \mathrm{H}$, $\left.\mathrm{R}\left(\mathrm{CH}_{3}\right)_{3}\right), 1.62$ (m, 2H, RNCH$\left.{ }_{2} \mathrm{CH}_{2}\right), 1.78$ (m, 2H, $\left.\mathrm{RNCH}_{2} \mathrm{CH}_{2} \mathrm{CH}_{2} \mathrm{CH}_{2} \mathrm{OH}\right), 2.74$ (t, 4H, 2 x NHCOCH 2$), 2.84$ (t, 4H, 2 x SSCH $\left.2 \mathrm{CH}_{2}\right), 3.20$ (t, 2H, $\left.\mathrm{RNCH}_{2} \mathrm{CH}_{2} \mathrm{CH}_{2} \mathrm{CH}_{2} \mathrm{OH}\right), 3.41$ (t, 
$\left.4 \mathrm{H}, \quad \mathrm{CH}_{2} \mathrm{CH}_{2} \mathrm{NCH}_{2} \mathrm{CH}_{2}\right), \quad 3.51$ (t, $\left.4 \mathrm{H}, \quad 2 \quad \mathrm{x} \quad \mathrm{SSCH}_{2} \mathrm{CH}_{2}\right), \quad 3.62 \quad(\mathrm{t}, \quad 2 \mathrm{H}$, $\left.\mathrm{RNCH}_{2} \mathrm{CH}_{2} \mathrm{CH}_{2} \mathrm{CH}_{2} \mathrm{OH}\right)$.

\section{Polyplex preparation}

Polyplexes were prepared in HEPES buffer $(20 \mathrm{mM}$, pH 7.4, supplemented with $5.0 \mathrm{wt} \%$ glucose). A typical procedure to prepare polyplexes at a mass ratio of 48/1 (polymer/DNA) is as follows: polymer solution $(800 \mu \mathrm{L}, 900 \mu \mathrm{g} / \mathrm{mL})$ was added to the DNA solution (200 $\mu \mathrm{L}, 75 \mu \mathrm{g} / \mathrm{mL}$ ), followed by $5 \mathrm{~s}$ vortexing and $30 \mathrm{~min}$ incubation at room temperature. Size and surface charge of the polyplexes were measured at $25{ }^{\circ} \mathrm{C}$ with a Zetasizer Nano ZS (Malvern Instruments, Malvern). Recorded values are the mean of three measurements, standard deviations are indicated as error bars.

\section{Agarose gel retardation}

Polyplexes were prepared at polymer/DNA mass ratio 48 as described previously. DTT solution in HEPES buffer was added to the polyplex solutions to result in a final DTT concentration of $2.5 \mathrm{mM}$. After $30 \mathrm{~min}$ incubation at ambient temperature, $6 \mathrm{X}$ loading buffer containing bromophenol (Ferments) was mixed with resulting dispersions. The solutions $(10 \mu \mathrm{L})$ were loaded on a $0.8 \% \mathrm{w} / \mathrm{v}$ agarose gel containing $1 \mathrm{x}$ SYBR ${ }^{\circledR}$ Safe DNA Gel Stain (Invitrogen ${ }^{\mathrm{TM}}$ ). Electrophoresis was performed at $90 \mathrm{~V}$ for $60 \mathrm{~min}$ in a TBE running buffer. After development of the gel, the picture was acquired using FluorChem (Proteinsimple, Westburg, Leusden, the Netherlands) under UV excitation.

\section{In Vitro Transfection and Cell Viability Assays}

Transfection experiments were performed on COS-7 cells (SV-40 transformed African green monkey kidney cells) using the plasmid pCMV-GFP as a reporter gene. Transfections and cell viabilities were conducted in parallel using polyplexes formed at polymer/plasmid DNA mass ratios ranging from 6 to 48 .

Cells were seeded in at a density of $10^{4}$ cells per well $\left(2.94 \times 10^{4}\right.$ cells $\left./ \mathrm{cm}^{2}\right)$ and maintained in complete medium at $37{ }^{\circ} \mathrm{C}$ in a humidified atmosphere containing $5 \% \mathrm{CO}_{2}$ until $60-80 \%$ confluency. In a standard transfection experiment, cells were first incubated with medium (100 $\mu \mathrm{L}$, with/without serum) for $30 \mathrm{~min}$ and then loaded with $100 \mu \mathrm{L}$ polyplex dispersions ( $1 \mu \mathrm{g}$ DNA per well). After $1 \mathrm{~h}$ incubation, polyplexes were removed, and fresh complete culture medium $(100 \mu \mathrm{L})$ was added and cells were cultured for an additional $48 \mathrm{~h}$. Transfection efficiency was determined qualitatively through fluorescence 
imaging via an EVOS digital inverted microscope (EMS, Wageningen, the Netherlands). A reference was prepared from PEI $(25 \mathrm{KDa}) / \mathrm{DNA}$ at a polymer/DNA mass ratio of 1.33/1. MTT assays were conducted to determine the number of viable cells, with a value of $100 \%$ cell viability for untreated cells.

Quantitative determination of transfection efficiency was performed by flow cytometry. Cells were seeded in 48 -well plates with densities of ca. $1.6 \times 10^{4}$ cells per well $\left(1.6 \times 10^{4}\right.$ cells $/ \mathrm{cm}^{2}$ ) and maintained in complete medium at $37{ }^{\circ} \mathrm{C}$ in a humidified atmosphere containing 5\% $\mathrm{CO}_{2}$ until $60-80 \%$ confluency. Cells were first incubated with medium (200 $\mu \mathrm{L}$, with/without serum) for $30 \mathrm{~min}$ and then loaded with $200 \mu \mathrm{L}$ polyplex dispersions (1 $\mu \mathrm{g}$ DNA per well). After $1 \mathrm{~h}$ incubation, the polyplexes were aspirated, fresh and warm complete culture medium $(200 \mu \mathrm{L})$ was added and eventually cells were cultured for $48 \mathrm{~h}$. The cells were fixed by adding trypsin solution $(0.25 \%, 150 \mu \mathrm{L})$, and centrifuged $(600 \mathrm{~g}, 5$ min, ambient temperature). The pellets were resuspended in HBSS buffer (200 $\mu \mathrm{L})$, and measured by the FACSCalibur (Becton-Dickinson, Breda, the Netherlands) at an excitation wavelength of $488 \mathrm{~nm}$ and an emission wavelength of $530 \mathrm{~nm}$. Data was processed by the FACS Cellquest Software. A PEI $(25 \mathrm{~K}) / \mathrm{DNA}$ formulation prepared at a polymer/DNA mass ratio of $1.33 / 1$ was used as a reference. MTT assay was conducted to characterize the number of viable cells with MTT value of $100 \%$ cell viability for untreated cells (i.e., cells not exposed to transfection systems).

\section{RESULTS AND DISCUSSION}

\section{Monomer and copolymers preparation and characterization}

The thiourea-present primary amine monomer PTBA was synthesized via reaction of pyridylisothiocyanate with mono Boc-protected butanediamine (Boc-DAB). Subsequent deprotection of the Boc group yielded the monomer as white solid in $88.1 \%$ yield. Fourier transform infrared (FT-IR) spectra (see Figure S2) shows a strong signal at $1354 \mathrm{~cm}^{-1}$, which corresponds to the characteristic $\mathrm{C}=\mathrm{S}$ stretching absorption, validating the presence of thiourea bonds in the monomer of PTBA. Both NMR and FT-IR results confirm the successful preparation of thiourea-functionalized monomer PTBA. 


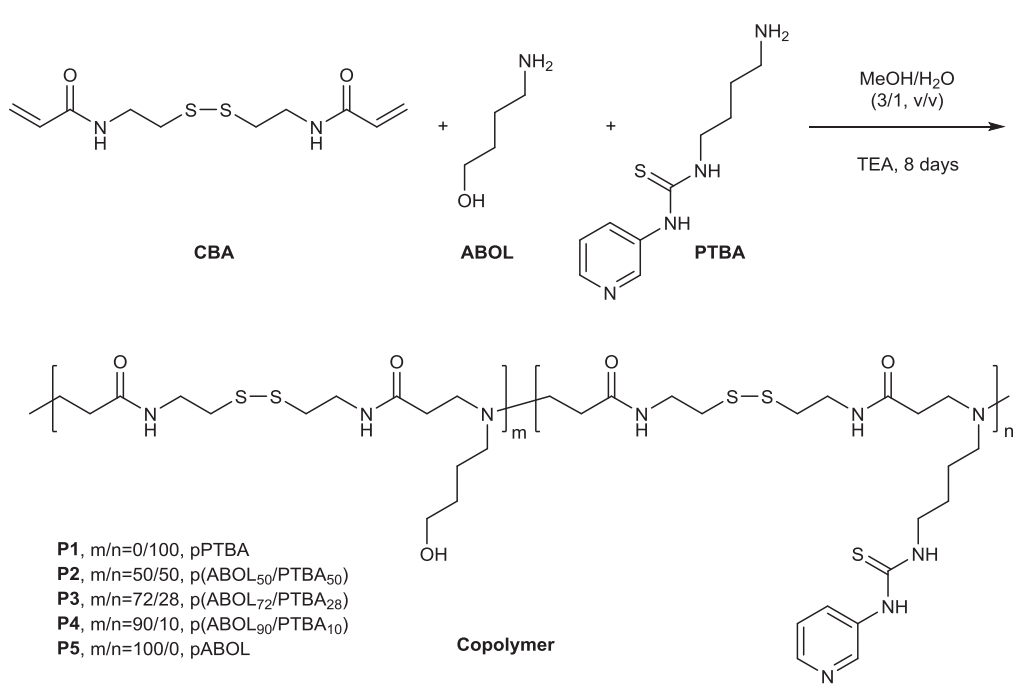

Scheme 2. Synthesis of thiourea-functional PAAs through Michael-type addition of CBA to ABOL and PTBA.

Polymers P1-P5 were synthesized via Michael type polyaddition of $N, N^{\prime}$ cystaminebisacrylamide (CBA) to mixtures of 4-amino-1-butanol (ABOL) and PTBA in equimolar amounts of total primary amines (Scheme 2). The ratios of thiourea functionalities were varied by altering the feed ratio of ABOL and PTBA. In order to perform Michael type polymerization, TEA was added to neutralize the PTBA to endow free primary amine groups to couple with acrylamide groups from CBA. Excess of primary amine was added to the polymerization mixture at the end of the polymerization to consume any residual acrylamide groups, which may cause toxicity towards cells. ${ }^{67,68}$ The NMR spectra of the isolated polymers are in good agreement with their structures. The absence of signals between 5.00 and $7.00 \mathrm{ppm}$ in all NMR spectra indicates complete consumption of acrylamide groups. The presence and intensity of the signals between 7.00 and $9.00 \mathrm{ppm}$, assigned to the pyridyl groups, implies the successful incorporation of PTBA monomer into the polymers according to the feed ratio and indicates the tunable incorporation of thiourea functionalities into the polymers. The ratio of PTBA/ABOL groups in the polymers was determined based on integral ratio between the two different ethylene groups ( $\mathrm{RNCH}_{2} \mathrm{CH}_{2} \mathrm{CH}_{2} \mathrm{CH}_{2} \mathrm{NHCSNH}-\mathrm{Py} / \mathrm{RNCH}_{2} \mathrm{CH}_{2} \mathrm{CH}_{2} \mathrm{CH}_{2} \mathrm{OH}$ ) in the polymers. All polymers incorporated with thiourea moieties exhibit signals at $1354 \mathrm{~cm}^{-1}$ $(\mathrm{C}=\mathrm{S}$ stretching absorption), further confirming the successful incorporation of PTBA into the polymers. Size exclusion chromatography analysis on the polymers revealed molecular 


\section{Chapter 3}

weights ranging from 6.0 to $9.2 \mathrm{kDa}$ with relatively narrow PDIs of approximately 1.5 , most likely due to elimination of low molecular weight oligomers during the dialysis step (Table 1).

Table 1. Characteristics of poly(amido amine)s functionalized with various thiourea groups

\begin{tabular}{l|l|l|l|l|l}
\hline \multirow{2}{*}{$\begin{array}{l}\text { Entry } \\
\text { No. }\end{array}$} & \multirow{2}{*}{ Polymer Acronym } & \multicolumn{2}{|l|}{ ABOL/PTBA mole ratio } & \multirow{2}{*}{$\mathrm{M}_{\mathrm{w}}(\mathrm{kDa})^{\mathrm{b}}$} & \multirow{2}{*}{$\mathrm{M}_{\mathrm{w}} / \mathrm{M}_{\mathrm{n}}{ }^{\mathrm{b}}$} \\
\cline { 3 - 4 } & & feed & found $^{\mathrm{a}}$ & & \\
\hline P1 & pABOL & $100 / 0$ & $100 / 0$ & 5.3 & 1.61 \\
P2 & p(ABOL $\left.90 / \mathrm{PTBA}_{10}\right)$ & $87.5 / 12.5$ & $90 / 10$ & 6.0 & 1.59 \\
P3 & p(ABOL & & & \\
P4 & p(ABA & & & \\
P5 & $75 / 25$ & $72 / 28$ & 6.8 & 1.45 \\
P5 & pPTBA & $50 / 50$ & $50 / 50$ & 6.0 & 1.47 \\
\hline
\end{tabular}

${ }^{\mathrm{a}}$ determined by integral ratios of NMR spectra; ${ }^{\mathrm{b}}$ determined via GPC.

\section{Polyplex Preparation and Characterization}

The performance of polymeric gene vectors is dictated by their ability to form polyplexes and guide DNA through various barriers to arrive at the target site. ${ }^{2,69}$ Polymers P4 and P5 showed limited solubility and formation of large aggregates. Therefore, these polymers are excluded in the following study and only the thiourea functionalized polymers P2 and P3, together with $\mathbf{P 1}$ as the control polymer lacking thiourea functionalities, are further investigated. As illustrated in Figure 1, all these three polymers are able to condense plasmid DNA into polyplexes with hydrodynamic diameters ranging from $126 \mathrm{~nm}$ to 400 $\mathrm{nm}$, with positive charge of +10 to $+30 \mathrm{mV}$ when the polymer/DNA mass ratio is above 12. The size of polyplexes decreases and the zeta potential of the polyplexes increases with increasing polymer to DNA ratio, which can be rationalized by the fact that more positive charge carriers become available to condense DNA with increasing polymer/DNA mass ratio. ${ }^{23,56}$ Generally, the surface charge of polyplexes is closely related to their cytotoxicity profiles and their cellular internalization across the anionic cell membrane. ${ }^{70}$ At the same mass ratio, the polymers with higher percentage of thiourea functionalities form smaller polyplexes with similar surface charge. The formation of smaller polyplexes can be attributed to additional hydrogen bonding interactions between the thiourea moieties 
(strong hydrogen bonding donor) in the polymer and the phosphate groups present in DNA, besides the electrostatic interactions.

A

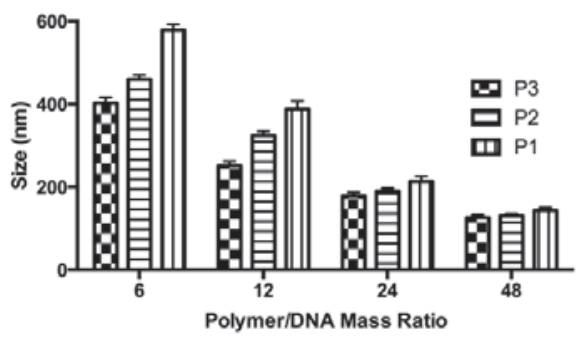

B

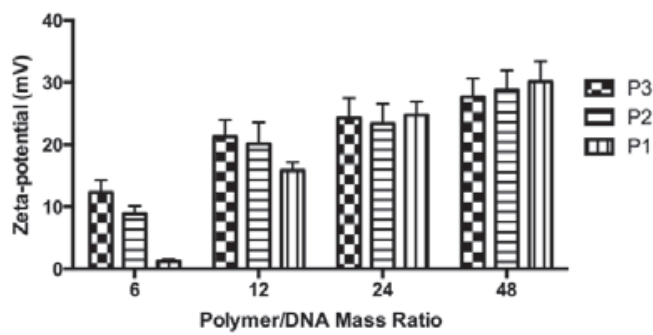

Figure 1. Characterization of polyplexes prepared under various polymer/DNA mass ratios through DLS. (A) Hydrodynamic sizes versus mass ratios; (B) Zeta-potentials versus mass ratios.

Successful gene delivery requires efficient DNA unpacking after polyplexes have entered the cell. ${ }^{25,71}$ In order to evaluate the responsiveness of the polyplexes to the reducing intracellular environment, ${ }^{72,73}$ these conditions were mimicked by incubation of the polyplexes with $2.5 \mathrm{mM}$ DTT for $30 \mathrm{~min}$. Based on the gel electrophoresis (Figure S3, in supporting information), free DNA bands are distinctively observed for DTT-treated polyplexes, while no DNA bands are distinguished in the absence of DTT. The results demonstrate that DNA is well retained by the PAAs, but rapidly liberated under reducing conditions through fragmentation of the PAAs by disulfide bond cleavage. We and others have previously shown that disulfide-containing PAA-based polyplexes show efficient nucleotide unpacking under reducing conditions which renders these polymers promising gene delivery systems. ${ }^{56,57,74}$

\section{In vitro transfection efficiency and cytotoxicity}

The transfection efficiency of the polyplexes was evaluated in COS-7 cells with plasmid DNA encoding for green fluorescent protein (GFP) as reporter gene. The preliminary screening of the PAAs was performed on 96-well plates at four different polymer/DNA mass ratios (i.e., 48, 24, 12, and 6) at both serum-free and $10 \%$ serum conditions. The transfection results were first qualitatively evaluated with confocal fluorescence microscopy and are illustrated in Figure 2 and Figure 3. GFP expression was observed in COS-7 cells both under serum-free and $10 \%$ serum conditions when polymer/DNA mass ratios were above 6. All polymers show enhanced GFP expression in COS-7 cells under serum-free condition, compared with common standard transfection agent of PEI ( $25 \mathrm{k})$ at 
its optimal condition ( $\mathrm{N} / \mathrm{P}$ ratio 10$)$. Moreover, the presence of thiourea functionalities (10\% for $\mathbf{P 2}$ and $28 \%$ for $\mathbf{P 3}$ ) in PAAs results in increased transfection efficiency compared with pABOL (P1), especially at the lower polymer/DNA mass ratios (12 and 6), suggesting the beneficiary effect of thiourea groups on transfection efficiency. This beneficiary effect is augmented under serum-present transfection conditions. In 10\% serum presence, GFP expression is severely impeded in the case of cells exposed to PEI and P1, while pronounced GFP expression is maintained in the case of cells treated with the thiourea-PAAs-based polyplexes of polymer/DNA mass ratios 6 and 12 .
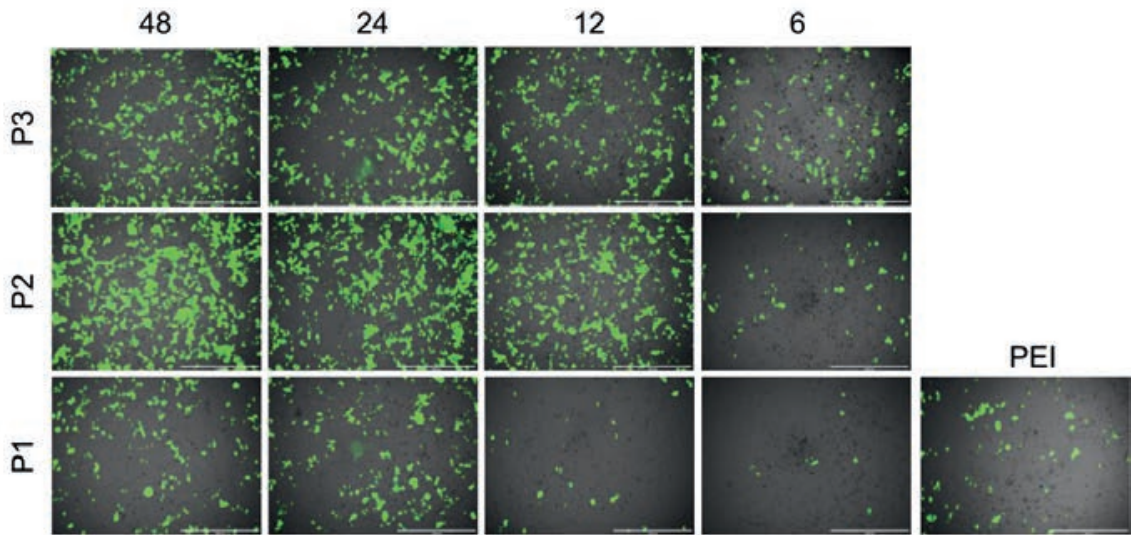

Figure 2. Overlaid GFP images of COS-7 cells transfected by pCMV-GFP via PAAs or PEI after $2 \mathrm{~d}$ incubation under $0 \%$ serum conditions. 4 x magnification, bars $=1000 \mu \mathrm{m}$ (horizontal number denotes polymer/DNA mass ratios).
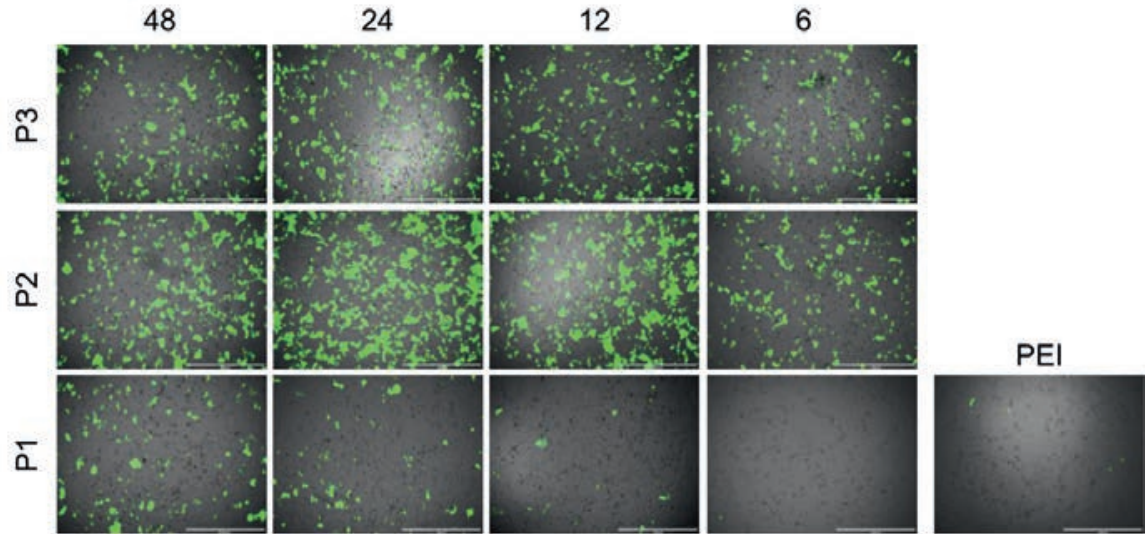

Figure 3. Overlaid GFP images of COS-7 cells transfected by pCMV-GFP via PAAs or PEI after $2 \mathrm{~d}$ incubation under $10 \%$ serum conditions. $4 \mathrm{X}$ magnification, bars $=1000 \mu \mathrm{m}$ (horizontal number denotes polymer/DNA mass ratios). 
Cell viabilities of COS-7 cells exposed to the polyplexes were evaluated through MTT assays and are presented in Figure 4. Cell viabilities of over $90 \%$ were found for cells exposed to polyplexes prepared from PAA throughout polymer/DNA mass ratios of 6,12 , 24, and 48 at serum-free conditions. Higher viabilities were observed for polyplexes in the presence of $10 \%$ serum as compared to serum-free conditions. The viabilities of cells treated by PAA-polyplexes (over 90\%) are substantially higher than those of cells exposed to PEI-polyplexes (60\% viability for $0 \%$ serum and $75 \%$ viability for $10 \%$ serum). The lower cell viability observed upon exposing cells to PEI-based polyplexes is attributed to the intrinsic toxicity of PEI, as has been reported before. ${ }^{75}$

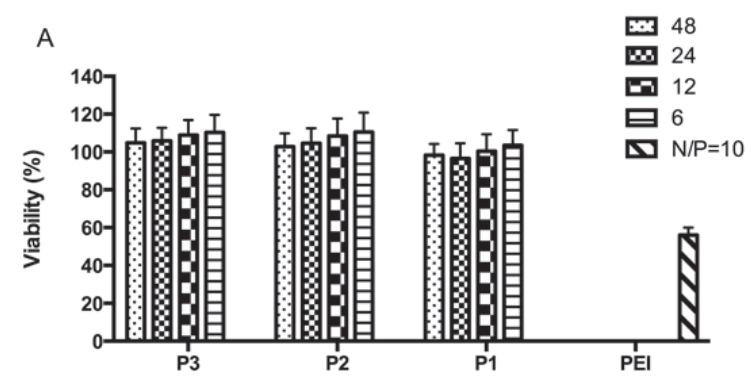

B

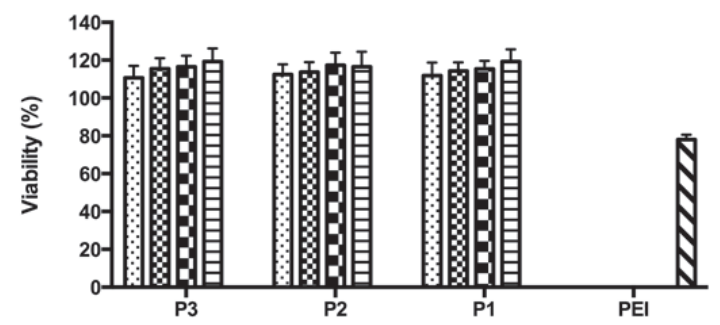

Figure 4. Cell viability of COS-7 cells treated with polyplexes at different polymer/DNA mass weights via MTT assay under $0 \%$ serum (A) and $10 \%$ serum (B).

The transfection performance of polymers P1, P2 and P3 was further evaluated in a quantitative manner via fluorescence-activated cell sorting (FACS). In Figure 5, the transfection performances of the three polymers are presented as percentages of GFPpositive cells of the total cells. As displayed, P2 and P3 deliver 6.5-fold to 4.5-fold higher GFP expression in cells at polymer/DNA mass ratios of 12 as compared to $\mathbf{P 1}$ under serum-free conditions. The presence of serum (10\%) substantially decreases the transfection efficiencies of P1 and PEI, but only a minor effect is observed for the transfection efficiencies of $\mathbf{P 2}$ and $\mathbf{P 3}$. 
A

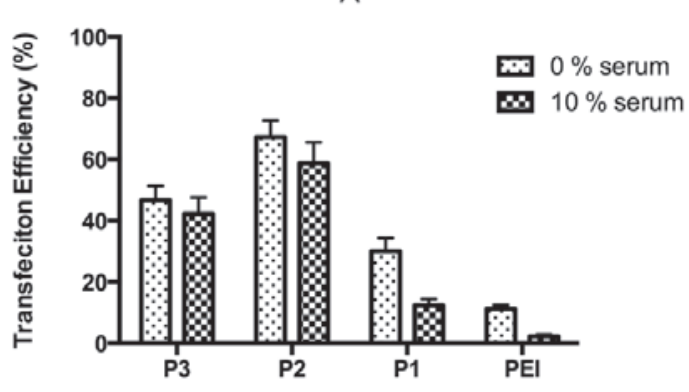

B

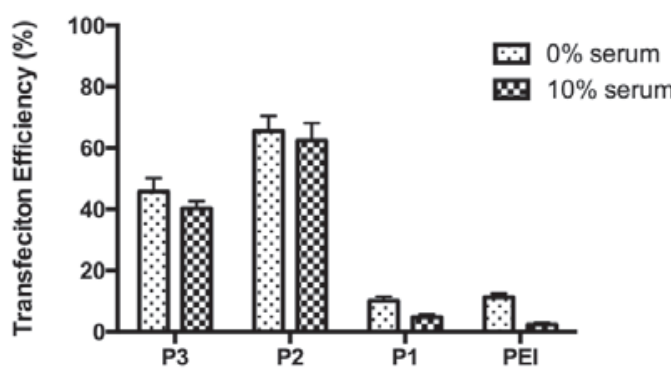

Figure 5. Transfection efficiency of P1, P2, P3, and PEI in COS-7 cells via FACS under both serum-free and serum-present conditions at polymer/DNA mass weight ratios of 24 (A) and 12 (B) respectively.

\section{CONCLUSIONS}

A thiourea-functionalized amine monomer could be successfully incorporated into PAA polymers via Michael type polyaddition, yielding a series of disulfide-backboned cationic polymers with varying percentages of thiourea-moieties closely according to the feed ratio of the monomers. The thiourea-containing polymers were demonstrated to form stable nanosized polyplexes with DNA, with enhanced colloidal stability under physiological conditions, which is attributed to hydrogen bonding between polymer and DNA. Polymers with $10 \%$ and $28 \%$ thiourea groups delivered up to 6-fold and 15-fold transfection enhancement compared to the control polymer (pABOL) under serum-free and serumpresent conditions, respectively, without introducing cytotoxicity. These results demonstrate that the presence of thiourea groups in PAAs is beneficial for polyplex stability and transfection efficiency and enhances the serum tolerance of PAA polyplexes without compromising their biological activity. These results indicate that (co)functionalization of polymeric gene vectors with thiourea groups may be a new avenue to enhance the transfection capabilities of polymers with minimal introduction of toxicity. 


\section{ACKNOWLEDGMENT}

The work is generously supported by NanoNextNL, a micro and nanotechnology consortium of the Government of the Netherlands and 130 partners. The authors thank Alexander Moerer and Dr. Karin Roelofs for their kind assistance in cell culturing and FACS measurements. 
Chapter 3

SUPPORTING INFORMATION

NMR

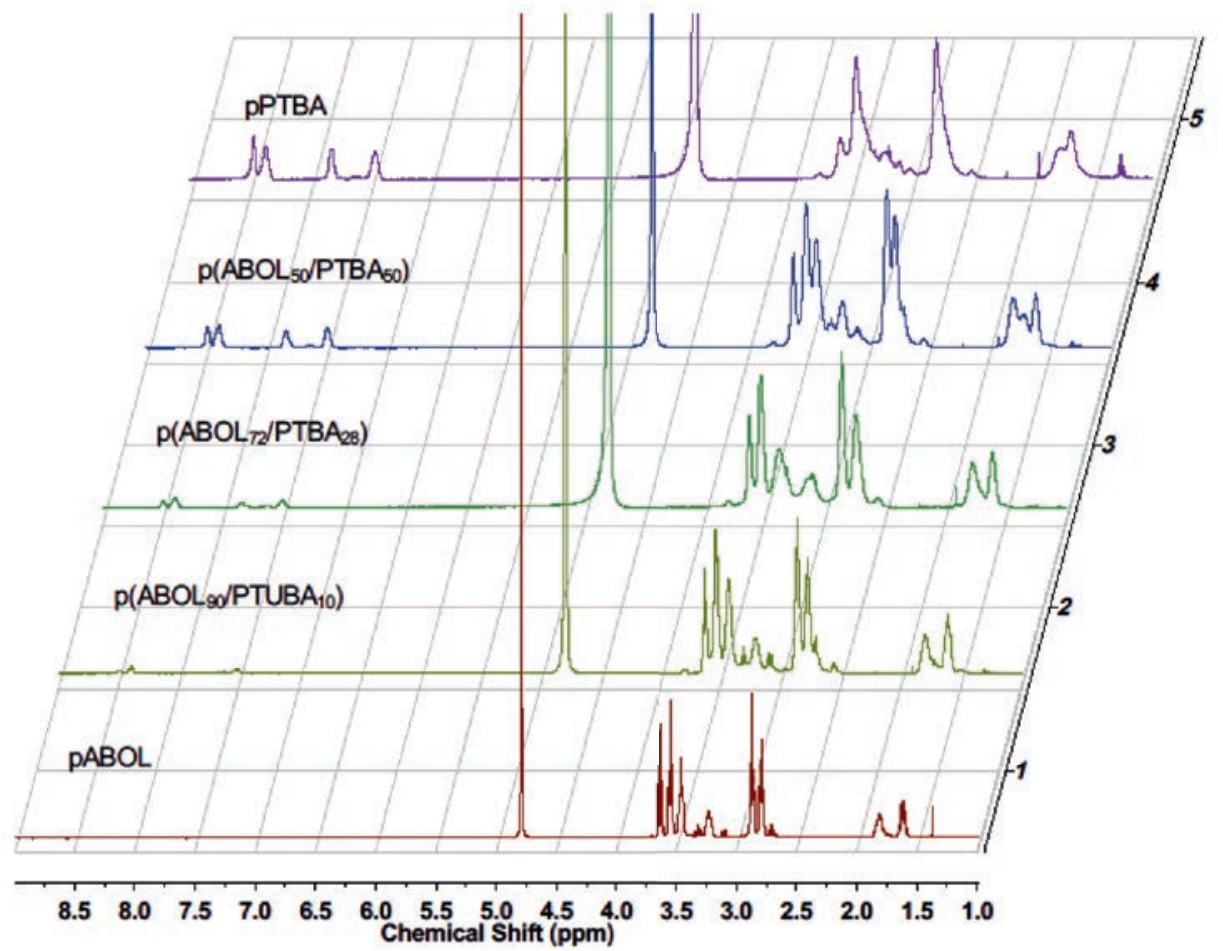

Figure S1. ${ }^{1} \mathrm{H}-\mathrm{NMR}$ spectra of PAAs in $\mathrm{D}_{2} \mathrm{O}$ (400 MHz). From bottom to top: P1, P2, P3, P4 and P5 respectively. 


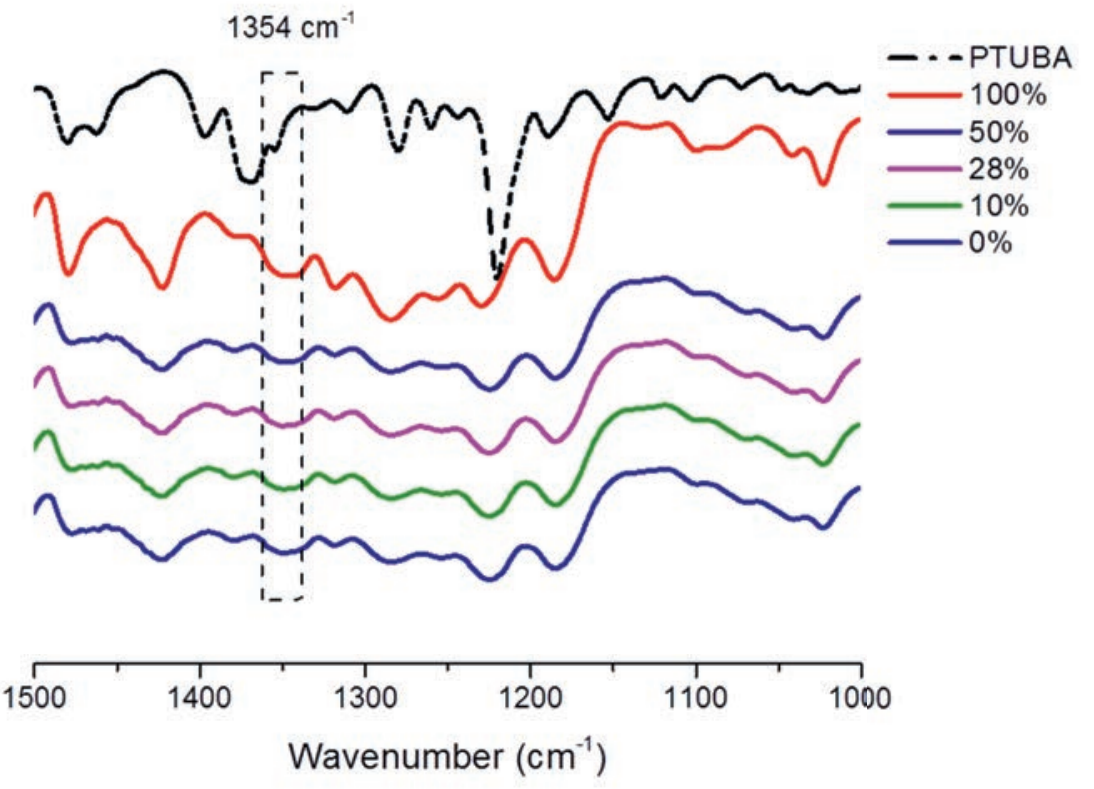

Figure S2. FT-IR spectra of monomer PTUBA, and synthesized PAAs with different thiourea functionalities of $100 \%, 50 \%, 28 \%, 10 \%$ and $0 \%$. 


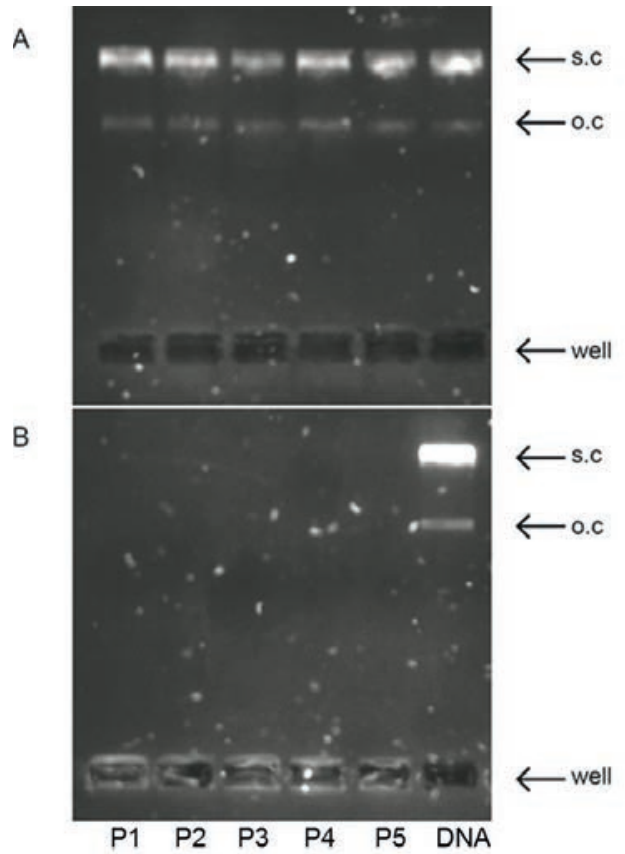

Figure S3 Agarose gel electrophoresis of polyplexes $(\mathrm{w} / \mathrm{w}=48)$ treated without $(\mathrm{B})$ and with DTT $(\mathrm{A})(\mathrm{s.c.}=$ supercoiled, o.c. $=$ open circular). 


\section{REFERENCES}

(1) De Smedt, S. C.; Demeester, J.; Hennink, W. E. Cationic polymer based gene delivery systems. Pharm. Res. 2000, 17, 113-126.

(2) Pack, D. W.; Hoffman, A. S.; Pun, S.; Stayton, P. S. Design and development of polymers for gene delivery. Nat. Rev. Drug Discov. 2005, 4, 581-593.

(3) Mastrobattista, E.; Hennink, W. E. Polymers for Gene Delivery Charged for Success. Nat. Mater. 2012, 11, 10-12.

(4) Yin, H.; Kanasty, R. L.; Eltoukhy, A. A.; Vegas, A. J.; Dorkin, J. R.; Anderson, D. G. Non-viral vectors for gene-based therapy. Nat. Rev. Genet. 2014, 15, 541-555.

(5) Ahmed, M.; Narain, R. Progress of RAFT based polymers in gene delivery. Prog. Polym. Sci. 2013, 38, 767-790.

(6) Deshayes, S.; Kasko, A. M. Polymeric biomaterials with engineered degradation. $J$. Polym. Sci., Part A: Polym. Chem. 2013, 51, 3531-3566.

(7) Tong, R.; Tang, L.; Ma, L.; Tu, C.; Baumgartner, R.; Cheng, J. Smart chemistry in polymeric nanomedicine. Chem. Soc. Rev. 2014, 43, 6982-7012.

(8) Jiang, Q. Y.; Lai, L. H.; Shen, J.; Wang, Q. Q.; Xu, F. J.; Tang, G. P. Gene delivery to tumor cells by cationic polymeric nanovectors coupled to folic acid and the cellpenetrating peptide octaarginine. Biomaterials 2011, 32, 7253-7262.

(9) Zhou, J. B.; Liu, J.; Cheng, C. J.; Patel, T. R.; Weller, C. E.; Piepmeier, J. M.; Jiang, Z. Z.; Saltzman, W. M. Biodegradable poly(amine-co-ester) terpolymers for targeted gene delivery. Nat. Mater. 2012, 11, 82-90.

(10) Vercauteren, D.; Piest, M.; van der Aa, L. J.; Al Soraj, M.; Jones, A. T.; Engbersen, J. F. J.; De Smedt, S. C.; Braeckmans, K. Flotillin-dependent endocytosis and a phagocytosis-like mechanism for cellular internalization of disulfide-based poly(amido amine)/DNA polyplexes. Biomaterials 2011, 32, 3072-3084.

(11) Zugates, G. T.; Anderson, D. G.; Little, S. R.; Lawhorn, I. E.; Langer, R. Synthesis of poly(beta-amino ester)s with thiol-reactive side chains for DNA delivery. J. Am. Chem. Soc. 2006, 128, 12726-12734.

(12) Li, J.; Zhu, Y.; Hazeldine, S. T.; Firestine, S. M.; Oupicky, D. Cyclam-Based Polymeric Copper Chelators for Gene Delivery and Potential PET Imaging. Biomacromolecules 2012, 13, 3220-3227.

(13) Chen, H. H.; Ho, Y. P.; Jiang, X.; Mao, H. Q.; Wang, T. H.; Leong, K. W. Quantitative comparison of intracellular unpacking kinetics of polyplexes by a model constructed from quantum Dot-FRET. Mol. Ther. 2008, 16, 324-332. 
(14) Bryson, J. M.; Fichter, K. M.; Chu, W. J.; Lee, J. H.; Li, J.; Madsen, L. A.; McLendon, P. M.; Reineke, T. M. Polymer beacons for luminescence and magnetic resonance imaging of DNA delivery. Proc. Natl. Acad. Sci. U.S.A. 2009, 106, 16913-16918.

(15) Knipe, J. M.; Peters, J. T.; Peppas, N. A. Theranostic agents for intracellular gene delivery with spatiotemporal imaging. Nano Today 2013, 8, 21-38.

(16) Dong, D. W.; Xiang, B.; Gao, W.; Yang, Z. Z.; Li, J. Q.; Qi, X. R. pH-responsive complexes using prefunctionalized polymers for synchronous delivery of doxorubicin and siRNA to cancer cells. Biomaterials 2013, 34, 4849-4859.

(17) Zhu, C.; Jung, S.; Luo, S.; Meng, F.; Zhu, X.; Park, T. G.; Zhong, Z. Co-delivery of siRNA and paclitaxel into cancer cells by biodegradable cationic micelles based on PDMAEMA-PCL-PDMAEMA triblock copolymers. Biomaterials 2010, 31, 24082416 .

(18) Li, J.; Zhu, Y.; Hazeldine, S. T.; Li, C. Y.; Oupicky, D. Dual-Function CXCR4 Antagonist Polyplexes To Deliver Gene Therapy and Inhibit Cancer Cell Invasion. Angew. Chem. Int. Ed. 2012, 51, 8740-8743.

(19) Xu, M. H.; Qian, J. M.; Suo, A. L.; Cui, N.; Yao, Y.; Xu, W. J.; Liu, T.; Wang, H. J. Co-delivery of doxorubicin and P-glycoprotein siRNA by multifunctional triblock copolymers for enhanced anticancer efficacy in breast cancer cells. J. Mater. Chem. B 2015, 3, 2215-2228.

(20) Bloomfield, V. A. DNA condensation by multivalent cations. Biopolymers 1997, 44, 269-282.

(21) Meneksedag-Erol, D.; Tang, T.; Uludağ, H. Molecular modeling of polynucleotide complexes. Biomaterials 2014, 35, 7068-7076.

(22) Carnerup, A. M.; Ainalem, M. L.; Alfredsson, V.; Nylander, T. Watching DNA Condensation Induced by Poly(amido amine) Dendrimers with Time-Resolved Cryo-TEM. Langmuir 2009, 25, 12466-12470.

(23) Schaaf, P.; Schlenoff, J. B. Saloplastics: processing compact polyelectrolyte complexes. Adv. Mater. 2015, 27, 2420-2432.

(24) Miyata, K.; Nishiyama, N.; Kataoka, K. Rational design of smart supramolecular assemblies for gene delivery: chemical challenges in the creation of artificial viruses. Chem. Soc. Rev. 2012, 41, 2562-2574. 
(25) Jones, C. H.; Chen, C. K.; Ravikrishnan, A.; Rane, S.; Pfeifer, B. A. Overcoming Nonviral Gene Delivery Barriers: Perspective and Future. Mol. Pharmaceutics 2013, 10, 4082-4098.

(26) Liu, Z.; Zhang, Z.; Zhou, C.; Jiao, Y. Hydrophobic modifications of cationic polymers for gene delivery. Prog. Polym. Sci. 2010, 35, 1144-1162.

(27) Zhang, R. J.; Zheng, N.; Song, Z. Y.; Yin, L. C.; Cheng, J. J. The effect of sidechain functionality and hydrophobicity on the gene delivery capabilities of cationic helical polypeptides. Biomaterials 2014, 35, 3443-3454.

(28) Allen, M. H.; Green, M. D.; Getaneh, H. K.; Miller, K. M.; Long, T. E. Tailoring Charge Density and Hydrogen Bonding of Imidazolium Copolymers for Efficient Gene Delivery. Biomacromolecules 2011, 12, 2243-2250.

(29) Cao, Z. Q.; Liu, W. G.; Liang, D. C.; Guo, G.; Zhang, J. Y. Design of Poly(vinyldiaminotriazine)-Based Nonviral Vectors via Specific Hydrogen Bonding with Nucleic Acid Base Pairs. Adv. Funct. Mater. 2007, 17, 246-252.

(30) Prevette, L. E.; Kodger, T. E.; Reineke, T. M.; Lynch, M. L. Deciphering the Role of Hydrogen Bonding in Enhancing pDNA-Polycation Interactions. Langmuir 2007, 23, 9773-9784.

(31) Feng, M.; Ibrahim, B. M.; Wilson, E. M.; Doh, K. O.; Bergman, B. K.; Park, C.; Yeo, Y. Stabilization of a hyaluronate-associated gene delivery system using calcium ions. Biomater. Sci. 2014, 2, 936-942.

(32) Matsumoto, S.; Christie, R. J.; Nishiyama, N.; Miyata, K.; Ishii, A.; Oba, M.; Koyama, H.; Yamasaki, Y.; Kataoka, K. Environment-Responsive Block Copolymer Micelles with a Disulfide Cross-Linked Core for Enhanced siRNA Delivery. Biomacromolecules 2009, 10, 119-127.

(33) Nakai, T.; Kanamori, T.; Sando, S.; Aoyama, Y. Remarkably size-regulated cell invasion by artificial viruses. saccharide-dependent self-aggregation of glycoviruses and its consequences in glycoviral gene delivery. J. Am. Chem. Soc. 2003, $125,8465-8475$.

(34) Aoyama, Y.; Kanamori, T.; Nakai, T.; Sasaki, T.; Horiuchi, S.; Sando, S.; Niidome, T. Artificial viruses and their application to gene delivery. Size-controlled gene coating with glycocluster nanoparticles. J. Am. Chem. Soc. 2003, 125, 3455-3457.

(35) Diaz-Moscoso, A.; Balbuena, P.; Gomez-Garcia, M.; Mellet, C. O.; Benito, J. M.; Le Gourrierec, L.; Di Giorgio, C.; Vierling, P.; Mazzaglia, A.; Micali, N.; Defaye, 
J.; Fernandez, J. M. G. Rational design of cationic cyclooligosaccharides as efficient gene delivery systems. Chem. Commun. 2008, 2001-2003.

(36) Leblond, J.; Mignet, N.; Largeau, C.; Seguin, J.; Scherman, D.; Herscovici, J. Lipopolythiourea transfecting agents: Lysine thiourea derivatives. Bioconjugate Chem. 2008, 19, 306-314.

(37) Leblond, J.; Mignet, N.; Largeau, C.; Spanedda, M. V.; Seguin, J.; Scherman, D.; Herscovici, J. Lipopolythioureas: A new non-cationic system for gene transfer. Bioconjugate Chem. 2007, 18, 484-493.

(38) Bastings, M. M. C.; Koudstaal, S.; Kieltyka, R. E.; Nakano, Y.; Pape, A. C. H.; Feyen, D. A. M.; van Slochteren, F. J.; Doevendans, P. A.; Sluijter, J. P. G.; Meijer, E. W.; Chamuleau, S. A. J.; Dankers, P. Y. W. A Fast pH-Switchable and SelfHealing Supramolecular Hydrogel Carrier for Guided, Local Catheter Injection in the Infarcted Myocardium. Adv. Healthcare Mater. 2014, 3, 70-78.

(39) Amin, M. C.; Ahmad, N.; Pandey, M.; Abeer, M. M.; Mohamad, N. Recent advances in the role of supramolecular hydrogels in drug delivery. Expert Opin. Drug Delivery 2014, 1-13.

(40) Boekhoven, J.; Stupp, S. I. 25th anniversary article: supramolecular materials for regenerative medicine. Adv. Mater. 2014, 26, 1642-1659.

(41) Aida, T.; Meijer, E. W.; Stupp, S. I. Functional supramolecular polymers. Science 2012, 335, 813-817.

(42) Dong, R.; Zhou, Y.; Huang, X.; Zhu, X.; Lu, Y.; Shen, J. Functional supramolecular polymers for biomedical applications. Adv. Mater. 2015, 27, 498526.

(43) Banwell, E. F.; Abelardo, E. S.; Adams, D. J.; Birchall, M. A.; Corrigan, A.; Donald, A. M.; Kirkland, M.; Serpell, L. C.; Butler, M. F.; Woolfson, D. N. Rational design and application of responsive alpha-helical peptide hydrogels. Nat. Mater. 2009, 8, 596-600.

(44) Blanco, J. L. J.; Bootello, P.; Benito, J. M.; Mellet, C. O.; Fernandez, J. M. G. Urea-, thiourea-, and guanidine-linked glycooligomers as phosphate binders in water. J. Org. Chem. 2006, 71, 5136-5143.

(45) Kral, T.; Leblond, J.; Hof, M.; Scherman, D.; Herscovici, J.; Mignet, N. Lipopolythiourea/DNA interaction: A biophysical study. Biophys. Chem. 2010, 148, 68-73. 
(46) Bühlmann, P.; Nishizawa, S.; Xiao, K. P.; Umezawa, Y. Strong hydrogen bondmediated complexation of $\mathrm{H}_{2} \mathrm{PO}^{-}$by neutral bis-thiourea hosts. Tetrahedron 1997, $53,1647-1654$.

(47) Benito, J. M.; Gomez-Garcia, M.; Blanco, J. L. J.; Mellet, C. O.; Fernandez, J. M. G. Carbohydrate-based receptors with multiple thiourea binding sites. Multipoint hydrogen bond recognition of dicarboxylates and monosaccharides. J. Org. Chem. 2001, 66, 1366-1372.

(48) Leblond, J.; Mignet, N.; Leseurre, L.; Largeau, C.; Bessodes, M.; Scherman, D.; Herscovici, J. Design, synthesis, and evaluation of enhanced DNA binding new lipopolythioureas. Bioconjugate Chem. 2006, 17, 1200-1208.

(49) Li, C.; Yang, Y. W.; Liang, Z. X.; Wu, G. L.; Gao, H. Post-modification of poly(glycidyl methacrylate)s with alkyl amine and isothiocyanate for effective pDNA delivery. Polym. Chem. 2013, 4, 4366-4374.

(50) Li, Y. C.; Tian, H. Y.; Ding, J. X.; Dong, X.; Chen, J.; Chen, X. S. Thiourea modified polyethylenimine for efficient gene delivery mediated by the combination of electrostatic interactions and hydrogen bonds. Polym. Chem. 2014, 5, 3598-3607.

(51) Pinel, S.; Aman, E.; Erblang, F.; Dietrich, J.; Frisch, B.; Sirman, J.; Kichler, A.; Sibler, A.-P.; Dontenwill, M.; Schaffner, F.; Zuber, G. Quantitative measurement of delivery and gene silencing activities of siRNA polyplexes containing pyridylthiourea-grafted polyethylenimines. J. Controlled Release 2014, 182, 1-12.

(52) Creusat, G.; Thomann, J. S.; Maglott, A.; Pons, B.; Dontenwill, M.; Guerin, E.; Frisch, B.; Zuber, G. Pyridylthiourea-grafted polyethylenimine offers an effective assistance to siRNA-mediated gene silencing in vitro and in vivo. J. Controlled Release 2012, 157, 418-426.

(53) Whitehead, K. A.; Langer, R.; Anderson, D. G. Knocking down barriers: advances in siRNA delivery. Nat. Rev. Drug Discov. 2009, 8, 129-138.

(54) Lonez, C.; Vandenbranden, M.; Ruysschaert, J.-M. Cationic liposomal lipids: From gene carriers to cell signaling. Prog. Lipid Res. 2008, 47, 340-347.

(55) Lv, H. T.; Zhang, S. B.; Wang, B.; Cui, S. H.; Yan, J. Toxicity of cationic lipids and cationic polymers in gene delivery. J. Controlled Release 2006, 114, 100-109.

(56) Lin, C.; Zhong, Z.; Lok, M. C.; Jiang, X.; Hennink, W. E.; Feijen, J.; Engbersen, J. F. J. Novel Bioreducible Poly(amido amine)s for Highly Efficient Gene Delivery. Bioconjugate Chem. 2007, 18, 138-145. 
(57) Piest, M.; Engbersen, J. F. J. Role of boronic acid moieties in poly(amido amine)s for gene delivery. J. Controlled Release 2011, 155, 331-340.

(58) Grigsby, C. L.; Ho, Y. P.; Lin, C.; Engbersen, J. F.; Leong, K. W. Microfluidic preparation of polymer-nucleic acid nanocomplexes improves nonviral gene transfer. Sci.Rep. 2013, 3, 3155.

(59) Song, Y.; Lou, B.; Zhao, P.; Lin, C. Multifunctional disulfide-based cationic dextran conjugates for intravenous gene delivery targeting ovarian cancer cells. Mol. Pharmaceutics 2014, 11, 2250-2261.

(60) Ou, M.; Xu, R.; Kim, S. H.; Bull, D. A.; Kim, S. W. A family of bioreducible poly(disulfide amine)s for gene delivery. Biomaterials 2009, 30, 5804-5814.

(61) Vader, P.; van der Aa, L.; Engbersen, J. J.; Storm, G.; Schiffelers, R. DisulfideBased Poly(amido amine)s for siRNA Delivery: Effects of Structure on siRNA Complexation, Cellular Uptake, Gene Silencing and Toxicity. Pharm. Res. 2011, 28, 1013-1022.

(62) Cohen, S.; Coué, G.; Beno, D.; Korenstein, R.; Engbersen, J. F. J. Bioreducible poly(amidoamine)s as carriers for intracellular protein delivery to intestinal cells. Biomaterials 2012, 33, 614-623.

(63) Ferruti, P. Poly(amidoamine)s: Past, present, and perspectives. J. Polym. Sci., Part A: Polym. Chem. 2013, 51, 2319-2353.

(64) Oupicky, D.; Li, J. Bioreducible polycations in nucleic acid delivery: past, present, and future trends. Macromol. Biosci. 2014, 14, 908-922.

(65) Lin, C.; Engbersen, J. F. J. The role of the disulfide group in disulfide-based polymeric gene carriers. Expert Opin. Drug Delivery 2009, 6, 421-439.

(66) van der Aa, L. J.; Vader, P.; Storm, G.; Schiffelers, R. M.; Engbersen, J. F. J. Intercalating quaternary nicotinamide-based poly(amido amine)s for gene delivery. J. Controlled Release 2014, 195, 11-20.

(67) Schweikl, H.; Schmalz, G. Triethylene glycol dimethacrylate induces large deletions in the hprt gene of V79 cells. Mutat. Res. 1999, 438, 71-78.

(68) Lynn, D. M.; Langer, R. Degradable Poly( $\beta$-amino esters): Synthesis, Characterization, and Self-Assembly with Plasmid DNA. J. Am. Chem. Soc. 2000, 122, 10761-10768.

(69) Mintzer, M. A.; Simanek, E. E. Nonviral Vectors for Gene Delivery. Chem. Rev. 2009, 109, 259-302. 
(70) Canton, I.; Battaglia, G. Endocytosis at the nanoscale. Chem. Soc. Rev. 2012, 41, 2718-2739.

(71) Yue, Y. N.; Wu, C. Progress and perspectives in developing polymeric vectors for in vitro gene delivery. Biomater. Sci. 2013, 1, 152-170.

(72) Schafer, F. Q.; Buettner, G. R. Redox environment of the cell as viewed through the redox state of the glutathione disulfide/glutathione couple. Free Radical Bio. Med. 2001, 30, 1191-1212.

(73) Klein, P. M.; Wagner, E. Bioreducible polycations as shuttles for therapeutic nucleic acid and protein transfection. Antioxid. Redox Signal. 2014, 21, 804-817.

(74) Hoon Jeong, J.; Christensen, L. V.; Yockman, J. W.; Zhong, Z.; Engbersen, J. F. J.; Jong Kim, W.; Feijen, J.; Wan Kim, S. Reducible poly(amido ethylenimine) directed to enhance RNA interference. Biomaterials 2007, 28, 1912-1917.

(75) Boussif, O.; Lezoualch, F.; Zanta, M. A.; Mergny, M. D.; Scherman, D.; Demeneix, B.; Behr, J. P. A Versatile Vector for Gene and Oligonucleotide Transfer into Cells in Culture and in-Vivo - Polyethylenimine. Proc. Natl. Acad.Sci. U.S.A. 1995, 92, 7297-7301. 



\section{Chapter 4. Effects of Incorporation of Fluoroalkyl Groups in Bioreducible Poly(amido amine)s on Gene Delivery}

Guoying Si, Jos M.J. Paulusse* and Johan F.J. Engbersen*

Department of Controlled Drug Delivery, MIRA Institute for Biomedical Technology and Technical Medicine, Faculty of Science and Technology, University of Twente, P.O. Box 217, 7500 AE Enschede, The Netherlands

KEYWORDS

Gene delivery; cationic polymers; fluorination; bioreducible; serum tolerance. 


\section{ABSTRACT}

The full potential of cationic polymers as non-viral gene vectors is largely impeded due to low transfection efficiency and the interference by serum proteins. Herein, we modified a promising class of gene vectors consisting of bioreducible poly(amido amine)s (PAAs) with fluoroalkyl moieties at various functionalization ratios $(100 \%, 50 \%, 25 \%, 10 \%$ and $0 \%$ ) via the amine-anhydride reaction. Fluorinated PAAs showed excellent solubility in water at pH 7.4, independent of the degree of fluorination, and compacted plasmid DNA (pCMV-GFP) into nanosized polyplexes with diameters from several micrometers down to $150 \mathrm{~nm}$, and zeta-potential from $+10 \mathrm{mV}$ to $+30 \mathrm{mV}$ upon increasing polymer/DNA mass ratios from 6 to 48. DNA was fully trapped by the cationic polymers, while liberated upon addition of DTT as corroborated with gel electrophoresis. Fluorination resulted in enhanced biocompatibility of the PAAs towards COS-7 cells as revealed by MTT assays. The potency of fluorinated PAAs in transfection of COS-7 was enhanced up to 8 fold under serum-free conditions and remained satisfactory even in the presence of serum $(10 \%)$ as compared to non-fluorinated PAA analogues. In addition, the fluorinated PAAs are superior over standard transfection agent of PEI both in terms of preserving cell viability and transfection efficiency, suggesting that introduction of fluoroalkyl substitutes is an effective strategy to design effective non-viral gene vectors.

\section{INTRODUCTION}

Gene therapy remains a major challenge due to the lack of effective delivery carriers with minimal toxicities. ${ }^{1-5}$ Although displaying high transfection efficiencies, viral carriers are plagued with poor biosafety, ${ }^{6,7}$ limited DNA packaging capacity, ${ }^{8}$ and complicated scaleup. ${ }^{9}$ Non-viral carriers have therefore been proposed as alternatives to avoid aforementioned shortcomings. Although their clinical potency has so far remained low, ${ }^{10,11}$ cationic polymers have received wide attention, ${ }^{12}$ owing to their ability to condense DNA into positively charged polyplexes through electrostatic interactions. ${ }^{13-15}$ The polyplexes aid DNA to enter into cells, ${ }^{16,17}$ promote DNA to escape from the endosome, ${ }^{18-20}$ and ultimately deliver the genetic cargo inside the nucleus to achieve gene expression. ${ }^{21-23}$

A myriad of cationic polymers has been devised as non-viral gene carrier, usually with moderate transfection efficacies concomitant with considerable degrees of toxicity. ${ }^{24,25}$ Residual cationic polymer may destroy the integrity of cell membrane, ${ }^{26}$ impair the mitochondria, ${ }^{27}$ and eventually reduce the cell viability. ${ }^{26,28}$ Various approaches have been 
proposed to achieve the ideal balance of cationic charge for high transfection efficiency and decreased toxicity, such as introducing cationic motifs with amino acids, ${ }^{29}$ peptides, ${ }^{30}$ and additional polymer poly(L-lysine), ${ }^{31}$ and even superparamagnetic iron oxide nanoparticles ${ }^{32}$ to enhance transfection efficiency and maintain toxicity to a minimum. From our previous work, ${ }^{33}$ it has been shown that bioreducible poly(amido amine)s (PAAs) equipped with primary amines as pendant groups along the polymer chain are interesting degradable cationic polymers that fragmentate upon exposure to reducing milieu. The primary amines from this polymer have been functionalized with boronic acid groups,${ }^{34,35}$ nicotinamide groups,${ }^{36,37}$ and charge-reversal groups ${ }^{38}$ to modify the pendent primary amines to reduce the positive charge density and endow the polymers with improved functionality and high tolerance to cell viability. The modified PAAs were used as carriers for DNA, ${ }^{35-37}$ siRNA, ${ }^{35}$ proteins, ${ }^{38}$ and as building blocks for smart hydrogels ${ }^{39}$ and multilayered films ${ }^{40}$ with excellent biocompatibility.

As described in previous chapter, hydrogen bonding was applied to increase the stability of polyplexes. In this chapter, the hydrophobic interactions were explored to stabilize the polyplexes by using the primary amine groups to introduce fluoroalkyl groups in the PAAs. Pharmacokinetic behavior of drug molecules, ${ }^{41}$ proteins, ${ }^{42,43}$ and cells ${ }^{44}$ are found to be substantially altered by fluorination. ${ }^{45}$ Fluorination also increases stability of protein against thermal unfolding, chemical denaturation, and proteolytic degradation, while preserving biological activity. ${ }^{46-50}$ Fluorinated polymers display high affinity towards cell membranes, ${ }^{51}$ and are able to transverse lipid bilayers of cell membranes and endosome/lysosome membranes more easily, thereby favoring endosomal escape of polymer and possible cargo. ${ }^{52}$ These beneficial properties are related to the hydrophobicity and lipophobicity of fluorinated polymers. ${ }^{53-55}$ For lipid-mediated gene delivery, Vierling et al. have shown the favorable effect of the presence of fluoroalkyl by combining fluorinated glycerophosphoethanolamine helper lipids with common cationic lipids to enhance gene transfection both in vitro and in vivo. ${ }^{56,57}$ Lebeau et al. showed that incorporation of fluorinated motifs close to the cationic lipid polar head resulted in enhancement of transfection potency through increased colloidal stability of the formed lipoplexes. ${ }^{58,59}$ Cheng et al. modified dendrimers ${ }^{60,61}$ with different fluorinated compounds $^{62}$ to obtain enhanced transfection efficiency with reduced cytotoxicity. ${ }^{61}$ Moreover, this method was also expanded to the common standard transfection agent PEI, resulting in higher transfection efficiency and improved biocompatibility. ${ }^{63}$ Fluorinated 
vectors (both lipids and polymers) typically show good serum compatibility at appreciable transfection efficiencies even up to $50 \%$ serum. $^{61}$

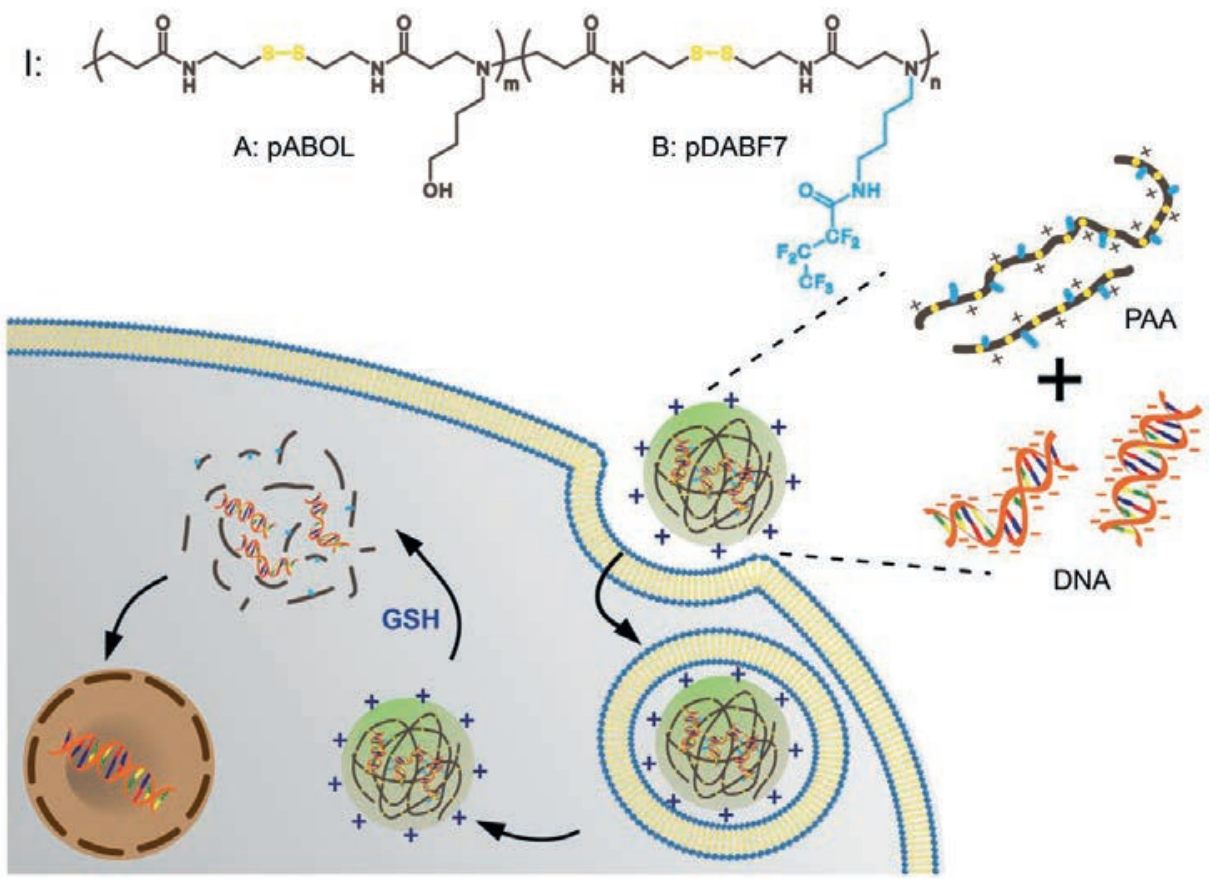

Scheme 1 Schematic representation of fluorinated disulfide-linked poly(amido amine)s for efficient gene delivery.

In this chapter, bioreducible PAA (I) was prepared with variable ratios of units of pABOL (A) and the units containing the perfluoro-butylamide moiety (B, i.e., $0 \%, 10 \%, 25 \%, 50 \%$, and $100 \%$ ) (Scheme 1). The effects of fluorination of the PAAs on the transfection efficiency and cytotoxicity were investigated through in vitro studies on COS-7 cells. In addition, the effects of increased serum concentrations on transfection efficiency was investigated.

\section{EXPERIMENTAL PROCEDURES}

\section{Materials and Methods}

All monomers, $N, \quad N^{\prime}$-cystaminebisacrylamide (CBA, Polysciences), $\quad N$-Boc-1,4butanediamine (Boc-DAB, Sigma-Aldrich), 4-amino-1-butanol (ABOL, Sigma-Aldrich), heptafluorobutyric anhydride (F7, $\geq 99.0 \%$, Sigma-Aldrich), dithiothreitol (DTT, $\geq 99.5 \%$, Sigma-Aldrich), branched polyethylenimine (PEI, Mw 25 kDa, Sigma-Aldrich) and 
triethylamine (TEA, $\geq 99 \%$, Sigma-Aldrich) were used as received without further purification. All solvents used are of analytical grade. Water used in these experiments is treated through a Milli-Q Gradient System (Millipore, Bedford, MA). Plasmid DNAs, pCMV-GFP and pCMV- $\triangle \mathrm{GFP}$ were purchased from Plasmid Factory (Bielefeld, Germany).

${ }^{1} \mathrm{H}$ NMR and ${ }^{19} \mathrm{~F}$ NMR were taken on a Bruker Spectrometer (400 MHz) in deuterated solvents. Molecular weights were determined by gel permeation chromatography (GPC, Waters Alliance 2695) relative to PEG standards, using a Mixed-M column (PL-aquagel$\mathrm{OH} 8$ micron, $300 \times 7.5 \mathrm{~mm}$ ) with mobile phase of $N, N$-dimethylformamide (DMF) containing $\mathrm{LiCl}(50 \mathrm{mM})$.

Synthesis of fluorinated PAAs $\mathbf{p}\left(\mathbf{A B O L} / \mathbf{D A B F} 7_{\mathbf{n}}\right)$. The procedure to prepare fluorinated PAAs is exemplified for $\mathrm{p}\left(\mathrm{ABOL}_{50} / \mathrm{DABF}_{50}\right)$. Into a glass vial with methanol/water (v/v, 3/1, $5.00 \mathrm{~mL})$, CBA (2.62 g, $10.0 \mathrm{mmol})$, Boc-DAB (0.945 g, 5.00 $\mathrm{mmol})$ and ABOL (0.450 g, $5.00 \mathrm{mmol})$ were consecutively charged. After stirring at 50 ${ }^{\circ} \mathrm{C}$ for $7 \mathrm{~d}$, Boc-DAB (0.189 $\left.\mathrm{g}, 1.00 \mathrm{mmol}\right)$ was added to the homogeneous viscous mixture. After $2 \mathrm{~d}$ stirring at $50{ }^{\circ} \mathrm{C}$, the mixture was cooled down to ambient temperature and diluted with methanol $(50.0 \mathrm{~mL})$ and subsequently purged with $\mathrm{HCl}$ gas for $30 \mathrm{~min}$ to deprotect the primary amine groups from the Boc-DAB moieties. The mixture was concentrated under reduced pressure and resuspended in methanol $(50.0 \mathrm{~mL})$, followed by addition of excess of triethylamine (TEA) and excess of heptafluorobutyric anhydride (F7). After stirring overnight at room temperature and evaporating solvent under reduced pressure, the viscous residue was diluted with water $(25.0 \mathrm{~mL})$, acidified to $\mathrm{pH} 4$, purified by dialysis (MWCO $1000 \mathrm{Da}$ ), and lyophilized to give the fluorinated polymer $\mathrm{p}\left(\mathrm{ABOL}_{50} / \mathrm{DABF}_{50}\right)$ as an amorphous solid (1.89 g, $46.8 \%$ yield). ${ }^{1} \mathrm{H}$ NMR $\left(\mathrm{D}_{2} \mathrm{O}, 400\right.$ $\mathrm{MHz}): \delta_{\mathrm{H}} 1.56-1.66\left(\mathrm{~m}, 4 \mathrm{H}, \mathrm{RNCH}_{2} \mathrm{CH}_{2} \mathrm{CH}_{2} \mathrm{CH}_{2} \mathrm{NHCOF}_{7}\right), 2.44$ (t, 4H, 2 x $\mathrm{NHCOCH}_{2}$ ), $2.55\left(\mathrm{~m}, \quad 4 \mathrm{H}, \quad \mathrm{RNCH}_{2} \mathrm{CH}_{2} \mathrm{CH}_{2} \mathrm{CH}_{2} \mathrm{NHCOF}_{7}\right), 2.84\left(\mathrm{~m}, \quad 8 \mathrm{H}, 2\right.$ x $\quad \mathrm{SSCH}_{2} \mathrm{CH}_{2}+$ $\left.\mathrm{CH}_{2} \mathrm{CH}_{2} \mathrm{NCH}_{2} \mathrm{CH}_{2}\right), 3.00$ (t, $\left.2 \mathrm{H}, \quad \mathrm{RNCH}_{2} \mathrm{CH}_{2} \mathrm{CH}_{2} \mathrm{CH}_{2} \mathrm{NHCOF}_{7}\right), 3.50$ (t, 4H, $2 \mathrm{x}$ $\left.\mathrm{SSCH}_{2} \mathrm{CH}_{2}\right) .{ }^{19} \mathrm{~F}$ NMR $\left(\mathrm{D}_{2} \mathrm{O}, 400 \mathrm{MHz}\right): \delta_{\mathrm{F}}-81.4\left(\mathrm{t}, 3 \mathrm{~F}, \mathrm{CF}_{3}\right),-121.5\left(\mathrm{~m}, 2 \mathrm{~F}, \mathrm{CF}_{2} \mathrm{CF}_{3}\right)$, $128.0\left(\mathrm{t}, 2 \mathrm{~F}, \mathrm{COCF}_{2}\right)$.

\section{Polyplex preparation}

Polyplexes were prepared in HEPES buffer $(20 \mathrm{mM}, \mathrm{pH} 7.4)$. The typical procedure to prepare polyplex of mass ratio $48 / 1$ is described as below: polymer solution ( $800 \mu \mathrm{L}, 900$ 
$\mu \mathrm{g} / \mathrm{mL})$ was added into DNA solution $(200 \mu \mathrm{L}, 75 \mu \mathrm{g} / \mathrm{mL})$, followed by $5 \mathrm{~s}$ vortexing and $30 \mathrm{~min}$ incubation at room temperature. Sizes and surface charges of polyplexes were measured at $25^{\circ} \mathrm{C}$ with a Zetasizer Nano ZS (Malvern Instruments, Malvern). The values are recorded as the mean of three measurements with their standard deviation as error bar.

\section{Agarose gel retardation}

Polyplexes were prepared at polymer/DNA mass ratio 48 as described previously. DTT solution in HEPES buffer was added to polyplex solutions to give the final DTT concentration of $2.5 \mathrm{mM}$. After $30 \mathrm{~min}$ incubation at ambient temperature, $6 \mathrm{X}$ loading buffer containing bromophenol (Ferments) was mixed with resulting dispersions. The dispersions $(10 \mu \mathrm{L})$ was loaded on a $0.8 \% \mathrm{w} / \mathrm{v}$ agarose gel containing $1 \mathrm{x}$ SYBR ${ }^{\circledR}$ Safe DNA Gel Stain (Invitrogen ${ }^{\mathrm{TM}}$ ). Electrophoresis was performed at $90 \mathrm{~V}$ for $60 \mathrm{~min}$ in a TBE (Tris-borate-EDTA, 1X) running buffer. After gel development, the picture was acquired using FluorChem (Proteinsimple, Westburg, Leusden, the Netherlands) under UV excitation.

\section{In Vitro Transfection and Cell Viability Assays}

Transfection experiments were performed on COS-7 cells (SV-40 transformed African green monkey kidney cells) using the plasmid pCMV-GFP as a reporter gene. Transfections and cell viabilities were conducted in parallel using polyplexes formed at polymer/plasmid DNA mass ratios ranging from 6 to 48 .

Gene expression experiments and cell viability evaluations were carried out in separate 96well plates. Cells were seeded in at a density of $10^{4}$ cells per well $\left(2.94 \times 10^{4}\right.$ cells $\left./ \mathrm{cm}^{2}\right)$ and maintained in complete medium at $37{ }^{\circ} \mathrm{C}$ in a humidified atmosphere containing $5 \%$ $\mathrm{CO}_{2}$ until $60 \%$ - $80 \%$ confluency. In a standard transfection experiment, cells were first incubated with medium (100 $\mu \mathrm{L}$, with/without serum) for $30 \mathrm{~min}$ and then loaded with 100 $\mu \mathrm{L}$ polyplex dispersions ( $1 \mu \mathrm{g}$ DNA per well). After $1 \mathrm{~h}$ incubation, polyplexes were removed, and fresh complete culture medium $(100 \mu \mathrm{L})$ was added and cells were cultured for an additional $48 \mathrm{~h}$. Transfection efficiency was determined qualitatively through fluorescence imaging via an EVOS digital inverted microscope (EMS, Wageningen, the Netherlands). A reference was prepared from PEI (25 KDa)/DNA at a polymer/DNA mass ratio of 1.33/1. MTT assays were conducted to determine the number of viable cells, with a value of $100 \%$ cell viability for untreated cells. 
Quantitative determination of transfection efficiency was performed by flow cytometry. Cells were seeded in 48 -well plates with densities of ca. $1.6 \times 10^{4}$ cells per well $\left(1.6 \times 10^{4}\right.$ cells $/ \mathrm{cm}^{2}$ ) and maintained in complete medium at $37{ }^{\circ} \mathrm{C}$ in a humidified atmosphere containing 5\% $\mathrm{CO}_{2}$ until $60 \%$ - 80\% confluency. Cells were first incubated with medium (200 $\mu \mathrm{L}$, with/without serum) for $30 \mathrm{~min}$ and then loaded with $200 \mu \mathrm{L}$ polyplex dispersions ( $1 \mu \mathrm{g}$ DNA per well). After $1 \mathrm{~h}$ incubation, the polyplexes were aspirated, fresh and warm complete culture medium $(200 \mu \mathrm{L})$ was added and eventually cells were cultured for $48 \mathrm{~h}$. The cells were fixed by adding trypsin solution $(0.25 \%, 150 \mu \mathrm{L})$, and centrifuged $(600 \mathrm{~g}, 5$ min, ambient temperature). The pellets were resuspended in HBSS buffer (200 $\mu \mathrm{L})$, and measured by the FACSCalibur (Becton-Dickinson, Breda, the Netherlands) at an excitation wavelength of $488 \mathrm{~nm}$ and an emission wavelength of $530 \mathrm{~nm}$. Data was processed by the FACS Cellquest Software. A PEI $(25 \mathrm{~K}) / \mathrm{DNA}$ formulation prepared at a polymer/DNA mass ratio of $1.33 / 1$ was used as a reference.

\section{RESULTS AND DISCUSSION}

\section{Polymer synthesis and characterization}

Poly(amido amine) polymers incorporating different percentages $(100 \%, 50 \%, 25 \%, 12 \%$, and $0 \%$ ) of Boc protected aminobutyl side chains next to hydroxybutyl side chains were prepared via Michael-type polyaddition of $N, N^{\prime}$-cystaminebisacrylamide (CBA) with mixtures of $N$-Boc-1,4-butanediamine (Boc-DAB) and 4-amino-1-butanol (ABOL) at the appropriate molar ratios. After removal of the Boc-protecting groups of the obtained polymers, the resulting free amine groups were reacted with heptafluorobutyric anhydride (F7) to afford the fluorinated PAAs $\mathrm{p}\left(\mathrm{ABOL}_{\mathrm{m}} / \mathrm{DABF}_{\mathrm{n}}\right)$ (Scheme 2).
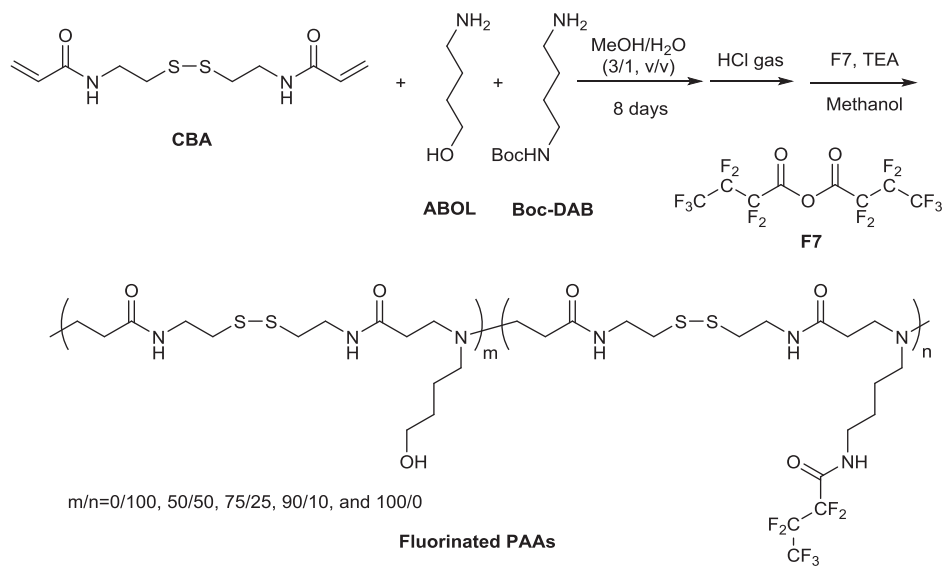

Scheme 2. Synthetic route of preparation of fluorinated PAAs. 
In line with our previous reports, ${ }^{33,36}$ the viscosity of the reaction mixture during the polymerization increased gradually without any occurrence of gelation, indicating the formation of linear polymers. ${ }^{1} \mathrm{H}$ NMR spectroscopy indicated the disappearance of signals at 5-7 ppm confirming complete consumption of acrylamide groups that are potentially toxic to cells. ${ }^{64,65}$ Extensive dialysis followed by lyophilization yielded the fluorinated PAAs as $\mathrm{HCl}$ salts. The molecular composition of the fluorinated PAAs is determined by ${ }^{1} \mathrm{H}$ NMR spectroscopy. The methylene group proximal to the hydroxyl group of ABOL, with a chemical shift of $\delta=3.62 \mathrm{ppm}$, was compared with the methylene signal close to the amide moiety, with a chemical shift of $\delta=3.50$. The composition of the PAAs is in good agreement with the feed ratios, demonstrating the ease of altering the polymer composition. The ${ }^{19} \mathrm{~F}$ NMR spectra of the products confirmed the successful introduction of the fluoroalkyl moieties in the PAAs. GPC analysis revealed mono-modal size distributions, with molecular weights ranging from 5.2-8.1 kDa and polydispersity indices (PDI) between 1.5-1.7 (Table 1). The PDI of the polymer is counterintuitively small, which is likely due to the removal of small oligomers during the dialysis procedure.

Table 1. Characteristics of fluoroalkyl-substituted poly(amido amine)s with various functionalization extents

\begin{tabular}{|c|c|c|c|c|}
\hline \multirow{2}{*}{ Polymer Acronym } & \multicolumn{2}{|c|}{ Fluorination Percentage (\%) } & \multirow{2}{*}{$\mathrm{M}_{\mathrm{w}}(\mathrm{kDa})^{\mathrm{b}}$} & \multirow{2}{*}{$\mathrm{PDI}^{\mathrm{b}}$} \\
\hline & feed & real $^{\mathrm{a}}$ & & \\
\hline pDABF7 & 100 & 100 & 8.2 & 1.49 \\
\hline $\mathrm{p}\left(\mathrm{ABOL}_{50} / \mathrm{DABF}_{50}\right)$ & 50 & 50 & 7.5 & 1.54 \\
\hline $\mathrm{p}\left(\mathrm{ABOL}_{75} / \mathrm{DABF}_{25}\right)$ & 25 & 25 & 7.3 & 1.67 \\
\hline $\mathrm{p}\left(\mathrm{ABOL}_{90} / \mathrm{PABF}_{10}\right)$ & 12.5 & 10 & 6.8 & 1.47 \\
\hline pABOL & 0 & 0 & 5.3 & 1.61 \\
\hline
\end{tabular}

${ }^{\mathrm{a}}$ determined by integral ratios of NMR spectra; ${ }^{\mathrm{b}}$ determined via GPC.

\section{Polyplex preparation and characterization}

The characteristics of the polyplexes, prepared from the polymers at various polymer/DNA mass ratios at $\mathrm{pH} 7.4$ were evaluated and are presented in Figure 1. The polyplexes displayed diameters ranging from as large as $1.4 \mu \mathrm{m}$ to ca. $100 \mathrm{~nm}$ with surface charges ranging from $+3 \mathrm{mV}$ to $+38 \mathrm{mV}$. As the polymer/DNA mass ratio increases, the polyplexes typically become smaller in size and display higher surface charge, underlining the 
dominant influence of electrostatic interactions during DNA condensation. ${ }^{13,66}$ As shown in Figure 1, increased fluorination of the PAAs results in polyplexes that are larger in diameter, and have decreased surface charge. This could be partially due to the increased molecular weight the polymer per protonable nitrogen, rendering less cationic charges available for polyplex formation. However, at polymer/DNA ratio 24 and 48, polyplexes made with PAAs containing 10\% fluorinated side groups have smaller size, but similar zeta-potential. This discrepancy is ascribed to that hydrophobic F7 group which facilitates DNA condensation through hydrophobic interactions in addition to electrostatic interactions. ${ }^{67}$ When the degree of fluorination increases, this hydrophobic interaction fails to compensate the loss in charge density, resulting in larger polyplexes with reduced surface charge.

A

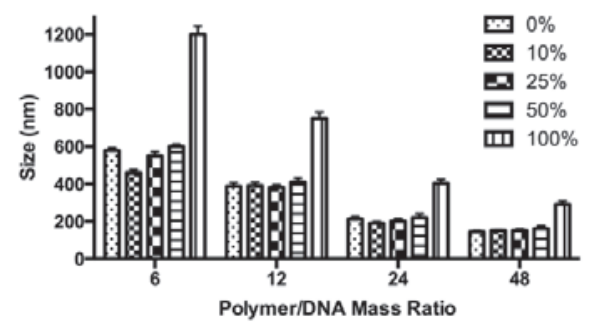

B

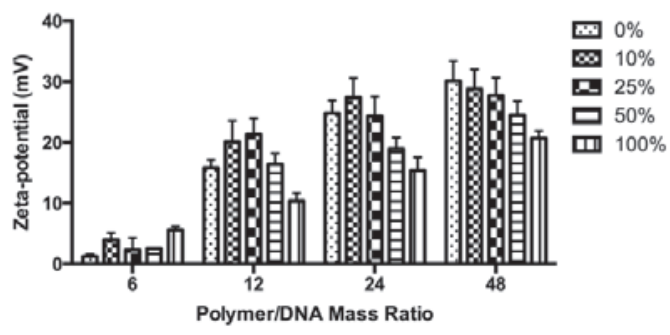

Figure 1. Characterization of polyplexes prepared under various polymer/DNA mass ratios through DLS. (A) Hydrodynamic sizes versus mass ratios; (B) Zeta-potentials versus mass ratios.

Polyplex stability was further investigated by agarose gel electrophoresis. As displayed in Figure 2, no DNA migration is discerned for the polyplexes, implying DNA has been completely entrapped in the wells through binding by the polymers. The polyplexes require high colloidal stability when at extracellular environment to retain and protect DNA, while they have to undergo rapid disintegration inside the cells to release the DNA cargo ${ }^{5,25}$ All PAA polymers contain reducible disulfide linkages, which enables rapid polyplex disassembly upon entering the reducing interior of cells. ${ }^{68,69}$ This reducing environment was mimicked by DTT $(2.5 \mathrm{mM})$. After incubating the polyplexes in the presence of DTT, polyplexes were subjected to gel electrophoresis displaying migrating DNA bands, similar to free DNA. These results demonstrate DNA is tightly packed by the fluorinated PAAs, but is also rapidly released upon exposure to reducing conditions through cleavage of the disulfide bonds in the polymer chain. 


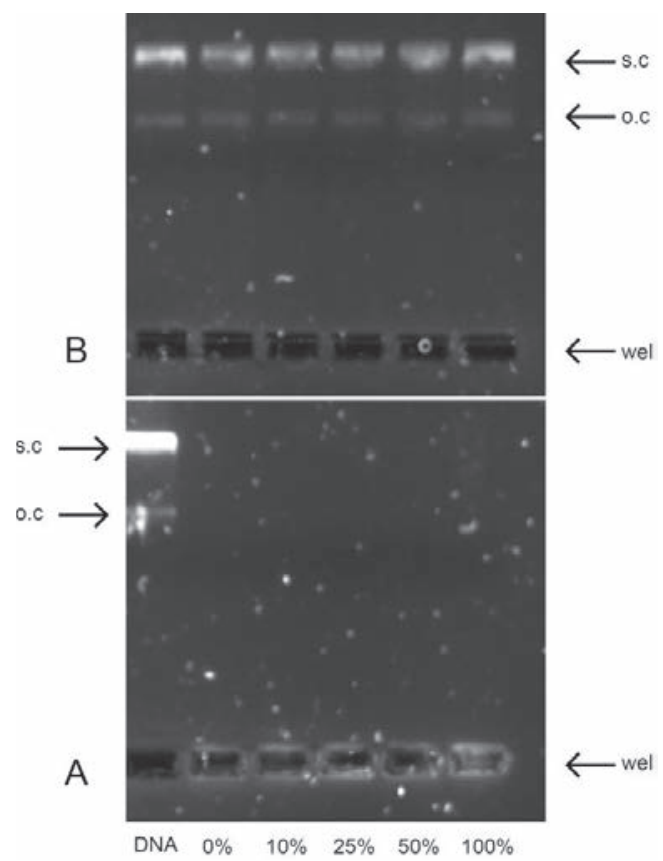

Figure 2. Agarose gel electrophoresis of polyplexes $(\mathrm{w} / \mathrm{w}=48)$ treated without DTT (A) and with DTT (B) (s.c. $=$ supercoiled, o.c. $=$ open circular $)$.

\section{In vitro transfection efficiency and cytotoxicity}

Transfection efficiency of pDNA/polymer polyplexes with different percentage of fluoroalkyl groups was investigated on COS-7 cells with GFP as the reporter gene under serum-free and $10 \%$ serum conditions. First, the transfection efficiency was evaluated at varying polymer/DNA mass ratios of $6,12,24$, and 48 under serum-free conditions. Overlaid GFP fluorescence images of transfected COS-7 cells are presented in Figure 3. Substantial improvement of GFP expression is observed for polyplexes containing only $10 \%$ fluorinated-PAAs at all polymer/DNA mass ratios. However, for polyplexes prepared from 25\% fluorinated PAAs significant GFP expression at mass ratios above 6, while in the case of polyplexes based on 50\% fluorinated PAAs, mass ratios above 12 are required. For polyplexes from the PAAs with 100\% fluorinated side group, at mass ratio 48 only a low GFP expression is observed which is probably related to their poor biophysical properties such as large particulate size and small surface charge. Importantly, transfection results of fluorinated PAAs (except for 100\% fluorinated) outperform non-fluorinated PAAs $(0 \%)$ at the same polymer/DNA mass ratio. Notably, as can be seen in Figure 4 the 
transfection performance of fluorinated PAAs is only marginally reduced in the presence of $10 \%$ serum as compared to non-fluorinated PAAs and reference PEI.

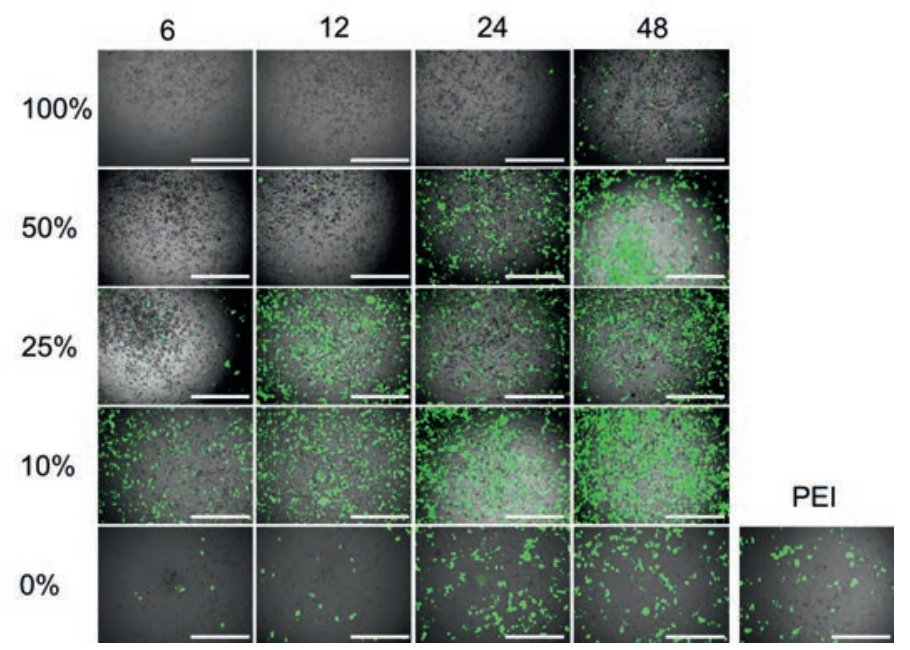

Figure 3. Overlaid GFP images of COS-7 cells transfected by pCMV-GFP in PAA or PEI polyplexes after 48 $\mathrm{h}$ incubation under $0 \%$ serum conditions. The percentages on the $\mathrm{Y}$-axis represent the percentage of fluorocontaining side groups in the PAAs, and the horizontal numbers denote the polymer/DNA mass ratios (4X magnification, bars $=1000 \mu \mathrm{m}$ ).

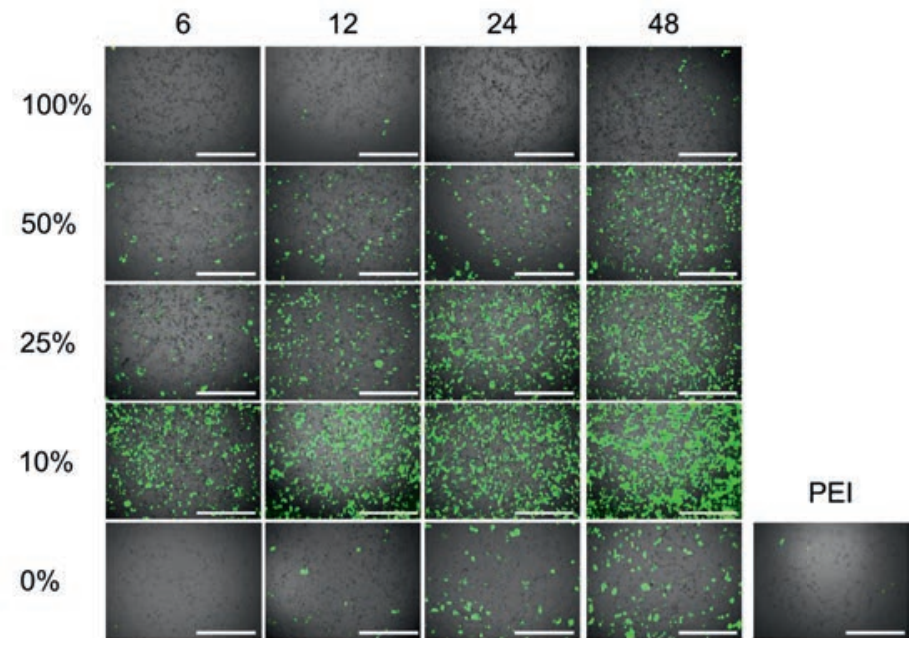

Figure 4. Overlaid GFP images of COS-7 cells transfected by pCMV-GFP in PAA or PEI polyplexes after 48 $\mathrm{h}$ incubation under $10 \%$ serum conditions. The percentages on the $\mathrm{Y}$-axis represent the percentage of fluorocontaining side groups in the PAAs, and the horizontal numbers denote the polymer/DNA mass ratios (4X magnification, bars $=1000 \mu \mathrm{m}$ ). 
The transfection performance of the fluorinated PAAs $(10 \%, 25 \%$ and $50 \%)$ was further evaluated quantitatively by flow cytometry for polyplexes at polymer/DNA mass ratios of 6 and 12 (Figure 5A and 5B). Comparison of the Figure 5A and 4B show that transfection efficiencies increase with increasing polymer/DNA ratio. Most likely this is due to increasing favorable biophysical characteristics, such as small hydrodynamic size and positive surface charge of these polyplexes. At polymer/DNA mass ratio 12 (Figure 5A) and in absence of serum, the transfection efficiency of $10 \%$ fluorinated PAAs is nearly 3 fold higher of that of the non-fluorinated PAAs ( $84 \%$ vs $30 \%$ transfection efficiency respectively). The presence of $10 \%$ serum only reduces the transfection efficiency of the fluorinated polymers from $84 \%, 65 \%$, and $42 \%$ to $78 \%, 58 \%$, and $34 \%$ respectively, whereas significant reduction of the non-fluorinated PAA from $30 \%$ to $12 \%$ is observed. Similar transfection results and serum effects are observed for polyplexes at polymer/DNA mass ratios of 6 (Figure 5B).

A

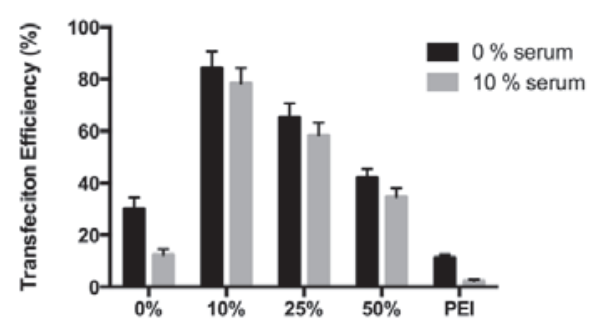

B

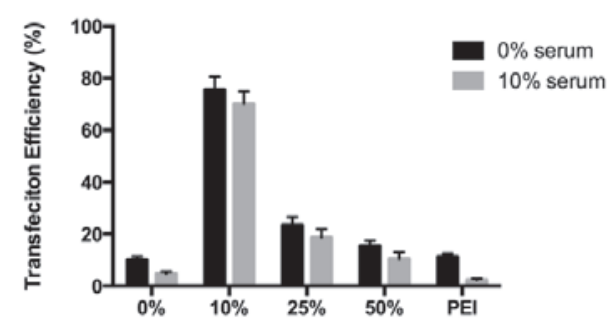

Figure 5. Transfection efficiencies of poly(amido amine)s functionalized with $50 \%, 25 \%, 10 \%$, and $0 \%$ fluorination at polymer/DNA mass ratios 12 (A) and 6 (B). (PEI, $25 \mathrm{k}$ branched-PEI, as reference; fluorination degree displayed as $\mathrm{X}$-axis.)

Translation of polymeric gene vectors to the clinic is substantially hurdled by the interaction with serum proteins that cause premature unpacking of DNA, therefore preventing effective transfection. ${ }^{70,71}$ Therefore the transfection performance of the $10 \%$ fluorinated PAAs at polymer/DNA mass ratios 6 and 12 was further investigated under different serum concentrations $(0 \%, 10 \%, 25 \%$, and 50\%). As shown in Figure 6, at polymer/DNA mass ratio 12 , over $50 \%$ transfection is achieved at serum concentration of $25 \%$, and still $20 \%$ transfection takes place under $50 \%$ serum condition. When the polymer/DNA mass ratio drops to 6 , the transfection efficiency is slightly reduced, but still reaches $75 \%, 70 \%, 39 \%$, and $10 \%$ in transfection efficiency at serum concentrations of $0 \%, 10 \%, 25 \%$, and $50 \%$, respectively. The excellent transfection capability of the $10 \%$ 
fluorinated PAAs under serum conditions make them promising vectors for in vivo application.

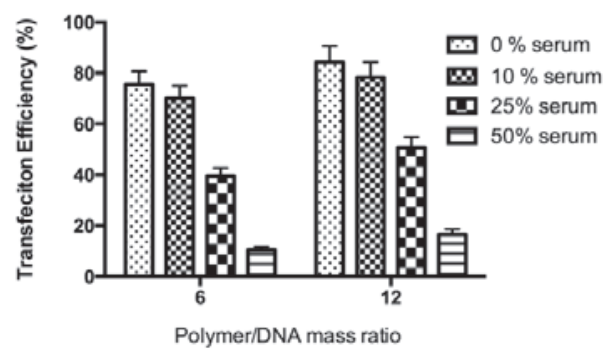

Figure 6. Transfection efficiency of COS-7 cells by polyplexes from $10 \%$ fluorinated poly(amido amine)s under different serum conditions as determined by flow cytometry.

Effective transfection agents should bear high transfection ability, together with minimal toxicity. ${ }^{72}$ As shown in Figure 7, the fluorinated PAAs based polyplexes maintained excellent cell viability of the COS-7 cells at all polymer/DNA mass ratios. Cell viabilities are well over $90 \%$ for all polymer/DNA mass ratios under serum-absent condition (Figure 7A). This is much better than polyplexes from the commonly employed cationic polymer PEI which show only $56 \%$ cell viability. In the presence of $10 \%$ serum the biocompatibility of polyplexes based on fluorinated PAAs is even slightly further enhanced, and no sign of cytotoxicity is observed (Figure 7B).
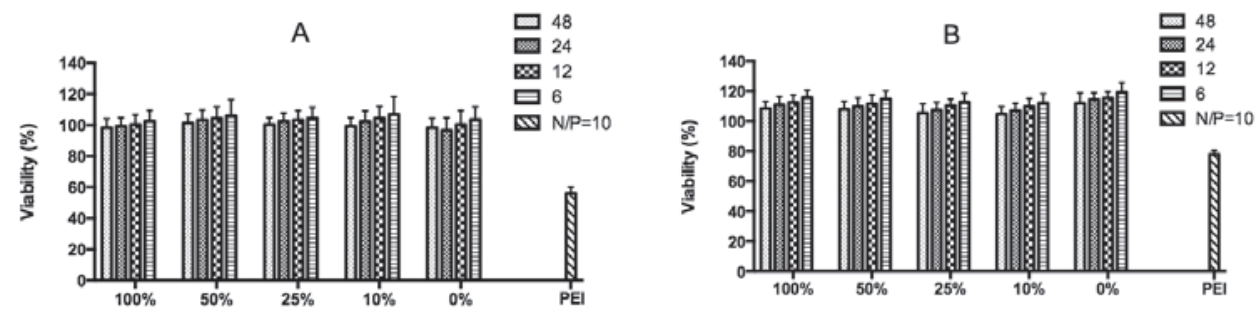

Figure 7. Cell viability of polyplexes at different polymer/DNA mass weights to COS-7 cells via MTT assay under $0 \%$ serum (A) and $10 \%$ serum (B) (the value in $\mathrm{X}$-axis denotes the actual percentage of fluorination degree in polymer).

\section{CONCLUSIONS}

Poly(amido amine)s with different degrees $(100 \%, 50 \%, 25 \%$, and $10 \%)$ of perfluorobutylamide side groups next to hydroxybutyl side groups were successfully prepared. Both the fluorinated and the non-fluorinated PAAs are able to condense DNA into nanosized polyplexes with sizes as low as $120 \mathrm{~nm}$ and surface charges around $+25 \mathrm{mV}$ through both 
electrostatic and hydrophobic interactions. Gel electrophoresis experiments show that DNA is effectively liberated from the polyplexes upon exposure to DTT, indicating that DNA is released from the polyplexes inside the reducing environment of the cell. After incubation with polyplexes, COS-7 cells maintain outstanding cell viability, confirming excellent biocompatibility of the polyplexes prepared from fluorinated PAAs. Moreover, significantly enhanced transfection efficiency of up to $80 \%$ is observed for the fluorinated polymer vectors, almost 3-fold higher than observed for the non-fluorinated analogues. Introduction of perfluoro-alkyl moieties is demonstrated to be effective and promising method to promote transfection efficiency, while maintaining minimal cytotoxicity.

\section{ACKNOWLEDGMENTS}

The work is generously supported by NanoNextNL, a micro and nanotechnology consortium of the Government of the Netherlands and 130 partners. G.S. is gratefully acknowledging Dr. Karin Roelofs for her training in cell culture and FACS measurement. 


\section{REFERENCES}

(1) Pack, D. W.; Hoffman, A. S.; Pun, S.; Stayton, P. S. Design and development of polymers for gene delivery. Nat. Rev. Drug Discov. 2005, 4, 581-593.

(2) De Smedt, S. C.; Demeester, J.; Hennink, W. E. Cationic polymer based gene delivery systems. Pharm. Res. 2000, 17, 113-126.

(3) Jeong, J. H.; Kim, S. W.; Park, T. G. Molecular design of functional polymers for gene therapy. Prog. Polym. Sci. 2007, 32, 1239-1274.

(4) Kay, M. A. State-of-the-art gene-based therapies: the road ahead. Nat. Rev. Genet. 2011, 12, 316-328.

(5) Yin, H.; Kanasty, R. L.; Eltoukhy, A. A.; Vegas, A. J.; Dorkin, J. R.; Anderson, D. G. Non-viral vectors for gene-based therapy. Nat. Rev. Genet. 2014, 15, 541-555.

(6) Baum, C.; Kustikova, O.; Modlich, U.; Li, Z. X.; Fehse, B. Mutagenesis and oncogenesis by chromosomal insertion of gene transfer vectors. Hum. Gene. Ther. 2006, 17, 253-263.

(7) Bessis, N.; GarciaCozar, F. J.; Boissier, M. C. Immune responses to gene therapy vectors: influence on vector function and effector mechanisms. Gene Ther. 2004, 11, S10-S17.

(8) Thomas, C. E.; Ehrhardt, A.; Kay, M. A. Progress and problems with the use of viral vectors for gene therapy. Nat. Rev. Genet. 2003, 4, 346-358.

(9) Bouard, D.; Alazard-Dany, N.; Cosset, F. L. Viral vectors: from virology to transgene expression. Brit. J. Pharmacol. 2009, 157, 153-165.

(10) Mintzer, M. A.; Simanek, E. E. Nonviral Vectors for Gene Delivery. Chem. Rev. 2009, 109, 259-302.

(11) Kataoka, K.; Harashima, H. Gene delivery systems: viral vs. non-viral vectors. Adv. Drug Deliv. Rev. 2001, 52, 151-151.

(12) Mastrobattista, E.; Hennink, W. E. Polymers for Gene Delivery Charged for Success. Nat. Mater. 2012, 11, 10-12.

(13) Schaaf, P.; Schlenoff, J. B. Saloplastics: processing compact polyelectrolyte complexes. Adv. Mater. 2015, 27, 2420-2432.

(14) Bloomfield, V. A. DNA condensation by multivalent cations. Biopolymers 1997, 44, 269-282.

(15) Meneksedag-Erol, D.; Tang, T.; Uludağ, H. Molecular modeling of polynucleotide complexes. Biomaterials 2014, 35, 7068-7076. 
(16) Midoux, P.; Breuzard, G.; Gomez, J. P.; Pichon, C. Polymer-Based Gene Delivery: A Current Review on the Uptake and Intracellular Trafficking of Polyplexes. Curr. Gene Ther. 2008, 8, 335-352.

(17) Akinc, A.; Battaglia, G. Exploiting endocytosis for nanomedicines. Cold Spring Harbor perspectives in biology 2013, 5, a016980.

(18) Boussif, O.; Lezoualch, F.; Zanta, M. A.; Mergny, M. D.; Scherman, D.; Demeneix, B.; Behr, J. P. A Versatile Vector for Gene and Oligonucleotide Transfer into Cells in Culture and in-Vivo - Polyethylenimine. Proc. Natl. Acad. Sci. U.S.A. 1995, 92, 7297-7301.

(19) Behr, J.-P. The Proton Sponge: a Trick to Enter Cells the Viruses Did Not Exploit. CHIMIA International Journal for Chemistry 1997, 51, 34-36.

(20) Berg, K.; Selbo, P. K.; Prasmickaite, L.; Tjelle, T. E.; Sandvig, K.; Moan, D.; Gaudernack, G.; Fodstad, O.; Kjolsrud, S.; Anholt, H.; Rodal, G. H.; Rodal, S. K.; Hogset, A. Photochemical internalization: A novel technology for delivery of macromolecules into cytosol. Cancer Res. 1999, 59, 1180-1183.

(21) Schaffer, D. V.; Fidelman, N. A.; Dan, N.; Lauffenburger, D. A. Vector unpacking as a potential barrier for receptor-mediated polyplex gene delivery. Biotechnol. Bioeng. 2000, 67, 598-606.

(22) Oupicky, D.; Li, J. Bioreducible polycations in nucleic acid delivery: past, present, and future trends. Macromol. Biosci. 2014, 14, 908-922.

(23) Lin, C.; Engbersen, J. F. J. The role of the disulfide group in disulfide-based polymeric gene carriers. Expert Opin. Drug Delivery 2009, 6, 421-439.

(24) Liu, Z.; Zhang, Z.; Zhou, C.; Jiao, Y. Hydrophobic modifications of cationic polymers for gene delivery. Prog. Polym. Sci. 2010, 35, 1144-1162.

(25) Yue, Y. N.; Wu, C. Progress and perspectives in developing polymeric vectors for in vitro gene delivery. Biomater. Sci. 2013, 1, 152-170.

(26) Lv, H. T.; Zhang, S. B.; Wang, B.; Cui, S. H.; Yan, J. Toxicity of cationic lipids and cationic polymers in gene delivery. J. Controlled Release 2006, 114, 100-109.

(27) Grandinetti, G.; Ingle, N. P.; Reineke, T. M. Interaction of Poly(ethylenimine)DNA Polyplexes with Mitochondria: Implications for a Mechanism of Cytotoxicity. Mol. Pharmaceutics 2011, 8, 1709-1719.

(28) Morille, M.; Passirani, C.; Vonarbourg, A.; Clavreul, A.; Benoit, J. P. Progress in developing cationic vectors for non-viral systemic gene therapy against cancer. Biomaterials 2008, 29, 3477-3496. 
(29) Zeng, H. X.; Little, H. C.; Tiambeng, T. N.; Williams, G. A.; Guan, Z. B. Multifunctional Dendronized Peptide Polymer Platform for Safe and Effective siRNA Delivery. J. Am. Chem. Soc. 2013, 135, 4962-4965.

(30) Huang, S. X.; Li, J. F.; Han, L.; Liu, S. H.; Ma, H. J.; Huang, R. Q.; Jiang, C. Dual targeting effect of Angiopep-2-modified, DNA-loaded nanoparticles for glioma. Biomaterials 2011, 32, 6832-6838.

(31) Patil, M. L.; Zhang, M.; Minko, T. Multifunctional Triblock Nanocarrier (PAMAM-PEG-PLL) for the Efficient Intracellular siRNA Delivery and Gene Silencing. Acs Nano 2011, 5, 1877-1887.

(32) Su, H. Y.; Liu, Y. H.; Wang, D.; Wu, C. Q.; Xia, C. C.; Gong, Q. Y.; Song, B.; Ai, H. Amphiphilic starlike dextran wrapped superparamagnetic iron oxide nanoparticle clsuters as effective magnetic resonance imaging probes. Biomaterials 2013, 34, 1193-1203.

(33) Lin, C.; Zhong, Z.; Lok, M. C.; Jiang, X.; Hennink, W. E.; Feijen, J.; Engbersen, J. F. J. Novel Bioreducible Poly(amido amine)s for Highly Efficient Gene Delivery. Bioconjugate Chem. 2007, 18, 138-145.

(34) Piest, M.; Engbersen, J. F. J. Role of boronic acid moieties in poly(amido amine)s for gene delivery. J. Controlled Release 2011, 155, 331-340.

(35) Piest, M.; Ankone, M.; Engbersen, J. F. J. Carbohydrate-interactive pDNA and siRNA gene vectors based on boronic acid functionalized poly(amido amine)s. $J$. Controlled Release 2013, 169, 266-275.

(36) Mateos-Timoneda, M. A.; Lok, M. C.; Hennink, W. E.; Feijen, J.; Engbersen, J. F. J. Poly(amido amine)s as gene delivery vectors: Effects of quaternary nicotinamide moieties in the side chains. ChemMedChem 2008, 3, 478-486. van der Aa, L. J.; Vader, P.; Storm, G.; Schiffelers, R. M.; Engbersen, J. F. J. Intercalating quaternary nicotinamide-based poly(amido amine)s for gene delivery. J. Controlled Release 2014, 195, 11-20.

(38) Coue, G.; Freese, C.; Unger, R. E.; Kirkpatrick, C. J.; Engbersen, J. F. J. Bioresponsive poly(amidoamine)s designed for intracellular protein delivery. Acta Biomater. 2013, 9, 6062-6074.

(39) Piest, M.; Zhang, X.; Trinidad, J.; Engbersen, J. F. J. pH-responsive, dynamically restructuring hydrogels formed by reversible crosslinking of PVA with phenylboronic acid functionalised PPO-PEO-PPO spacers (Jeffamines[registered sign]). Soft Matter 2011, 7, 11111-11118. 
(40) Hujaya, S. D.; Marchioli, G.; Roelofs, K.; van Apeldoorn, A. A.; Moroni, L.; Karperien, M.; Paulusse, J. M.; Engbersen, J. F. Poly(amido amine)-based multilayered thin films on $2 \mathrm{D}$ and $3 \mathrm{D}$ supports for surface-mediated cell transfection. J. Controlled Release 2015, 205, 181-189.

(41) Muller, K.; Faeh, C.; Diederich, F. Fluorine in pharmaceuticals: Looking beyond intuition. Science 2007, 317, 1881-1886.

(42) Buer, B. C.; Meagher, J. L.; Stuckey, J. A.; Marsh, E. N. G. Structural basis for the enhanced stability of highly fluorinated proteins. Proc. Natl. Acad. Sci. U.S.A. 2012, 109, 4810-4815.

(43) Chou, D. H.; Webber, M. J.; Tang, B. C.; Lin, A. B.; Thapa, L. S.; Deng, D.; Truong, J. V.; Cortinas, A. B.; Langer, R.; Anderson, D. G. Glucose-responsive insulin activity by covalent modification with aliphatic phenylboronic acid conjugates. Proc. Natl. Acad. Sci. U.S.A. 2015, 112, 2401-2406.

(44) Wang, Y.; Lee, W. C.; Manga, K. K.; Ang, P. K.; Lu, J.; Liu, Y. P.; Lim, C. T.; Loh, K. P. Fluorinated graphene for promoting neuro-induction of stem cells. $A d v$. Mater. 2012, 24, 4285-4290.

(45) Purser, S.; Moore, P. R.; Swallow, S.; Gouverneur, V. Fluorine in medicinal chemistry. Chem. Soc. Rev. 2008, 37, 320-330.

(46) Bilgicer, B.; Xing, X.; Kumar, K. Programmed self-sorting of coiled coils with leucine and hexafluoroleucine cores. J. Am. Chem. Soc. 2001, 123, 11815-11816.

(47) Tang, Y.; Ghirlanda, G.; Petka, W. A.; Nakajima, T.; DeGrado, W. F.; Tirrell, D. A. Fluorinated Coiled-Coil Proteins Prepared In Vivo Display Enhanced Thermal and Chemical Stability Angew. Chem. Int. Ed. 2001, 40, 1494-1496.

(48) Bilgicer, B.; Kumar, K. De novo design of defined helical bundles in membrane environments. Proc. Natl. Acad. Sci. U.S.A. 2004, 101, 15324-15329.

(49) Lee, H. Y.; Lee, K. H.; Al-Hashimi, H. M.; Marsh, E. N. G. Modulating protein structure with fluorous amino acids: Increased stability and native-like structure conferred on a 4-helix bundle protein by hexafluoroleucine. J. Am. Chem. Soc. 2006, $128,337-343$.

(50) Gottler, L. M.; Lee, H. Y.; Shelburne, C. E.; Ramamoorthy, A.; Marsh, E. N. G. Using fluorous amino acids to modulate the biological activity of an antimicrobial peptide. ChemBioChem 2008, 9, 370-373.

(51) Kasuya, M. C. Z.; Nakano, S.; Katayama, R.; Hatanaka, K. Evaluation of the hydrophobicity of perfluoroalkyl chains in amphiphilic compounds that are 
incorporated into cell membrane. Journal of Fluorine Chemistry 2011, 132, 202206.

(52) Marsh, E. N. G. Towards the nonstick egg: designing fluorous proteins. Chem. Biol. 2000, 7, R153-R157.

(53) Percec, V.; Imam, M. R.; Peterca, M.; Leowanawat, P. Self-Organizable Vesicular Columns Assembled from Polymers Dendronized with Semifluorinated Janus Dendrimers Act As Reverse Thermal Actuators. J. Am. Chem. Soc. 2012, 134, 4408-4420.

(54) Brittain, S. M.; Ficarro, S. B.; Brock, A.; Peters, E. C. Enrichment and analysis of peptide subsets using fluorous affinity tags and mass spectrometry. Nat. Biotech. 2005, 23, 463-468.

(55) Percec, V.; Glodde, M.; Bera, T. K.; Miura, Y.; Shiyanovskaya, I.; Singer, K. D.; Balagurusamy, V. S. K.; Heiney, P. A.; Schnell, I.; Rapp, A.; Spiess, H. W.; Hudson, S. D.; Duan, H. Self-organization of supramolecular helical dendrimers into complex electronic materials. Nature 2002, 417, 384-387.

(56) Boussif, O.; Gaucheron, J.; Boulanger, C.; Santaella, C.; Kolbe, H. V. J.; Vierling, P. Enhanced in vitro and in vivo cationic lipid-mediated gene delivery with a fluorinated glycerophosphoethanolamine helper lipid. J. Gene Med. 2001, 3, 109114.

(57) Gaucheron, J.; Boulanger, C.; Santaella, C.; Sbirrazzuoli, N.; Boussif, O.; Vierling, P. In vitro cationic lipid-mediated gene delivery with fluorinated glycerophosphoethanolamine helper lipids. Bioconjugate Chem. 2001, 12, 949963.

(58) Klein, E.; Ciobanu, M.; Klein, J.; Machi, V.; Leborgne, C.; Vandamme, T.; Frisch, B.; Pons, F.; Kichler, A.; Zuber, G.; Lebeau, L. "HFP” Fluorinated Cationic Lipids for Enhanced Lipoplex Stability and Gene Delivery. Bioconjugate Chem. 2010, 21, $360-371$.

(59) Klein, E.; Leborgne, C.; Ciobanu, M.; Klein, J.; Frisch, B.; Pons, F.; Zuber, G.; Scherman, D.; Kichler, A.; Lebeau, L. Nucleic acid transfer with hemifluorinated polycationic lipids. Biomaterials 2010, 31, 4781-4788.

(60) Liu, H.; Wang, Y.; Wang, M.; Xiao, J.; Cheng, Y. Fluorinated poly(propylenimine) dendrimers as gene vectors. Biomaterials 2014, 35, 5407-5413. 
(61) Wang, M.; Liu, H.; Li, L.; Cheng, Y. A fluorinated dendrimer achieves excellent gene transfection efficacy at extremely low nitrogen to phosphorus ratios. Nat. Commun. 2014, 5, 3053.

(62) Wang, M.; Cheng, Y. The effect of fluorination on the transfection efficacy of surface-engineered dendrimers. Biomaterials 2014, 35, 6603-6613.

(63) Lv, J.; Chang, H.; Wang, Y.; Wang, M.; Xiao, J.; Zhang, Q.; Cheng, Y. Fluorination on polyethylenimine allows efficient $2 \mathrm{D}$ and $3 \mathrm{D}$ cell culture gene delivery. J. Mater. Chem. B 2015, 3, 642-650.

(64) Lynn, D. M.; Langer, R. Degradable Poly( $\beta$-amino esters): Synthesis, Characterization, and Self-Assembly with Plasmid DNA. J. Am. Chem. Soc. 2000, 122, 10761-10768.

(65) Schweik1, H.; Schmalz, G. Triethylene glycol dimethacrylate induces large deletions in the hprt gene of V79 cells. Mutat. Res. 1999, 438, 71-78.

(66) Niebel, Y.; Buschmann, M. D.; Lavertu, M.; De Crescenzo, G. Combined Analysis of Polycation/ODN Polyplexes by Analytical Ultracentrifugation and Dynamic Light Scattering Reveals their Size, Refractive Index Increment, Stoichiometry, Porosity, and Molecular Weight. Biomacromolecules 2014.

(67) Piest, M.; Engbersen, J. F. J. Effects of charge density and hydrophobicity of poly(amido amine)s for non-viral gene delivery. J. Controlled Release 2010, 148, 83-90.

(68) Meng, F. H.; Hennink, W. E.; Zhong, Z. Reduction-sensitive polymers and bioconjugates for biomedical applications. Biomaterials 2009, 30, 2180-2198.

(69) Lee, Y. S.; Kim, S. W. Bioreducible polymers for therapeutic gene delivery. $J$. Controlled Release 2014, 190, 424-439.

(70) Audouy, S.; Molema, G.; De Leij, L.; Hoekstra, D. Serum as a modulator of lipoplex-mediated gene transfection: Dependence of amphiphile, cell type and complex stability. J. Gene Med. 2000, 2, 465-476.

(71) Morille, M.; Passirani, C.; Vonarbourg, A.; Clavreul, A.; Benoit, J.-P. Progress in developing cationic vectors for non-viral systemic gene therapy against cancer. Biomaterials 2008, 29, 3477-3496.

(72) Lachelt, U.; Wagner, E. Nucleic Acid Therapeutics Using Polyplexes: A Journey of 50 Years (and Beyond). Chem. Rev. 2015, 115, 11043-11078. 


\section{Chapter 5. Poly(amido amine)s/DNA Polyplexes with Incorporated Gold Nanorods as Vectors for Imaging and Gene Delivery}

Guoying Si, Jos M.J. Paulusse* and Johan F.J. Engbersen*

Department of Controlled Drug Delivery, MIRA Institute for Biomedical Technology and Technical Medicine, Faculty of Science and Technology, University of Twente, P.O. Box 217, 7500 AE Enschede, The Netherlands

KEYWORDS

Gold nanorods, disulfides, gene delivery, colloidal stability, serum, crosslinking. 


\section{ABSTRACT}

Disulfide-containing poly(amido amine)s (pABOL) were prepared by Michael-type polyaddition of $N, N^{\prime}$-cystaminebisacrylamide and 4-aminio-1-butanol (ABOL). Gold nanorods (GNRs) were coated with pABOL by displacing toxic surfactant of hexadecyltrimethylammonium bromide (CTAB) on the surface of GNRs by pABOL through the gold-sulfur interaction. Therefore, GNRs were exposed overnight to pABOL polymer, followed by several centrifugation and re-suspension steps, resulting in modified GNRs solution with well-preserved optical properties of GNRs. Modified pABOL-GNRs condensed plasmid DNA into polyplexes with sizes below $200 \mathrm{~nm}$ and positive surface charges of approximately $+30 \mathrm{mV}$, affording hybrid polyplexes with absorbance in the near-infrared (NIR) range. The hybrid polyplexes exhibit smaller particles size and improved colloidal stability, as compared to regular polyplexes consisting only of pABOL and plasmid DNA. In vitro transfection experiments revealed that the hybrid polyplexes induce comparable transgene activity without demonstrating added cytotoxicity as compared to GNR-free polyplexes under serum-free conditions. In the presence of serum (10\% fetal bovine serum , FBS), the hybrid polyplexes show 3 -fold and 17-fold improved transfection efficiency compared to GNR-free polyplexes and optimized standard PEI (25 $\mathrm{kDa}$ ) formulation, respectively.

\section{INTRODUCTION}

Gene delivery, the delivery of genetic materials into eukaryotic cells, holds great promises for the treatment of broad scope of gene-related diseases, ${ }^{1}$ like immunodeficiency, ${ }^{2}$ cystic fibrosis, ${ }^{3}$ Parkinson's disease, ${ }^{4}$ chronic granulomatous disorder, ${ }^{5}$ and cancer. ${ }^{6}$ For successful application, gene delivery systems should meet various criteria. Maintaining intactness of genetic materials (plasmid DNA, ${ }^{7,8}$ mRNA, $^{9,10}$ siRNA $^{11-13}$ or microRNA ${ }^{14}$ ) during the delivery route requires gene vectors, ${ }^{8}$ which are able to encapsulate the genetic materials into nanosized complexes ${ }^{15}$ which provide protection against degradation. ${ }^{16}$ Upon intravenous administration, minimal interaction with vascular endothelial cells and blood components is needed, ${ }^{17}$ and furthermore the delivery vehicles should survive the reticuloendothelial system. ${ }^{18}$ Furthermore, the gene vectors should allow cellular uptake via the negatively charged cell membrane ${ }^{19}$ and escape from the lysosomal pathway to arrive in the cytosol and deliver the therapeutic payload in the cytosol (mRNA, siRNA, and miRNA) or for DNA through nuclear membrane. ${ }^{20}$ Two types of gene vectors are distinguished: viral vectors and non-viral vectors. ${ }^{21}$ Viral vectors show high transfection 
efficiency, ${ }^{22}$ however these vectors struggle with a number of discerned difficulties such as difficult manufacturing and storage, ${ }^{23}$ low gene loading, and potential side effects (insertional mutagenesis, ${ }^{24}$ cytotoxicity, ${ }^{25}$ immunogenicity, ${ }^{26}$ and carcinogenicity ${ }^{27}$ ). These severe limitations have prompted strong efforts in the development of non-viral vectors with aid of innovative nanotechnology. ${ }^{28}$

Due to their relative ease of synthesis and modification, a large variety of polymers have been developed to evaluate as non-viral gene delivery vectors. ${ }^{29}$ Among these are poly(ethylenimine $),{ }^{30} \quad \operatorname{poly}(\mathrm{L}-\mathrm{lysine}),{ }^{31} \quad \operatorname{poly}(\beta$-amino $\quad$ esters $),{ }^{32} \quad \operatorname{poly}((2-$ (dimethylamino)ethyl methacrylate), ${ }^{33}$ polyamidoamine dendrimers, ${ }^{34}$ chitosan, ${ }^{35,36}$ and stealth polymers like Pluronic ${ }^{37,38}$ and PEG. ${ }^{39}$ More recently, several non-viral vectors with "intelligent" features, ${ }^{40}$ being responsive to specific stimulus, such as $\mathrm{pH},{ }^{41}$ temperature, ${ }^{42}$ redox potential, ${ }^{43}$ enzymes, ${ }^{44}$ and infections ${ }^{45}$ have been developed. In addition, the ease to modify polymers allows the addition of new functionalities to gene delivery systems, ${ }^{16}$ for example, linking of targeting groups to realize specific delivery, ${ }^{46}$ coupling of imaging motifs to trace vectors, ${ }^{47}$ and incorporation of multiple payloads for synergistic performance. ${ }^{48}$ Among various polymers, poly(amido amine)s (PAAs) are especially interesting polymers owing to their excellent water solubility, minimal toxicity, remarkable biodegradability and biocompatibility, and sophisticated synthetic modularity. ${ }^{49}$ PAAs with disulfides along the backbone are liable to space-selective cleavage due to the glutathione concentration gradient outside and inside cells, and have been successfully employed as polymeric vectors for plasmid DNA, ${ }^{50}$ siRNA, ${ }^{51}$ and even proteins. ${ }^{52}$

Usually, serum proteins cause aggregation of cationic polyplexes, leading to reduced transfection efficiency due to insufficient cellular uptake of polyplexes..$^{50,53,54}$ To minimize polyplexes aggregation, polyplexes have been stabilized by providing the polyplexes with a hydrophilic corona by grafting with hydrophilic groups, such as poly(ethylene glycol) $(\mathrm{PEG}),{ }^{55-57}$ dextran, ${ }^{58}$ hyaluronic acid, ${ }^{59}$ and silica nanogels. ${ }^{60,61}$ The presence of hydrophilic groups was found to reduce cytotoxicity, enhance water solubility, diminish interaction with blood components, and can accommodate additional ligands. However, these hydrophilic groups shield the interaction of such polyplexes with cell membranes, resulting in reduced cellular uptake and thus low transfection efficiency. ${ }^{62}$ Chemical crosslinking was proposed to improve the colloidal stability of polyplexes through a myriad of crosslinking agents with different responsive linkages, such as redox potential, ${ }^{63-}$ 
${ }^{65}$ and $\mathrm{pH} .{ }^{66}$ However, these crosslinking stabilization approaches demand tedious efforts during the crosslinking procedure ${ }^{63}$ and retard the DNA unpacking from the gene vectors resulting in much lowered transfection efficiency ${ }^{63,67}$ Non-covalent crosslinking emerged as an appealing alternative to improve colloidal stability ${ }^{68}$ but has not been fully explored yet.

Gold nanorods (GNRs) have become of interest in gene delivery due to their unique chemical and physical properties of being biologically inert, large surface areas, functionalization flexibility, and customizable optical property. ${ }^{69,70}$ However hexadecyltrimethylammonium bromide (CTAB), a crucial surfactant during the synthesis, exhibits potential cytotoxicity, which necessitates surface modification..$^{71-75}$ The surface modification procedure relies on either a cumbersome layer-by-layer assembly, ${ }^{76-80}$ tedious CTAB displacement with various materials with higher biocompatibility, ${ }^{81-84}$ or expensive functionalization with nucleotide motifs, ${ }^{85-87}$ which substantially impedes the translation potential into the clinic. In this chapter, a facile GNRs surface functionalization is proposed with disulfide-containing PAAs by simple mixing. The PAA-modified GNRs are able to condense DNA under the formation of hybrid polyplexes (DNA/PAA-GNR). The embedded GNRs form physical crosslinks in the DNA-PAA matrix, which enhance colloidal stability, which is expected to become translated in increased stability in the presence of serum, leading to improved transfection under these conditions.

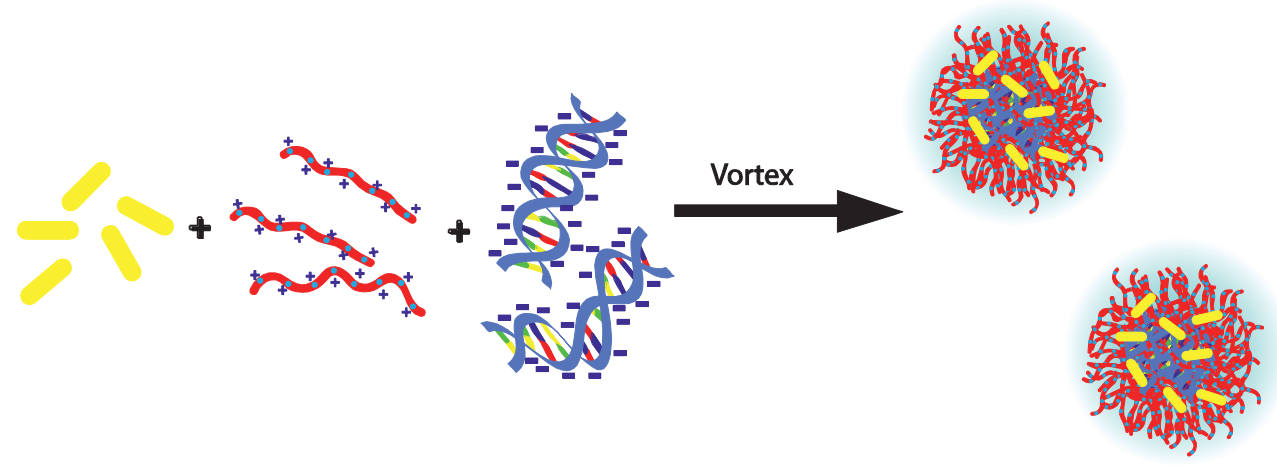

Scheme 1. Preparation of hybrid polyplexes consisted of GNRs (yellow cylinder), disulfide-containing PAAs, and plasmid DNA via self-assembly.

Besides the hydrogen bonding and hydrophobic interactions to stabilize the polyplexes as described in the previous two chapters, physical crosslinking of GNRs was used in this chapter. The GNRs were prepared by the seed-mediated growth method, and subsequently 
were modified with disulfide-linked PAAs. After mixing with DNA, self-assembled hybrid polyplexes were formed (Scheme 1). The hybrid polyplexes were characterized in hydrodynamic size, zeta-potential, morphology, and optical properties. The transfection efficiency mediated by the hybrid polyplexes was evaluated on COS-7 cells together with cell viabilities.

\section{EXPERIMENTAL PROCEDURE}

\section{Materials and Methods}

Tetrachloroauric acid $\left(\mathrm{HAuCl}_{4} \cdot 3 \mathrm{H}_{2} \mathrm{O}, 99.99 \%\right.$, Acros), sodium borohydride $\left(\mathrm{NaBH}_{4}, 99 \%\right.$, Sigma-Aldrich), ascorbic acid (AA, 99\%, Sigma-Aldrich), hexadecyltrimethylammonium bromide (CTAB, $\geq 96.0 \%$, Fluka), dithiothreitol (DTT, Sigma-Aldrich) and silver nitrate $\left(\mathrm{AgNO}_{3}, 99.8 \%\right.$, Merck) were directly used without further purification. All monomers, 4amino-1-butanol (ABOL, 98\%, Sigma-Aldrich), $N, N^{\prime}$-cystaminebisacrylamide (CBA, Polysciences), and tert-butylamine (tBA, Sigma-Aldrich) were purchased in the highest purity and used without further purification. All solvents used were of analytical grade unless otherwise specified. Water used in these experiments was purified with a Milli-Q Gradient System (Millipore, Bedford, MA). Plasmid DNA, plasmid pCMV-LacZ, pCMVGFP, and pCMV- $\triangle$ GFP were purchased from Plasmid Factory (Bielefeld, Germany). Branched polyethylenimine (PEI, $\mathrm{M}_{\mathrm{w}} 25 \mathrm{kDa}$ ) was purchased from Sigma-Aldrich.

${ }^{1} \mathrm{H}$ NMR and ${ }^{13} \mathrm{C}$ NMR were taken on a Varian Inova Spectrometer $(400 \mathrm{MHz})$ in deuterated solvents. Molecular weights were determined by gel permeation chromatography (GPC) relative to PEG standards, using a GPCmax with an acetate buffer $\mathrm{pH} 4.5$ containing $30 \%(\mathrm{v} / \mathrm{v})$ methanol as eluent.

\section{Gold nanorod synthesis}

Preparation of growth solution: To a gold salt $\left(\mathrm{HAuCl}_{4}\right)$ solution $(5.0 \mathrm{~mL}, 10 \mathrm{mM})$, a CTAB solution was added $(95 \mathrm{~mL}, 0.1 \mathrm{mM})$ with gently shaking to yield a dark yellow solution. A freshly prepared silver nitrate solution $(700 \mu \mathrm{L}, 0.01 \mathrm{M})$ was pipetted into the above mixture and subsequently a freshly prepared ascorbic acid solution $(550 \mu \mathrm{L}, 0.1 \mathrm{M})$ was added under mild stirring (approximate $325 \mathrm{rpm}$ ) to yield a colorless growth solution.

Preparation of gold seed solution: To a gold salt $\left(\mathrm{HAuCl}_{4}\right)$ solution $(0.25 \mathrm{~mL}, 10 \mathrm{mM})$, a CTAB solution was added $(9.5 \mathrm{~mL}, 0.1 \mathrm{mM})$ under mild stirring. Subsequently, a cold (4.0 $\left.{ }^{\circ} \mathrm{C}\right)$ and freshly prepared sodium borohydride $\left(\mathrm{NaBH}_{4}\right)$ solution $(0.6 \mathrm{~mL}, 0.01 \mathrm{M})$ was 
pipetted to the mixture all at once under vigorous stirring (1100 rpm) which was continued for $2 \mathrm{~min}$. The resulting light-brownish seed solution was added within $5 \mathrm{~min}$ to the growth solution.

Growth phase: The seed solution $(120 \mu \mathrm{L})$ was pipetted into the growth solution followed by gentle stirring $(325 \mathrm{rpm})$ for $10 \mathrm{~s}$. Subsequently, the resultant mixture was transferred to a water bath and kept at $27^{\circ} \mathrm{C}$. The mixture turned from colorless to brown within 10-20 min, and was left undisturbed in the water bath overnight. Next day the suspension was centrifuged at $8500 \mathrm{rpm} / 25 \mathrm{~min}$ and the supernatants was decanted. The pellet was resuspended in water and the previous procedure was repeated. Finally the pellet was resuspended in $2.0 \mathrm{~mL}$ water to yield a stock GNR solution which was stored at $4^{\circ} \mathrm{C}$ for further use.

Synthesis of pABOL. CBA (0.520 g, $2.00 \mathrm{mmol})$ and ABOL (0.182 g, $2.00 \mathrm{mmol})$ were successively added into a brown reaction flask and dissolved in methanol/water (3/1, v/v) $\mathrm{CaCl}_{2}$ solution $(200 \mathrm{mM}, 1.00 \mathrm{~mL})$. Polymerization was proceeded in the dark at $70{ }^{\circ} \mathrm{C}$ under stirring. The polymerization mixture became homogeneous within $20 \mathrm{~min}$ and polymerization was allowed to react further for $24 \mathrm{~h}$ to yield a viscous mixture. Subsequently, 3 equivalents of tBA $(0.448 \mathrm{~g}, 6.00 \mathrm{mmol})$ were added to consume any unreacted acrylamide groups and the reaction was stirred for another $24 \mathrm{~h}$ at $70{ }^{\circ} \mathrm{C}$. The resulting milky suspension was diluted with water to a volume of approximately $20.0 \mathrm{~mL}$, acidified with $4 \mathrm{M} \mathrm{HCl}$ solution to $\mathrm{pH} \sim 4$, and purified by Amicon ultrafiltration (MWCO $1000 \mathrm{Da})$ with acidic water $(\mathrm{pH} \sim 4)$. After lyophilization, $\mathrm{pABOL}$ was obtained in its $\mathrm{HCl}$ salt form $\left(0.364 \mathrm{~g}, 40.2 \%\right.$ yield). The number average molecular weight $\left(\mathrm{M}_{\mathrm{n}}\right)$ of the synthesized polymer pABOL was calculated from the NMR spectrum using the integrated areas of two methylene peaks of the butanol side groups (1.62 ppm and $1.78 \mathrm{ppm})$ and the methyl peaks of the tert-butyl end group (1.33 ppm) with $\mathrm{M}_{\mathrm{n}}$ of $\sim 6.1 \mathrm{KDa}$ (average number of repeat units of 16). ${ }^{1} \mathrm{H}$ NMR $\left(\mathrm{D}_{2} \mathrm{O}, 400 \mathrm{MHz}\right): \delta 1.33\left(\mathrm{~s}, 9 \mathrm{H}, \mathrm{R}\left(\mathrm{CH}_{3}\right)_{3}\right), 1.62(\mathrm{~m}$, $2 \mathrm{H}, \mathrm{RNCH}_{2} \mathrm{CH}_{2}$ ), 1.78 (m, $\left.2 \mathrm{H}, \mathrm{RNCH}_{2} \mathrm{CH}_{2} \mathrm{CH}_{2} \mathrm{CH}_{2} \mathrm{OH}\right), 2.74$ (t, 4H, 2 x $\mathrm{NHCOCH}_{2}$ ), $2.84\left(\mathrm{t}, 4 \mathrm{H}, 2 \times \mathrm{SSCH}_{2} \mathrm{CH}_{2}\right), 3.20$ (t, 2H, $\left.\mathrm{RNCH}_{2} \mathrm{CH}_{2} \mathrm{CH}_{2} \mathrm{CH}_{2} \mathrm{OH}\right), 3.41$ (t, $4 \mathrm{H}$, $\mathrm{CH}_{2} \mathrm{CH}_{2} \mathrm{NCH}_{2} \mathrm{CH}_{2}$ ), 3.51 (t, 4H, $2 \times \mathrm{SSCH}_{2} \mathrm{CH}_{2}$ ), 3.62 (t, 2H, $\mathrm{RNCH}_{2} \mathrm{CH}_{2} \mathrm{CH}_{2} \mathrm{CH}_{2} \mathrm{OH}$ ).

Polymer and gold nanoparticles modification. Stock GNR suspension (10 $\mu \mathrm{L})$ was dispersed in pABOL solution $\left(1.0 \mathrm{~mL}, 2.0 \mathrm{mg} / \mathrm{mL}, \mathrm{H}_{2} \mathrm{O}\right)$ in an Eppendorf tube, and incubated at $4.0^{\circ} \mathrm{C}$ overnight. After that, the pABOL-GNR constructs were isolated from 
the free polymers in solution by centrifugation $(9000 \mathrm{rpm}, 10 \mathrm{~min})$, and the resulting pellets were redispersed in water.

Hybrid polyplexes preparation. Hybrid polyplexes (DNA/pABOL-GNR) from DNA and the pABOL-GNR constructs were prepared in HEPES buffer $(20 \mathrm{mM}, \mathrm{pH}$ 7.4). Therefore, the desired amount stock GNR solution was added into $800 \mu \mathrm{L}$ polymer solution, followed by $5 \mathrm{~s}$ vortexing. The resulting mixture was added into $200 \mu \mathrm{L}$ DNA solution, followed by $5 \mathrm{~s}$ vortexing and $30 \mathrm{~min}$ incubation at room temperature. Size and surface charge of the polyplexes were measured at $25{ }^{\circ} \mathrm{C}$ with a Zetasizer Nano ZS (Malvern Instruments, Malvern). The value is recorded as the mean of three measurements and their standard deviation is given in the error bar in the figures. The extinction spectra were recorded on Shimadzu PC3101 UV-Vis-NIR spectrophotometer. Normal polyplexes (DNA/pABOL) were also prepared following the same protocol as hybrid ones, however with skipping the step of mixing GNRs and polymer solution.

\section{In Vitro Transfection}

The transfection ability of the polyplexes was evaluated on COS-7 cells with plasmid DNA green fluorescent protein (GFP) as encoding reporter gene. Cells were seeded in 48 well plates with density of $1.6 \times 10^{4}$ per well and cultured in complete medium (DMEM with $10 \% \mathrm{FBS}, 200 \mu \mathrm{L}$ ) at $37{ }^{\circ} \mathrm{C}$ under humidified atmosphere with $5 \% \mathrm{CO}_{2}$ to reach $60-80 \%$ confluency. Cell medium was refreshed with medium $(200 \mu \mathrm{L})$ with designed serum concentration, and cells were maintained in the new medium for $30 \mathrm{~min}$, after which polyplex dispersion $(200 \mu \mathrm{L}, 1.0 \mu \mathrm{g}$ DNA per well) was added. After 60 min incubation at $37^{\circ} \mathrm{C}$, the polyplexes were replaced with fresh warm complete medium $(200 \mu \mathrm{L})$, and cells were kept in the medium for another $48 \mathrm{~h}$. After this period, the medium was replaced by trypsin solution $(0.25 \%, 200 \mu \mathrm{L})$, and cells were spun down (600 g, 5 min, R.T.), resuspended in HBSS buffer $(200 \mu \mathrm{L})$, and measured by with FACS (FACSCalibur, Becton-Dickinson, Breda, the Netherlands) at an excitation wavelength of $488 \mathrm{~nm}$ and emission wavelength of $530 \mathrm{~nm}$. FACS Cellquest Software was applied to process data. A PEI $(25 \mathrm{~K}) / \mathrm{DNA}$ formulation prepared at its optimal condition $(\mathrm{N} / \mathrm{P}=10)$ was used as a reference.

\section{Cell Viability Assays}

The cell viability of COS-7 cells exposed to polyplexes was evaluated through MTT assays. In 48 well plates, cells were seeded with density of $1.6 \times 10^{4}$ per well and cultured 
in complete medium (DMEM with 10\% FBS, $200 \mu \mathrm{L}$ ) at $37{ }^{\circ} \mathrm{C}$ under humidified atmosphere with $5 \% \mathrm{CO}_{2}$ to reach confluency ranged from $60-80 \%$. Cells were refreshed with warm medium $(200 \mu \mathrm{L})$ with designed serum concentration, and maintained in the new medium for 30 min after which polyplex dispersions $(200 \mu \mathrm{L}, 1.0 \mu \mathrm{g}$ DNA per well) was added. After $60 \mathrm{~min}$ incubation at $37^{\circ} \mathrm{C}$, the polyplexes were replaced with fresh warm complete medium $(200 \mu \mathrm{L})$, and cells were allowed to grow for another $48 \mathrm{~h}$. From the cells untreated with polyplexes, half of the cells were killed by incubating in $100 \mathrm{X}$ triton $(4 \%, 20 \mu \mathrm{L})$ for $15 \mathrm{~min}$ (viability $0 \%$ ), and residual half was used as control with viability of $100 \%$. All cells were washed with DPBS $(200 \mu \mathrm{L})$, and successively incubated in MTT solution $(0.5 \mathrm{mg} / \mathrm{mL}, 200 \mu \mathrm{L})$ at $37{ }^{\circ} \mathrm{C}$ under $5 \% \mathrm{CO}_{2}$ condition for $4 \mathrm{~h}$. After refreshing MTT with DMSO $(200 \mu \mathrm{L})$, the resulting formazone crystals were quantified with a plate reader (Tecan Infinite M200) at wavelength $540 \mathrm{~nm}$ with reference $680 \mathrm{~nm}$. All measurements are performed in triplet.

\section{RESULTS AND DISCUSSION}

Gold nanorod synthesis. Gold nanorods (GNRs) were synthesized in via the seedmediated growth method (Figure 1A). ${ }^{88,89}$ In this wet-chemistry method, preformed gold nanospheres serve as the seeds on which metal is grown along preferential directions directed by the surfactant hexadecyltrimethylammonium bromide (CTAB) in the presence of silver nitrate $\left(\mathrm{AgNO}_{3}\right)$. The optical spectra of the synthesized GNRs possess two absorption peaks, one at approximately $513 \mathrm{~nm}$ and one at $773 \mathrm{~nm}$ (Figure 1B). This is in correspondence with literature report of GNRs being hemispherically capped cylinders with two plasmon peaks due to asymmetry. ${ }^{90}$ One peak, assigned as the longitudinal plasmon peak, is due to oscillation of electrons along the longitudinal axis, and other assigned as the transverse plasmon peak due to oscillations along the transverse axis. ${ }^{91}$ The transverse plasmon peak is like in spheres, located around $520 \mathrm{~nm}$, whereas the longitudinal plasmon peak is at longer wavelength and dependent of the aspect ratio of the particle. The concentration of GNRs was determined by the optical spectra, defined as optical density (O.D.). The extinction coefficient value of the longitudinal plasmon peak has been taken into consideration for calculating the number of particles per $\mathrm{mL}$ using Lambert-Beer law. 


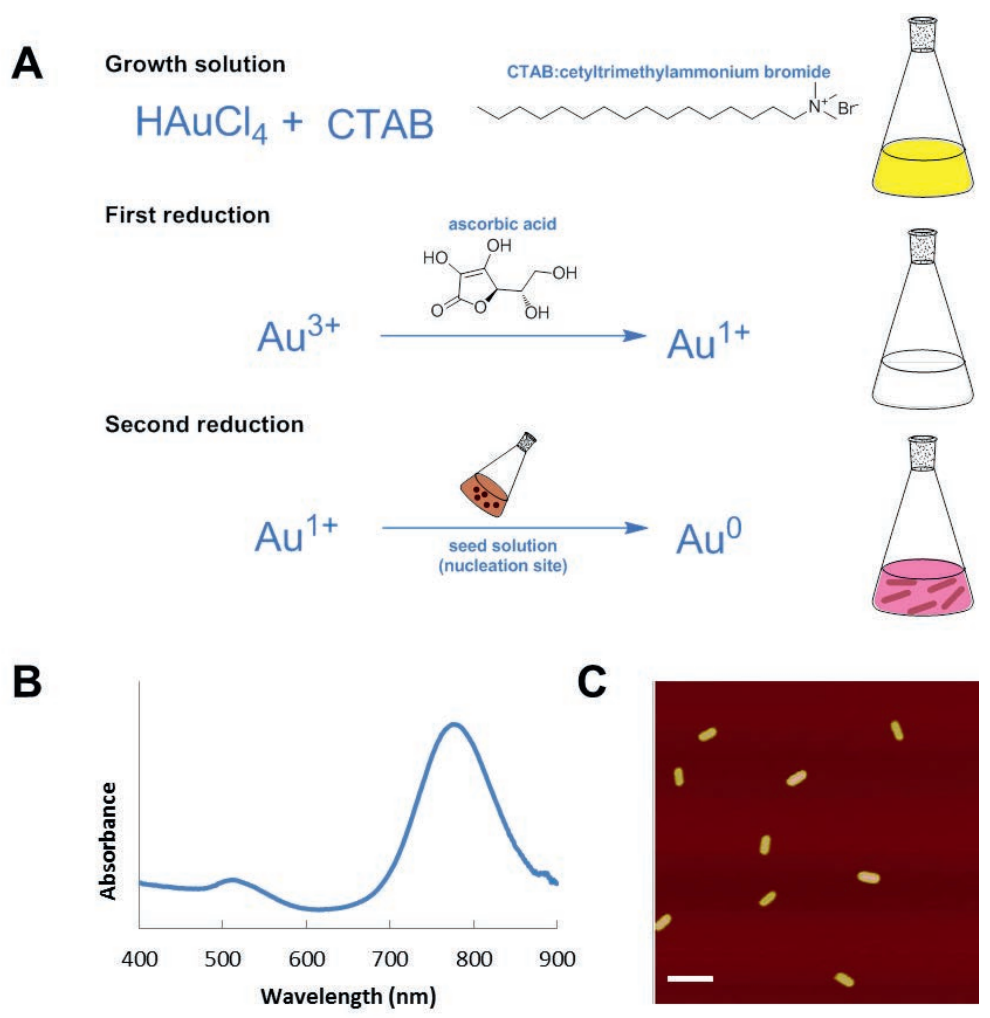

Figure 1. Synthesis and characterization of gold nanorods (GNRs) via the seed-mediated growth method. A) Schematic illustration of GNRs synthetic route; GNRs suspension in water after twice centrifugation and resuspension; B) the absorption spectra of GNR suspension in water; and C) morphology of GNRs by atomic force microscopy (scale bar equals $100 \mathrm{~nm}$ ).

Atomic force microscopy (AFM) was applied to characterize the purified gold nanorods. From the AFM image, it can be seen that uniform gold nanorods with good morphology were obtained with average diameter of $13 \mathrm{~nm}$ and average length of $68 \mathrm{~nm}$ (Figure 1C).

Polymer synthesis. The bioreducible poly(amido amine) pABOL with repetitive disulfide bonds along its backbone was synthesized via Michael type addition of the primary amine monomer 1-amino-4-butanol (ABOL) to $N, N$ '-cystaminebisacrylamide (CBA) under catalysis of $\mathrm{CaCl}_{2}$ (Figure 2A). 


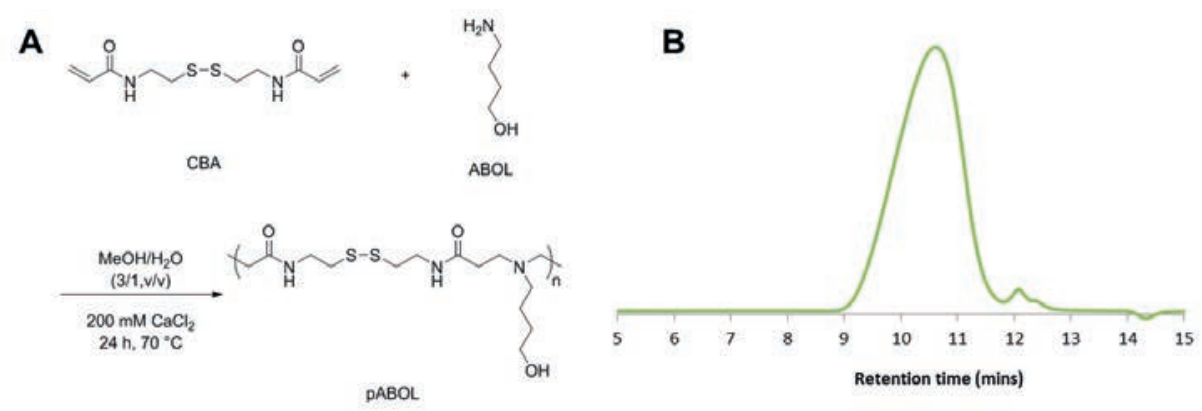

Figure 2. Synthesis of pABOL. A) Synthetic route and structure of pABOL; B) Characterization of pABOL through gel permeation chromatography (GPC).

During the polymerization a gradual viscosity rise was observed without any occurrence of gelation. After $24 \mathrm{~h}$ polymerization, excess of tert-butylamine was added into the reaction mixture to consume any residual acrylamide groups. The polymer was isolated through exhaustive dialysis (1000 Da cut-off), followed by freeze-drying. The resulting polymer has good solubility in water. The ${ }^{1} \mathrm{H}$ NMR spectra are in full accordance with the expected structure. The complete disappearance of the signals between 5 and $7 \mathrm{ppm}$, assigned to the acrylamide group, indicated that pABOL is only end-capped with amino groups. Gel permeation chromatography (GPC) measurements showed a single peak with PDI of 1.24 (Figure 2B).

\section{Polymers coating gold nanorods}

Disulfide groups have a relatively strong affinity for gold surfaces and the disulfide bonds along pABOL enable the polymer to displace the cytotoxic CTAB from the gold nanorods, and thus make the GNRs more compatible with biological material. The displacement of CTAB by pABOL proceeds smoothly by incubation the CTAB-GNR suspension with pABOL solution overnight. The resulting pABOL-GNR particles can be purified by centrifugation of the mixture and redispersion of the pellet in water, yielding a colloidal stable solution without further color change (Figure 3A). The extinction spectra of polymer-coated GNRs and original GNRs are presented in Figure 3B. The polymer-coated GNRs showed two absorption bands that were similar to the original GNRs solution, however with a $10 \mathrm{~nm}$ red-shift of the longitudinal plasmon band (Figure 3B). The $10 \mathrm{~nm}$ red-shift due to the displacement of CTAB with pABOL was similar to the red-shift observed upon PEGlyation of GNRs with thiol-functional poly(ethylene glycol). ${ }^{92}$ Gold nanorods without polymer are irreversibly aggregated during the centrifugation, and it is 
clear that the encapsulation of the GNRs in pABOL is responsible for the stability of the GNRs in solution. This greatly enhances the utility of the gold nanorods for several applications.

A

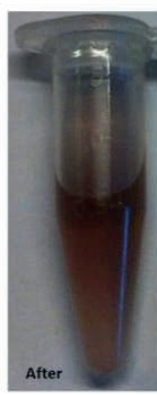

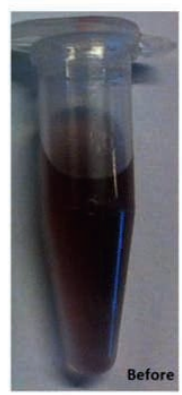

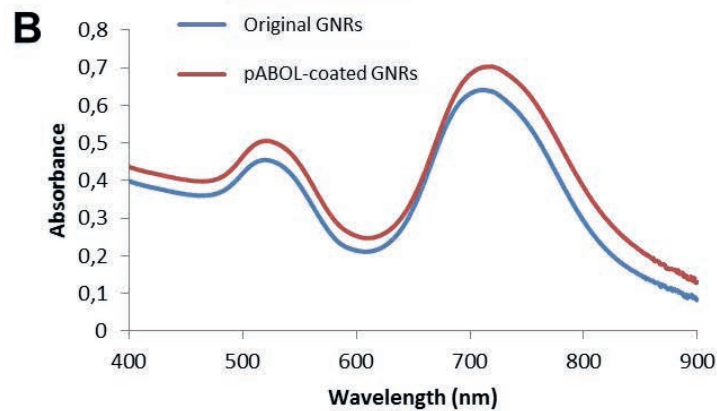

Figure 3. Coating with GNRs with pABOL. A) Photographic images of solution of GNRs after and before pABOL coating; and B) the extinction spectra of GNRs.

\section{Hybrid polyplexes}

A requirement for cationic polymers to function as gene delivery vectors is that they are able to condense genetic materials into nanosized polyplexes. ${ }^{93}$ From previous research it has appeared that pABOL complexes with DNA to nanosized particles (polyplexes) at pABOL/DNA weight ratio 48/1. ${ }^{50}$ Therefore, pABOL and DNA weight ratio in these experiments was also set to $48 / 1$ for preparation of the hybrid polyplexes. For the normal DNA/pABOL polyplexes (without GNR), the average size and zeta-potential were $142 \mathrm{~nm}$ and $+26 \mathrm{mV}$, respectively. For the DNA/pABOL-GNR polyplexes, the average size and zeta-potential were $126 \mathrm{~nm}$ and $+28 \mathrm{mV}$, respectively. Thus the introduction of GNRs gives stronger condensing of DNA, resulting in smaller polyplexes. It can be assumed that the GNRs' action as chemical crosslinkers in the polyplexes networks and the binding affinity of the GNRs for pABOL is responsible for the higher packing density in these polyplexes.

The stability of both polyplexes was investigated by following their size in time by DLS measurements. The size of the DNA/pABOL-GNR polyplexes and DNA/pABOL polyplexes increases in time in $\mathrm{pH} 7.4$ HEPES buffer. This can be attributed to slow degradation of polymers due to hydrolysis of amide bonds along the pABOL chain. ${ }^{94}$ As illustrated in Figure 4A, the size of the hybrid polyplexes remains within $200 \mathrm{~nm}$ within 24 $\mathrm{h}$ storage while the DNA/pABOL polyplexes increase to sizes over $200 \mathrm{~nm}$ already after 6 h. The slower size increase of the DNA/pABOL-GNR polyplexes can again be attributed 
to the cross-linking stability of the GNRs with the disulfide bonds of pABOL. ${ }^{69,89}$ The stability observed upon 3-fold dilution with HEPES buffer also demonstrated that the hybrid polyplexes are much more stable than polyplexes without GNRs (Figure 4B).
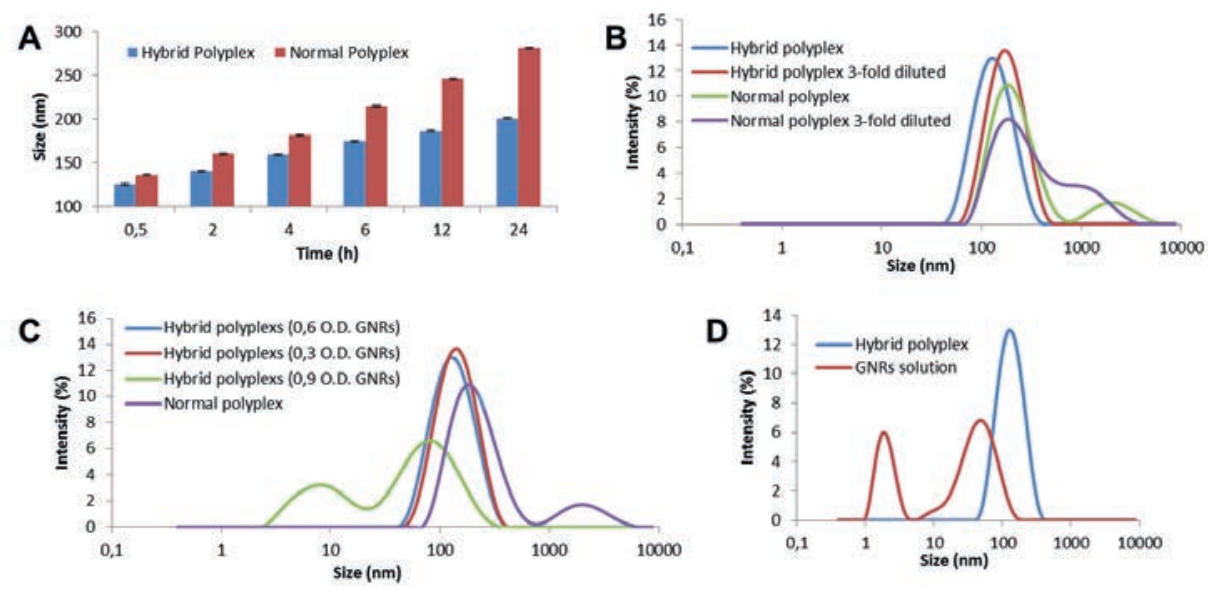

Figure 4. Hybrid polyplexes and interaction between GNRs and pABOL through DLS. A) Size evolution of hybrid polyplexes and normal polyplexes in pH 7.4 HEPES buffer; B) Size distribution diagram of hybridand normal- polyplexes upon dilution; C) Effect of different amount of GNRs during hybrid polyplexes preparation; and D) Size distribution diagrams of GNRs solution and hybrid polyplexes.

DLS analysis was applied to obtain information about the nature of the GNR in the hybrid polyplexes. Particles with non-spherical shapes, such as nanorods, can be more precisely characterized by multiple angle or depolarized DLS measurements. As depicted in Figure 4B and Figure 4C, the GNR solution showed two peaks in the size distribution diagram, one with an average hydrodynamic diameter at 5-6 nm, and one at 70-80 $\mathrm{nm}$. These peaks are ascribed to the rod-shape of the GNRs. The small size peak is related to the rotational diffusion of the nanorods rather than to an actual dimension of the nanorods. ${ }^{95}$ As the hybrid polyplexes show a single size distribution peak at $105 \mathrm{~nm}$, it can be concluded that this implies a homogenous particle system. With different amounts of GNRs, two peaks in size distribution diagram appeared again when GNRs (O.D. $=0.9)$ applied during hybrid polyplexes (Figure 4C). In all, based on the DLS results, the homogenous hybrid polyplexes were successfully prepared.

Extinction spectra of obtained hybrid polyplexes were recorded on UV-Vis spectrometry (Figure 5A). From the spectra, the hybrid polyplexes showed strong absorption in NIR wavelength as well as absorption in $520 \mathrm{~nm}$ from transverse plasmon band. Compared to 
the original GNRs (Figure 1B), the red-shift in the absorption spectra of hybrid polyplexes was ascribed to change of dielectric constant of the environment around the GNRs. These results confirm that the GNRs have been incorporated into the polyplexes without compromising their morphologies.

Finally, the hybrid polyplexes were characterized through transmission electron microscopy (TEM). TEM measurements (Figure 5B) show that the hybrid polyplexes have size of around 100-200 $\mathrm{nm}$ and one uniform and hemispherically capped shape. These size and morphology of GNRs obtained from TEM is in agreement with the results of AFM. The larger size of the hybrid polyplexes obtained from DLS can be ascribed to different sample conditions, as DLS measures the particles in aqueous solution.
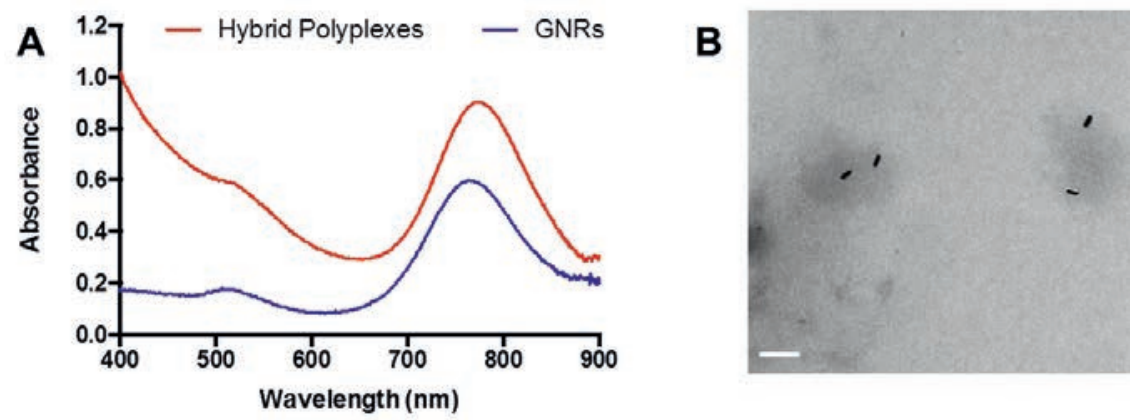

Figure 5. Characterization of hybrid polyplexes with GNRs (0.6 O.D.). A) Extinction spectra of GNRs solution and hybrid polyplexes; B) TEM image of hybrid polyplexes (Scale bar= $100 \mathrm{~nm}$ ).

\section{In vitro transfection and cytotoxicity}

The transfection activities of the hybrid polyplexes at polymer/DNA mass ratios $6,12,24$, and 48 were evaluated in COS-7 cells with plasmid DNA encoding for green fluorescent protein (GFP) as a reporter gene. The transfection efficiency is presented as the percentage of GFP-positive cells in total cells based on fluorescence-activated cell sorting (FACS) experiments. As shown in Figure 6, the transfection efficiency increases with increasing polymer/DNA mass ratio for hybrid polyplexes as well as normal polyplexes. This effect can be related to the smaller size and higher surface charge of polyplexes at higher polymer/DNA mass ratios. The transfection mediated by hybrid polyplexes exhibits comparable values as observed for GNR-free polyplexes, but both higher than optimized PEI (branched, $25 \mathrm{kDa}$ ) formulations with polymer/DNA mass ratios above 6 . When the transfection experiment was carried out in the presence of $10 \%$ fetal bovine serum (FBS), 
hybrid polyplexes induced substantially higher (up to nearly 3-fold) transfection activities as compared to GNR-free polyplexes, while transfection mediated by PEI polyplexes at their optimal polymer/DNA ratio becomes minimal. The introduction of fetal bovine serum (FBS, 10\%) induces aggregation of polyplexes, leading to the reduction in transfection of polyplexes. ${ }^{53}$ It is clear that the hybrid polyplexes exhibit significantly less serum interference than GNR-free polyplexes and PEI-based formulations, which is evidently the stabilization effect of the GNRs in these polyplexes.
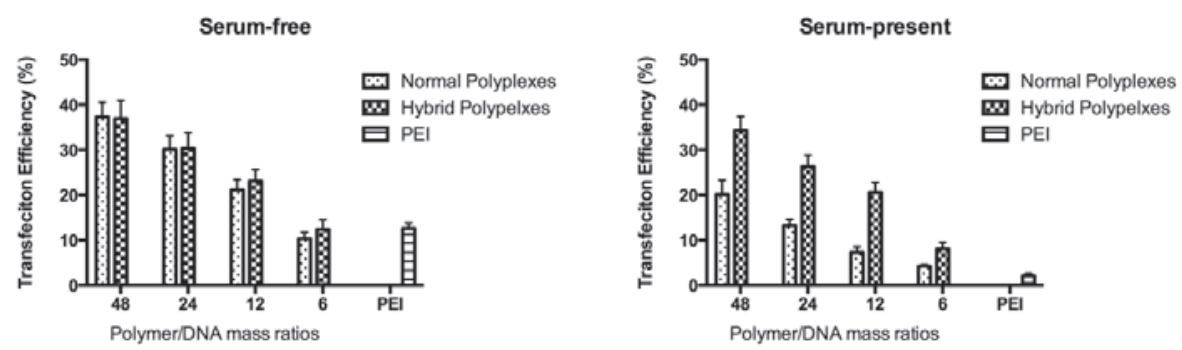

Figure 6. Transfection efficiency mediated by hybrid-and normal-polyplexes at serum-free (left) and serumpresent (right) conditions with PEI as reference.

For potential utility in clinical application, gene vectors should possess low cytotoxicity. Evaluation by MTT assays showed that the cells remained their viability over $90 \%$ after treatment with hybrid polyplexes and GNR-free polyplexes, while cell viabilities of only ca. 60\% were observed after treatment with PEI-based polyplexes under serum-free conditions. Also in the presence of serum excellent cell viabilities were obtained for hybrid and GNR-free polyplexes. The results demonstrate that hybrid polyplexes and GNR-free polyplexes are essentially non-toxic. This makes the hybrid polyplexes interesting gene vectors with unique optical properties in NIR range, which may endow light-triggered transfection with concomitant imaging modularity. 

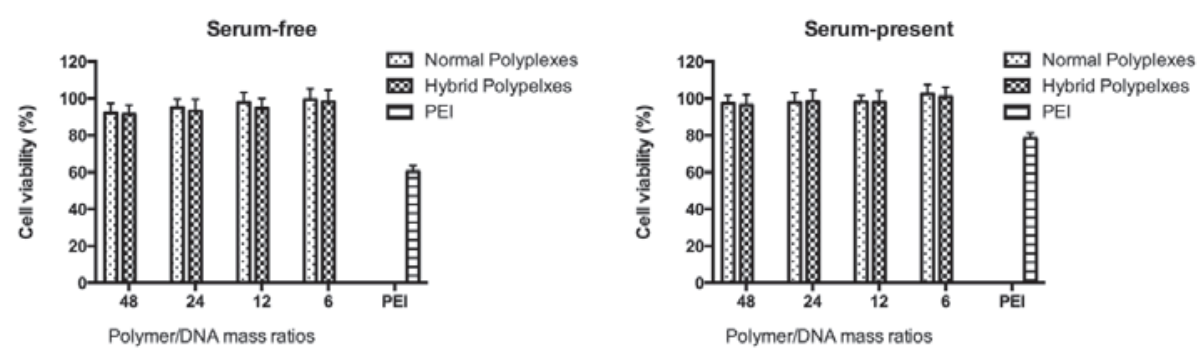

Figure 7. Cell viability of cells treated with hybrid polyplexes, normal polyplexes, or PEI-based polyplexes at serum-free (right) and serum-present (left) conditions via MTT assays.

\section{CONCLUSIONS}

Gold nanorods (GNRs) were prepared through the seed-mediated growth method with sizes of $13 \times 68 \mathrm{~nm}$ and a NIR ranged surface plasmon band at $773 \mathrm{~nm}$. The GNRs could be readily incorporated in the disulfide-containing pABOL network without compromising their colloidal stability and optical properties. Through mixing GNRs, pABOL, and plasmid DNA, hybrid polyplexes were prepared of nanosized dimensions $(<200 \mathrm{~nm})$ and positive surface charge $(+28 \mathrm{mV})$. The polyplexes exhibited strong absorption in NIR window (700-850 nm). Compared with normal polyplexes comprising plasmid DNA and pABOL, hybrid polyplexes of DNA/pABOL-GNR shown smaller size, slightly higher surface charge, and enhanced colloidal stability, owing to the action of GNRs as stabilizing crosslinker in these polyplexes. The hybrid polyplexes exhibit transfection efficiency in COS-7 cells comparable to normal polyplexes without inducing cytotoxicity under serumfree conditions. Under serum conditions (10\% FBS), hybrid polyplexes induce ca. 3-fold and 17-fold higher transfection efficiencies as compared to GNR-free polyplexes and optimized PEI (25 kDa) respectively. The remarkably high transfection activities mediated of the hybrid polyplexes under the serum conditions are most likely related with their enhanced colloidal stability.

\section{ACKNOWLEDGMENT}

The work is generously supported by NanoNextNL, a micro and nanotechnology consortium of the Government of the Netherlands and 130 partners. G.S. thanks Dr. Karin Roelofs gratefully for her kind aid in cell culture and FACS measurements. 


\section{REFERENCES}

(1) Miyata, K.; Nishiyama, N.; Kataoka, K. Rational design of smart supramolecular assemblies for gene delivery: chemical challenges in the creation of artificial viruses. Chem. Soc. Rev. 2012, 41, 2562-2574.

(2) Cavazzana-Calvo, M.; Hacein-Bey, S.; De Saint Basile, G.; Gross, F.; Yvon, E.; Nusbaum, P.; Selz, F.; Hue, C.; Certain, S.; Casanova, J. L.; Bousso, P.; Le Deist, F.; Fischer, A. Gene therapy of human severe combined immunodeficiency (SCID)-X1 disease. Science 2000, 288, 669-672.

(3) Clark, K. L.; Hughes, S. A.; Bulsara, P.; Coates, J.; Moores, K.; Parry, J.; Carr, M.; Mayer, R. J.; Wilson, P.; Gruenloh, C.; Levin, D.; Darton, J.; Weber, W.-M.; Sobczak, K.; Gill, D. R.; Hyde, S. C.; Davies, L. A.; Pringle, I. A.; Sumner-Jones, S. G.; Jadhav, V.; Jamison, S.; Strapps, W. R.; Pickering, V.; Edbrooke, M. R. Pharmacological Characterization of a Novel ENaC[alpha] siRNA (GSK2225745) With Potential for the Treatment of Cystic Fibrosis. Mol. Ther. Nucleic Acids 2013, 2, e65.

(4) Kaplitt, M. G.; Feigin, A.; Tang, C.; Fitzsimons, H. L.; Mattis, P.; Lawlor, P. A.; Bland, R. J.; Young, D.; Strybing, K.; Eidelberg, D.; During, M. J. Safety and tolerability of gene therapy with an adeno-associated virus (AAV) borne GAD gene for Parkinson's disease: an open label, phase I trial. The Lancet, 369, 2097-2105.

(5) Grez, M.; Reichenbach, J.; Schwable, J.; Seger, R.; Dinauer, M. C.; Thrasher, A. J. Gene Therapy of Chronic Granulomatous Disease: The Engraftment Dilemma. Mol. Ther. 2011, 19, 28-35.

(6) El-Aneed, A. An overview of current delivery systems in cancer gene therapy. $J$. Controlled Release 2004, 94, 1-14.

(7) Scholz, C.; Wagner, E. Therapeutic plasmid DNA versus siRNA delivery: Common and different tasks for synthetic carriers. J. Controlled Release 2012, 161, 554-565.

(8) Mastrobattista, E.; Hennink, W. E. Polymers for Gene Delivery Charged for Success. Nat. Mater. 2012, 11, 10-12.

(9) Sahin, U.; Kariko, K.; Tureci, O. mRNA-based therapeutics [mdash] developing a new class of drugs. Nat. Rev. Drug Discov. 2014, 13, 759-780.

(10) Wang, Y.; Su, H.-h.; Yang, Y.; Hu, Y.; Zhang, L.; Blancafort, P.; Huang, L. Systemic Delivery of Modified mRNA Encoding Herpes Simplex Virus 1 
Thymidine Kinase for Targeted Cancer Gene Therapy. Mol. Ther. 2013, 21, 358367.

(11) Kanasty, R.; Dorkin, J. R.; Vegas, A.; Anderson, D. Delivery materials for siRNA therapeutics. Nat. Mater. 2013, 12, 967-977.

(12) Wang, Y.; Huang, L. A window onto siRNA delivery. Nat. Biotech. 2013, 31, 611612.

(13) Whitehead, K. A.; Langer, R.; Anderson, D. G. Knocking down barriers: advances in siRNA delivery. Nat. Rev. Drug Discov. 2009, 8, 129-138.

(14) Zhang, Y.; Wang, Z.; Gemeinhart, R. A. Progress in microRNA delivery. J. Controlled Release 2013, 172, 962-974.

(15) Bloomfield, V. A. DNA condensation by multivalent cations. Biopolymers 1997, 44, 269-282.

(16) Pamies, P.; Stoddart, A. Materials for drug delivery. Nat. Mater. 2013, 12, 957.

(17) Schatzlein, A. G. Non-viral vectors in cancer gene therapy: Principles and progress. Anti-Cancer Drug 2001, 12, 275-304.

(18) Jones, C. H.; Chen, C. K.; Ravikrishnan, A.; Rane, S.; Pfeifer, B. A. Overcoming Nonviral Gene Delivery Barriers: Perspective and Future. Mol. Pharmaceutics 2013, 10, 4082-4098.

(19) Akinc, A.; Battaglia, G. Exploiting endocytosis for nanomedicines. Cold Spring Harbor perspectives in biology 2013, 5, a016980.

(20) Labhasetwar, V. Nanotechnology for drug and gene therapy: the importance of understanding molecular mechanisms of delivery. Curr. Opin. Biotech. 2005, 16, 674-680.

(21) Niidome, T.; Huang, L. Gene therapy progress and prospects: Nonviral vectors. Gene Ther. 2002, 9, 1647-1652.

(22) Robbins, P. D.; Ghivizzani, S. C. Viral Vectors for Gene Therapy. Pharmacol. Therapeut. 1998, 80, 35-47.

(23) Croyle, M. A.; Cheng, X.; Wilson, J. M. Development of formulations that enhance physical stability of viral vectors for gene therapy. Gene Ther. 2001, 8, 1281-1290.

(24) Daniel, R.; Smith, J. A. Integration site selection by retroviral vectors: Molecular mechanism and clinical consequences. Hum. Gene. Ther. 2008, 19, 557-568.

(25) Rothe, M.; Modlich, U.; Schambach, A. Biosafety Challenges for Use of Lentiviral Vectors in Gene Therapy. Curr. Gene Ther. 2013, 13, 453-468. 
(26) Lowenstein, P. R.; Mandel, R. J.; Xiong, W. D.; Kroeger, K.; Castro, M. G. Immune responses to adenovirus and adeno-associated vectors used for gene therapy of brain diseases: The role of immunological synapses in understanding the cell biology of neuroimmune interactions. Curr. Gene Ther. 2007, 7, 347-360.

(27) Giacca, M.; Zacchigna, S. Virus-mediated gene delivery for human gene therapy. $J$. Controlled Release 2012, 161, 377-388.

(28) Farokhzad, O. C.; Langer, R. Impact of Nanotechnology on Drug Delivery. Acs Nano 2009, 3, 16-20.

(29) Pack, D. W.; Hoffman, A. S.; Pun, S.; Stayton, P. S. Design and development of polymers for gene delivery. Nat. Rev. Drug Discov. 2005, 4, 581-593.

(30) Boussif, O.; Lezoualch, F.; Zanta, M. A.; Mergny, M. D.; Scherman, D.; Demeneix, B.; Behr, J. P. A Versatile Vector for Gene and Oligonucleotide Transfer into Cells in Culture and in-Vivo - Polyethylenimine. Proc. Natl. Acad. Sci. U.S.A. 1995, 92, 7297-7301.

(31) Wolfert, M. A.; Schacht, E. H.; Toncheva, V.; Ulbrich, K.; Nazarova, O.; Seymour, L. W. Characterization of vectors for gene therapy formed by self-assembly of DNA with synthetic block co-polymers. Hum. Gene. Ther. 1996, 7, 2123-2133.

(32) Lynn, D. M.; Langer, R. Degradable Poly( $\beta$-amino esters): Synthesis, Characterization, and Self-Assembly with Plasmid DNA. J. Am. Chem. Soc. 2000, 122, 10761-10768.

(33) Cherng, J. Y.; van de Wetering, P.; Talsma, H.; Crommelin, D. J. A.; Hennink, W. E. Effect of size and serum proteins on transfection efficiency of poly $((2-$ dimethylamino)ethyl methacrylate)-plasmid nanoparticles. Pharm. Res. 1996, 13, 1038-1042.

(34) Tang, M. X.; Redemann, C. T.; Szoka, F. C. In Vitro Gene Delivery by Degraded Polyamidoamine Dendrimers. Bioconjugate Chem. 1996, 7, 703-714.

(35) Roy, K.; Mao, H.-Q.; Huang, S. K.; Leong, K. W. Oral gene delivery with chitosan-DNA nanoparticles generates immunologic protection in a murine model of peanut allergy. Nat. Med. 1999, 5, 387-391.

(36) Mao, H.-Q.; Roy, K.; Troung-Le, V. L.; Janes, K. A.; Lin, K. Y.; Wang, Y.; August, J. T.; Leong, K. W. Chitosan-DNA nanoparticles as gene carriers: synthesis, characterization and transfection efficiency. J. Controlled Release 2001, 70, 399421. 
(37) Kabanov, A. V.; Batrakova, E. V.; Alakhov, V. Y. Pluronic ${ }^{\circledR}$ block copolymers as novel polymer therapeutics for drug and gene delivery. J. Controlled Release 2002, $82,189-212$.

(38) Lemieux, P.; Guérin, N.; Paradis, G.; Proulx, R.; Chistyakova, L.; Kabanov, A.; Alakhov, V. A combination of poloxamers increases gene expression of plasmid DNA in skeletal muscle. Gene Ther. 2000, 7, 986-991.

(39) Vllasaliu, D.; Fowler, R.; Stolnik, S. PEGylated nanomedicines: recent progress and remaining concerns. Expert Opin. Drug Delivery 2014, 11, 139-154.

(40) Stuart, M. A. C.; Huck, W. T. S.; Genzer, J.; Muller, M.; Ober, C.; Stamm, M.; Sukhorukov, G. B.; Szleifer, I.; Tsukruk, V. V.; Urban, M.; Winnik, F.; Zauscher, S.; Luzinov, I.; Minko, S. Emerging applications of stimuli-responsive polymer materials. Nat. Mater. 2010, 9, 101-113.

(41) Du, J.; Tang, Y.; Lewis, A. L.; Armes, S. P. pH-Sensitive Vesicles Based on a Biocompatible Zwitterionic Diblock Copolymer. J. Am. Chem. Soc. 2005, 127, 17982-17983.

(42) Schmaljohann, D. Thermo- and $\mathrm{pH}$-responsive polymers in drug delivery. $A d v$. Drug Deliv. Rev. 2006, 58, 1655-1670.

(43) Son, S.; Namgung, R.; Kim, J.; Singha, K.; Kim, W. J. Bioreducible Polymers for Gene Silencing and Delivery. Acc. Chem. Res. 2012, 45, 1100-1112.

(44) de la Rica, R.; Aili, D.; Stevens, M. M. Enzyme-responsive nanoparticles for drug release and diagnostics. Adv. Drug Deliv. Rev. 2012, 64, 967-978.

(45) Kwon, J.; Kim, J.; Park, S.; Khang, G.; Kang, P. M.; Lee, D. InflammationResponsive Antioxidant Nanoparticles Based on a Polymeric Prodrug of Vanillin. Biomacromolecules 2013, 14, 1618-1626.

(46) Kamaly, N.; Xiao, Z.; Valencia, P. M.; Radovic-Moreno, A. F.; Farokhzad, O. C. Targeted polymeric therapeutic nanoparticles: design, development and clinical translation. Chem. Soc. Rev. 2012, 41, 2971-3010.

(47) Gao, X.; Cui, Y.; Levenson, R. M.; Chung, L. W. K.; Nie, S. In vivo cancer targeting and imaging with semiconductor quantum dots. Nat. Biotech. 2004, 22, 969-976.

(48) Wang, Y.; Gao, S.; Ye, W.-H.; Yoon, H. S.; Yang, Y.-Y. Co-delivery of drugs and DNA from cationic core-shell nanoparticles self-assembled from a biodegradable copolymer. Nat. Mater. 2006, 5, 791-796. 
(49) Ferruti, P. Poly(amidoamine)s: Past, present, and perspectives. J. Polym. Sci., Part A: Polym. Chem. 2013, 51, 2319-2353.

(50) Lin, C.; Zhong, Z.; Lok, M. C.; Jiang, X.; Hennink, W. E.; Feijen, J.; Engbersen, J. F. J. Novel Bioreducible Poly(amido amine)s for Highly Efficient Gene Delivery. Bioconjugate Chem. 2007, 18, 138-145.

(51) van der Aa, L. J.; Vader, P.; Storm, G.; Schiffelers, R. M.; Engbersen, J. F. J. Optimization of poly(amido amine)s as vectors for siRNA delivery. J. Controlled Release 2011, 150, 177-186.

(52) Coué, G.; Engbersen, J. F. J. Functionalized linear poly(amidoamine)s are efficient vectors for intracellular protein delivery. J. Controlled Release 2011, 152, 90-98.

(53) Audouy, S.; Molema, G.; De Leij, L.; Hoekstra, D. Serum as a modulator of lipoplex-mediated gene transfection: Dependence of amphiphile, cell type and complex stability. J. Gene Med. 2000, 2, 465-476.

(54) Morille, M.; Passirani, C.; Vonarbourg, A.; Clavreul, A.; Benoit, J.-P. Progress in developing cationic vectors for non-viral systemic gene therapy against cancer. Biomaterials 2008, 29, 3477-3496.

(55) Petersen, H.; Fechner, P. M.; Martin, A. L.; Kunath, K.; Stolnik, S.; Roberts, C. J.; Fischer, D.; Davies, M. C.; Kissel, T. Polyethylenimine-graft-Poly(ethylene glycol) Copolymers: Influence of Copolymer Block Structure on DNA Complexation and Biological Activities as Gene Delivery System. Bioconjugate Chem. 2002, 13, 845854.

(56) Verbaan, F. J.; Oussoren, C.; Snel, C. J.; Crommelin, D. J. A.; Hennink, W. E.; Storm, G. Steric stabilization of poly(2-(dimethylamino)ethyl methacrylate)-based polyplexes mediates prolonged circulation and tumor targeting in mice. J. Gene Med. 2004, 6, 64-75.

(57) Sung, S.-J.; Min, S. H.; Cho, K. Y.; Lee, S.; Min, Y.-J.; Yeom, Y. I.; Park, J.-K. Effect of Polyethylene Glycol on Gene Delivery of Polyethylenimine. Biol. Pharm. Bull. 2003, 26, 492-500.

(58) Tseng, W.-C.; Jong, C.-M. Improved Stability of Polycationic Vector by DextranGrafted Branched Polyethylenimine. Biomacromolecules 2003, 4, 1277-1284.

(59) He, Y.; Cheng, G.; Xie, L.; Nie, Y.; He, B.; Gu, Z. Polyethyleneimine/DNA polyplexes with reduction-sensitive hyaluronic acid derivatives shielding for targeted gene delivery. Biomaterials 2013, 34, 1235-1245. 
(60) Suma, T.; Miyata, K.; Anraku, Y.; Watanabe, S.; Christie, R. J.; Takemoto, H.; Shioyama, M.; Gouda, N.; Ishii, T.; Nishiyama, N.; Kataoka, K. Smart Multilayered Assembly for Biocompatible siRNA Delivery Featuring Dissolvable Silica, Endosome-Disrupting Polycation, and Detachable PEG. ACS Nano 2012, 6, 6693-6705.

(61) Gouda, N.; Miyata, K.; Christie, R. J.; Suma, T.; Kishimura, A.; Fukushima, S.; Nomoto, T.; Liu, X.; Nishiyama, N.; Kataoka, K. Silica nanogelling of environment-responsive PEGylated polyplexes for enhanced stability and intracellular delivery of siRNA. Biomaterials 2013, 34, 562-570.

(62) Hatakeyama, H.; Akita, H.; Harashima, H. A multifunctional envelope type nano device (MEND) for gene delivery to tumours based on the EPR effect: A strategy for overcoming the PEG dilemma. Adv. Drug Deliv. Rev. 2011, 63, 152-160.

(63) Miyata, K.; Kakizawa, Y.; Nishiyama, N.; Harada, A.; Yamasaki, Y.; Koyama, H.; Kataoka, K. Block catiomer polyplexes with regulated densities of charge and disulfide cross-linking directed to enhance gene expression. J. Am. Chem. Soc. 2004, 126, 2355-2361.

(64) Piao, J.-G.; Yan, J.-J.; Wang, M.-Z.; Wu, D.-C.; You, Y.-Z. A new method to cross-link a polyplex for enhancing in vivo stability and transfection efficiency. Biomater. Sci. 2014, 2, 390-398.

(65) Fröhlich, T.; Edinger, D.; Russ, V.; Wagner, E. Stabilization of polyplexes via polymer crosslinking for efficient siRNA delivery. Eur. J. Pharm. Sci. 2012, 47, 914-920.

(66) He, H.; Bai, Y.; Wang, J.; Deng, Q.; Zhu, L.; Meng, F.; Zhong, Z.; Yin, L. Reversibly Cross-Linked Polyplexes Enable Cancer-Targeted Gene Delivery via Self-Promoted DNA Release and Self-Diminished Toxicity. Biomacromolecules 2015, 16, 1390-1400.

(67) Oupický, D.; Carlisle, R. C.; Seymour, L. W. Triggered intracellular activation of disulfide crosslinked polyelectrolyte gene delivery complexes with extended systemic circulation in vivo. Gene Ther. 2001, 8, 713-724.

(68) Baoum, A.; Xie, S.-X.; Fakhari, A.; Berkland, C. "Soft" Calcium Crosslinks Enable Highly Efficient Gene Transfection Using TAT Peptide. Pharm. Res. 2009, 26, 2619-2629.

(69) Boisselier, E.; Astruc, D. Gold nanoparticles in nanomedicine: preparations, imaging, diagnostics, therapies and toxicity. Chem. Soc. Rev. 2009, 38, 1759-1782. 
(70) Dreaden, E. C.; Alkilany, A. M.; Huang, X. H.; Murphy, C. J.; El-Sayed, M. A. The golden age: gold nanoparticles for biomedicine. Chem. Soc. Rev. 2012, 41, 27402779 .

(71) Hauck, T. S.; Ghazani, A. A.; Chan, W. C. W. Assessing the effect of surface chemistry on gold nanorod uptake, toxicity, and gene expression in mammalian cells. Small 2008, 4, 153-159.

(72) Alkilany, A. M.; Shatanawi, A.; Kurtz, T.; Caldwell, R. B.; Caldwell, R. W. Toxicity and Cellular Uptake of Gold Nanorods in Vascular Endothelium and Smooth Muscles of Isolated Rat Blood Vessel: Importance of Surface Modification. Small 2012, 8, 1270-1278.

(73) Cheung, K. L.; Chen, H.; Chen, Q.; Wang, J.; Ho, H. P.; Wong, C. K.; Kong, S. K. CTAB-coated gold nanorods elicit allergic response through degranulation and cell death in human basophils. Nanoscale 2012, 4, 4447-4449.

(74) Zhang, Z. J.; Wang, J.; Chen, C. Y. Gold Nanorods Based Platforms for LightMediated Theranostics. Theranostics 2013, 3, 223-238.

(75) Locatelli, E.; Monaco, I.; Comes Franchini, M. Surface modifications of gold nanorods for applications in nanomedicine. RSC Advances 2015, 5, 21681-21699.

(76) Huang, J. Y.; Jackson, K. S.; Murphy, C. J. Polyelectrolyte Wrapping Layers Control Rates of Photothermal Molecular Release from Gold Nanorods. Nano Lett. 2012, 12, 2982-2987.

(77) Chen, H.; Chi, X.; Li, B.; Zhang, M.; Ma, Y.; Achilefu, S.; Gu, Y. Drug loaded multilayered gold nanorods for combined photothermal and chemotherapy. Biomater. Sci. 2014.

(78) Pissuwan, D.; Niidome, T. Polyelectrolyte-coated gold nanorods and their biomedical applications. Nanoscale 2015, 7, 59-65.

(79) Xu, L.; Liu, Y.; Chen, Z.; Li, W.; Liu, Y.; Wang, L.; Liu, Y.; Wu, X.; Ji, Y.; Zhao, Y.; Ma, L.; Shao, Y.; Chen, C. Surface-Engineered Gold Nanorods: Promising DNA Vaccine Adjuvant for HIV-1 Treatment. Nano Lett. 2012, 12, 2003-2012.

(80) Richardson, J. J.; Björnmalm, M.; Caruso, F. Technology-driven layer-by-layer assembly of nanofilms. Science 2015, 348 .

(81) Li, Z. M.; Huang, P.; Zhang, X. J.; Lin, J.; Yang, S.; Liu, B.; Gao, F.; Xi, P.; Ren, Q. S.; Cui, D. X. RGD-Conjugated Dendrimer-Modified Gold Nanorods for in Vivo Tumor Targeting and Photothermal Therapy. Mol. Pharmaceutics 2010, 7, 94-104. 
(82) Chen, R.; Wang, X.; Yao, X. K.; Zheng, X. C.; Wang, J.; Jiang, X. Q. Near-IRtriggered photothermal/photodynamic dual-modality therapy system via chitosan hybrid nanospheres. Biomaterials 2013, 34, 8314-8322.

(83) Huang, H.-C.; Barua, S.; Kay, D. B.; Rege, K. Simultaneous Enhancement of Photothermal Stability and Gene Delivery Efficacy of Gold Nanorods Using Polyelectrolytes. ACS Nano 2009, 3, 2941-2952.

(84) Taruttis, A.; Lozano, N.; Nunes, A.; Jasim, D. A.; Beziere, N.; Herzog, E.; Kostarelos, K.; Ntziachristos, V. siRNA liposome-gold nanorod vectors for multispectral optoacoustic tomography theranostics. Nanoscale 2014, 6, 1345113456.

(85) Xiao, Z.; Ji, C.; Shi, J.; Pridgen, E. M.; Frieder, J.; Wu, J.; Farokhzad, O. C. DNA Self-Assembly of Targeted Near-Infrared-Responsive Gold Nanoparticles for Cancer Thermo-Chemotherapy. Angew. Chem. Int. Ed. 2012, 51, 11853-11857.

(86) Li, W.; Wang, J.; Ren, J.; Qu, X. Near-Infrared- and pH-Responsive System for Reversible Cell Adhesion using Graphene/Gold Nanorods Functionalized with iMotif DNA. Angew. Chem. Int. Ed. 2013, 52, 6726-6730.

(87) Chen, C.-C.; Lin, Y.-P.; Wang, C.-W.; Tzeng, H.-C.; Wu, C.-H.; Chen, Y.-C.; Chen, C.-P.; Chen, L.-C.; Wu, Y.-C. DNA-Gold Nanorod Conjugates for Remote Control of Localized Gene Expression by near Infrared Irradiation. J. Am. Chem. Soc. 2006, $128,3709-3715$.

(88) Nikoobakht, B.; El-Sayed, M. A. Preparation and Growth Mechanism of Gold Nanorods (NRs) Using Seed-Mediated Growth Method. Chem. Mater. 2003, 15, 1957-1962.

(89) Daniel, M.-C.; Astruc, D. Gold Nanoparticles: Assembly, Supramolecular Chemistry, Quantum-Size-Related Properties, and Applications toward Biology, Catalysis, and Nanotechnology. Chem. Rev. 2004, 104, 293-346.

(90) Pérez-Juste, J.; Pastoriza-Santos, I.; Liz-Marzán, L. M.; Mulvaney, P. Gold nanorods: Synthesis, characterization and applications. Coord. Chem. Rev. 2005, 249, 1870-1901.

(91) Vigderman, L.; Khanal, B. P.; Zubarev, E. R. Functional Gold Nanorods: Synthesis, Self-Assembly, and Sensing Applications. Adv. Mater. 2012, 24, 4811-4841.

(92) Liao, H.; Hafner, J. H. Gold Nanorod Bioconjugates. Chem. Mater. 2005, 17, 46364641. 
(93) Hubbell, J. A.; Langer, R. Translating materials design to the clinic. Nat. Mater. 2013, 12, 963-966.

(94) Ferruti, P.; Marchisio, M. A.; Duncan, R. Poly(amido-amine)s: Biomedical applications. Macromol. Rapid Comm. 2002, 23, 332-355.

(95) Liu, H.; Pierre-Pierre, N.; Huo, Q. Dynamic light scattering for gold nanorod size characterization and study of nanorod-protein interactions. Gold Bull. 2012, 45, 187-195. 


\section{Chapter 6. Novel Poly(amino ether)s with Various Disulfide Content as Gene Vectors}

Guoying Si, Alexander Moerer, Jos M.J. Paulusse* and Johan F.J. Engbersen*

Department of Controlled Drug Delivery, MIRA Institute for Biomedical Technology and Technical Medicine, Faculty of Science and Technology, University of Twente, P.O. Box 217, 7500 AE Enschede, The Netherlands

\section{KEYWORDS}

Disulfides, cationic polymers, gene delivery, poly(amine ether)s, serum tolerance.

Part of this chapter has been in preparation for publication. 


\section{ABSTRACT}

A class of novel poly(amino ether)s (PAEs) with varying amounts of disulfide linkages in their main chain were prepared by reaction of 4-amino-1-butanol (ABOL) with varying ratios of 2-hydroxyethyl disulfide diglycidyl ether (SS-DE) and 1,4-butanediol diglycidyl ether (CC-DE). The PAEs display high buffer capacities in pH range 5.1-7.4 and efficiently condense DNA into nanosized $(<100 \mathrm{~nm})$ and positively charged $(+30-+44 \mathrm{mV})$ polyplexes. Transfection experiments on COS-7 cells revealed that the transfection efficiency of polyplexes based on PAEs dramatically increases with increasing disulfide content. MTT assays showed the PAE polyplexes are essentially non-toxic. In addition, in the presence of serum, PAEs proved to be effective gene vectors.

\section{INTRODUCTION}

The success of gene therapy is still impeded by the lack of efficient and safe delivery vectors. ${ }^{1,2}$ Viral gene vectors constitute approximately $70 \%$ of the vectors used in ongoing clinical trials. ${ }^{1}$ However, these vectors are associated with several limitations, such as immunogenicity, low DNA loading capacity, and technical barriers for manufacturing on large scale..$^{3-7}$ These limitations have encouraged strong efforts in the development of a great variety of non-viral vectors, ${ }^{5-9}$ in particular cationic polymer-based gene vectors. ${ }^{10-18}$

A diverse collection of polymers was developed as gene vectors, ranging from effective, though rather toxic poly (L-lysine), ${ }^{19-22}$ polyethylenimine (PEI), ${ }^{23}$ and poly(2dimethylaminoethyl)methacrylate (pDMAEMA), ${ }^{24,25}$ to the versatile and considerably less toxic poly(amino ester)s, ${ }^{26,27}$ poly(amido amine)s, ${ }^{28-30}$ and others. ${ }^{16,31,32}$ Michael addition of amines to bisacrylates and bisacrylamides was adopted in the preparation of poly(amino ester)s ${ }^{26,33-35}$ and poly(amido amine) $\mathrm{s}^{29,36}$ respectively, resulting in efficient gene delivery vectors with remarkable biocompatibility. The reaction of epoxides with amines is ubiquitously found in common epoxy resins ${ }^{37}$ and has recently gained renewed attention from polymer chemistry due to controlled polymerization of linear poly(amino ether)s (PAEs). ${ }^{38-41}$ Cationic PAEs have already been successfully applied as gene vectors without compromising cell viability. ${ }^{42-45}$ However these PAEs lack degradability, which may inflict considerable risks to their wide deployment in clinical application. ${ }^{45}$ Incorporating degradable motifs in the polymer chain such as ketal, ester, and other linkages has shown its feasibility in other non-degradable cationic polymers. ${ }^{18,46,47}$ Disulfide bonds are receiving increasing attention to render polymeric gene vectors bio-responsive, owning to their 
cleavage in the reductive cytoplasmic compartment. ${ }^{28,46,48-55}$ Here, we present the synthesis and characterization of PAEs with varying amounts of disulfide linkages and in vitro studies to evaluate their abilities to form polyplexes with DNA and performance in gene delivery (Scheme 1).

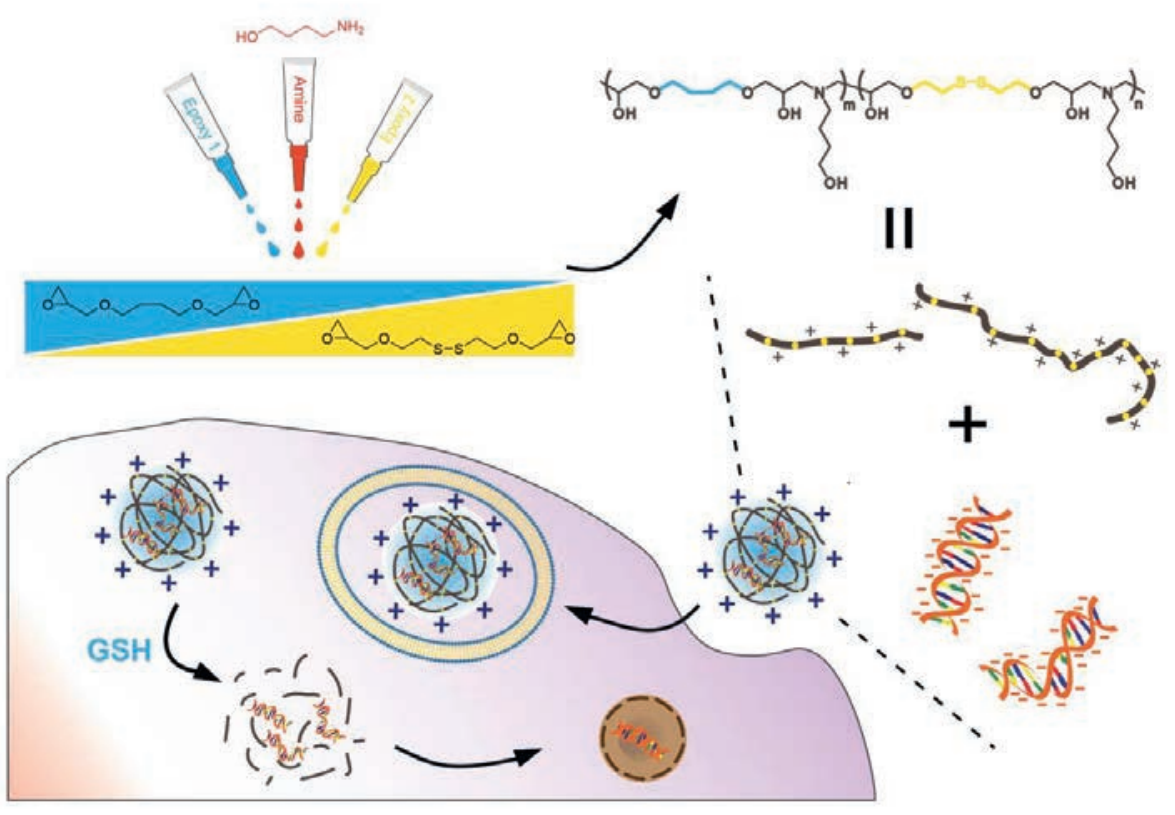

Scheme 1. Schematic illustration of cationic polymeric gene vectors with various disulfide content through epoxy-amine chemistry.

\section{EXPERIMENTAL PROCEDURES}

\section{Materials and Methods}

Epichlorohydrin ( $\geq 98 \%$, Sigma-Aldrich), 2-hydroxyethyl disulfide (technical grade, SigmaAldrich), tetrabutylammonium bromide (TBAB, $\geq 98 \%$, Sigma-Aldrich), sodium hydroxide ( $\mathrm{NaOH}$, pellet, Sigma-Aldrich), 1,4-butanediol diglycidyl ether (CC-DE, $\geq 95 \%$, SigmaAldrich), 4-amino-1-butanol (ABOL, Sigma-Aldrich), and dithiothreitol (DTT, SigmaAldrich) were used directly as received without further purification. All solvents used were analytical grade and used without further purification. Water used in these experiments was treated through a Milli-Q Gradient System (Millipore, Bedford, MA). DNA plasmids, pCMV-GFP and pCMV- $\triangle \mathrm{GFP}$, were purchased from Plasmid Factory (Bielefeld, Germany). Branched polyethylenimine (PEI, $\mathrm{M}_{\mathrm{w}} 25 \mathrm{kDa}$ ) was purchased from SigmaAldrich. 
Monomers and polymers were characterized by NMR spectroscopy on a Bruker $400 \mathrm{MHz}$ spectrometer in deuterated solvents. Molecular weights were determined by gel permeation chromatography (GPC) relative to PEG standards, using a Waters Alliance 2695 separation module equipped with a PL-aquagel-OH 8 micron Mixed-M column (300 x $7.5 \mathrm{~mm})$ with $N, N$-dimethylformamide (DMF) containing $\mathrm{LiCl}(50 \mathrm{mM})$ as eluent at $35^{\circ} \mathrm{C}$.

Synthesis of 2-hydroxyethyl disulfide diglycidyl ether (SS-DE). The synthesis of 2hydroxyethyl disulfide diglycidyl ether was referred to literature. ${ }^{56}$ To a mixture of 2hydroxyethyl disulfide $(0.772 \mathrm{~g}, 5.00 \mathrm{mmol})$, sodium hydroxide $(0.800 \mathrm{~g}, 20.0 \mathrm{mmol})$ and tetrabutylammonium bromide $(12.37 \mathrm{mg}, 34.8 \mu \mathrm{mol})$, epichlorohydrin $(1.45 \mathrm{~mL}, 18.4$ mmol) was added during $5 \mathrm{~min}$. The mixture was heated to $40{ }^{\circ} \mathrm{C}$ and stirred for $3 \mathrm{~h}$. The resulting mixture was subjected to silica column chromatography to obtain 2-hydroxyethyl disulfide diglycidyl ether (SS-DE) as a clear liquid $\left(0.700 \mathrm{~g}, 52.2 \%\right.$ yield). ${ }^{1} \mathrm{H} \mathrm{NMR}\left(\mathrm{CDCl}_{3}\right.$, $400 \mathrm{MHz}): \delta_{\mathrm{H}} 2.62(\mathrm{~m}, 2 \mathrm{H}$, epoxide ring 2 x OCHHCHO), $2.80(\mathrm{~m}, 2 \mathrm{H}$, epoxide ring $2 \times$ OCHHCHO), $2.90\left(\mathrm{t}, 4 \mathrm{H}, 2 \times \mathrm{OCHHCH}_{2} \mathrm{~S}\right), 3.16(\mathrm{~m}, 2 \mathrm{H}$, epoxide ring $2 \times \mathrm{OCHHCHO})$, $3.40(\mathrm{~m}, 2 \mathrm{H}, 2 \times \mathrm{CHCHHO}), 3.78\left(\mathrm{~m}, 6 \mathrm{H}, 2 \times \mathrm{CHCHHO}+2 \times \mathrm{OCH}_{2} \mathrm{CH}_{2} \mathrm{~S}\right) .{ }^{13} \mathrm{C} \mathrm{NMR}$ $\left(\mathrm{CDCl}_{3}, 400 \mathrm{MHz}\right): \delta_{\mathrm{C}} 38.51,44.22,50.77,69.62,71.70$.

Synthesis of poly(amino ether)s. Poly(amino ether)s (PAEs) with varying disulfide content were prepared by ring open polymerization of diglycidyl ethers SS-DE and CC-DE in the appropriate ratio with equimolar amounts of 4-amino-1-butanol.

The procedure to prepare PAE P3 with equimolar amounts of SS-DE (50 mol\%) and CCDE (50 mol\%) is as follows: into a glass vial, diglycidyl ether disulfide SS-DE (0.266 g, $1.00 \mathrm{mmol}$ ), 1,4-butanediol diglycidyl ether CC-DE (0.202 g, $1.00 \mathrm{mmol}$ ), 4-amino-1butanol (ABOL, $0.180 \mathrm{~g}, 2.00 \mathrm{mmol})$, and ethanol $(1.00 \mathrm{~mL})$ were successively loaded. The obtained mixture was stirred at ambient temperature for $72 \mathrm{~h}$, yielding a viscous mixture. The resulting mixture was diluted with water to a total volume of $15.0 \mathrm{~mL}$, acidified with 4 $\mathrm{M} \mathrm{HCl}$ solution to $\mathrm{pH}=4$, and purified via dialysis (MWCO $1.0 \mathrm{kDa}$ ) against water overnight. The remaining solution was lyophilized, yielding polymer with $50 \mathrm{~mol} \%$ disulfide (P3) as a white solid.

P1 (0\% disulfide, $0.315 \mathrm{~g}, 48.1 \%$ yield). ${ }^{1} \mathrm{H}$ NMR $\left(\mathrm{D}_{2} \mathrm{O}, 400 \mathrm{MHz}\right): \delta 1.59-1.64(\mathrm{~m}, 6 \mathrm{H}$, $\mathrm{OCH}_{2} \mathrm{CH}_{2} \mathrm{CH}_{2} \mathrm{CH}_{2} \mathrm{O}+\mathrm{NCH}_{2} \mathrm{CH}_{2} \mathrm{CH}_{2} \mathrm{CH}_{2} \mathrm{OH}$ ), $1.78-1.82$ (m, $2 \mathrm{H}, \mathrm{NCH}_{2} \mathrm{CH}_{2} \mathrm{CH}_{2} \mathrm{CH}_{2} \mathrm{OH}$ ), 
3.28-3.42 (m, 6H, $\left.2 \times \mathrm{NCH}_{2} \mathrm{CHOHCH}_{2}+\mathrm{NCH}_{2} \mathrm{CH}_{2} \mathrm{CH}_{2} \mathrm{CH}_{2} \mathrm{OH}\right), 3.52-3.66(\mathrm{~m}, 10 \mathrm{H}, 2 \times$ $\mathrm{CH}_{2} \mathrm{OCH}_{2}+\mathrm{NCH}_{2} \mathrm{CH}_{2} \mathrm{CH}_{2} \mathrm{CH}_{2} \mathrm{OH}$ ), 4.20-4.27 (bs, $2 \mathrm{H}, 2 \times \mathrm{OCH}_{2} \mathrm{CHOHCH}_{2} \mathrm{~N}$ ).

P5 (100\% disulfide, $0.347 \mathrm{~g}, 44.2 \%$ yield). ${ }^{1} \mathrm{H}$ NMR ( $\left.{ }_{2} \mathrm{O}, 400 \mathrm{MHz}\right): \delta 1.59-1.69(\mathrm{~m}, 2 \mathrm{H}$, $\mathrm{NCH}_{2} \mathrm{CH}_{2} \mathrm{CH}_{2} \mathrm{CH}_{2} \mathrm{OH}$ ), 1.74-1.83 (m, $2 \mathrm{H}, \mathrm{NCH}_{2} \mathrm{CH}_{2} \mathrm{CH}_{2} \mathrm{CH}_{2} \mathrm{OH}$ ), 2.95-2.98 (t, 4H, $2 \times$ $\left.\mathrm{SCH}_{2} \mathrm{CH}_{2}\right), 3.36-3.45\left(\mathrm{~m}, 6 \mathrm{H}, 2 \times \mathrm{NCH}_{2} \mathrm{CHOHCH}_{2}+\mathrm{NCH}_{2} \mathrm{CH}_{2} \mathrm{CH}_{2} \mathrm{CH}_{2} \mathrm{OH}\right), 3.60-3.68$ (m, $6 \mathrm{H}, 2 \times \mathrm{OCH}_{2} \mathrm{CHOHCH}_{2} \mathrm{~N}+\mathrm{NCH}_{2} \mathrm{CH}_{2} \mathrm{CH}_{2} \mathrm{CH}_{2} \mathrm{OH}$ ), 3.81-3.90 (m, 4H, $2 \times \mathrm{SCH}_{2} \mathrm{CH}_{2}$ ), 4.29-4.31 (bs, $\left.2 \mathrm{H}, 2 \times \mathrm{OCH}_{2} \mathrm{CHOHCH}_{2} \mathrm{~N}\right)$.

The copolymers are : P2 (25\% disulfide, $0.314 \mathrm{~g}, 41.7 \%$ yield); P3 (50\% disulfide, 0.211 g, $29.3 \%$ yield); $\mathbf{P 4}$ (75\% disulfide, $0.198 \mathrm{~g}, 28.8 \%$ yield). The ${ }^{1} \mathrm{H}$ NMR spectra were comparable to P1 and P5 with similar peak patterns but various integral values.

\section{Polyplex preparation}

The PAE/DNA polyplexes at polymer/DNA mass ratio 24 were prepared by adding polymer solution $(450 \mu \mathrm{g} / \mathrm{mL}, 800 \mu \mathrm{L})$ into DNA solution $(75 \mu \mathrm{g} / \mathrm{mL}, 200 \mu \mathrm{L})$, followed by $5 \mathrm{~s}$ vortexing and $30 \mathrm{~min}$ incubation at room temperature. All polymer and DNA solutions were prepared in water. Size and surface charge of the polyplexes were measured at $25{ }^{\circ} \mathrm{C}$ with a Zetasizer Nano ZS (Malvern Instruments, Malvern). Data is presented as mean value \pm standard deviation.

\section{Agarose gel retardation}

Polyplexes were prepared at polymer/DNA mass ratios of 12 following aforementioned procedure. Next, water (without DTT or containing DTT) was added into the polyplex solutions to give the final DTT concentration of $2.5 \mathrm{mM}$. After $30 \mathrm{~min}$ incubation at ambient temperature, $6 \mathrm{X}$ loading buffer containing bromophenol (Ferments, $5.0 \mu \mathrm{L}$ ) was mixed with resulting dispersions. The obtained mixture $(10 \mu \mathrm{L})$ was loaded on a $0.8 \% \mathrm{w} / \mathrm{v}$ agarose gel containing 1X SYBR ${ }^{\circledR}$ Safe DNA Gel Stain (Invitrogen ${ }^{\mathrm{TM}}$ ). The loaded gel was developed at $90 \mathrm{~V}$ for $60 \mathrm{~min}$ in a TBE (Tris-borate-EDTA, 1X) running buffer, and subsequently visualized using FluorChem M Imager (Proteinsimple, Westburg, Leusden, the Netherlands) under the exposure to UV light.

\section{Buffer capacity}

The buffering capacity of the polymers was determined by acid-base titration. PAE polymer was weighed to a total amount equal to $5 \mathrm{mmol}$ protonable amine groups, and dissolved in 
$\mathrm{NaCl}$ aqueous solution $(150 \mathrm{mM}, 10 \mathrm{~mL})$. The $\mathrm{pH}$ of the polymer solution was acidified to below $\mathrm{pH} 2$ and the solution was subsequently titrated with $\mathrm{NaOH}$ solution $(0.1 \mathrm{M})$ using an automatic titrator (Metrohm $702 \mathrm{SM}$ Tirino). As a reference, PEI (25 kDa) and $\mathrm{NaCl}$ aqueous solution were titrated following the same method. The percentage of amine groups being protonated in the $\mathrm{pH}$ range 5.1 to 7.4 was defined as the buffer capacity and was calculated from the following equation: ${ }^{57}$

$$
\text { Buffer capacity }(\%)=\frac{\Delta \mathrm{V}_{\mathrm{NaOH}} \times 0.1 \mathrm{M}}{\mathrm{N} \mathrm{mol}} \times 100 \%
$$

wherein, $\Delta \mathrm{V}_{\mathrm{NaOH}}$ denotes the $\mathrm{NaOH}$ volume required to bring the $\mathrm{pH}$ value of the polymer solution from 5.1 to 7.4 , and $\mathrm{N}$ mol $(5 \mathrm{mmol})$ denotes the total amount of protonable amine groups in the PAE polymer.

\section{In Vitro Transfection and Cell Viability Assays}

Transfection experiments were performed on COS-7 cells (SV-40 transformed African green monkey kidney cells) using reporter genes of pCMV-GFP and pCMV- $\triangle$ GFP.

Assessments of reporter gene expression (GFP expression), as well as the evaluation of cell viability by MTT assay, were carried out in separate 96-well plates. Cells were seeded in 96 well plates with densities of approximately $1.0 \times 10^{4}$ cells per well $\left(2.94 \times 10^{4}\right.$ cells $\left./ \mathrm{cm}^{2}\right)$ and maintained in complete medium at $37^{\circ} \mathrm{C}$ in a humidified atmosphere containing $5 \%$ $\mathrm{CO}_{2}$ until $60 \%-80 \%$ confluency. In a standard transfection experiment, cells were first incubated with medium ( $100 \mu \mathrm{L}$, with/without serum) for $30 \mathrm{~min}$ and subsequently loaded with $100 \mu \mathrm{L}$ polyplex dispersions $(0.25 \mu \mathrm{g}$ DNA per well) prepared in HEPES buffer (20 $\mathrm{mM}, \mathrm{pH} 7.4$, supplemented with $5.0 \mathrm{wt} \%$ glucose) (HBG). DNA concentration was $0.25 \mu \mathrm{g}$ per well which is about 4 times lower than commonly used to keep toxicity effects to minimum. After $1 \mathrm{~h}$ incubation, polyplexes were removed, fresh and warm complete culture medium $(100 \mu \mathrm{L})$ was added and cells were further cultured for $48 \mathrm{~h}$. The transfection was visualized through fluorescence imaging via an EVOS digital inverted microscope (EMS, Wageningen, the Netherlands). The PEI (25 K)/DNA formulation was prepared at a polymer/DNA mass ratio 1.25/1 and used as a positive control. MTT assays were conducted to characterize the number of viable cells with MTT value of $100 \%$ cell viability for untreated cells (i.e., cells not exposed to transfection systems).

Quantitation of transfection efficiency was performed by flow cytometry on cells exposed to polyplexes prepared at polymer/DNA mass ratios 6,12 , and 24. Cells were seeded in 48- 
well plates with densities of approximately $1.6 \times 10^{4}$ cells per well $\left(1.6 \times 10^{4}\right.$ cells $\left./ \mathrm{cm}^{2}\right)$ and maintained in complete medium at $37{ }^{\circ} \mathrm{C}$ in a humidified atmosphere containing $5 \% \mathrm{CO}_{2}$ until $60 \%$ - 80\% confluency. Cells were incubated with medium $(200 \mu \mathrm{L}$, with/without serum) for $30 \mathrm{~min}$ and subsequently loaded with $200 \mu \mathrm{L}$ polyplex dispersions $(0.5 \mu \mathrm{g}$ DNA per well). After $1 \mathrm{~h}$ incubation, polyplexes were aspirated, fresh and warm complete culture medium $(200 \mu \mathrm{L})$ was added and cells were further cultured for $48 \mathrm{~h}$. The cells were detached by adding trypsin solution $(0.25 \%, 150 \mu \mathrm{L})$, and were centrifuged $(600 \mathrm{~g}, 5 \mathrm{~min}$, ambient). The resulting pellets were resuspended in HBSS buffer $(200 \mu \mathrm{L})$, and measured by the FACSCalibur (Becton-Dickinson, Breda, the Netherlands) at excitation of $488 \mathrm{~nm}$ and emission of $530 \mathrm{~nm}$. The data were processed by the FACS Cellquest Software.

\section{RESULTS AND DISCUSSION}

\section{Monomer and polymer synthesis and characterization}

The disulfide-containing monomer 2-hydroxyethyl disulfide diglycidyl ether (SS-DE) was synthesized by reacting 2-hydroxyethyl disulfide with epichlorohydrin in the presence of tetrabutylammonium bromide as a phase-transfer catalyst. As non-reducible comonomer, the commercially available 1,4-butanediol diglycidyl ether (CC-DE) was used. The amine monomer employed in this study is 4-amino-1-butanol (ABOL), as the presence of this monomeric unit has been demonstrated earlier to display favorable properties in transfection efficiency in a series of poly(amido amine)s. ${ }^{28}$

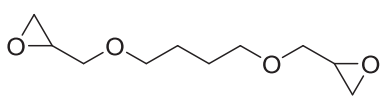

1,4-butanediol diglycidyl ether (CC-DE)

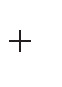

2-hydroxyethyl disulfide diglycidyl ether (SS-DE)

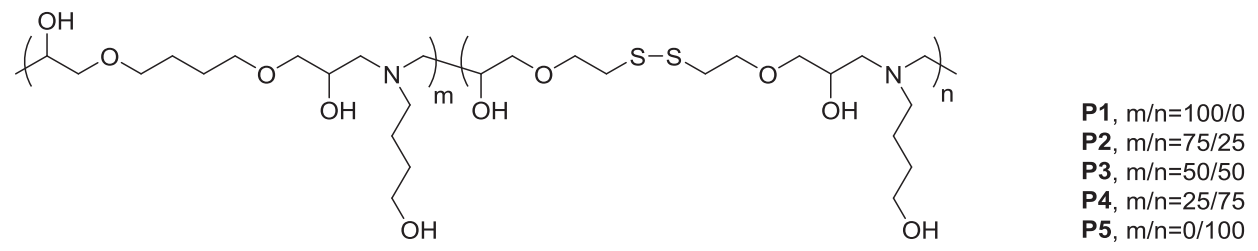

poly(amine ether)s (PAEs)

Scheme 2. Synthesis of poly(amino ether)s with varying disulfide content by epoxy-amine reaction. 
Poly(amino ether)s (PAEs) with different ratios of disulfide-moieties were obtained via ringopening polymerization of primary amines (ABOL) with a mixture of bifunctional epoxides SS-DE and CC-DE in disulfide molar ratios of $0 \%, 25 \%, 50 \%, 75 \%$, and 100\% (see Scheme 2). The polymerization was performed in ethanol at room temperature, resulting in the reaction mixture becoming increasingly viscous. PAEs were purified through dialysis and subsequently lyophilized to give amorphous sticky solids in $30-45 \%$ yields. The polymers were characterized by ${ }^{1} \mathrm{H}$ NMR spectroscopy and the signals at 2.95-2.98 ppm that can be attributed to the methylene groups adjacent to disulfide bonds confirmed the incorporation of disulfide moieties into the backbone of the PAEs. The percentage of disulfide incorporation matched the feed ratios closely, underlining the flexibility in controlling disulfide content in the polymerization. Gel permeation chromatography (GPC) was applied to determine molecular weights and polydispersity of the obtained PAEs (see Table 1). Molecular weights range from 6.0-10 kDa with polydispersities of 1.37-1.69. The relatively low polydispersities obtained in the resulting polymers could be attributed to the removal of small oligomer fractions in the dialysis step. Homopolymers P1 (10.3 kDa) and P5 (9.4 kDa) display higher molecular weight than the copolymers.

Table 1. Characteristics of poly(amino ether)s with various disulfide content

\begin{tabular}{lllllll}
\hline \multirow{2}{*}{ Poly(amino ether) } & $\begin{array}{l}\text { Disulfide } \\
\text { content }^{\mathrm{a}}(\%)\end{array}$ & $\begin{array}{l}\text { Yield } \\
(\%)\end{array}$ & $\begin{array}{l}\mathrm{M}_{\mathrm{n}}{ }^{\mathrm{b}} \\
(\mathrm{kDa})\end{array}$ & $\begin{array}{l}\mathrm{PDI}^{\mathrm{b}} \\
(-)\end{array}$ & $\begin{array}{l}\text { Degree } \\
\text { polymerization }^{\mathrm{b}} \\
(\%)\end{array}$ & $\begin{array}{l}\text { of } \\
\text { capacity }^{\mathrm{c}} \\
(\%)\end{array}$ \\
\hline P1 & 0 & 48.1 & 10.3 & 1.69 & 35.2 & 20.7 \\
P2 & 25 & 28.8 & 5.2 & 1.37 & 16.9 & 19.1 \\
P3 & 50 & 29.3 & 6.0 & 1.42 & 18.5 & 25.5 \\
P4 & 75 & 41.7 & 6.3 & 1.37 & 18.6 & 25.5 \\
P5 & 100 & 44.2 & 9.4 & 1.68 & 26.3 & 27.2 \\
\hline
\end{tabular}

${ }^{a}$ Determined by $1 \mathrm{H}$ NMR spectroscopy; ${ }^{\mathrm{b}}$ Determined by GPC; ${ }^{\mathrm{c}}$ Determined by titration and calculated in the $\mathrm{pH}$ range $5.1-7.4$.

PAEs are rich in tertiary amines in the main chain of the polymer and are anticipated to have increased buffer capacity as compared to branched PEI (PEI, $25 \mathrm{kDa}$ ). As shown in the titration curves of PAEs (Figure 1), all PAEs display part of plateau region (buffer region) in the $\mathrm{pH}$ range 5.1-7.4, which give these PAEs slightly higher buffer capacities than PEI 
(18\%). The buffer capacity of the PAEs is higher at increased disulfide content, which can be ascribed to the inductive effect of the disulfides which makes the amine slightly less basic. ${ }^{58}$ The somewhat higher buffer capacity of $\mathbf{P 1}$ compared to $\mathbf{P} 2$ could be related to a higher tendency for aggregation of the unprotonated (parts of the) polymer of this higher molecular weight polymer $(10.3 \mathrm{kDa})$ compared to $\mathbf{P 2}$ with molecular weight of $5.2 \mathrm{kDa}$. The amino groups in less polar (aggregated) environment will be less readily protonated (lower $\mathrm{pK}_{\mathrm{a}}$ ). Most disulfide-containing PAEs have higher buffer capacity (25\%-27\%) than that P1 (20.7\%) despite the former having lower molecular weight than latter. Thus, the disulfide serves as dominant factor in determining polymer's buffer capacities over its molecular weight, which is in line with our previous observations. ${ }^{28,58}$ The buffer capacities of the PAEs contribute to the capability of polyplexes to escape from the endosomal compartments, which is a necessary condition for eventual gene expression.

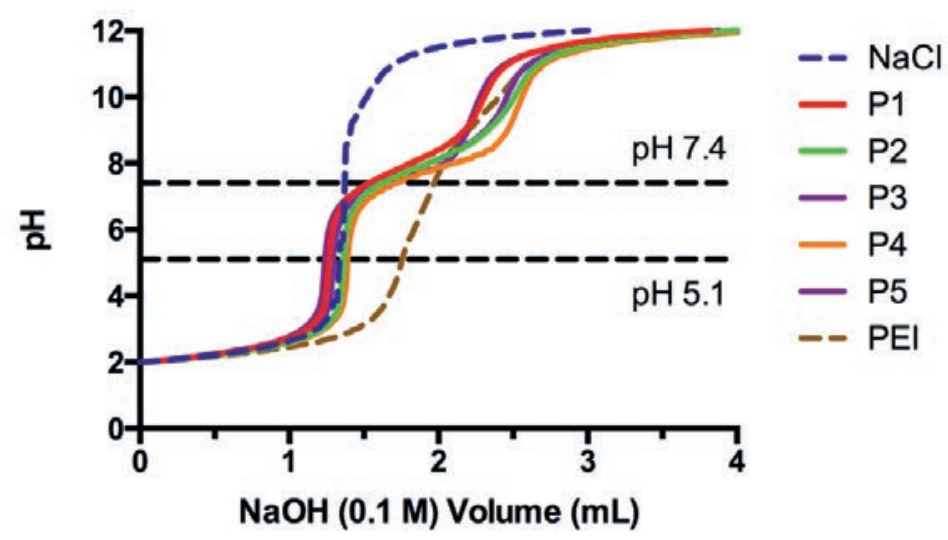

Figure 1. Titration curves of poly(amino ether)s with various disulfide content.

\section{Polyplexes formation and characterization}

The ability to condense DNA into polyplexes with appropriate physicochemical properties determines their fate as gene delivery vectors. ${ }^{9,46}$ Polyplexes were prepared by combining solutions of the respective PAEs into DNA solutions at different polymer/DNA mass ratios (i.e., 3, 6, 12, and 24). Polyplexes were characterized by dynamic light scattering (DLS) to determine their hydrodynamic sizes and their surface charges. As shown in Figure 2, all PAEs condense DNA into polyplexes with hydrodynamic sizes ranging from 60-100 nm and positive surface charges of from $+30 \mathrm{mV}$ up to $+44 \mathrm{mV}$. As polymer/DNA mass ratios increase, the polyplexes become more compact, which is in agreement with the additional 
charges available to interact with DNA. ${ }^{59,60}$ Interesting, at higher polymer/DNA mass ratios of 12 and 24, polyplexes made from homopolymers (P1 and P5) are bigger than those made from the copolymers $\mathbf{P 2}, \mathbf{P 3}$, and $\mathbf{P 4}$. In principle, the zeta-potentials of polyplexes increase with increasing polymer/DNA mass ratio, as is illustrated by polyplexes made of PAEs P1.

A

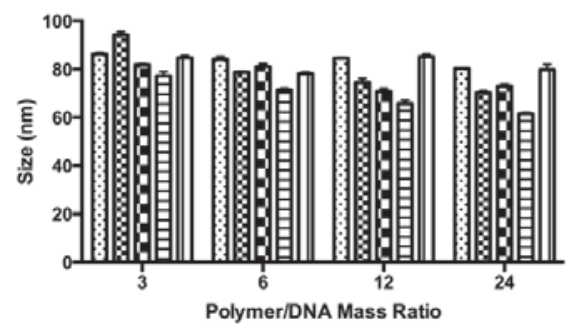

B

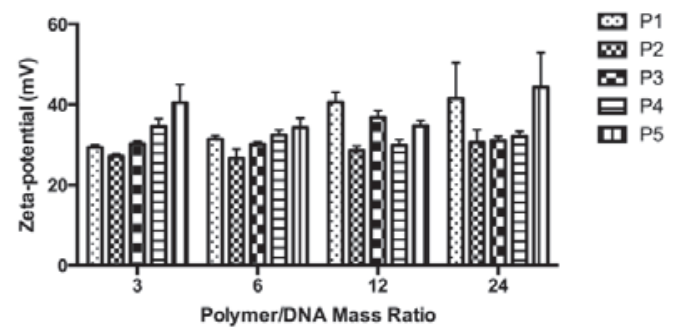

Figure 2. Characteristics of polyplexes prepared from poly(amino ether)s and plasmid pCMV-GFP under various polymer/DNA mass ratios. (A) Hydrodynamic sizes versus mass ratios; (B) Zeta-potentials versus mass ratios.

Agarose gel electrophoresis was performed to assess DNA complexation by the PAEs, as depicted in Figure 3. Whereas free plasmid DNA migrates in the gel under the influence of the electrical field, DNA trapped inside polyplexes remained stationary in the agarose gel. Subsequently, the response of polyplexes to a reducing environment was evaluated by incubating the polyplexes in $2.5 \mathrm{mM}$ DTT. DNA was fully released from polyplexes based on disulfide-containing PAEs, but remained trapped in the wells for polyplexes based on non-reducible PAE P1. A disulfide content of only $25 \mathrm{~mol} \%$ already results in sufficient polymer cleavage to release the DNA, though actual intracellular conditions may require higher incorporation ratios.
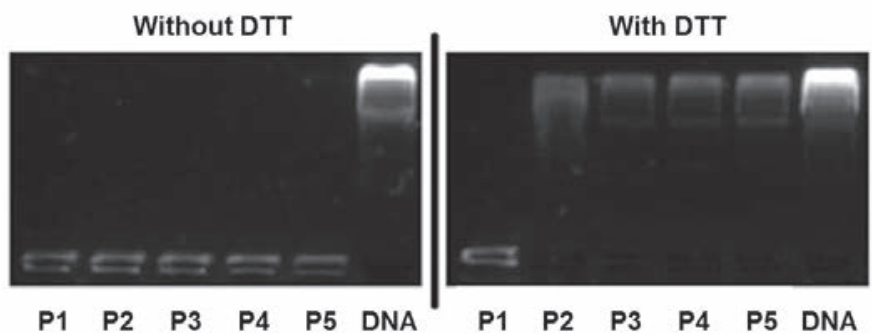

Figure 3. Agarose gel electrophoresis of untreated polyplexes (w/w=12) (left); and polyplexes treated with 2.5 mM DTT (right). 


\section{In vitro transfection efficiency and cytotoxicity}

The transfection efficiency of polyplexes was investigated on COS-7 cells by using the plasmid pCMV-GFP as a reporter gene, expressing fluorescent GFP, while cell viabilities were studied by MTT assays. COS-7 cells were exposed to polyplexes with polymer/DNA mass ratios of 6,12 , and 24, and transfection efficiency was assessed by fluorescence microscopy and flow cytometry. GFP expression increases with increasing polymer/DNA mass ratios, which is in line with earlier observations for other polymeric vectors, such as $\mathrm{PEI},{ }^{23}$ poly(amino ester), ${ }^{26,61}$ and poly(amido amine)s, ${ }^{28}$ owing to enhanced cellular uptake of polyplexes with smaller size and cell membrane destabilization from excess of cationic species. ${ }^{17,62}$ At polymer/DNA mass ratios of 24 , less than $5 \%$ transfection is observed when polymers with disulfide contents of $0 \%, 25 \%$, and $50 \%$ were employed, while substantial transfection occurs when the disulfide content in the polymers increases to $75 \%$ and $100 \%$ (Figure 4 and Figure S). In these cases the transfection efficiency was $25 \%$ and $85 \%$, respectively.

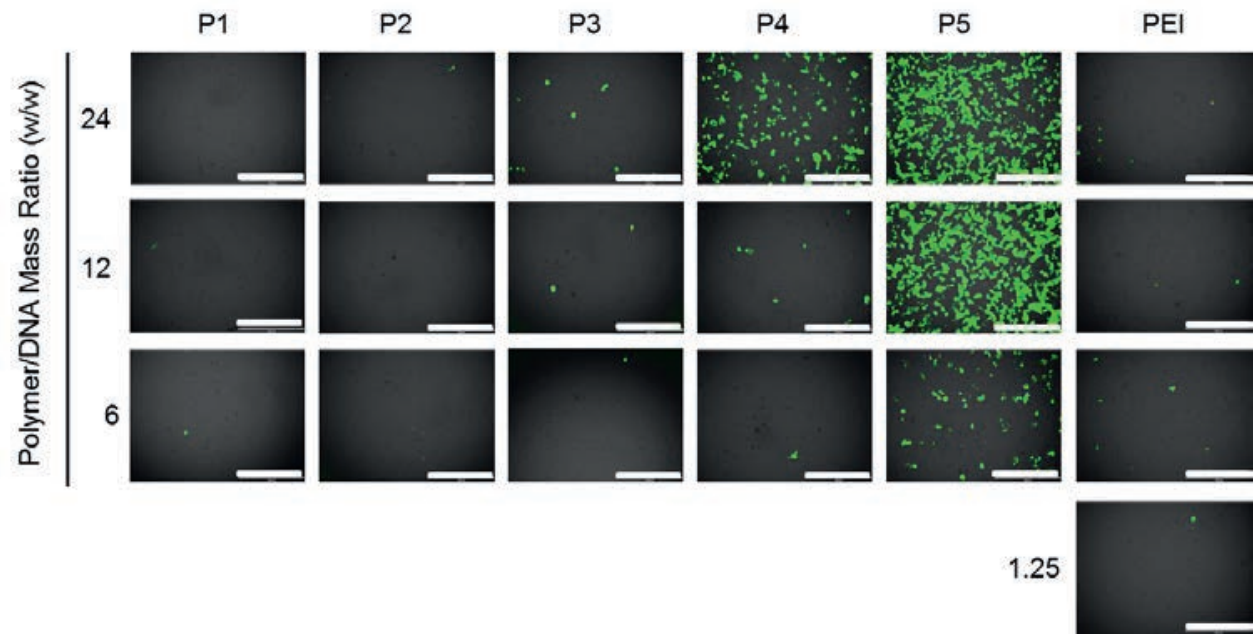

Figure 4. Overlaid fluorescence images of COS-7 cells transfected with pCMV-GFP through PAEs and PEI under serum-free conditions. $4 \mathrm{X}$ magnification, bars $=1000 \mu \mathrm{m}$. (the numbers aligned vertically mean polymer/DNA mass ratios).

Serum protein is known to destabilize polyplexes and consequently hamper transfection by polymeric vectors. ${ }^{63,64}$ The influence of serum on the transfection of COS-7 cells was investigated and fluorescence images are presented in Figure 5. When transfections are carried out in the presence of $10 \%$ serum, still appreciable transfection activity is observed, 
though reduced as compared to serum-free conditions. These transfection activities demonstrate the PAEs maintain their transfection abilities. In comparison, PEI displays a substantial loss of transfection capability in the presence of serum, underling the serumtolerance of PAEs. This serum-tolerance is attributed to the abundant hydroxyl groups resulting from oxirane ring-opening that play similar anti-fouling effect as poly(ethylene glycol). ${ }^{45,65}$

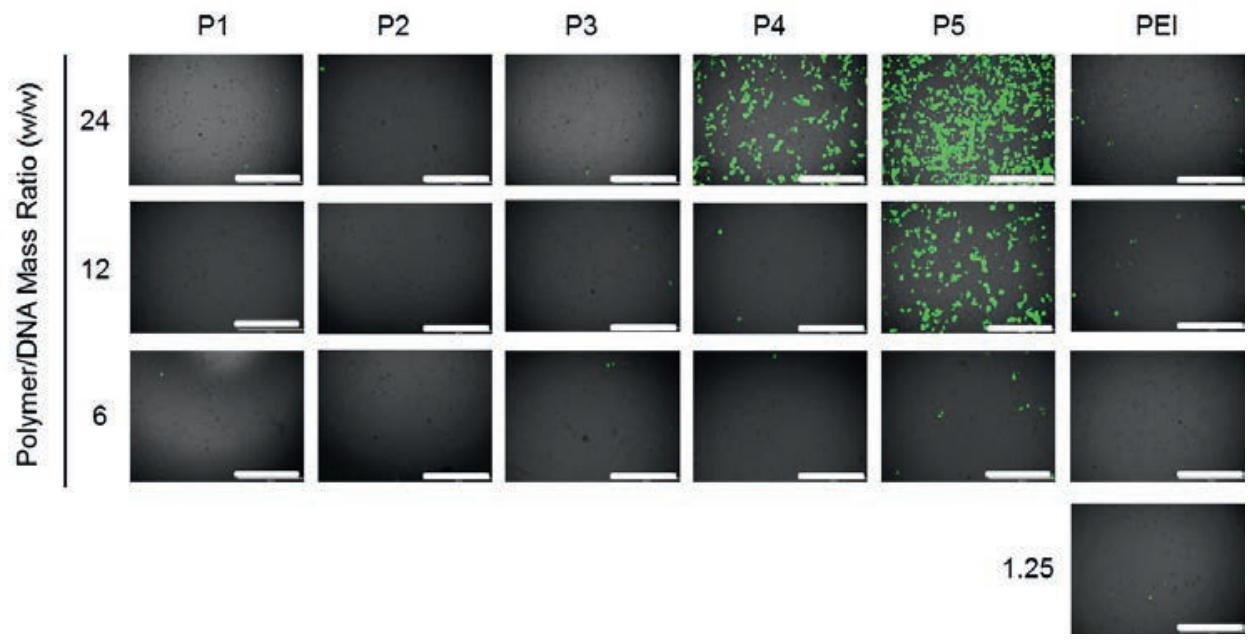

Figure 5. Overlaid fluorescence images of COS-7 cells transfected with pCMV-GFP through PAEs and PEI under serum-present conditions (10\% FBS). 4X magnification, bars=1000 $\mu \mathrm{m}$. (the numbers aligned vertically mean polymer/DNA mass ratios)

The cell viability of cells treated with PAEs-based polyplexes was studied through MTT assays. As shown in Figure 6, COS-7 cells remain excellent viabilities for all polymer/DNA mass ratios $(24,12$, and 6$)$ employed in the absence or presence of serum. Although here cell viability is also high for the polymer P1, lacking the disulfide moieties, it is well accepted that disulfide increased biocompatibility of cationic polymeric gene vectors. ${ }^{66}$ These results show that PAEs with disulfide have excellent biocompatibility, which makes these polymers promising materials in gene delivery and tissue engineering. 
$0 \%$ FBS

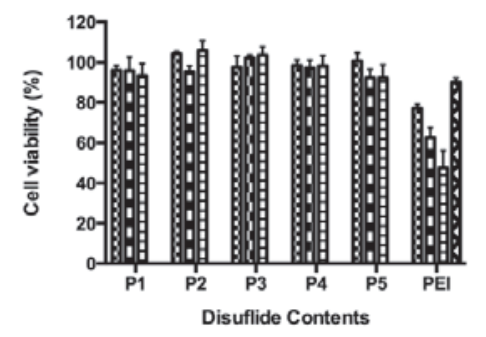

$10 \%$ FBS

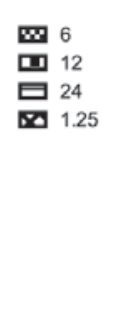

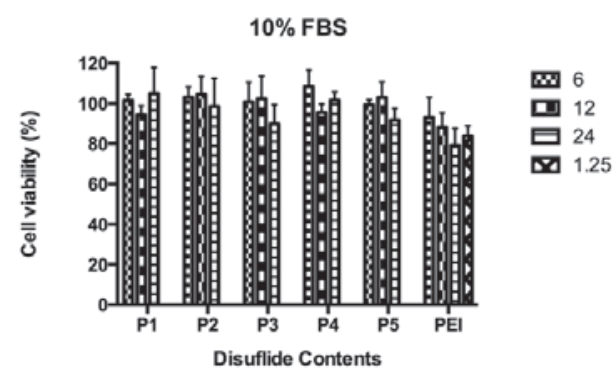

Figure 6. Cell viabilities of COS-7 cells treated with polyplexes at different polymer/DNA mass ratios under serum-free conditions (left); and 10\% serum (right). PEI-based polyplex at mass ratio of 1.25 is incorporated as a reference.

\section{CONCLUSIONS}

Linear poly(amino ether)s with varying disulfide content were readily obtained by epoxyamine polyaddition reaction between the primary amine 4-amino-1-butanol and mixtures of 1,4-butanediol diglycidyl ether and disulfide-containing diglycidyl ether. The resulting PAEs have high buffer capacities and bear excellent DNA condensation abilities, forming nanosized and positively-charged polyplexes. The polyplexes made from PAEs with high content of disulfide (over 50\%) are able to induce high transfection activity on COS-7 cells. Moreover, the presence of serum only has marginal effect on the transfection of PAEs-based polyplexes. Polyplexes formed from disulfide-containing PAEs show much higher transfection efficiency, lower cytotoxicity, and better serum tolerance than those of PEI, implying their promising potential as efficient and safe non-viral gene vectors.

\section{ACKNOWLEDGMENT}

The work is generously supported by NanoNextNL, a micro and nanotechnology consortium of the Government of the Netherlands and 130 partners. G.S. thanks Dr. Karin Roelofs for her training in cell culture and FACS measurements. 


\section{SUPPORTING INFORMATION}

$0 \%$ FBS

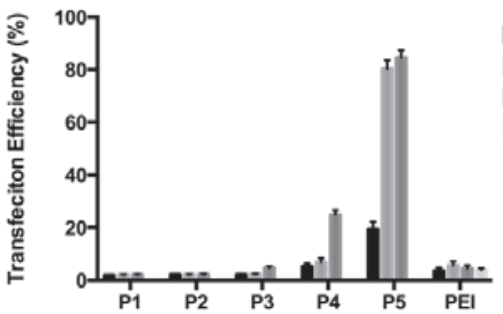

$10 \%$ FBS

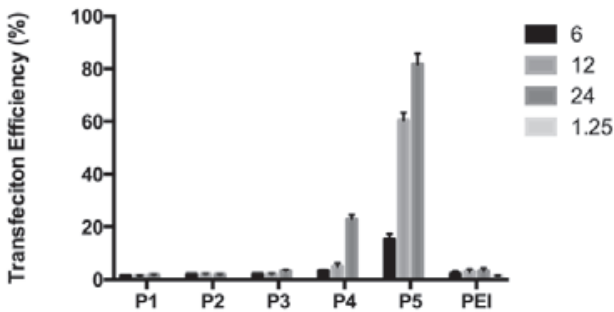

Figure S. Transfection efficiency of COS-7 cells by polyplexes at polymer/DNA mass ratios 6, 12, and 24 from poly(amino ether)s with various disulfide content and PEI under different serum conditions (Left: 0\% FBS; Right: $10 \%$ FBS) as determined by flow cytometry (polyplexes prepared at polymer/DNA mass ratio 1.25 are used as control). 


\section{REFERENCES}

(1) Ginn, S. L.; Alexander, I. E.; Edelstein, M. L.; Abedi, M. R.; Wixon, J. Gene therapy clinical trials worldwide to 2012 - an update. J. Gene Med. 2013, 15, 65-77.

(2) Kay, M. A. State-of-the-art gene-based therapies: the road ahead. Nat. Rev. Genet. 2011, 12, 316-328.

(3) Mingozzi, F.; High, K. A. Therapeutic in vivo gene transfer for genetic disease using AAV: progress and challenges. Nat. Rev. Genet. 2011, 12, 341-355.

(4) Giacca, M.; Zacchigna, S. Virus-mediated gene delivery for human gene therapy. $J$. Controlled Release 2012, 161, 377-388.

(5) Kataoka, K.; Harashima, H. Gene delivery systems: viral vs. non-viral vectors. Adv. Drug Deliv. Rev. 2001, 52, 151-151.

(6) Mintzer, M. A.; Simanek, E. E. Nonviral Vectors for Gene Delivery. Chem. Rev. 2009, 109, 259-302.

(7) Seow, Y.; Wood, M. J. Biological Gene Delivery Vehicles: Beyond Viral Vectors. Mol. Ther. 2009, 17, 767-777.

(8) Davis, M. E. Non-viral gene delivery systems. Curr. Opin. Biotech. 2002, 13, 128131.

(9) Jones, C. H.; Chen, C. K.; Ravikrishnan, A.; Rane, S.; Pfeifer, B. A. Overcoming Nonviral Gene Delivery Barriers: Perspective and Future. Mol. Pharmaceutics 2013, 10, 4082-4098.

(10) De Smedt, S. C.; Demeester, J.; Hennink, W. E. Cationic polymer based gene delivery systems. Pharm. Res. 2000, 17, 113-126.

(11) Pack, D. W.; Hoffman, A. S.; Pun, S.; Stayton, P. S. Design and development of polymers for gene delivery. Nat. Rev. Drug Discov. 2005, 4, 581-593.

(12) Jeong, J. H.; Kim, S. W.; Park, T. G. Molecular design of functional polymers for gene therapy. Prog. Polym. Sci. 2007, 32, 1239-1274.

(13) Liu, Z.; Zhang, Z.; Zhou, C.; Jiao, Y. Hydrophobic modifications of cationic polymers for gene delivery. Prog. Polym. Sci. 2010, 35, 1144-1162.

(14) Chu, D. S. H.; Schellinger, J. G.; Shi, J. L.; Convertine, A. J.; Stayton, P. S.; Pun, S. H. Application of Living Free Radical Polymerization for Nucleic Acid Delivery. Acc. Chem. Res. 2012, 45, 1089-1099.

(15) Mastrobattista, E.; Hennink, W. E. Polymers for Gene Delivery Charged for Success. Nat. Mater. 2012, 11, 10-12. 
(16) Ahmed, M.; Narain, R. Progress of RAFT based polymers in gene delivery. Prog. Polym. Sci. 2013, 38, 767-790.

(17) Yue, Y. N.; Wu, C. Progress and perspectives in developing polymeric vectors for in vitro gene delivery. Biomater. Sci. 2013, 1, 152-170.

(18) Draghici, B.; Ilies, M. A. Synthetic Nucleic Acid Delivery Systems: Present and Perspectives. J. Med. Chem. 2015, 58, 4091-4130.

(19) Laemmli, U. K. Characterization of DNA Condensates Induced by Poly(Ethylene Oxide) and Polylysine. Proc. Natl. Acad. Sci. U.S.A. 1975, 72, 4288-4292.

(20) Wu, G. Y.; Wu, C. H. Receptor-mediated in vitro gene transformation by a soluble DNA carrier system. J. Biol. Chem. 1987, 262, 4429-4432.

(21) Choi, Y. H.; Liu, F.; Kim, J. S.; Choi, Y. K.; Park, J. S.; Kim, S. W. Polyethylene glycol-grafted poly-L-lysine as polymeric gene carrier. J. Controlled Release 1998, $54,39-48$.

(22) Kim, S. W. Polylysine Copolymers for Gene Delivery. Cold Spring Harbor Protocols 2012, 2012, 433-438.

(23) Boussif, O.; Lezoualch, F.; Zanta, M. A.; Mergny, M. D.; Scherman, D.; Demeneix, B.; Behr, J. P. A Versatile Vector for Gene and Oligonucleotide Transfer into Cells in Culture and in-Vivo - Polyethylenimine. Proc. Natl. Acad. Sci. U.S.A. 1995, 92, 7297-7301.

(24) Cherng, J. Y.; van de Wetering, P.; Talsma, H.; Crommelin, D. J. A.; Hennink, W. E. Effect of size and serum proteins on transfection efficiency of poly $((2-$ dimethylamino)ethyl methacrylate)-plasmid nanoparticles. Pharm. Res. 1996, 13, 1038-1042.

(25) Agarwal, S.; Zhang, Y.; Maji, S.; Greiner, A. PDMAEMA based gene delivery materials. Mater. Today 2012, 15, 388-393.

(26) Lynn, D. M.; Langer, R. Degradable Poly( $\beta$-amino esters): Synthesis, Characterization, and Self-Assembly with Plasmid DNA. J. Am. Chem. Soc. 2000, 122, 10761-10768.

(27) Kozielski, K. L.; Tzeng, S. Y.; Green, J. J. A bioreducible linear poly(beta-amino ester) for siRNA delivery. Chem. Commun. 2013, 49, 5319-5321.

(28) Lin, C.; Zhong, Z.; Lok, M. C.; Jiang, X.; Hennink, W. E.; Feijen, J.; Engbersen, J. F. J. Novel Bioreducible Poly(amido amine)s for Highly Efficient Gene Delivery. Bioconjugate Chem. 2007, 18, 138-145. 
(29) Ferruti, P.; Marchisio, M. A.; Duncan, R. Poly(amido-amine)s: Biomedical applications. Macromol. Rapid Comm. 2002, 23, 332-355.

(30) Yu, Z. Q.; Yan, J. J.; You, Y. Z. Synthesis of bioreducible and acid labile poly(amido amine)s via Michael-addition reactions and their application in gene delivery. $J$. Controlled Release 2011, 152, E179-E181.

(31) Pamies, P.; Stoddart, A. Materials for drug delivery. Nat. Mater. 2013, 12, 957.

(32) Tong, R.; Tang, L.; Ma, L.; Tu, C.; Baumgartner, R.; Cheng, J. Smart chemistry in polymeric nanomedicine. Chem. Soc. Rev. 2014, 43, 6982-7012.

(33) Lynn, D. M.; Anderson, D. G.; Putnam, D.; Langer, R. Accelerated Discovery of Synthetic Transfection Vectors: Parallel Synthesis and Screening of a Degradable Polymer Library. J. Am. Chem. Soc. 2001, 123, 8155-8156.

(34) Anderson, D. G.; Lynn, D. M.; Langer, R. Semi-automated synthesis and screening of a large library of degradable cationic polymers for gene delivery. Angew. Chem. Int. Ed. 2003, 42, 3153-3158.

(35) Sunshine, J.; Green, J. J.; Mahon, K. P.; Yang, F.; Eltoukhy, A. A.; Nguyen, D. N.; Langer, R.; Anderson, D. G. Small-Molecule End-Groups of Linear Polymer Determine Cell-Type Gene-Delivery Efficacy. Adv. Mater. 2009, 21, 4947-4951.

(36) Ferruti, P. Poly(amidoamine)s: Past, present, and perspectives. J. Polym. Sci., Part A: Polym. Chem. 2013, 51, 2319-2353.

(37) Zhang, C.; Myers, J. N.; Chen, Z. Molecular Behavior at Buried Epoxy/Poly(ethylene terephthalate) Interface. Langmuir 2014, 30, 12541-12550.

(38) van der Ende, A. E.; Kravitz, E. J.; Harth, E. Approach to formation of multifunctional polyester particles in controlled nanoscopic dimensions. J. Am. Chem. Soc. 2008, 130, 8706-8713.

(39) Kang, T.; Amir, R. J.; Khan, A.; Ohshimizu, K.; Hunt, J. N.; Sivanandan, K.; Montanez, M. I.; Malkoch, M.; Ueda, M.; Hawker, C. J. Facile access to internally functionalized dendrimers through efficient and orthogonal click reactions. Chem. Commun. 2010, 46, 1556-1558.

(40) Amir, R. J.; Albertazzi, L.; Willis, J.; Khan, A.; Kang, T.; Hawker, C. J. Multifunctional Trackable Dendritic Scaffolds and Delivery Agents. Angew. Chem. Int. Ed. 2011, 50, 3425-3429.

(41) Saha, A.; De, S.; Stuparu, M. C.; Khan, A. Facile and General Preparation of Multifunctional Main-Chain Cationic Polymers through Application of Robust, 
Efficient, and Orthogonal Click Chemistries. J. Am. Chem. Soc. 2012, 134, 1729117297.

(42) Barua, S.; Joshi, A.; Banerjee, A.; Matthews, D.; Sharfstein, S. T.; Cramer, S. M.; Kane, R. S.; Rege, K. Parallel Synthesis and Screening of Polymers for Nonviral Gene Delivery. Mol. Pharmaceutics 2008, 6, 86-97.

(43) Vu, L.; Ramos, J.; Potta, T.; Rege, K. Generation of a Focused Poly(amino ether) Library: Polymer-mediated Transgene Delivery and Gold-Nanorod based Theranostic Systems. Theranostics 2012, 2, 1160-1173.

(44) Zhang, Q.-F.; Yu, Q.-Y.; Geng, Y.; Zhang, J.; Wu, W.-X.; Wang, G.; Gu, Z.; Yu, X.Q. Ring-Opening Polymerization for Hyperbranched Polycationic Gene Delivery Vectors with Excellent Serum Tolerance. ACS Appl. Mater. Interfaces 2014, 6, 15733-15742.

(45) Zhang, Q. F.; Yi, W. J.; Wang, B.; Zhang, J.; Ren, L. F.; Chen, Q. M.; Guo, L. D.; $\mathrm{Yu}, \mathrm{X}$. Q. Linear polycations by ring-opening polymerization as non-viral gene delivery vectors. Biomaterials 2013, 34, 5391-5401.

(46) Oupicky, D.; Li, J. Bioreducible polycations in nucleic acid delivery: past, present, and future trends. Macromol. Biosci. 2014, 14, 908-922.

(47) Alvarez-Lorenzo, C.; Concheiro, A. Smart drug delivery systems: from fundamentals to the clinic. Chem. Commun. 2014.

(48) Lee, M. H.; Yang, Z.; Lim, C. W.; Lee, Y. H.; Dongbang, S.; Kang, C.; Kim, J. S. Disulfide-Cleavage-Triggered Chemosensors and Their Biological Applications. Chem. Rev. 2013, 113, 5071-5109.

(49) Gongora-Benitez, M.; Tulla-Puche, J.; Albericio, F. Multifaceted Roles of Disulfide Bonds. Peptides as Therapeutics. Chem. Rev. 2014, 114, 901-926.

(50) Meng, F. H.; Hennink, W. E.; Zhong, Z. Reduction-sensitive polymers and bioconjugates for biomedical applications. Biomaterials 2009, 30, 2180-2198.

(51) Cheng, R.; Feng, F.; Meng, F. H.; Deng, C.; Feijen, J.; Zhong, Z. Y. Glutathioneresponsive nano-vehicles as a promising platform for targeted intracellular drug and gene delivery. J. Controlled Release 2011, 152, 2-12.

(52) Bauhuber, S.; Hozsa, C.; Breunig, M.; Gopferich, A. Delivery of Nucleic Acids via Disulfide-Based Carrier Systems. Adv. Mater. 2009, 21, 3286-3306.

(53) van der Aa, L. J.; Vader, P.; Storm, G.; Schiffelers, R. M.; Engbersen, J. F. J. Optimization of poly(amido amine)s as vectors for siRNA delivery. J. Controlled Release 2011, 150, 177-186. 
(54) van der Aa, L. J.; Vader, P.; Storm, G.; Schiffelers, R. M.; Engbersen, J. F. J. Intercalating quaternary nicotinamide-based poly(amido amine)s for gene delivery. J. Controlled Release 2014, 195, 11-20.

(55) Hujaya, S. D.; Marchioli, G.; Roelofs, K.; van Apeldoorn, A. A.; Moroni, L.; Karperien, M.; Paulusse, J. M.; Engbersen, J. F. Poly(amido amine)-based multilayered thin films on 2D and 3D supports for surface-mediated cell transfection. J. Controlled Release 2015, 205, 181-189.

(56) Steinhilber, D.; Sisson, A. L.; Mangoldt, D.; Welker, P.; Licha, K.; Haag, R. Synthesis, Reductive Cleavage, and Cellular Interaction Studies of Biodegradable, Polyglycerol Nanogels. Adv. Funct. Mater. 2010, 20, 4133-4138.

(57) Zhong, Z.; Feijen, J.; Lok, M. C.; Hennink, W. E.; Christensen, L. V.; Yockman, J. W.; Kim, Y.-H.; Kim, S. W. Low Molecular Weight Linear Polyethylenimine-bpoly(ethylene glycol)-b-polyethylenimine Triblock Copolymers: Synthesis, Characterization, and in Vitro Gene Transfer Properties. Biomacromolecules 2005, 6, 3440-3448.

(58) Piest, M.; Lin, C.; Mateos-Timoneda, M. A.; Lok, M. C.; Hennink, W. E.; Feijen, J.; Engbersen, J. F. J. Novel poly(amido amine)s with bioreducible disulfide linkages in their diamino-units: Structure effects and in vitro gene transfer properties. $J$. Controlled Release 2008, 130, 38-45.

(59) Meneksedag-Erol, D.; Tang, T.; Uludağ, H. Molecular modeling of polynucleotide complexes. Biomaterials 2014, 35, 7068-7076.

(60) Schaaf, P.; Schlenoff, J. B. Saloplastics: processing compact polyelectrolyte complexes. Adv. Mater. 2015, 27, 2420-2432.

(61) Green, J. J.; Langer, R.; Anderson, D. G. A Combinatorial Polymer Library Approach Yields Insight into Nonviral Gene Delivery. Acc. Chem. Res. 2008, 41, 749-759.

(62) Yue, Y.; Jin, F.; Deng, R.; Cai, J.; Chen, Y.; Lin, M. C. M.; Kung, H.-F.; Wu, C. Revisit complexation between DNA and polyethylenimine - Effect of uncomplexed chains free in the solution mixture on gene transfection. J. Controlled Release 2011, $155,67-76$.

(63) Audouy, S.; Molema, G.; De Leij, L.; Hoekstra, D. Serum as a modulator of lipoplexmediated gene transfection: Dependence of amphiphile, cell type and complex stability. J. Gene Med. 2000, 2, 465-476. 
(64) Morille, M.; Passirani, C.; Vonarbourg, A.; Clavreul, A.; Benoit, J.-P. Progress in developing cationic vectors for non-viral systemic gene therapy against cancer. Biomaterials 2008, 29, 3477-3496.

(65) Luo, X.; Huang, F.; Qin, S.; Wang, H.; Feng, J.; Zhang, X.; Zhuo, R. A strategy to improve serum-tolerant transfection activity of polycation vectors by surface hydroxylation. Biomaterials 2011, 32, 9925-9939.

(66) Lin, C.; Engbersen, J. F. J. The role of the disulfide group in disulfide-based polymeric gene carriers. Expert Opin. Drug Delivery 2009, 6, 421-439. 


\section{Chapter 7. Efficient Gene Vectors Based on Bioreducible Poly(amino ether)s with Various Side Groups}

Guoying Si, Alexander Moerer, Johan F.J. Engbersen* and Jos M.J. Paulusse*

Department of Controlled Drug Delivery, MIRA Institute for Biomedical Technology and Technical Medicine, Faculty of Science and Technology, University of Twente, P.O. Box 217, 7500 AE Enschede, The Netherlands

KEYWORDS

Cationic polymers; bioreducible polymers; serum tolerance; gene delivery; buffer capacity.

Part of this chapter has been in preparation for publication. 


\section{ABSTRACT}

Facile and efficient epoxy-amine reaction was adopted in the preparation of novel disulfidelinked cationic poly(amino ether)s (PAEs) with structural variations, and their potential as non-viral gene delivery vectors was evaluated. PAEs prepared from polyaddition of 2hydroxyethyl disulfide diglycidyl ether and various amines have molecular weights ranging from 4.5 to $9.0 \mathrm{kDa}$ and are characterized by high buffer capacities of up to $76 \%$. The PAEs display excellent DNA complexation, as evidenced by the formation of polyplexes with sizes below $100 \mathrm{~nm}$, while being able to release DNA through disulfide cleavage upon exposure to reducing conditions. Minimal cytotoxicity was observed on COS-7 cells for all polymer/DNA mass ratios. PAEs prepared from 4-amino-1-butanol (ABOL), 5-amino-1pentanol (APOL), and 3-morpholinopropylamine (MPA) display high transfection efficiency as observed by the expression of green fluorescent protein (GFP). The three polymers display up to 20 -fold higher transfection efficiency at condition $10 \%$ serum as compared to PEI.

\section{INTRODUCTION}

Gene therapy, termed as medication of genes as drugs for curing human diseases, has gained increasing attention over the past decades owing to its high therapeutic promise in many presently incurable diseases. ${ }^{1-4}$ However, due to the potential degradation of genes by endonucleases, direct medication of genes yields little to no effect in patients due to ineffective delivery, increasing the demand for effective gene vectors. ${ }^{5,6}$ Viral gene vectors are potent in transfection efficacy but come with problems in biosafety. ${ }^{7,8}$ Non-viral vectors can be designed to be biocompatible, but transfection efficacies are still low. ${ }^{9-11}$ Developing effective, biocompatible non-viral vector is therefore of great interest. ${ }^{3}$

Cationic polymers have been extensively investigated as promising non-viral gene vectors, since they are able to condense DNA, readily accessible and highly modular. ${ }^{12-14}$ Poly(1lysine) (PLL), ${ }^{15-19}$ poly(ethylene imine) (PEI), ${ }^{20-22}$ poly[2-(dimethylamino) ethyl methacrylate] (PDMAEMA), ${ }^{23-25}$ poly(amido amine) (PAMAM) dendrimers, ${ }^{26-28}$ have been used as cationic polymeric gene vectors. However, high cytotoxicity associated with these polymeric vectors severely impedes realizing their full potential in clinical application. To overcome this challenge, recent efforts have been focused on the development of biocompatible and biodegradable polymers including carbohydrate-based polymers $(\beta$ cyclodextrin, ${ }^{29,30}$ chitosan, ${ }^{31}$ dextran, ${ }^{32,33}$ poly(glycoamido amine),${ }^{34-36}$ etc.), phosphorus- 
containing polymers, ${ }^{37,38}$ poly(amino ester)s, ${ }^{39-43}$ poly(4-hydroxy-L-proline ester) ${ }^{44,45}$ and poly[ $\alpha$-(4-aminobutyl)-L-glycolic acid] (PAGA). ${ }^{46}$ Among these systems, disulfidecontaining poly(amino ester) $\mathrm{s}^{47,48}$ and poly(amido amine) $\mathrm{s}^{49-54}$ showed encouraging in vitro and in vivo transfection efficacies. Disulfide bonds have been found to promote condensation of DNA to form stable DNA/cationic polyplexes, help the polyplexes escape from endosomal barriers, and reduce the cytotoxicities of the gene vectors. ${ }^{55}$

The amine-epoxide addition reaction has been widely used in polymer chemistry. ${ }^{56-59}$ The reaction generates tertiary amines, which are readily protonated under physiological conditions to facilitate complexation of DNA. ${ }^{60,61}$ Rege and coworkers have prepared a library of cationic polymers through reaction of the epoxides of diglycidyl ethers with amines to explore these polymers for gene delivery. ${ }^{62,63}$ They found for polyplexes of pDNA with a number of these cationic polymers bear higher transfection efficacies and lower cytotoxicities than the common reference PEI. ${ }^{62,63}$ Yu's group has prepared linear ${ }^{64}$ and branched $^{65}$ cationic polymers by copolymerizing diglycidyl ethers with various amines (secondary and primary) through amine-epoxide reaction. The linear cationic polymers showed lower cytotoxicities and higher transfection efficiencies as compared to PEI. ${ }^{64,65}$

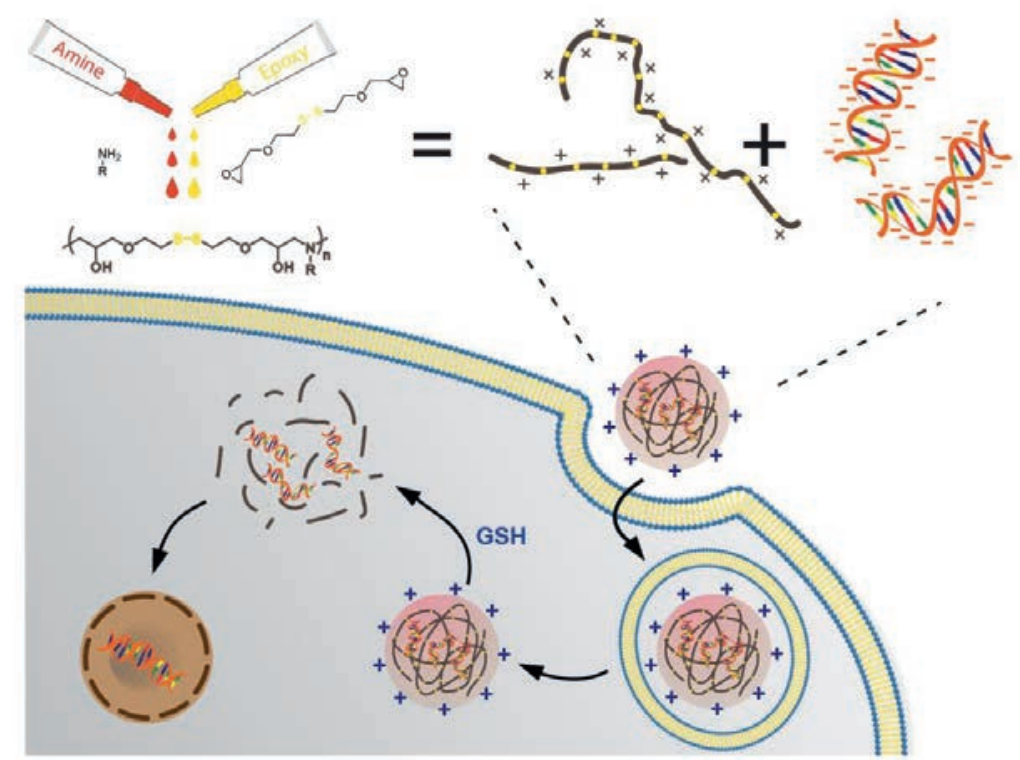

Scheme 1. Schematic illustration of disulfide-containing poly(amino ether)s as gene vectors. 
As demonstrated in Chapter 6, the disulfide content variation in PAEs was found to influence the performance of PAEs in gene delivery. PAEs with $100 \%$ disulfide content have the highest transfection efficiency, a strong DNA condensation ability, high buffer capacity, efficient transfection, low cytotoxicity, and marginal interference from serum protein. In this chapter, we describe the study of the effects of different side groups on transfection activity and cytotoxicity of PAEs containing $100 \%$ disulfide bonds in their main chain prepared by epoxide-amine reaction (see Scheme 1).

\section{EXPERIMENTAL PROCEDURES}

\section{Materials and Methods}

Epichlorohydrin ( $\geq 98 \%$, Sigma-Aldrich), 2-hydroxyethyl disulfide (technical grade, SigmaAldrich), tetrabutylammonium bromide (TBAB, $\geq 98 \%$, Sigma-Aldrich), sodium hydroxide (NaOH, pellet, Sigma-Aldrich), 1,4-butanediol diglycidyl ether ( $\geq 95 \%$, Sigma-Aldrich), and dithiothreitol (DTT, Sigma-Aldrich) were used directly as received without further purification. All monomer amines, 2-amino-1-ethanol (AEOL, Sigma-Aldrich), 3-amino propanol (APrOL, Sigma-Aldrich), 4-amino-1-butanol (ABOL, Sigma-Aldrich), 5-amino1-pentanol (APOL, Sigma-Aldrich), 6-amino-1-hexanol (AHXL, Sigma-Aldrich), 3pyrrolidinopropylamine (PPA, Sigma-Aldrich), 3-methoxypropylamine (MOPA, SigmaAldrich), 3-morpholinopropylamine (MPA, Sigma-Aldrich), and N-Boc-1,4-butanediamine (DAB-Boc, Sigma-Aldrich) were directly used without any further purification. All solvents used were of analytical grade. Water used in these experiments was purified with a Milli-Q Gradient System (Millipore, Bedford, MA). Plasmid DNA, plasmid pCMV-GFP was purchased from Plasmid Factory (Bielefeld, Germany). Branched polyethylenimine (PEI, $\mathrm{M}_{\mathrm{w}} 25 \mathrm{kDa}$ ) was purchased from Sigma-Aldrich.

${ }^{1} \mathrm{H}$ NMR and ${ }^{13} \mathrm{C}$ NMR spectra were recorded on a Bruker NMR spectrometer (400 MHz) in deuterated solvents. Molecular weights were determined by gel permeation chromatography (GPC, Waters Alliance 2695) relative to PEG standards, using a Mixed-M column (PL-aquagel-OH 8 micron, $300 \times 7.5 \mathrm{~mm}$ ) with $N, N$-dimethylformamide (DMF) containing $\mathrm{LiCl}(50 \mathrm{mM})$ as eluent.

Synthesis of 2-hydroxyethyl disulfide diglycidyl ether. The synthetic procedure was referred to previous chapter in this thesis. To a mixture of 2-hydroxyethyl disulfide $(0.772$ g, $5.00 \mathrm{mmol})$, sodium hydroxide $(0.800 \mathrm{~g}, 20.0 \mathrm{mmol})$ and tetrabutylammonium bromide (12.37 mg, $34.8 \mu \mathrm{mol})$, epichlorohydrin $(1.45 \mathrm{~mL}, 18.4 \mathrm{mmol})$ was added during $5 \mathrm{~min}$. The 
mixture was heated to $40{ }^{\circ} \mathrm{C}$ and stirred for $3 \mathrm{~h}$. The resulting mixture was subjected to column chromatography to obtain 2-hydroxyethyl disulfide diglycidyl ether $(0.700 \mathrm{~g}, 52.2$ $\%$ yield) as liquid. ${ }^{1} \mathrm{H} \mathrm{NMR}\left(\mathrm{CDCl}_{3}, 400 \mathrm{MHz}\right): \delta 2.62(\mathrm{~m}, 2 \mathrm{H}$, epoxide ring $2 \mathrm{x}$ OCHHCHO), 2.80 ( $\mathrm{m}, 2 \mathrm{H}$, epoxide ring 2 x OCHHCHO), $2.90\left(\mathrm{t}, 4 \mathrm{H}, 2 \times \mathrm{OCHHCH}_{2} \mathrm{~S}\right)$, $3.16(\mathrm{~m}, 2 \mathrm{H}$, epoxide ring 2 x OCHНCHO), 3.40 (m, 2H, 2 x CHCHHO), 3.78 (m, 6H, 2 x $\left.\mathrm{CHCHHO}+2 \times \mathrm{OCH}_{2} \mathrm{CH}_{2} \mathrm{~S}\right) .{ }^{13} \mathrm{C} \mathrm{NMR}\left(\mathrm{CDCl}_{3}, 400 \mathrm{MHz}\right): \delta 38.51,44.22,50.77,69.62$, 71.70 .

Synthesis of poly(amino ether)s. A representative procedure is the synthesis of pABOL: Into a glass vial, 2-hydroxyethyl disulfide diglycidyl ether $(0.533 \mathrm{~g}, 2.00 \mathrm{mmol})$, 4-amino1-butanol (ABOL, $0.180 \mathrm{~g}, 2.00 \mathrm{mmol})$, and ethanol $(1.00 \mathrm{~mL}$ ) was successively charged. After 3 days stirring at ambient temperature, the resultant viscous mixture was diluted with water to the final volume of $15.0 \mathrm{~mL}$, acidified with $4 \mathrm{M}$ aqueous $\mathrm{HCl}$ solution to $\mathrm{pH} 4$, and purified via dialysis (MWCO $1.0 \mathrm{kDa}$ ) against water overnight. The final polymer was obtained after lyophilization yielding a white solid $(0.420 \mathrm{~g}, 56.3 \%$ yield $) .{ }^{1} \mathrm{H}$ NMR $\left(\mathrm{D}_{2} \mathrm{O}\right.$, $400 \mathrm{MHz}): \quad 1.59-1.69\left(\mathrm{~m}, \quad 2 \mathrm{H}, \quad \mathrm{NCH}_{2} \mathrm{CH}_{2} \mathrm{CH}_{2} \mathrm{CH}_{2} \mathrm{OH}\right), \quad 1.74-1.83 \quad(\mathrm{~m}, \quad 2 \mathrm{H}$, $\left.\mathrm{NCH}_{2} \mathrm{CH}_{2} \mathrm{CH}_{2} \mathrm{CH}_{2} \mathrm{OH}\right), 2.95-2.98\left(\mathrm{t}, 4 \mathrm{H}, 2 \times \mathrm{SCH}_{2} \mathrm{CH}_{2}\right), 3.36-3.45(\mathrm{~m}, 6 \mathrm{H}, 2 \times$ $\left.\mathrm{NCH}_{2} \mathrm{CHOHCH}_{2}+\mathrm{NCH}_{2} \mathrm{CH}_{2} \mathrm{CH}_{2} \mathrm{CH}_{2} \mathrm{OH}\right), 3.60-3.68\left(\mathrm{~m}, 6 \mathrm{H}, 2 \times \mathrm{OCH}_{2} \mathrm{CHOHCH}_{2} \mathrm{~N}+\right.$ $\left.\mathrm{NCH}_{2} \mathrm{CH}_{2} \mathrm{CH}_{2} \mathrm{CH}_{2} \mathrm{OH}\right), 3.81-3.90\left(\mathrm{~m}, 4 \mathrm{H}, 2 \times \mathrm{SCH}_{2} \mathrm{CH}_{2}\right), 4.29-4.31$ (bs, $2 \mathrm{H}, 2 \times$ $\mathrm{OCH}_{2} \mathrm{CHOHCH}{ }_{2} \mathrm{~N}$ ). Other PAEs were prepared analogously by using different amines.

pAEOL (0.513 g, 70.5\% yield): ${ }^{1} \mathrm{H}$ NMR ( $\left.{ }_{2} \mathrm{O}, 400 \mathrm{MHz}\right): 2.96-2.99$ (t, $\left.4 \mathrm{H}, 2 \times \mathrm{SCH}_{2} \mathrm{CH}_{2}\right)$, 3.43-3.47 (m, 6H, $\left.2 \times \mathrm{NCH}_{2} \mathrm{CHOHCH}_{2}+\mathrm{NCH}_{2} \mathrm{CH}_{2} \mathrm{OH}\right), 3.61-3.70(\mathrm{~m}, 4 \mathrm{H}, 2 \times$ $\mathrm{OCH}_{2} \mathrm{CHOHCH}_{2} \mathrm{~N}$ ), 3.81-3.91 (m, 4H, $\left.2 \times \mathrm{SCH}_{2} \mathrm{CH}_{2}\right), 3.95$ (m, 2H, $\left.\mathrm{NCH}_{2} \mathrm{CH}_{2} \mathrm{OH}\right), 4.24-$ 4.27 (bs, $\left.2 \mathrm{H}, 2 \times \mathrm{OCH}_{2} \mathrm{CHOHCH}_{2} \mathrm{~N}\right)$.

pAPrOL $\left(0.402 \mathrm{~g}, 53.2 \%\right.$ yield): ${ }^{1} \mathrm{H}$ NMR $\left(\mathrm{D}_{2} \mathrm{O}, 400 \mathrm{MHz}\right): 1.92-2.09(\mathrm{~m}, 2 \mathrm{H}$, $\left.\mathrm{NCH}_{2} \mathrm{CH}_{2} \mathrm{CH}_{2} \mathrm{OH}\right), \quad 2.96-2.99$ (t, $\left.4 \mathrm{H}, 2 \times \mathrm{SCH}_{2} \mathrm{CH}_{2}\right), 3.39-3.48(\mathrm{~m}, 6 \mathrm{H}, 2 \times$ $\left.\mathrm{NCH}_{2} \mathrm{CHOHCH}_{2}+\mathrm{NCH}_{2} \mathrm{CH}_{2} \mathrm{CH}_{2} \mathrm{OH}\right), 3.60-3.69\left(\mathrm{~m}, 4 \mathrm{H}, 2 \times \mathrm{OCH}_{2} \mathrm{CHOHCH}_{2} \mathrm{~N}\right), 3.71-$ 3.79 (m, $2 \mathrm{H}, \mathrm{NCH}_{2} \mathrm{CH}_{2} \mathrm{CH}_{2} \mathrm{OH}$ ), 3.80-3.91 (m, 4H, $2 \times \mathrm{SCH}_{2} \mathrm{CH}_{2}$ ), 4.29-4.31 (bs, $2 \mathrm{H}, 2 \times$ $\left.\mathrm{OCH}_{2} \mathrm{CHOHCH} \mathrm{H}_{2} \mathrm{~N}\right)$.

pAPOL $(0.530 \mathrm{~g}, \quad 65.2 \%$ yield $):{ }^{1} \mathrm{H}$ NMR ( $\left.\mathrm{D}_{2} \mathrm{O}, 400 \mathrm{MHz}\right): 1.40-1.47 \quad(\mathrm{~m}, 2 \mathrm{H}$, $\mathrm{NCH}_{2} \mathrm{CH}_{2} \mathrm{CH}_{2} \mathrm{CH}_{2} \mathrm{CH}_{2} \mathrm{OH}$ ), 1.58-1.65 (m, 2H, $\mathrm{NCH}_{2} \mathrm{CH}_{2} \mathrm{CH}_{2} \mathrm{CH}_{2} \mathrm{OH}$ ), 1.79-1.81 (m, 2H, $\mathrm{NCH}_{2} \mathrm{CH}_{2} \mathrm{CH}_{2} \mathrm{CH}_{2} \mathrm{CH}_{2} \mathrm{OH}$ ), 2.96-2.99 (t, 4H, $\left.2 \times \mathrm{SCH}_{2} \mathrm{CH}_{2}\right), 3.34-3.47(\mathrm{~m}, 6 \mathrm{H}, 2 \times$ 
$\left.\mathrm{NCH}_{2} \mathrm{CHOHCH}_{2}+\mathrm{NCH}_{2} \mathrm{CH}_{2} \mathrm{CH}_{2} \mathrm{CH}_{2} \mathrm{CH}_{2} \mathrm{OH}\right), 3.61-3.68\left(\mathrm{~m}, 6 \mathrm{H}, 2 \times \mathrm{OCH}_{2} \mathrm{CHOHCH}_{2} \mathrm{~N}\right.$ $+\mathrm{NCH}_{2} \mathrm{CH}_{2} \mathrm{CH}_{2} \mathrm{CH}_{2} \mathrm{CH}_{2} \mathrm{OH}$ ), 3.81-3.91 (m, 4H, $\left.2 \times \mathrm{SCH}_{2} \mathrm{CH}_{2}\right), 4.23-4.30$ (bs, $2 \mathrm{H}, 2 \times$ $\left.\mathrm{OCH}_{2} \mathrm{CHOHCH}{ }_{2} \mathrm{~N}\right)$.

pAHXL $(0.326 \mathrm{~g}, 38.8 \%$ yield $):{ }^{1} \mathrm{H}$ NMR ( $\left.\mathrm{D}_{2} \mathrm{O}, 400 \mathrm{MHz}\right): 1.41-1.44 \quad(\mathrm{~m}, 4 \mathrm{H}$, $\mathrm{NCH}_{2} \mathrm{CH}_{2} \mathrm{CH}_{2} \mathrm{CH}_{2} \mathrm{CH}_{2} \mathrm{CH}_{2} \mathrm{OH}$ ), $1.55-1.58$ (m, $\left.2 \mathrm{H}, \mathrm{NCH}_{2} \mathrm{CH}_{2} \mathrm{CH}_{2} \mathrm{CH}_{2} \mathrm{CH}_{2} \mathrm{CH}_{2} \mathrm{OH}\right), 1.77$ (m, $2 \mathrm{H}, \mathrm{NCH}_{2} \mathrm{CH}_{2} \mathrm{CH}_{2} \mathrm{CH}_{2} \mathrm{CH}_{2} \mathrm{CH}_{2} \mathrm{OH}$ ), 2.96-2.99 (t, 4H, $2 \times \mathrm{SCH}_{2} \mathrm{CH}_{2}$ ), 3.33-3.42 (m, $\left.6 \mathrm{H}, 2 \times \mathrm{NCH}_{2} \mathrm{CHOHCH}_{2}+\mathrm{NCH}_{2} \mathrm{CH}_{2} \mathrm{CH}_{2} \mathrm{CH}_{2} \mathrm{CH}_{2} \mathrm{CH}_{2} \mathrm{OH}\right), 3.59-3.63(\mathrm{~m}, 6 \mathrm{H}, 2 \times$ $\mathrm{OCH}_{2} \mathrm{CHOHCH}{ }_{2} \mathrm{~N}+\mathrm{NCH}_{2} \mathrm{CH}_{2} \mathrm{CH}_{2} \mathrm{CH}_{2} \mathrm{CH}_{2} \mathrm{CH}_{2} \mathrm{OH}$ ), 3.81-3.89 (m, 4H, $2 \times \mathrm{SCH}_{2} \mathrm{CH}_{2}$ ), 4.22-4.25 (bs, $2 \mathrm{H}, 2 \times \mathrm{OCH}_{2} \mathrm{CHOHCH}_{2} \mathrm{~N}$ ).

pMPA $\left(0.775 \mathrm{~g}, 93.2 \%\right.$ yield): ${ }^{1} \mathrm{H}$ NMR $\left(\mathrm{D}_{2} \mathrm{O}, 400 \mathrm{MHz}\right): 2.23\left(\mathrm{~s}, 2 \mathrm{H}, \mathrm{NCH}_{2} \mathrm{CH}_{2} \mathrm{CH}_{2} \mathrm{~N}\right)$, 2.96-2.99 (t, 4H, $\left.\left.2 \times \mathrm{SCH}_{2} \mathrm{CH}_{2}\right), 3.22-3.44\left(\mathrm{~m}, 12 \mathrm{H}, 2 \times \mathrm{CH}_{2} \mathrm{~N}_{(\mathbf{C}} \mathrm{CH}_{2}\right)_{2}\right), 3.59-3.66(\mathrm{~m}, 4 \mathrm{H}$, $\left.2 \times \mathrm{OCH}_{2} \mathrm{CHOHCH}_{2} \mathrm{~N}\right), 3.82-3.90\left(\mathrm{~m}, 4 \mathrm{H}, 2 \times \mathrm{SCH}_{2} \mathrm{CH}_{2}\right), 3.98\left(\mathrm{~m}, 4 \mathrm{H}, \mathrm{CH}_{2} \mathrm{OCH}_{2}-\right.$ morpholine ring), 4.23-4.28 (bs, $\left.2 \mathrm{H}, 2 \times \mathrm{OCH}_{2} \mathrm{CHOHCH}_{2} \mathrm{~N}\right)$.

pPPA $(0.122 \mathrm{~g}, \quad 14.2 \%$ yield $):{ }^{1} \mathrm{H}$ NMR $\left(\mathrm{D}_{2} \mathrm{O}, 400 \mathrm{MHz}\right): 1.59-1.69 \quad(\mathrm{~m}, 2 \mathrm{H}$, $\mathrm{NCH}_{2} \mathrm{CH}_{2} \mathrm{CH}_{2} \mathrm{CH}_{2} \mathrm{OH}$ ), 1.74-1.83 (m, 2H, $\left.\mathrm{NCH}_{2} \mathrm{CH}_{2} \mathrm{CH}_{2} \mathrm{CH}_{2} \mathrm{OH}\right), 2.95-2.98$ (t, 4H, $2 \times$ $\left.\mathrm{SCH}_{2} \mathrm{CH}_{2}\right), 3.36-3.45\left(\mathrm{~m}, 6 \mathrm{H}, 2 \times \mathrm{NCH}_{2} \mathrm{CHOHCH}_{2}+\mathrm{NCH}_{2} \mathrm{CH}_{2} \mathrm{CH}_{2} \mathrm{CH}_{2} \mathrm{OH}\right), 3.60-3.68$ (m, $6 \mathrm{H}, 2 \times \mathrm{OCH}_{2} \mathrm{CHOHCH}_{2} \mathrm{~N}+\mathrm{NCH}_{2} \mathrm{CH}_{2} \mathrm{CH}_{2} \mathrm{CH}_{2} \mathrm{OH}$ ), 3.81-3.90 (m, 4H, $2 \times \mathrm{SCH}_{2} \mathrm{CH}_{2}$ ), 4.29-4.31 (bs, $2 \mathrm{H}, 2 \times \mathrm{OCH}_{2} \mathrm{CHOHCH}_{2} \mathrm{~N}$ ).

pMOPA $(0.382 \mathrm{~g}, 48.7 \%$ yield $):{ }^{1} \mathrm{H}$ NMR ( $\left.\mathrm{D}_{2} \mathrm{O}, 400 \mathrm{MHz}\right): 1.98-2.16$ (m, 2H, $\left.\mathrm{NCH}_{2} \mathrm{CH}_{2} \mathrm{CH}_{2} \mathrm{OCH}_{3}\right), 2.95-2.98\left(\mathrm{t}, 4 \mathrm{H}, 2 \times \mathrm{SCH}_{2} \mathrm{CH}_{2}\right), 3.30-3.43(\mathrm{~m}, 9 \mathrm{H}, 2 \times$ $\left.\mathrm{NCH}_{2} \mathrm{CHOHCH}_{2}+\mathrm{NCH}_{2} \mathrm{CH}_{2} \mathrm{CH}_{2} \mathrm{OCH}_{3}\right), 3.58-3.65\left(\mathrm{~m}, 6 \mathrm{H}, 2 \times \mathrm{OCH}_{2} \mathrm{CHOHCH}_{2} \mathrm{~N}+\right.$ $\left.\mathrm{NCH}_{2} \mathrm{CH}_{2} \mathrm{CH}_{2} \mathrm{OCH}_{3}\right), 3.81-3.89\left(\mathrm{~m}, 4 \mathrm{H}, 2 \times \mathrm{SCH}_{2} \mathrm{CH}_{2}\right), 4.25-4.29(\mathrm{bs}, 2 \mathrm{H}, 2 \times$ $\left.\mathrm{OCH}_{2} \mathrm{CHOHCH}_{2} \mathrm{~N}\right)$.

PDAB was prepared according to the procedure described above, followed by deprotection of the Boc-group under $\mathrm{HCl}$ gas purging. pDAB-Boc (150 mg, $0.325 \mathrm{mmol}$ Boc groups) was dissolved in methanol $(50.0 \mathrm{~mL})$ and $\mathrm{HCl}$ gas was passed through the solution during $30 \mathrm{~min}$. After concentration under reduced pressure, the remaining solution was diluted with water $(15.0 \mathrm{~mL})$, basified to $\mathrm{pH} 4$ with $\mathrm{NaOH}$ solution $(1.0 \mathrm{M})$, purified by dialysis (MWCO $1 \mathrm{kDa})$, and finally lyophilized to obtain the $\mathbf{p D A B}$ polymer as an amorphous solid $(0.070$ mg, 70.5\% yield): ${ }^{1} \mathrm{H}$ NMR ( $\left.\mathrm{D}_{2} \mathrm{O}, 400 \mathrm{MHz}\right): 1.74-1.80\left(\mathrm{~m}, 2 \mathrm{H}, \mathrm{NCH}_{2} \mathrm{CH}_{2} \mathrm{CH}_{2} \mathrm{CH}_{2} \mathrm{NH}_{2}\right.$ ), 1.86-1.88 (m, 2H, $\mathrm{NCH}_{2} \mathrm{CH}_{2} \mathrm{CH}_{2} \mathrm{CH}_{2} \mathrm{NH}_{2}$ ), 2.96-2.99 (t, 4H, $2 \times \mathrm{SCH}_{2} \mathrm{CH}_{2}$ ), 3.05-3.09 (t, 
$\left.2 \mathrm{H}, \quad \mathrm{NCH}_{2} \mathrm{CH}_{2} \mathrm{CH}_{2} \mathrm{CH}_{2} \mathrm{NH}_{2}\right), \quad 3.38-3.45\left(\mathrm{~m}, \quad 6 \mathrm{H}, 2 \times \mathrm{NCH}_{2} \mathrm{CHOHCH}_{2}+\right.$ $\mathrm{NCH}_{2} \mathrm{CH}_{2} \mathrm{CH}_{2} \mathrm{CH}_{2} \mathrm{NH}_{2}$ ), 3.60-3.65 (m, 6H, $\left.2 \times \mathrm{OCH}_{2} \mathrm{CHOHCH}_{2} \mathrm{~N}\right), 3.82-3.91(\mathrm{~m}, 4 \mathrm{H}, 2 \times$ $\mathrm{SCH}_{2} \mathrm{CH}_{2}$ ), 4.26-4.28 (bs, $2 \mathrm{H}, 2 \times \mathrm{OCH}_{2} \mathrm{CHOHCH}_{2} \mathrm{~N}$ ).

\section{Polyplex preparation}

Polyplexes were prepared in water, and characterized with a Zetasizer Nano ZS (Malvern Instruments, Malvern) at $25{ }^{\circ} \mathrm{C}$ to determine their hydrodynamic sizes and surface charges. The results are presented as averages of triplicate measurements with standard deviations as error bars. PAE/DNA polyplexes at a mass ratio of 24 were prepared by adding polymer solutions $(450 \mu \mathrm{g} / \mathrm{mL}, 800 \mu \mathrm{L})$ into DNA solutions $(75 \mu \mathrm{g} / \mathrm{mL}, 200 \mu \mathrm{L})$, followed by $5 \mathrm{~s}$ vortexing and $30 \mathrm{~min}$ incubation at room temperature.

\section{Agarose gel retardation}

Polyplexes were made at different polymer/DNA mass ratio 24 according to the previous procedure. Next, water buffer (with and without DTT) was added into polyplex solutions to give the final DTT concentration of $2.5 \mathrm{mM}$. After 30 min ambient incubation, $6 \mathrm{X}$ loading buffer containing bromophenol (Ferments) was mixed with resultant dispersions. Aliquots $(10 \mu \mathrm{L})$ of the resultant dispersions were loaded on a $0.8 \% \mathrm{w} / \mathrm{v}$ agarose gel containing $1 \mathrm{X}$ SYBR ${ }^{\circledR}$ Safe DNA Gel Stain (Invitrogen ${ }^{\mathrm{TM}}$ ). Electrophoresis was performed at $90 \mathrm{~V}$ for 60 min in a TBE (Tris-borate-EDTA, 1X) running buffer. After development, the gel was photographed using a FluorChem M Imager (Proteinsimple, Westburg, Leusden, the Netherlands) under UV excitation.

\section{Buffer capacity titration}

The buffering capacity of the polymers was determined by acid-base titration. PAE polymer ( $5 \mathrm{mmol}$ of protonable amine groups) was dissolved in $\mathrm{NaCl}$ aqueous solution (150 mM, 10 $\mathrm{mL}$ ). The $\mathrm{pH}$ of the polymer solution was lowered to $\leq 2.0$ and the solution was titrated with $\mathrm{NaOH}$ solution $(0.1 \mathrm{M})$ using an automatic titrator (Metrohm $702 \mathrm{SM}$ Tirino). As a reference, $\mathrm{PEI}(25 \mathrm{kDa})$ and $\mathrm{NaCl}$ aqueous solution were titrated following the same method. The percentage of amine groups protonated from $\mathrm{pH} 5.1$ to 7.4 was defined as the buffer capacity that can be calculated from following equation: ${ }^{66}$

$$
\text { Buffer capacity }(\%)=\frac{\Delta \mathrm{V}_{\mathrm{NaOH}} \times 0.1 \mathrm{M}}{\mathrm{N} \mathrm{mol}} \times 100 \%
$$


wherein, $\Delta \mathrm{V}_{\mathrm{NaOH}}$ denotes $\mathrm{NaOH}$ volume required to bring the $\mathrm{pH}$ value of the polymer solution from 5.1 to 7.4 , and $\mathrm{N} \mathrm{mol}(5 \mathrm{mmol})$ denotes the total number of protonable amine groups in the PAE polymer.

\section{In Vitro Transfection and Cell Viability Assays}

Transfection experiments were performed on COS-7 cells (SV-40 transformed African green monkey kidney cells) using the plasmid pCMV-GFP as a reporter gene. Transfections and cell viabilities were conducted in parallel using polyplexes formed at polymer/plasmid DNA mass ratios of 6 and 12. Gene expression experiments and cell viability evaluations were carried out in separate 96-well plates. Cells were seeded in at a density of $10^{4}$ cells per well $\left(2.94 \times 10^{4}\right.$ cells $\left./ \mathrm{cm}^{2}\right)$ and maintained in complete medium at $37{ }^{\circ} \mathrm{C}$ in a humidified atmosphere containing 5\% $\mathrm{CO}_{2}$ until $60 \%-80 \%$ confluency. In a standard transfection experiment, cells were first incubated with medium $(100 \mu \mathrm{L}$, with/without serum) for $30 \mathrm{~min}$ and then loaded with $100 \mu \mathrm{L}$ polyplex dispersions (0.25 $\mu \mathrm{g}$ DNA per well). After $1 \mathrm{~h}$ incubation, polyplexes were removed, and fresh complete culture medium (100 $\mu \mathrm{L})$ was added and cells were cultured for an additional $48 \mathrm{~h}$. Transfection efficiency was determined qualitatively through fluorescence imaging via an EVOS digital inverted microscope (EMS, Wageningen, the Netherlands). A reference was prepared from PEI (25 K)/DNA at a polymer/DNA mass ratio of 1.25/1. MTT assays were conducted to determine the number of viable cells, with a value of $100 \%$ cell viability for untreated cells.

Quantitative determination of transfection efficiency was performed by flow cytometry. Cells were seeded in 48 -well plates with densities of $1.6 \times 10^{4}$ cells per well $\left(1.6 \times 10^{4}\right.$ cells $/ \mathrm{cm}^{2}$ ) and maintained in complete medium at $37{ }^{\circ} \mathrm{C}$ in a humidified atmosphere containing 5\% $\mathrm{CO}_{2}$ until $60 \%$ - 80\% confluency. Cells were first incubated with medium (200 $\mu \mathrm{L}$, with/without serum) for $30 \mathrm{~min}$ and then loaded with $200 \mu \mathrm{L}$ polyplex dispersions $(0.5 \mu \mathrm{g}$ DNA per well). After $1 \mathrm{~h}$ incubation, the polyplexes were aspirated, fresh and warm complete culture medium $(200 \mu \mathrm{L})$ was added and cells were cultured for an additional 48 h. The cells were fixated by adding trypsin solution $(0.25 \%, 150 \mu \mathrm{L})$, and centrifuged $(600$ g, $5 \mathrm{~min}$, ambient). Resulting pellets were re-suspended in HBSS buffer $(200 \mu \mathrm{L})$, and measured by the FACSCalibur (Becton-Dickinson, Breda, the Netherlands) at an excitation wavelength of $488 \mathrm{~nm}$ and an emission wavelength of $530 \mathrm{~nm}$. Data was processed with the FACS Cellquest Software. A PEI $(25 \mathrm{~K}) / \mathrm{DNA}$ formulation prepared at a polymer/DNA mass ratio of $1.25 / 1$ was used as a reference. MTT assays were conducted to characterize the 
number of viable cells with $100 \%$ cell viability for untreated cells (i.e., cells not exposed to transfection systems).

\section{RESULTS AND DISCUSSION}

\section{Polymer synthesis and characterization}

Disulfide containing poly(amino ether)s (PAEs) were synthesized by ring-opening polymerization of 2-hydroxyethyl disulfide diglycidyl ether (SS-DE) with various amines with different pendant groups as depicted in Scheme 2. During polymerization, the mixtures become viscous, although without occurrence of gelation, indicating the formation of polymers. As shown in Table 1, most polymers are obtained in yields over $40 \%$. The polymer structures were validated through NMR spectra, showing no residual epoxy rings in the polymers, which could be toxic in biological systems. The broad single peak located around $4.26 \mathrm{ppm}$ was assigned to the proton adjacent to the secondary alcohol that was derived from the ring-opening of epoxy group, which confirms the occurrence of the epoxy-amine reaction. Molecular weight and polydispersity index of the PAEs were determined by size exclusion chromatography (Table 1) and were found to be mainly from 4.5 to $9.0 \mathrm{kDa}$, with relatively narrow size distributions, which originates from the dialysis procedure before isolation of the polymers.
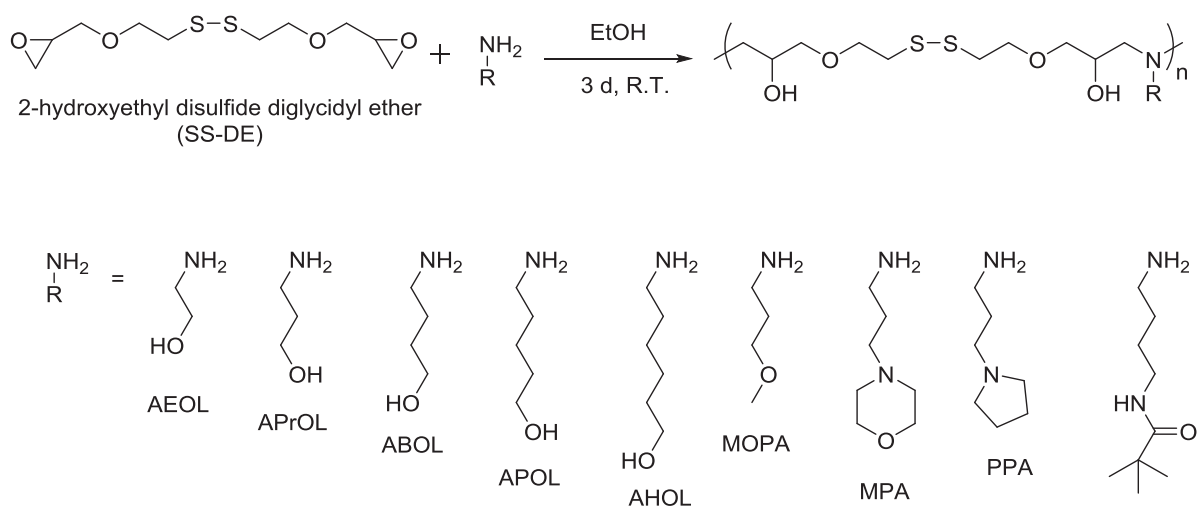

DAB-Boc

Scheme 2. Synthetic route of poly(amino ether)s by the epoxy-amine reaction of 2-hydroxyethyl disulfide diglycidyl ether (SS-DE) with various amines.

The primary amines with an additional tertiary amine in the chain (MPA and PPA) were employed to introduce additional cationic charge sites to increase the DNA binding capability in these polymers. From Table 1, the amine reactivity is reduced when tertiary 
amine present, leading to low molecular weight (ca. $5 \mathrm{kDa}$ ) compared to control groups prepared from amine without tertiary amine (7.1-9.6 kDa). The polymer pPPA has a molecular weight as low as $1.4 \mathrm{kDa}$, most likely due to the pyrrolidine group. These results indicate that the side groups have significant effect on the polymerization kinetics as revealed in poly(amino ester)s and poly(amino amine)s.

Table 1. Characteristics of bioreducible poly(amino ether)s prepared from different amines.

\begin{tabular}{|c|c|c|c|c|c|c|}
\hline Poly(amino ether)s & Yield $^{\mathrm{a}}(\%)$ & $\begin{array}{l}\mathrm{M}_{\mathrm{n}} \\
(\mathrm{kDa})\end{array}$ & $\mathrm{PDI}^{\mathrm{b}}$ & $\begin{array}{l}\text { Degree } \\
\text { polymerization } \\
\left(\mathrm{X}_{\mathrm{n}}\right)\end{array}$ & $\begin{aligned} \text { of } & \text { Buffer } \\
\text { b } & \text { Capacity } \\
& (\%)\end{aligned}$ & $\mathrm{c}$ \\
\hline pAEOL & 71 & 9.6 & 1.72 & 29.4 & 75.8 & \\
\hline pAPrOL & 53 & 5.2 & 1.48 & 15.1 & 33.8 & \\
\hline pABOL & 44 & 9.4 & 1.68 & 26.3 & 27.2 & \\
\hline pAPOL & 65 & 7.1 & 1.54 & 19.1 & 19.8 & \\
\hline pAHXL & 39 & 7.6 & 1.48 & 19.9 & 59.3 & \\
\hline pMOPA & 49 & 5.3 & 1.98 & 14.8 & 59.3 & \\
\hline pPPA & 14 & 1.4 & 1.71 & 3.5 & 47.3 & \\
\hline pMPA & 93 & 5.4 & 2.20 & 13.0 & 22.3 & \\
\hline pDAB-Boc & 66 & 5.6 & 1.93 & 12.7 & n.d. & \\
\hline pDAB & $50^{d}$ & $-{ }^{e}$ & $-{ }^{e}$ & 12.7 & 27.1 & \\
\hline
\end{tabular}

${ }^{a}$ Determined by obtained polymer and feed monomer masses; ${ }^{b}$ Determined by GPC (DMF as eluent); ${ }^{c}$ Determined by titration and calculated from the $\mathrm{pH}$ range between 5.1 and $7.4 ;{ }^{\mathrm{d}}$ Yield after polymerization and

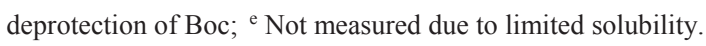

The polymer-DNA complexes normally follow the cellular pathways of endocytosis, and successively enter endosomal/lysosomal compartments where encapsulated DNA may degrade. It is assumed that complexes with high buffer capacity are able to escape the endosome through the so-called "proton sponge" effect. ${ }^{20,67}$ Buffer capacities of the PAEs were determined in the $\mathrm{pH}$ range 5.1-7.4 by titration of the polymers from acid solution with strong 0.1 M NaOH and listed in Table 1. The titration curves of PAEs bear relatively gentle slopes in this $\mathrm{pH}$ range (Figure 1), demonstrating their high buffer capacities of up to $76 \%$, as compared to branched $25 \mathrm{kDa}$ PEI (ca. 18\%). Remarkably, pAHXL has nearly 3-fold higher buffer capacity (59.3\%) than pAPOL (19.8\%) which differs only in a single 
additional methylene group (- $\left.\mathrm{CH}_{2}-\right)$ in the pendant group, and the two have similar degrees of polymerization.

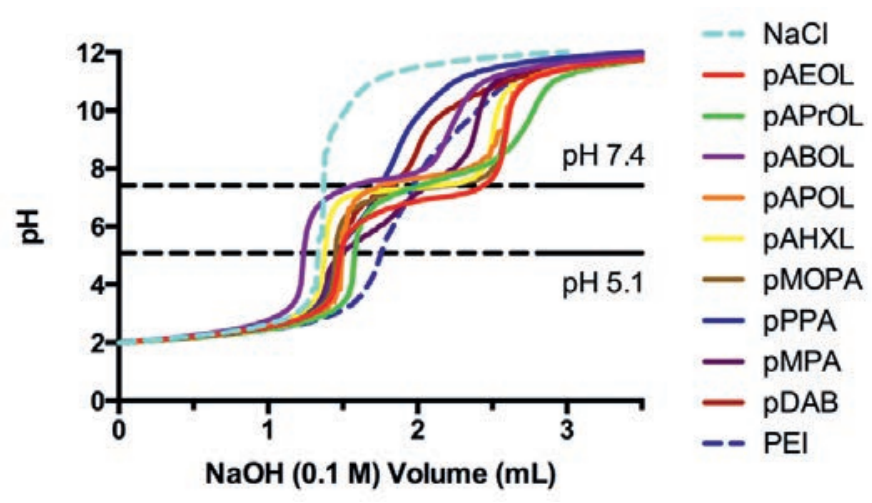

Figure 1. Titration curves of poly(amino ether)s. Titration curves of $\mathrm{NaCl}$ and b-PEI are added for comparison.

\section{DNA condensation and release}

The ability of bioreducible PAEs to condense DNA was evaluated by measuring size and surface charge density of polymer-DNA complexes (polyplexes) at various polymer/DNA mass ratios. The polymer/DNA mass ratios studied are 3, 6, 12, and 24. Physicochemical properties that favor polyplex transfection capability are generally small hydrodynamic size (below $200 \mathrm{~nm}$ ) and sufficient cationic surface charge density (approximately $+30 \mathrm{mV}$ ). The hydrodynamic diameters of the formed polyplexes are presented in Figure 2. All polyplexes display a hydrodynamic diameter below $100 \mathrm{~nm}$ and positive surface charge $(>+20 \mathrm{mV})$, confirming excellent DNA condensation of the PAEs. The extent of DNA condensation increases upon enhancing polymer/DNA mass ratio, owing to increase in available charge density, which is in line with the fact that the dominant driving forces of polyplex formation are electrostatic interactions. The smallest polyplex sizes were observed for pPPA, pMPA, and $\mathbf{p D A B}$, which all contain protonable side groups, and thus carry higher charge density as compared to other PAEs. It is reported that also hydrophobicity of pendant side groups plays an important role in the condensation ability of a polymer. ${ }^{68}$ However, this is not apparent in pAEOL, pAPrOL, PABOL, PAPOL, and PAHXL. These five polymers have increasing hydrophobicity, but form polyplexes of similar size and surface charge at equal polymer/DNA mass ratio. This might be due to the relatively high extent of protonation of the amines in water, which causes that electrostatic interactions dominate the complexation. 

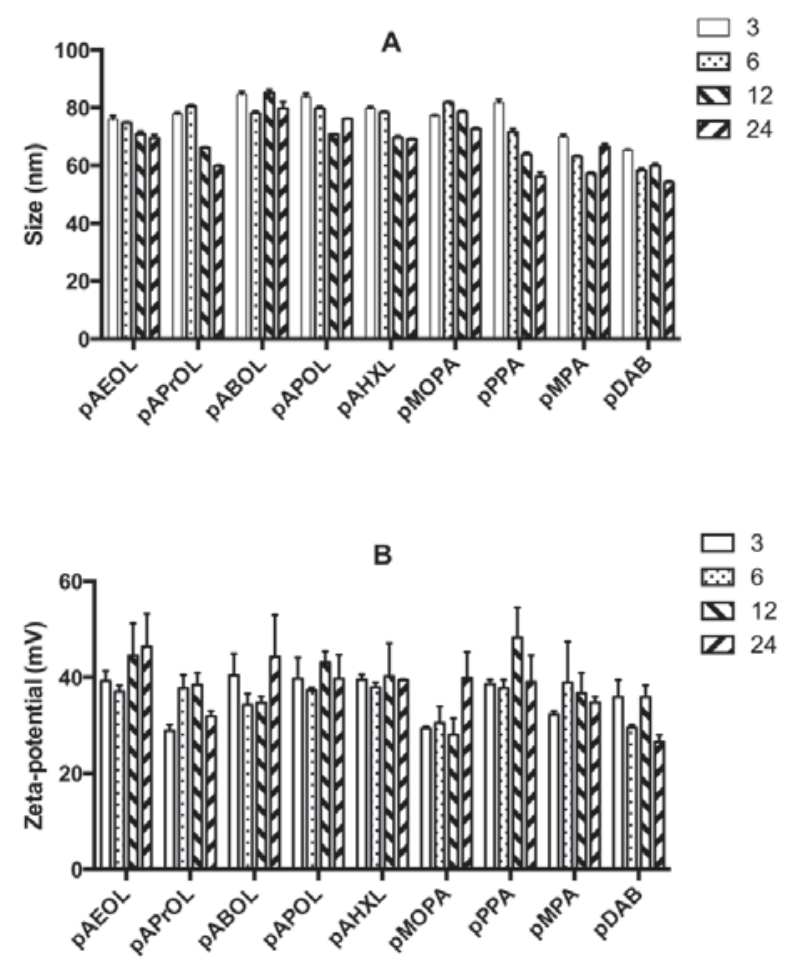

Figure 2. Characterization of polyplexes prepared by bioreducible PAEs at various polymer/DNA mass ratios through DLS measurement: A) hydrodynamic size, and B) surface charge of polyplexes.

Formation of stable polyplexes is an important aspect to achieve efficient gene delivery. However, inefficient DNA unpacking from polyplexes may also present a major barrier. Therefore, DNA should be released from vectors before successful transfection can occur. To determine both polyplex stability and capability for DNA unpacking from the polyplexes under reducing conditions, gel electrophoresis experiments were performed. It is envisioned that under the intracellular reducing conditions disulfide cleavage in polymers containing disulfide linkers in the main chain dissociates polyplexes and thus releases DNA. These conditions were mimicked by exposing polyplexes to the mild reducing agent DTT (2.5 $\mathrm{mM}$ ). Therefore, gel electrophoresis was carried out on the polyplexes in the absence and presence of DTT (See Figure 3). Negatively charged DNA was retarded by all PAEs at the highest polymer/DNA mass ratio 24, showing the effective encapsulation of DNA. However, after treatment with DTT, DNA migrates at a similar rate as naked DNA, indicating that polymer cleavage and polyplex disassembly releases DNA. DNA migration is observed from 
polyplexes with the disulfide-present PAEs, underlining that polymer degradation is important for DNA unpacking inside the reductive cytosol. Also, dynamic light scattering showed that disulfide-containing polyplexes instantly increase their nanoscale size to micrometers (data not shown).

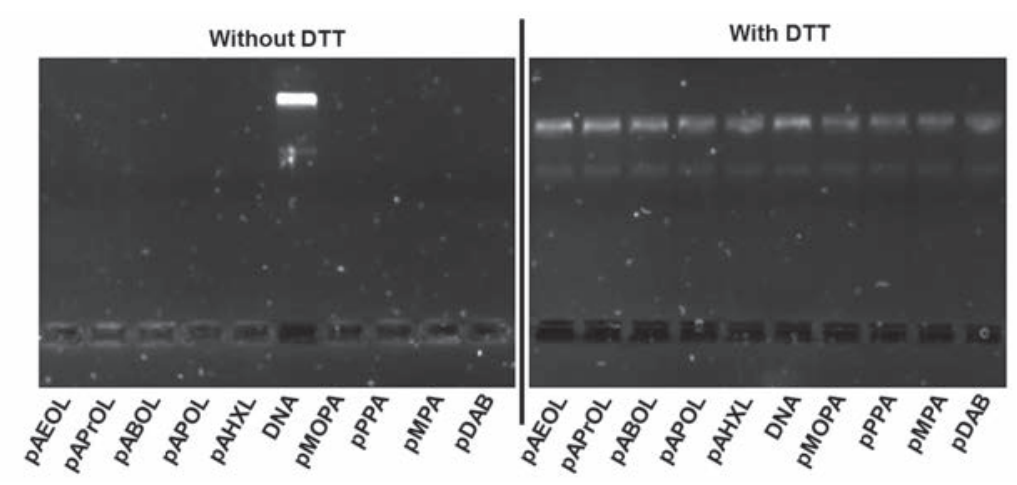

Figure 3. Agarose gel electrophoresis of polyplexes $(w / w=24)$ treated without DTT (left) and with DTT (right).

\section{In vitro transfection and cytotoxicity}

The cytotoxicity of the polyplexes was investigated on COS-7 cells by MTT assays. The optimal polymer/DNA mass ratio was set to 12 to keep polymer toxicity effect minimum as reported in Chapter 6. Cell viabilities of COS-7 cells exposed to polyplexes under serumfree and serum-present conditions (10\% FBS) are presented in Figure 4. Cells maintained excellent viabilities under serum-free and $10 \%$ serum conditions upon exposure to the PAEsbased polyplexes. The pDAB-based polyplexes form an exception, leading to markedly lower cell viabilities ( $56 \%$ and $79 \%$ at $0 \%$ and $10 \%$ FBS respectively). The observed cytotoxicity of $\mathbf{p D A B}$-based polyplexes can be attributed to the additional positive charges of the pendant primary amines, in line with previous observations for poly(amido amine)s and PEI. ${ }^{69}$ The high cell viability in cells treated with bioreducible PAEs (except pDAB) demonstrates these PAEs are essentially non-toxic. 


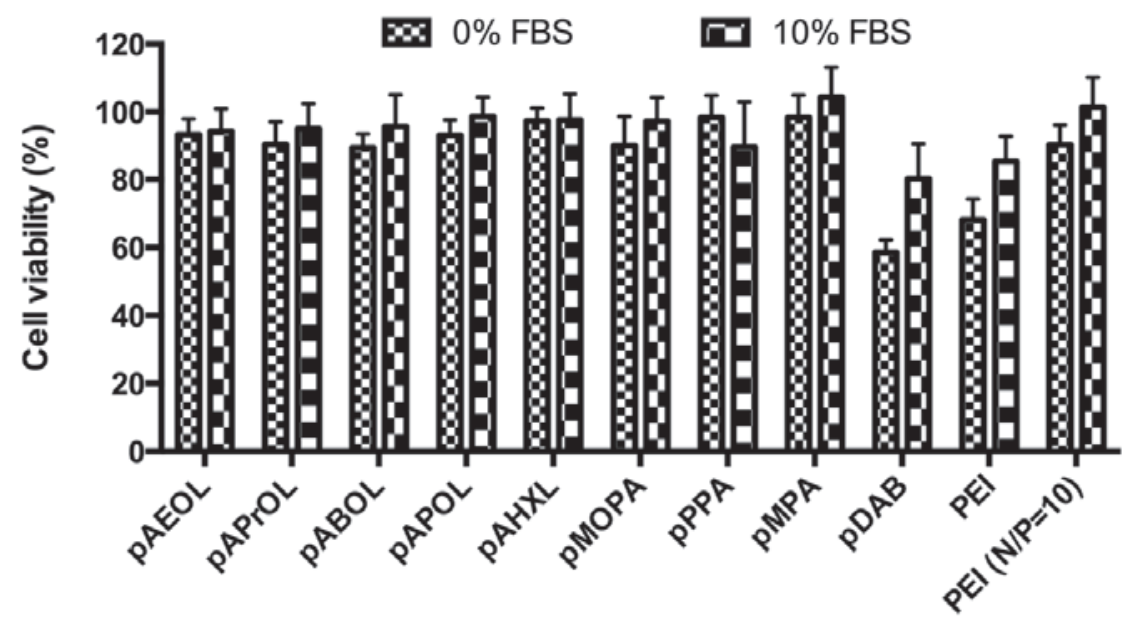

Figure 4. Cell viabilities of COS-7 treated with polyplexes at polymer/DNA mass ratio 12 via MTT assay under various serum conditions with PEI as references.

After evaluation of the biocompatibility of the reducible PAEs, their transfection performance was studied in vitro with the plasmid pCMV-GFP as a reporter gene leading to expression of GFP. The fluorescence images of COS-7 cells were employed to screen the PAE polymers using PEI as a reference (Figure 5). Based on the areas of green spots where the cells or cell clusters express GFP, the transfection efficiency is estimated in the order: pABOL > pMPA > pAPOL, while little or no transfection occurs in PAHXL, pAPrOL, PAEOL, pMOPA, pPPA, pDAB, and PEI. Moreover, considerable transfection activity is observed for polyplexes based on PABOL, PMPA, and PAPOL in the presence of serum $(10 \%)$. The results coincide with previous studies associated with polymer structural variation on transfection performance of cationic polymers. ${ }^{49}$ pABOL, pAPOL, and $\mathbf{p M P A}$ were further studied under various serum concentrations. 

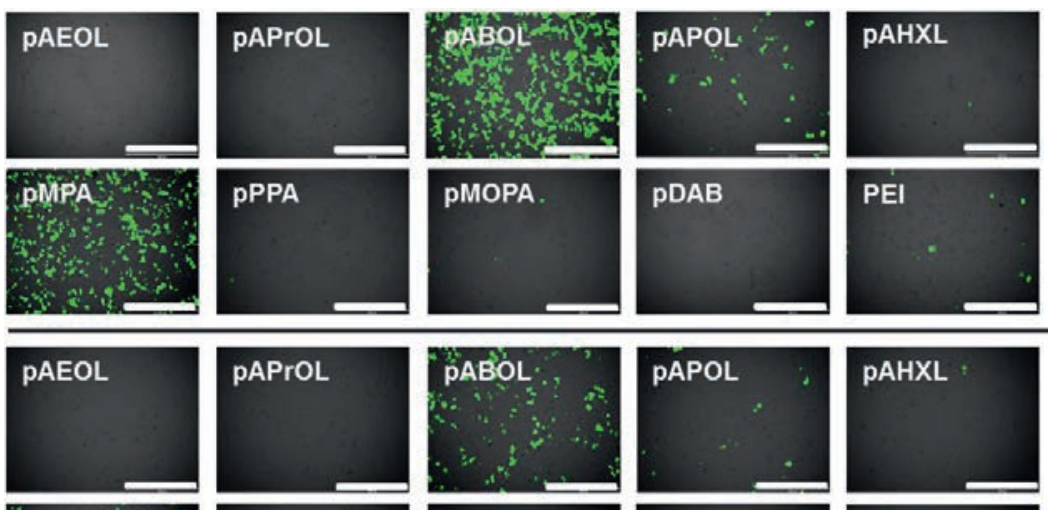

PEI 1.25/1
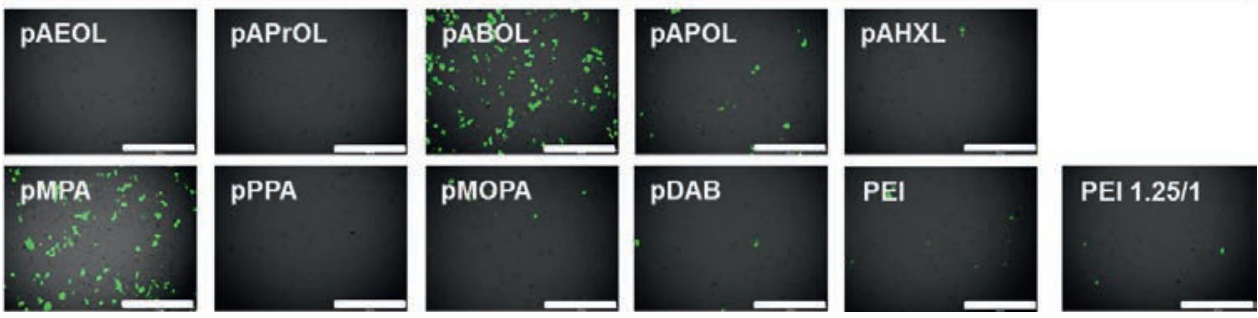

Figure 5. The inverted fluorescence images of COS-7 cells transfected with polyplexes from poly(amino ether)s and PEI at polymer/DNA mass ratio 12 under serum-free conditions (upper part) and serum conditions (lower part) with PEI $1.25 / 1$ as a reference. (Scale bars $=1000 \mu \mathrm{m}$ ).

FACS was carried out to quantitatively determine transfection efficiencies of the three polyplexes from $\mathbf{p A B O L}$, $\mathbf{\text { AAPOL}}$, and $\mathbf{\text { PMPA }}$ under three different serum conditions (Figure 6). Transfection efficiencies are presented as percentage of GFP-expressing cells of the total cell population. Under serum-free conditions, transfection efficiencies of polyplexes based on PABOL, PAPOL, and PMPA at polymer/DNA mass ratio 12 are respectively $85 \%, 63 \%$, and $20 \%$ respectively, as compared to polyplexes of PEI displaying only $5 \%$ transfection at this mass ratio. Generally, proteins in the serum lead to the aggregation of polyplexes, and thus significantly reduce transfection efficiency. However, in the presence of $10 \%$ serum, polyplexes based on PAEs gave transfection efficiencies which were only slightly reduced, with $80 \%$ for pABOL, $54 \%$ for pAPOL and $9 \%$ for pMPA, while PEIbased polyplexes did not display any significant transfection under its optimal conditions and only marginal transfection $(4.0 \%)$ at the higher polymer/DNA mass ratio of 12 . The reason for the potent transfection of PAEs under these $10 \%$ serum-conditions is probably the presence of abundant hydroxyl groups along the polymer chains which serve as a shielding layer to prevent interactions between serum proteins and the polyplexes. ${ }^{64,70}$ 

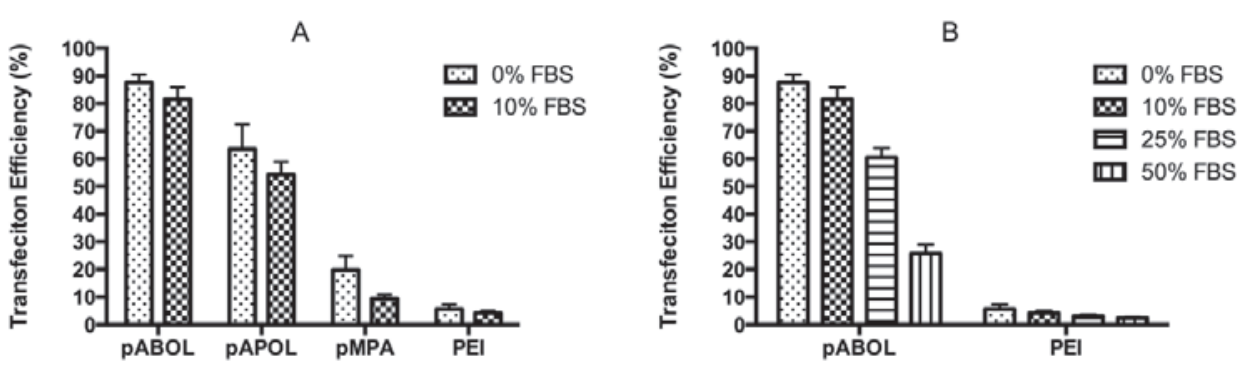

Figure 6. Transfection efficiency of polyplexes prepared of bioreducible PAEs through FACS at polymer/DNA mass ratio 12 with PEI ( $25 \mathrm{kDa}$ ) as reference: A) transfection efficiency mediated by $\mathbf{P A B O L}, \mathbf{p A P O L}$, and pMPA; B) transfection efficiency of PABOL at various FBS concentrations.

To further explore the effect of serum, the serum protein concentration was further elevated to mimic physiological serum conditions. Even under these conditions, transfection mediated by $\mathbf{p A B O L}$-based polyplexes remained relatively high at $60 \%$ and $30 \%$ at serum concentrations of $25 \%$ and $50 \%$ respectively (Figure $6 \mathrm{~B}$ ) This further demonstrates the notable potential of this polymer for in vivo application.

\section{CONCLUSIONS}

A unique and novel class of bioreducible poly(amino ether)s has been prepared by epoxyamine reaction between disulfide-containing diglycidyl ether with a variety of primary amines, enabling large structural variation of these polymers. The resulting PAEs have much higher buffer capacity than the reference polymer PEI. PAEs condense DNA into nanosized particles of 70-90 nm with positive surface charges above $+20 \mathrm{mV}$. Polyplexes of these disulfide-containing PAEs will release DNA upon exposure to reducing conditions. All PAEs show minimal- or non-toxicity to COS-7 cells, except the primary amine containing pDAB. From the PAEs that were evaluated for their transfection capabilities, pABOL, PAPOL, and PMPA display the most promising transfection efficiencies. The presence of serum was demonstrated to have only a marginal effect on transfection of polyplexes from these PAEs, while significantly reduced transfection efficiency is observed for PEI-based polyplexes. These results demonstrate that bioreducible PAEs are appealing candidates as efficient and safe gene vectors with vast translational potential for in vivo application. 


\section{ACKNOWLEDGMENT}

The work is generously supported by NanoNextNL, a micro and nanotechnology consortium of the Government of the Netherlands and 130 partners. The authors are gratefully indebted to Dr. Karin Roelofs for kind assistance in cell culturing and FACS measurements. 


\section{REFERENCES}

(1) Kataoka, K.; Harashima, H. Gene delivery systems: viral vs. non-viral vectors. $A d v$. Drug Deliv. Rev. 2001, 52, 151-151.

(2) Kay, M. A. State-of-the-art gene-based therapies: the road ahead. Nat. Rev. Genet. 2011, 12, 316-328.

(3) Yin, H.; Kanasty, R. L.; Eltoukhy, A. A.; Vegas, A. J.; Dorkin, J. R.; Anderson, D. G. Non-viral vectors for gene-based therapy. Nat. Rev. Genet. 2014, 15, 541-555.

(4) Mingozzi, F.; High, K. A. Therapeutic in vivo gene transfer for genetic disease using AAV: progress and challenges. Nat. Rev. Genet. 2011, 12, 341-355.

(5) Kawabata, K.; Takakura, Y.; Hashida, M. The Fate of Plasmid DNA after Intravenous-Injection in Mice - Involvement of Scavenger Receptors in Its HepaticUptake. Pharm. Res. 1995, 12, 825-830.

(6) Jones, C. H.; Chen, C. K.; Ravikrishnan, A.; Rane, S.; Pfeifer, B. A. Overcoming Nonviral Gene Delivery Barriers: Perspective and Future. Mol. Pharmaceutics 2013, 10, 4082-4098.

(7) Giacca, M.; Zacchigna, S. Virus-mediated gene delivery for human gene therapy. $J$. Controlled Release 2012, 161, 377-388.

(8) Daniel, R.; Smith, J. A. Integration site selection by retroviral vectors: Molecular mechanism and clinical consequences. Hum. Gene. Ther. 2008, 19, 557-568.

(9) Mintzer, M. A.; Simanek, E. E. Nonviral Vectors for Gene Delivery. Chem. Rev. 2009, 109, 259-302.

(10) Miyata, K.; Nishiyama, N.; Kataoka, K. Rational design of smart supramolecular assemblies for gene delivery: chemical challenges in the creation of artificial viruses. Chem. Soc. Rev. 2012, 41, 2562-2574.

(11) Davis, M. E. Non-viral gene delivery systems. Curr. Opin. Biotech. 2002, 13, 128 131.

(12) Pack, D. W.; Hoffman, A. S.; Pun, S.; Stayton, P. S. Design and development of polymers for gene delivery. Nat. Rev. Drug Discov. 2005, 4, 581-593.

(13) Mastrobattista, E.; Hennink, W. E. Polymers for Gene Delivery Charged for Success. Nat. Mater. 2012, 11, 10-12.

(14) De Smedt, S. C.; Demeester, J.; Hennink, W. E. Cationic polymer based gene delivery systems. Pharm. Res. 2000, 17, 113-126.

(15) Laemmli, U. K. Characterization of DNA Condensates Induced by Poly(Ethylene Oxide) and Polylysine. Proc. Natl. Acad. Sci. U.S.A. 1975, 72, 4288-4292. 
(16) Wu, G. Y.; Wu, C. H. Receptor-mediated in vitro gene transformation by a soluble DNA carrier system. J. Biol. Chem. 1987, 262, 4429-4432.

(17) Wu, G. Y.; Wu, C. H. Receptor-mediated gene delivery and expression in vivo. J. Biol. Chem. 1988, 263, 14621-14624.

(18) Choi, Y. H.; Liu, F.; Kim, J. S.; Choi, Y. K.; Park, J. S.; Kim, S. W. Polyethylene glycol-grafted poly-L-lysine as polymeric gene carrier. J. Controlled Release 1998, $54,39-48$.

(19) Kim, S. W. Polylysine Copolymers for Gene Delivery. Cold Spring Harbor Protocols 2012, 2012, 433-438.

(20) Boussif, O.; Lezoualch, F.; Zanta, M. A.; Mergny, M. D.; Scherman, D.; Demeneix, B.; Behr, J. P. A Versatile Vector for Gene and Oligonucleotide Transfer into Cells in Culture and in-Vivo - Polyethylenimine. Proc. Natl. Acad. Sci. U.S.A. 1995, 92, 7297-7301.

(21) Wightman, L.; Kircheis, R.; Rossler, V.; Carotta, S.; Ruzicka, R.; Kursa, M.; Wagner, E. Different behavior of branched and linear polyethylenimine for gene delivery in vitro and in vivo. J. Gene Med. 2001, 3, 362-372.

(22) Kircheis, R.; Wightman, L.; Wagner, E. Design and gene delivery activity of modified polyethylenimines. Adv. Drug Deliv. Rev. 2001, 53, 341-358.

(23) Cherng, J. Y.; van de Wetering, P.; Talsma, H.; Crommelin, D. J. A.; Hennink, W. E. Effect of size and serum proteins on transfection efficiency of poly ((2dimethylamino)ethyl methacrylate)-plasmid nanoparticles. Pharm. Res. 1996, 13, 1038-1042.

(24) Rungsardthong, U.; Deshpande, M.; Bailey, L.; Vamvakaki, M.; Armes, S. P.; Garnett, M. C.; Stolnik, S. Copolymers of amine methacrylate with poly(ethylene glycol) as vectors for gene therapy. J. Controlled Release 2001, 73, 359-380.

(25) Agarwal, S.; Zhang, Y.; Maji, S.; Greiner, A. PDMAEMA based gene delivery materials. Mater. Today 2012, 15, 388-393.

(26) Haensler, J.; Szoka, F. C., Jr. Polyamidoamine cascade polymers mediate efficient transfection of cells in culture. Bioconjugate Chem. 1993, 4, 372-379.

(27) KukowskaLatallo, J. F.; Bielinska, A. U.; Johnson, J.; Spindler, R.; Tomalia, D. A.; Baker, J. R. Efficient transfer of genetic material into mammalian cells using Starburst polyamidoamine dendrimers. Proc. Natl. Acad. Sci. U.S.A. 1996, 93, 48974902. 
(28) Dufès, C.; Uchegbu, I. F.; Schätzlein, A. G. Dendrimers in gene delivery. Adv. Drug Deliv. Rev. 2005, 57, 2177-2202.

(29) Gonzalez, H.; Hwang, S. J.; Davis, M. E. New class of polymers for the delivery of macromolecular therapeutics. Bioconjugate Chem. 1999, 10, 1068-1074.

(30) Lai, W. F. Cyclodextrins in non-viral gene delivery. Biomaterials 2014, 35, 401-411.

(31) Borchard, G. Chitosans for gene delivery. Adv. Drug Deliv. Rev. 2001, 52, 145-150.

(32) Rigby, P. G. Prolongation of survival of tumour-bearing animals by transfer to "immune" RNA with DEAE-dextran. Nature 1969, 221, 968-969.

(33) Hosseinkhani, H.; Azzam, T.; Tabata, Y.; Domb, A. J. Dextran-spermine polycation: an efficient nonviral vector for in vitro and in vivo gene transfection. Gene Ther 2004, 11, 194-203.

(34) Liu, Y. M.; Wenning, L.; Lynch, M.; Reineke, T. M. New poly(Dglucaramidoamine)s induce DNA nanoparticle formation and efficient gene delivery into mammalian cells. J. Am. Chem. Soc. 2004, 126, 7422-7423.

(35) Liu, Y. M.; Reineke, T. M. Hydroxyl stereochemistry and amine number within poly(glycoamidoamine)s affect intracellular DNA delivery. J. Am. Chem. Soc. 2005, 127, 3004-3015.

(36) Liu, Y. M.; Reineke, T. M. Poly(glycoamidoamine)s for gene delivery: Stability of polyplexes and efficacy with cardiomyoblast cells. Bioconjugate Chem. 2006, 17, 101-108.

(37) Luten, J.; van Steenis, J. H.; van Someren, R.; Kemmink, J.; SchuurmansNieuwenbroek, N. M.; Koning, G. A.; Crommelin, D. J.; van Nostrum, C. F.; Hennink, W. E. Water-soluble biodegradable cationic polyphosphazenes for gene delivery. J. Controlled Release 2003, 89, 483-497.

(38) Wang, J.; Mao, H. Q.; Leong, K. W. A novel biodegradable gene carrier based on polyphosphoester. J. Am. Chem. Soc. 2001, 123, 9480-9481.

(39) Lynn, D. M.; Langer, R. Degradable Poly( $\beta$-amino esters): Synthesis, Characterization, and Self-Assembly with Plasmid DNA. J. Am. Chem. Soc. 2000, 122, 10761-10768.

(40) Lynn, D. M.; Anderson, D. G.; Putnam, D.; Langer, R. Accelerated discovery of synthetic transfection vectors: parallel synthesis and screening of a degradable polymer library. J. Am. Chem. Soc. 2001, 123, 8155-5156. 
(41) Green, J. J.; Shi, J.; Chiu, E.; Leshchiner, E. S.; Langer, R.; Anderson, D. G. Biodegradable polymeric vectors for gene delivery to human endothelial cells. Bioconjugate Chem. 2006, 17, 1162-1169.

(42) Lim, Y.; Kim, S. M.; Lee, Y.; Lee, W.; Yang, T.; Lee, M.; Suh, H.; Park, J. Cationic hyperbranched poly(amino ester): a novel class of DNA condensing molecule with cationic surface, biodegradable three-dimensional structure, and tertiary amine groups in the interior. J. Am. Chem. Soc. 2001, 123, 2460-2461.

(43) Anderson, D. G.; Lynn, D. M.; Langer, R. Semi-Automated Synthesis and Screening of a Large Library of Degradable Cationic Polymers for Gene Delivery. Angew. Chem. Int. Ed. 2003, 42, 3153-3158.

(44) Putnam, D.; Langer, R. Poly(4-hydroxy-L-proline ester): Low-temperature polycondensation and plasmid DNA complexation. Macromolecules 1999, 32, 36583662.

(45) Lim, Y. B.; Choi, Y. H.; Park, J. S. A self-destroying polycationic polymer: Biodegradable poly(4-hydroxy-L-proline ester). J. Am. Chem. Soc. 1999, 121, 56335639.

(46) Lim, Y. B.; Kim, C. H.; Kim, K.; Kim, S. W.; Park, J. S. Development of a Safe Gene Delivery System Using Biodegradable Polymer, Poly[ $\alpha$-(4-aminobutyl)-1glycolic acid]. J. Am. Chem. Soc. 2000, 122, 6524-6525.

(47) Guerrero-Cazares, H.; Tzeng, S. Y.; Young, N. P.; Abutaleb, A. O.; QuinonesHinojosa, A.; Green, J. J. Biodegradable Polymeric Nanoparticles Show High Efficacy and Specificity at DNA Delivery to Human Glioblastoma in Vitro and in Vivo. ACS Nano 2014, 8, 5141-5153.

(48) Kozielski, K. L.; Tzeng, S. Y.; Green, J. J. A bioreducible linear poly(beta-amino ester) for siRNA delivery. Chem. Commun. 2013, 49, 5319-5321.

(49) Lin, C.; Zhong, Z.; Lok, M. C.; Jiang, X.; Hennink, W. E.; Feijen, J.; Engbersen, J. F. J. Novel Bioreducible Poly(amido amine)s for Highly Efficient Gene Delivery. Bioconjugate Chem. 2007, 18, 138-145.

(50) Ou, M.; Xu, R.; Kim, S. H.; Bull, D. A.; Kim, S. W. A family of bioreducible poly(disulfide amine)s for gene delivery. Biomaterials 2009, 30, 5804-5814.

(51) Vader, P.; van der Aa, L.; Engbersen, J. J.; Storm, G.; Schiffelers, R. Disulfide-Based Poly(amido amine)s for siRNA Delivery: Effects of Structure on siRNA Complexation, Cellular Uptake, Gene Silencing and Toxicity. Pharm. Res. 2011, 28, 1013-1022. 
(52) van der Aa, L. J.; Vader, P.; Storm, G.; Schiffelers, R. M.; Engbersen, J. F. J. Optimization of poly(amido amine)s as vectors for siRNA delivery. J. Controlled Release 2011, 150, 177-186.

(53) Piest, M.; Ankone, M.; Engbersen, J. F. J. Carbohydrate-interactive pDNA and siRNA gene vectors based on boronic acid functionalized poly(amido amine)s. $J$. Controlled Release 2013, 169, 266-275.

(54) van der Aa, L. J.; Vader, P.; Storm, G.; Schiffelers, R. M.; Engbersen, J. F. J. Intercalating quaternary nicotinamide-based poly(amido amine)s for gene delivery. J. Controlled Release 2014, 195, 11-20.

(55) Lin, C.; Engbersen, J. F. J. The role of the disulfide group in disulfide-based polymeric gene carriers. Expert Opin. Drug Delivery 2009, 6, 421-439.

(56) van der Ende, A. E.; Kravitz, E. J.; Harth, E. Approach to formation of multifunctional polyester particles in controlled nanoscopic dimensions. J. Am. Chem. Soc. 2008, 130, 8706-8713.

(57) Kang, T.; Amir, R. J.; Khan, A.; Ohshimizu, K.; Hunt, J. N.; Sivanandan, K.; Montanez, M. I.; Malkoch, M.; Ueda, M.; Hawker, C. J. Facile access to internally functionalized dendrimers through efficient and orthogonal click reactions. Chem. Commun. 2010, 46, 1556-1558.

(58) Amir, R. J.; Albertazzi, L.; Willis, J.; Khan, A.; Kang, T.; Hawker, C. J. Multifunctional Trackable Dendritic Scaffolds and Delivery Agents. Angew. Chem. Int. Ed. 2011, 50, 3425-3429.

(59) Espeel, P.; Du Prez, F. E. “Click”-Inspired Chemistry in Macromolecular Science: Matching Recent Progress and User Expectations. Macromolecules 2015, 48, 2-14.

(60) Saha, A.; De, S.; Stuparu, M. C.; Khan, A. Facile and General Preparation of Multifunctional Main-Chain Cationic Polymers through Application of Robust, Efficient, and Orthogonal Click Chemistries. J. Am. Chem. Soc. 2012, 134, 1729117297.

(61) Zhang, C.; Myers, J. N.; Chen, Z. Molecular Behavior at Buried Epoxy/Poly(ethylene terephthalate) Interface. Langmuir 2014, 30, 12541-12550.

(62) Barua, S.; Joshi, A.; Banerjee, A.; Matthews, D.; Sharfstein, S. T.; Cramer, S. M.; Kane, R. S.; Rege, K. Parallel Synthesis and Screening of Polymers for Nonviral Gene Delivery. Mol. Pharmaceutics 2008, 6, 86-97. 
(63) Vu, L.; Ramos, J.; Potta, T.; Rege, K. Generation of a Focused Poly(amino ether) Library: Polymer-mediated Transgene Delivery and Gold-Nanorod based Theranostic Systems. Theranostics 2012, 2, 1160-1173.

(64) Zhang, Q. F.; Yi, W. J.; Wang, B.; Zhang, J.; Ren, L. F.; Chen, Q. M.; Guo, L. D.; $\mathrm{Yu}, \mathrm{X}$. Q. Linear polycations by ring-opening polymerization as non-viral gene delivery vectors. Biomaterials 2013, 34, 5391-5401.

(65) Zhang, Q.-F.; Yu, Q.-Y.; Geng, Y.; Zhang, J.; Wu, W.-X.; Wang, G.; Gu, Z.; Yu, X.Q. Ring-Opening Polymerization for Hyperbranched Polycationic Gene Delivery Vectors with Excellent Serum Tolerance. ACS Appl. Mater. Interfaces 2014, 6, 15733-15742.

(66) Zhong, Z.; Feijen, J.; Lok, M. C.; Hennink, W. E.; Christensen, L. V.; Yockman, J. W.; Kim, Y.-H.; Kim, S. W. Low Molecular Weight Linear Polyethylenimine-bpoly(ethylene glycol)-b-polyethylenimine Triblock Copolymers: Synthesis, Characterization, and in Vitro Gene Transfer Properties. Biomacromolecules 2005, 6, 3440-3448.

(67) Sonawane, N. D.; Szoka, F. C.; Verkman, A. S. Chloride Accumulation and Swelling in Endosomes Enhances DNA Transfer by Polyamine-DNA Polyplexes. J. Biol. Chem. 2003, 278, 44826-44831.

(68) Liu, Z.; Zhang, Z.; Zhou, C.; Jiao, Y. Hydrophobic modifications of cationic polymers for gene delivery. Prog. Polym. Sci. 2010, 35, 1144-1162.

(69) Piest, M.; Engbersen, J. F. J. Effects of charge density and hydrophobicity of poly(amido amine)s for non-viral gene delivery. J. Controlled Release 2010, 148, 83-90.

(70) Luo, X.; Huang, F.; Qin, S.; Wang, H.; Feng, J.; Zhang, X.; Zhuo, R. A strategy to improve serum-tolerant transfection activity of polycation vectors by surface hydroxylation. Biomaterials 2011, 32, 9925-9939. 



\section{Chapter 8. Modular Synthesis of Bioreducible}

Gene Vectors through Polyaddition of $N, N^{\prime}-$ Dimethylcystamine to Various Diglycidyl Ethers

Guoying Si, Jos M.J. Paulusse* and Johan F.J. Engbersen*

Department of Controlled Drug Delivery, MIRA Institute for Biomedical Technology and Technical Medicine, Faculty of Science and Technology, University of Twente, P.O. Box 217, 7500 AE Enschede, The Netherlands

KEYWORDS

Cationic polymer; epoxy-amine reaction; bioreducible; gene delivery; disulfides.

This chapter has been submitted for publication. 


\section{ABSTRACT}

Bioreducible linear poly(amino ether)s (PAEs) are evaluated as promising gene vectors. PAEs were synthesized by reaction of disulfide-functional monomer, $N, N^{\prime}$ dimethylcystamine (DMC), with different diglycidyl ethers with molecular variations. The resulting PAEs display substantial buffer capacity (up to 64\%) in the endosomal acidification region $\mathrm{pH}$ 7.4-5.1. PAEs condense plasmid DNA with GFP as reporter gene into 80-200 nm sized polyplexes with positive surface charges ranging from +20 to $+40 \mathrm{mV}$. The polyplexes readily release DNA after exposure to reducing conditions (2.5 $\mathrm{mM} \mathrm{DTT})$ as demonstrated by agarose gel electrophoresis, due to cleavage of the disulfide groups present in the main chain of the polymers. Upon exposing COS-7 cells to polyplexes prepared at polymer/DNA ratios below 48, cell viabilities between $80 \%-100 \%$ were observed under serum-free conditions. These polyplexes show comparable or higher transfection efficiencies (ranging from 10\%-38\%), as compared to PEI (12\%) under serum-free conditions. Moreover, the PAE-based polyplexes yield transfection efficiencies as high as $32 \%$ and $28 \%$ under $10 \%$ and $25 \%$ serum conditions respectively.

\section{INTRODUCTION}

Non-viral gene vectors are extensively sought after to deliver DNA as therapeutics to cure human diseases. ${ }^{1-6}$ Non-viral gene vectors should be merited with high transfection efficiency, minimal or non-toxicity, as well as ease of manufacturing. ${ }^{7-9}$ Cationic polymers are interesting candidates to be developed to acquire the required properties for efficient gene delivery, using modern developments in polymer chemistry ${ }^{10-13}$ as well as nanotechnology. ${ }^{14-16}$ Cationic polymers can form polyplexes with DNA tightly packed inside by means of electrostatic interactions. ${ }^{17-20}$ After entering the cells through endocytosis, ${ }^{21}$ the polyplexes must escape from the endosome-lysosome pathway and unpack the DNA in nucleus in order to initiate gene expression. ${ }^{22-24}$

An important step before the initiation of gene expression is the unpacking of DNA from the polyplex. Many cues were proposed to facilitate DNA unpacking, ${ }^{25,26}$ such as the use of acidlabile cationic polymers, ${ }^{13,27,28}$ ester-based cationic polymers ${ }^{29,30}$ and biologically triggered cationic polymers. ${ }^{31-34}$ Among these approaches, the latter approach is arguably the most interesting, since it takes advantage of intracellular enzymes or related biomolecules. ${ }^{26,35}$ Glutathione, enzyme-related antioxidant dictating the reductive potential of cells, is more concentrated inside the cells than outside cells, thereby increasing the reductive potential 
inside cells. ${ }^{36-38}$ By introduction of disulfide-linkages in cationic polymers, ${ }^{39,40}$ this higher reductive potential has been utilized as a trigger to cleave the disulfide bonds and unpack DNA from their polyplexes after successful endosomal escape of the polyplexes into the cytosol. Introduction of disulfide moieties were successfully employed in polyethylenimine (PEI), ${ }^{41-45}$ poly(L-lysine) (PLL) ${ }^{46,47}$ peptides, ${ }^{48,49}$ and poly(amidoamine) dendrimers ${ }^{50}$ resulting in increased gene transfection and improved biocompatibility. Our group, as well as other groups, reported on disulfide-linked linear ${ }^{51,52}$ and branched $^{53}$ poly(amido amine)s displaying superb transfection efficiencies and excellent biocompatibility. ${ }^{54}$ Green and coworkers reported cationic poly(amino ester)s with disulfides along the backbone for efficient gene delivery. ${ }^{55}$ However, clinical application of these polymers has so far been restrained due to their impaired transfection in the presence of serum. ${ }^{16,56}$ The introduction of hydrophilic poly(ethylene glycol) onto these vectors was found to increase the serum tolerance of these polymers only to a limited extent, failing to meet the requirements for clinical application. ${ }^{16,56,57}$ Recently, we developed a new class of disulfide-based poly(amino ether)s (PAEs) by epoxy-amine addition reaction of 2-hydroxyethyl disulfide diglycidyl ether with a variety of primary amines, yielding a series of PAEs with different side groups along the polymer chain (Chapter 7 in this thesis). The resulting polymers showed to be effective non-viral gene delivery vectors, with high biocompatibility and improved serumtolerance. 


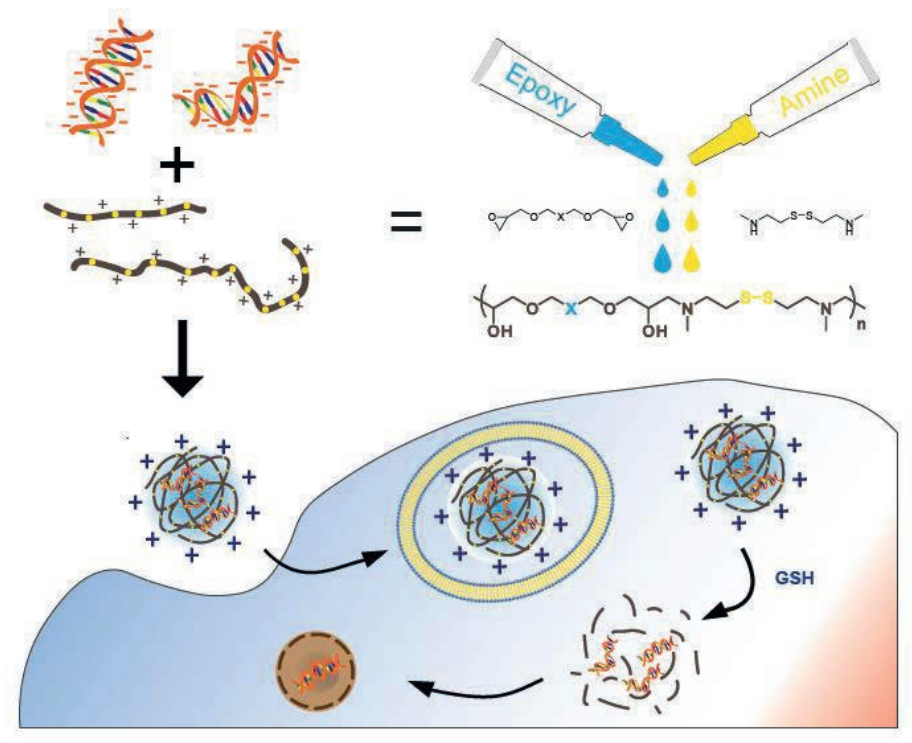

Scheme 1. Schematic illustration of modular synthetic approaches to prepare disulfide-linked polycations through polyaddition reaction of $N, N$ '-dimethylcystamine (DMC) to various diglycidyl ethers.

In this chapter, we report a complementary modular synthetic approach to generate disulfidelinked PAEs through polyaddition of $N, N^{\prime}$-dimethylcystamine (DMC) as the fixed bifunctional diamine monomer and a series of diglycidyl ethers as the variable epoxy monomer. This has yielded bioreducible PAEs with different structural moieties in the main chain of the polymers. Transfection efficiencies and cell viabilities of these polymers were investigated on COS-7 cells through flow cytometry and MTT assay.

\section{EXPERIMENTAL PROCEDURES}

\section{Materials and Methods}

Epichlorohydrin ( $\geq 98 \%$, Sigma-Aldrich), 2-hydroxyethyl disulfide (technical grade, SigmaAldrich), tetrabutylammonium bromide (TBAB, $\geq 98 \%$, Sigma-Aldrich), sodium hydroxide ( $\mathrm{NaOH}$, pellets, Sigma-Aldrich), 1,3-benzenedimethanol (98\%, Sigma-Aldrich), N,N'dimethylethylenediamine ( $>97.0 \%$, TCI Europe N.V.), 1,4-butanediol diglycidyl ether ( $\geq 95 \%$, Sigma-Aldrich), dithiothreitol (DTT, Sigma-Aldrich), triethylamine (TEA, $\geq 99 \%$, Sigma-Aldrich), borane dimethyl sulfide complex (BMS, Sigma-Aldrich), N,N'-Bis(2hydroxylethyl) ethylenediamine (>95.0\%, TCI Europe N.V.), di-tert-butyl dicarbonate ( $>95.0 \%$, TCI Europe N.V.), and thiazolidine (98\%, ACROS Organics) were used directly as received without further purification. Diglycidyl ethers, 1,4-cyclohexanedimethanol 
diglycidyl ether (3, Sigma-Aldrich) and neopentyl glycol diglycidyl ether (4, Sigma-Aldrich) were used as received. All solvents used were of analytical grade. Water used in these experiments was treated through a Milli-Q Gradient System (Millipore, Bedford, MA). Plasmid DNA, plasmids pCMV-GFP and pCMV- $\triangle$ GFP were purchased from Plasmid Factory (Bielefeld, Germany). Branched polyethylenimine (PEI, $\mathrm{M}_{\mathrm{w}} 25 \mathrm{kDa}$ ) was purchased from Sigma-Aldrich.

${ }^{1} \mathrm{H}$ NMR and ${ }^{13} \mathrm{C}$ NMR were recorded on a Bruker NMR spectrometer $(400 \mathrm{MHz})$ in deuterated solvents. Molecular weights were determined by gel permeation chromatography (GPC, Waters Alliance 2695) relative to PEG standards, using a Mixed-M column (PLaquagel-OH 8 micron, $300 \times 7.5 \mathrm{~mm}$ ) with $N, N$-dimethylformamide (DMF) containing LiCl $(50 \mathrm{mM})$ as mobile phase.

Synthesis of $\boldsymbol{N}, \boldsymbol{N}$ '-dimethylcystamine (DMC). The monomer was synthesized in its $\mathrm{HCl}$ salt form based on our previous report. ${ }^{58}$ Into a solution of thiazolidine $(5.0 \mathrm{~g}, 56 \mathrm{mmol})$ in anhydrous tetrahydrofuran (THF, $20 \mathrm{~mL}$ ) under nitrogen atmosphere, borane dimethyl sulfide complex (BMS, $10.61 \mathrm{~g}, 140 \mathrm{mmol})$ in anhydrous THF (20 mL) was slowly added under stirring and the mixture was subsequently refluxed overnight. After cooling down to ambient temperature, methanol $(20 \mathrm{~mL})$ was added by syringe to neutralize any residual BMS and the mixture was refluxed for an additional $3 \mathrm{~h}$. After cooling down to ambient temperature, the solution was purged with $\mathrm{HCl}$ gas, and the mixture was concentrated under reduced pressure. The resulting liquid was consecutively dissolved in methanol $(5.0 \mathrm{~mL})$ and precipitated in diethyl ether $(2 \times 50 \mathrm{~mL})$ to obtain a white oily precipitate. The precipitate was dissolved in water $(7.5 \mathrm{~mL})$, and titrated with saturated $\mathrm{I}_{2} / \mathrm{KI}$ solution until obtaining a persistent yellow color. After stirring for an additional $2 \mathrm{~h}$, the yellow solution turned colorless upon raising $\mathrm{pH}$ to 10 . The solution was extracted with chloroform $(4 \times 30 \mathrm{~mL})$. Afterwards the organic fractions were combined, dried over $\mathrm{MgSO}_{4}$, and concentrated under reduced pressure to yield a clear liquid. Subsequently, the liquid was dissolved in isopropanol $(20 \mathrm{~mL})$ and purged with $\mathrm{HCl}$ gas, yielding a turbid yellow mixture and a white precipitate. The precipitate was filtered off, washed with cold diethyl ether, and finally recrystallized from isopropanol/methanol to obtain the $\mathrm{HCl}$ salt as a white solid. $(2.12 \mathrm{~g}$, $30.0 \%$ yield). ${ }^{1} \mathrm{H}$ NMR ( $\left.\mathrm{D}_{2} \mathrm{O}, 400 \mathrm{MHz}\right): \delta_{\mathrm{H}} 2.76\left(\mathrm{~s}, 6 \mathrm{H}, \mathrm{CH}_{2} \mathrm{NHCH}_{3}\right), 3.05(\mathrm{t}, 4 \mathrm{H}$, $\left.\mathrm{SCH}_{2} \mathrm{CH}_{2}\right), 3.44\left(\mathrm{t}, 4 \mathrm{H}, \mathrm{SCH}_{2} \mathrm{CH}_{2}\right) .{ }^{13} \mathrm{C}$ NMR $\left(\mathrm{D}_{2} \mathrm{O}, 400 \mathrm{MHz}\right): \delta_{\mathrm{C}} 31.92,32.83,47.02$. 
Synthesis of $N, N^{\prime}$-bis(2-hydroxyethyl)- $N$, $N$ '-bis(tert-butoxycarbonyl) ethylenediamine.

To a mixture of $N, N^{\prime}$-bis(2-hydroxylethyl) ethylenediamine (6.00 g, $\left.40.0 \mathrm{mmol}\right)$ and triethylamine $(14.0 \mathrm{~mL}, 10.2 \mathrm{~g}, 100 \mathrm{mmol})$ in dichloromethane $(100 \mathrm{~mL})$, di-tert-butyl dicarbonate $(17.6 \mathrm{~g}, 40 \mathrm{mmol})$ in dichloromethane $(200 \mathrm{~mL})$ was charged dropwise under stirring at $0{ }^{\circ} \mathrm{C}$. The mixture was stirred at ambient temperature overnight. Solvent was removed under reduced pressure. The resulting solid was washed with ethyl acetate and diethyl ether and subsequently dried under vacuum, to yield a white solid $(11.2 \mathrm{~g}, 80.4 \%$ yield). ${ }^{1} \mathrm{H} \mathrm{NMR}\left(\mathrm{CDCl}_{3}, 400 \mathrm{MHz}\right): \delta_{\mathrm{H}} 1.45$ (s, 18H), 3.25-3.60 (m, 8H), 3.71-3.82 (m, 4H).

Synthesis of diglycidyl ethers. Diglycidyl ether monomers were synthesized via reaction of epichlorohydrin with the corresponding diols. Typical example of the Boc-protected form of 1 (Boc-1) was: into a mixture of $N, N^{\prime}$-bis(2-hydroxyethyl)- $N, N$ '-bis(tert-butoxycarbonyl) ethylenediamine $(1.75 \mathrm{~g}, 5.00 \mathrm{mmol})$, sodium hydroxide $(0.800 \mathrm{~g}, 20.0 \mathrm{mmol})$ and tetrabutylammonium bromide $(12.37 \mathrm{mg}, 34.8 \mu \mathrm{mol})$, epichlorohydrin $(1.45 \mathrm{~mL}, 18.4$ mmol) was added gradually. The mixture was heated to $40{ }^{\circ} \mathrm{C}$ and stirred for $3 \mathrm{~h}$. The resulting mixture was subjected to column chromatography to obtain diglycidyl ether of Boc-1 (1.95 g, $84.7 \%$ yield). ${ }^{1} \mathrm{H}$ NMR ( $\left.\mathrm{CDCl}_{3}, 400 \mathrm{MHz}\right): \delta_{\mathrm{H}} 1.46$ (s, 18H), 2.57 (s, 2H), $2.76(\mathrm{t}, 2 \mathrm{H}), 3.10(\mathrm{~m}, 2 \mathrm{H}), 3.36(\mathrm{~m}, 10 \mathrm{H}), 3.60(\mathrm{~m}, 4 \mathrm{H}), 3.72(\mathrm{~m}, 2 \mathrm{H}) .{ }^{13} \mathrm{C} \mathrm{NMR}\left(\mathrm{CDCl}_{3}\right.$, $400 \mathrm{MHz}): \delta 28.43,44.12,46.13,47.34,50.75,69.89,71.76,79.76,155.41$.

Diglycidyl ether of 5 (1.12 g, 89.5\% yield). ${ }^{1} \mathrm{H}$ NMR $\left(\mathrm{CDCl}_{3}, 400 \mathrm{MHz}\right): \delta_{\mathrm{H}} 2.62(\mathrm{~m}, 2 \mathrm{H}$, epoxide ring OCHHCHO), 2.81 ( $\mathrm{m}, 2 \mathrm{H}$, epoxide ring OCHHCHO), 3.20 ( $\mathrm{m}, 2 \mathrm{H}$, epoxide ring OCHHCHO), 3.45 (m, 2H, CHCHHO), 3.78 (m, 2H, CHCHHO), 4.59 (m, 4H, OCH phenyl ring), 7.27-7.36 (m, 4H, phenyl ring). ${ }^{13} \mathrm{C} \mathrm{NMR}\left(\mathrm{CDCl}_{3}, 400 \mathrm{MHz}\right): \delta_{\mathrm{C}} 44.36,50.93$, $71.01,73.27,127.13,128.64,138.22$.

Synthesis of poly(amino ether)s. Poly(amino ether)s (PAEs) were synthesized by ring open polymerization of bifunctional epoxide monomers with equimolar amounts of secondary amines. A typical procedure is given for the synthesis of DMC1:

Into a glass vial, diglycidyl ether Boc-1 (0.461 g, $1.00 \mathrm{mmol})$, DMC (0.254 g, $1.00 \mathrm{mmol})$, triethylamine $(0.400 \mathrm{~mL}, 2.87 \mathrm{mmol})$ and ethanol $(0.500 \mathrm{~mL})$ were charged. After $3 \mathrm{~d}$ stirring under ambient temperature, the resulting viscous mixture was diluted with methanol $(50.0 \mathrm{~mL})$, and purged with $\mathrm{HCl}$ gas for $30 \mathrm{~min}$ in order to remove the Boc protecting groups. The mixture was concentrated and the residue was dissolved in water $(15.0 \mathrm{~mL})$, acidified 
with $4 \mathrm{M} \mathrm{HCl}$ solution to $\mathrm{pH} \mathrm{4}$, and purified via dialysis (MWCO $1 \mathrm{kDa}$ ) against water overnight. Polymer DMC1 was obtained after lyophilization as an amorphous solid. The other PAE polymers DMC2-6 were synthesized analogously, however these polymers do not require the Boc removal step.

Polymer DMC1 (off-white solid, 0.162 g, 31.6\%): ${ }^{1} \mathrm{H}$ NMR (D $2 \mathrm{O}, 400 \mathrm{MHz}$ ): $\delta_{\mathrm{H}} 2.98$ (s, $6 \mathrm{H}, \mathrm{NCH}_{3}$ ), 3.10-3.16 (m, 4H, $\mathrm{CH}_{2} \mathrm{NHCH}_{2} \mathrm{CH}_{2} \mathrm{O}$ ), 3.26 (m, 4H, $\mathrm{NCH}_{2} \mathrm{CH}_{2} \mathrm{~S}$ ), 3.32-3.38 (b, $8 \mathrm{H}, \mathrm{CH}_{2} \mathrm{NHCH}_{2} \mathrm{CH}_{2} \mathrm{O}+\mathrm{OCH}_{2} \mathrm{CHOHCH}_{2} \mathrm{NCH}_{2} \mathrm{CH}_{2} \mathrm{~S}$ ), 3.35-3.64 (m, 8H, $\left.\mathrm{CH}_{2} \mathrm{OCH}_{2}\right), 3.79$ (t, $4 \mathrm{H}, \mathrm{OCH}_{2} \mathrm{CHOHCH}_{2} \mathrm{NCH}_{2} \mathrm{CH}_{2} \mathrm{~S}$ ), 4.30 (bs, $2 \mathrm{H}, \mathrm{OCH}_{2} \mathrm{CHOHCH}_{2} \mathrm{NCH}_{2} \mathrm{CH}_{2} \mathrm{~S}$ ).

Polymer DMC2 (white solid, 0.132 g, 33.2\%): ${ }^{1} \mathrm{H}$ NMR ( $\left.{ }_{2} \mathrm{O}, 400 \mathrm{MHz}\right): \delta_{\mathrm{H}} 2.95$ (s, 6H, $\left.\mathrm{NCH}_{3}\right), 2.96\left(\mathrm{~m}, 4 \mathrm{H}, \mathrm{OCH}_{2} \mathrm{CH}_{2} \mathrm{~S}\right), 3.09-3.14\left(\mathrm{~m}, 4 \mathrm{H}, \mathrm{NCH}_{2} \mathrm{CH}_{2} \mathrm{~S}\right), 3.30(\mathrm{~m}, 4 \mathrm{H}$, $\left.\mathrm{CH}_{2} \mathrm{OCH}_{2} \mathrm{CHOHCH}_{2} \mathrm{NCH}_{2} \mathrm{CH}_{2} \mathrm{~S}\right), 3.55-3.65\left(\mathrm{~m}, 8 \mathrm{H}, \mathrm{CH}_{2} \mathrm{OCH}_{2} \mathrm{CHOHCH}_{2} \mathrm{NCH}_{2} \mathrm{CH}_{2} \mathrm{~S}\right)$, 3.80-3.89 (m, 4H, $\left.\mathrm{OCH}_{2} \mathrm{CH}_{2} \mathrm{~S}\right), 4.25$ (bs, $2 \mathrm{H}, \mathrm{CH}_{2} \mathrm{OCH}_{2} \mathrm{CHOHCH}_{2} \mathrm{NCH}_{2} \mathrm{CH}_{2} \mathrm{~S}$ ).

Polymer of DMC3 (white solid, 0.086 g, 16.9\% yield): ${ }^{1} \mathrm{H}$ NMR $\left(\mathrm{D}_{2} \mathrm{O}, 400 \mathrm{MHz}\right): \delta_{\mathrm{H}} 0.90$ 1.01 and $1.75-1.79\left(\mathrm{~m}, 8 \mathrm{H}, 4 \times \mathrm{CH}_{2}\right.$ of cyclohexane ring), 1.29 and $1.49(\mathrm{~m}, 2 \mathrm{H}, \mathrm{CH}$ of cyclohexane ring), $2.98\left(\mathrm{~s}, 6 \mathrm{H}, \mathrm{NCH}_{3}\right), 3.11-3.18\left(\mathrm{~m}, 4 \mathrm{H}, \mathrm{NCH}_{2} \mathrm{CH}_{2} \mathrm{~S}\right), 3.20-3.31(\mathrm{~m}, 4 \mathrm{H}$, $\mathrm{CH}_{2} \mathrm{OCH}_{2} \mathrm{CHOHCH}_{2} \mathrm{NCH}_{2} \mathrm{CH}_{2} \mathrm{~S}$ ), 3.37-3.47 (m, $4 \mathrm{H}, \mathrm{CH}_{2} \mathrm{OCH}_{2} \mathrm{CHOHCH}_{2} \mathrm{NCH}_{2} \mathrm{CH}_{2} \mathrm{~S}$ ), 3.51-3.67 (m, $\left.\quad 8 \mathrm{H}, \quad \mathrm{CH}_{2} \mathrm{OCH}_{2} \mathrm{CHOHCH}_{2} \mathrm{NCH}_{2} \mathrm{CH}_{2} \mathrm{~S}\right), \quad 4.25 \quad$ (bs, $2 \mathrm{H}$, $\left.\mathrm{CH}_{2} \mathrm{OCH}_{2} \mathrm{CHOHCH}_{2} \mathrm{NCH}_{2} \mathrm{CH}_{2} \mathrm{~S}\right)$.

Polymer DMC4 (amorphous solid, $0.064 \mathrm{~g}, 13.9 \%$ yield): ${ }^{1} \mathrm{H}$ NMR $\left(\mathrm{D}_{2} \mathrm{O}, 400 \mathrm{MHz}\right): \delta_{\mathrm{H}}$ 0.91 (s, 6H, $\left.\mathrm{C}\left(\mathrm{CH}_{2} \mathrm{CH}_{3}\right)_{2}\right), 2.92$ (s, 6H, $\left.\mathrm{NCH}_{3}\right), 3.08-3.12$ (m, 4H, $\left.\mathrm{NCH}_{2} \mathrm{CH}_{2} \mathrm{~S}\right), 3.26-3.32$ $\left(\mathrm{m}, \quad 8 \mathrm{H}, \quad \mathrm{C}\left(\mathrm{CH}_{2} \mathrm{CH}_{3}\right)_{2}+\mathrm{CH}_{2} \mathrm{OCH}_{2} \mathrm{CHOHCH}_{2} \mathrm{NCH}_{2} \mathrm{CH}_{2} \mathrm{~S}\right), \quad 3.66-3.75 \quad(\mathrm{~m}, \quad 8 \mathrm{H}$, $\mathrm{CH}_{2} \mathrm{OCH}_{2} \mathrm{CHOHCH}_{2} \mathrm{NCH}_{2} \mathrm{CH}_{2} \mathrm{~S}$ ), 4.25 (bs, $2 \mathrm{H}, \mathrm{CH}_{2} \mathrm{OCH}_{2} \mathrm{CHOHCH}_{2} \mathrm{NCH}_{2} \mathrm{CH}_{2} \mathrm{~S}$ ).

Polymer of DMC5 (white solid, 0.220g, 43.7\%): ${ }^{1} \mathrm{H}$ NMR ( $\left.\mathrm{D}_{2} \mathrm{O}, 400 \mathrm{MHz}\right): \delta_{\mathrm{H}} 2.96(\mathrm{~s}, 6 \mathrm{H}$, $\left.\mathrm{NCH}_{3}\right), \quad 3.09-3.12\left(\mathrm{~m}, \quad 4 \mathrm{H}, \quad \mathrm{NCH}_{2} \mathrm{CH}_{2} \mathrm{~S}\right), \quad 3.24-3.30 \quad(\mathrm{~m}, 4 \mathrm{H}$, phenyl ring$\left.\mathrm{CH}_{2} \mathrm{OCH}_{2} \mathrm{CHOHCH}_{2} \mathrm{NCH}_{2} \mathrm{CH}_{2} \mathrm{~S}\right), \quad 3.57-3.64 \quad(\mathrm{~m}, \quad 8 \mathrm{H}, \quad$ phenyl ring$\left.\mathrm{CH}_{2} \mathrm{OCH}_{2} \mathrm{CHOHCH}_{2} \mathrm{NCH}_{2} \mathrm{CH}_{2} \mathrm{~S}\right), \quad 4.26$ (bs, $2 \mathrm{H}$, phenyl ring$\left.\mathrm{CH}_{2} \mathrm{OCH}_{2} \mathrm{CHOHCH}_{2} \mathrm{NCH}_{2} \mathrm{CH}_{2} \mathrm{~S}\right)$, 4.62-4.65 (m, 4H, phenyl ring$\mathrm{CH}_{2} \mathrm{OCH}_{2} \mathrm{CHOHCH}_{2} \mathrm{NCH}_{2} \mathrm{CH}_{2} \mathrm{~S}$ ), 7.40-7.45 (m, 4H, phenyl ring).

Polymer of DMC6 (amorphous solid, $0.183 \mathrm{~g}, 40.1 \%$ yield): ${ }^{1} \mathrm{H}$ NMR ( $\left.\mathrm{D}_{2} \mathrm{O}, 400 \mathrm{MHz}\right): \delta_{\mathrm{H}}$ 1.63 (bs, 4H, $\mathrm{OCH}_{2} \mathrm{CH}_{2} \mathrm{CH}_{2} \mathrm{CH}_{2} \mathrm{O}$ ), 2.96 (s, 6H, $\mathrm{NCH}_{3}$ ), 3.04-3.13 (m, 4H, $\mathrm{NCH}_{2} \mathrm{CH}_{2} \mathrm{~S}$ ), 
3.23-3.30 (m, 4H, $\left.\quad \mathrm{CH}_{2} \mathrm{OCH}_{2} \mathrm{CHOHCH}_{2} \mathrm{NCH}_{2} \mathrm{CH}_{2} \mathrm{~S}\right), \quad 3.52-3.62 \quad(\mathrm{~m}, \quad 12 \mathrm{H}$, $\mathrm{CH}_{2} \mathrm{OCH}_{2} \mathrm{CHOHCH}_{2} \mathrm{NCH}_{2} \mathrm{CH}_{2} \mathrm{~S}$ ), 4.25 (bs, $2 \mathrm{H}, \mathrm{CH}_{2} \mathrm{OCH}_{2} \mathrm{CHOHCH}_{2} \mathrm{~N}$ ).

\section{Polyplex preparation}

Polyplexes were prepared by adding polymer solution into DNA solution at designated polymer/DNA mass ratios. All polymer and DNA solutions were prepared in HEPES buffer (20 mM, pH 7.4). The procedure of polyplexes prepared at mass ratio 48 is as follows: In an Eppendorf tube $(1.5 \mathrm{~mL})$, DNA solution $(75 \mu \mathrm{g} / \mathrm{mL}, 200 \mu \mathrm{L})$ and polymer solution (900 $\mu \mathrm{g} / \mathrm{mL}, 800 \mu \mathrm{L}$ ) was successively added. The mixture was subjected to vortexing for $5 \mathrm{~s}$ and incubated at room temperature for $30 \mathrm{~min}$ to obtain the polyplex suspensions. Size and surface charge of the polyplexes were measured on a Zetasizer Nano ZS (Malvern Instruments, Malvern) at $25^{\circ} \mathrm{C}$. The data are presented as mean of three measurements with corresponding standard deviations as error bars.

\section{Agarose gel electrophoresis}

Polyplexes were prepared at polymer/DNA mass ratio 48 as described in the previous protocol. Polyplex solutions $(90 \mu \mathrm{L})$ were diluted with either DTT HEPES solution $(25 \mathrm{mM}$, $10 \mu \mathrm{L})$ or HEPES buffer $(10 \mu \mathrm{L})$, and incubated under ambient conditions for $30 \mathrm{~min}$. The resulting dispersions $(20 \mu \mathrm{L})$ were mixed with $6 \mathrm{X}$ loading buffer containing bromophenol (Ferments, $5.0 \mu \mathrm{L})$, and aliquoted $(10 \mu \mathrm{L})$ to load on agarose gel $(0.8 \% \mathrm{w} / \mathrm{v})$ containing $1 \mathrm{X}$ SYBR $^{\circledR}$ Safe DNA Gel Stain (Invitrogen ${ }^{\mathrm{TM}}$ ). The gel was developed at $90 \mathrm{~V}$ for $60 \mathrm{~min}$ in a TBE (Tris-borate-EDTA, 1X) running buffer and consecutively imaged via FluorChem (Proteinsimple, Westburg, Leusden, the Netherlands) under UV excitation.

\section{Buffer capacity titration}

Buffering capacities of the polymers were determined via acid-base titration. The PAE polymer in amount equal to $5 \mathrm{mmol}$ protonable amine groups was dissolved in $\mathrm{NaCl}$ aqueous solution $(150 \mathrm{mM}, 10 \mathrm{~mL})$. The $\mathrm{pH}$ of the polymer solution was acidified to $\leq 2.0$ and the solution was titrated with $\mathrm{NaOH}$ solution $(0.1 \mathrm{M})$ using an automatic titrator (Metrohm 702 SM Tirino). As a reference, b-PEI $(25 \mathrm{kDa})$ and $\mathrm{NaCl}$ aqueous solution were titrated following the same method. The percentage of amine groups protonated from $\mathrm{pH} 5.1$ to 7.4 was defined as the buffer capacity that can be calculated from following equation: ${ }^{59}$ 


$$
\text { Buffer capacity }(\%)=\frac{\Delta \mathrm{V}_{\mathrm{NaOH}} \times 0.1 \mathrm{M}}{\mathrm{N} \mathrm{mol}} \times 100 \%
$$

wherein, $\Delta \mathrm{V}_{\mathrm{NaOH}}$ denotes $\mathrm{NaOH}$ volume required to bring the $\mathrm{pH}$ value of the polymer solution from 5.1 to 7.4 , and $\mathrm{N}$ mole $(5 \mathrm{mmol})$ denotes the total moles of protonable amine groups in PAE polymer.

\section{Cytotoxicity Assays}

Cytotoxicity of polyplexes towards COS-7 cells was evaluated through MTT assays. In 96 well plates, ca. $10^{4}$ cells were seeded per well and allowed to grow overnight in complete medium (100 $\mu \mathrm{L}$, DMEM medium supplemented with $10 \% \mathrm{FBS})$ at $37{ }^{\circ} \mathrm{C}$ under $5 \% \mathrm{CO}_{2}$ conditions to reach $60-80 \%$ confluency. The medium was replaced with fresh medium (100 $\mu \mathrm{L}$, w/o 10\% FBS). After 30 min incubation, cells were loaded with either polyplex solutions at various polymer/DNA mass ratios $(100 \mu \mathrm{L}, 0.25 \mu \mathrm{g}$ DNA per well) or HEPES buffer (20 $\mathrm{mM}, \mathrm{pH} 7.4$, supplemented with $5.0 \mathrm{wt} \%$ glucose) and incubated for an additional $1 \mathrm{~h}$. All cells were refreshed with complete warm culture medium $(100 \mu \mathrm{L})$, and cultured for another $48 \mathrm{~h}$. Half the cells untreated with polyplexes were killed by incubating in 100X triton (4\%, $10 \mu \mathrm{L}$ ) for $15 \mathrm{~min}$, while the residual half were taken as a control to set viability to $100 \%$. All cells were washed with DPBS $(100 \mu \mathrm{L})$, and successively incubated in MTT solution $(0.5 \mathrm{mg} / \mathrm{mL}, 100 \mu \mathrm{L})$ at $37^{\circ} \mathrm{C}$ under $5 \% \mathrm{CO}_{2}$ condition for $4 \mathrm{~h}$. After refreshing MTT with DMSO $(100 \mu \mathrm{L})$, the resulting formazone crystals were quantified through plate reader (Tecan Infinite M200) at wavelength $540 \mathrm{~nm}$ with reference $680 \mathrm{~nm}$. Measurements are performed in triplicate.

\section{In Vitro Transfection Efficiency}

The plasmids of pCMV-GFP and pCMV- $\Delta \mathrm{GFP}$ were respectively used as positive and negative controls. In 48 well plates, cells were seeded at a density of $1.6 \times 10^{4}$ per well (1.6 $\times 10^{4}$ cells $/ \mathrm{cm}^{2}$ ) and cultured in complete medium (DMEM with $10 \% \mathrm{FBS}, 200 \mu \mathrm{L}$ ) at 37 ${ }^{\circ} \mathrm{C}$ under humidified atmosphere with $5 \% \mathrm{CO}_{2}$ to reach confluencies of $60-80 \%$. Cells were refreshed with warm medium $(200 \mu \mathrm{L})$ with designated serum concentration, and maintained in new medium for 30 min until finally treated with polyplex solutions $(200 \mu \mathrm{L}, 0.5 \mu \mathrm{g}$ DNA per well). After $60 \mathrm{~min}$ incubation at $37^{\circ} \mathrm{C}$, the polyplexes were replaced with fresh warm complete medium $(200 \mu \mathrm{L})$, and cells were allow to grow for another $48 \mathrm{~h}$. After replacing old medium with trypsin solution $(0.25 \%, 200 \mu \mathrm{L})$, cells were spun down $(600 \mathrm{~g}, 5 \mathrm{~min}$, 
R.T.), resuspended in HBSS buffer $(200 \mu \mathrm{L})$, and measured by the FACSCalibur (BectonDickinson, Breda, the Netherlands) at an excitation wavelength of $488 \mathrm{~nm}$ and emission at $530 \mathrm{~nm}$. FACS Cellquest Software was applied to process data. A PEI (25 K)/DNA formulation prepared at its optimal condition $(\mathrm{N} / \mathrm{P}=10)$ was used as a reference.

\section{RESULTS AND DISCUSSION}

\section{Monomer and Polymer Preparation and Characterization}

In our previous study on poly(amino ether)s (PAEs) (Chapter 6), the presence of disulfide bonds into the linear PAEs was found to improve their transfection capabilities, while maintaining excellent cell viabilities. The introduction of disulfides in this case was realized by polyaddition of a disulfide-containing diglycidyl ether monomer in combination with primary amines, yielding water-soluble bioreducible PAEs. Cystamine disulfide forms branched or crosslinked structures with various diglycidyl ethers due to the twofold reactivity of each of the two primary amines present in this molecule. ${ }^{60,61}$ The resulting structures suffer from poor water solubility, impeding their application as gene vectors. In order to form linear polymers derived from cystamine disulfide, $N, N$ '-dimethylcystamine disulfide (DMC), a cystamine analogue in which both amine groups are monomethylated, was employed as the bifunctional amine monomer. Reaction of this amine with a series of diglycidyl ethers with structural variation yields water-soluble bioreducible linear PAEs that are expected to be well applicable to be explored for their efficiency as gene vectors (Scheme 2).
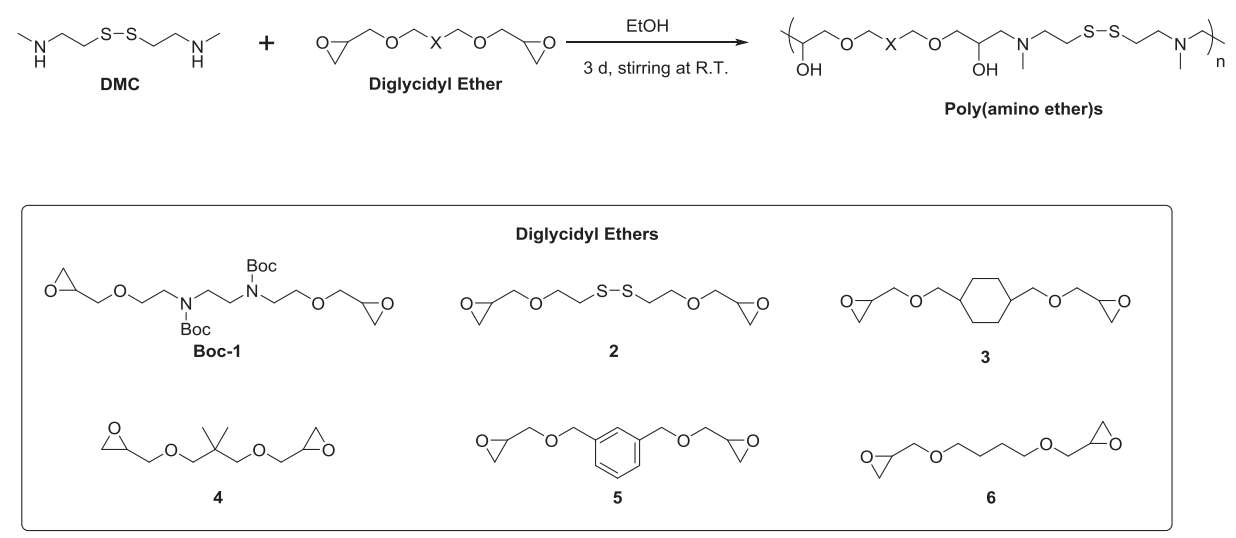

Scheme 2. Modular synthesis of bioreducible poly(amino ether)s through amine-epoxide reaction of $N, N^{\prime}-$ dimethylcystamine (DMC) with different diglycidyl ethers. 
The pool of diglycidyl ethers (DEs) consists of 6 different structures, as illustrated in Scheme 2. These are classified into 3 monomer groups: (i) high charge density (1), (ii) additional bioreducible linker (2), and (iii) varying hydrophobicity (3-6). All three factors are rationalized to play a role in transfection performance of cationic polymers. From these DEs, linear cationic PAEs were prepared by stirring the disulfide-containing amine DMC with the corresponding diglycidyl ethers in the presence of excess triethylamine. The mixtures typically became homogenous after a couple of hours and subsequently became viscous, indicating the formation polymers. No occurrence of gelation during the polymerization was observed, indicative for the formation of linear polymers. After removal of impurities and small oligomers through dialysis, the polymers were obtained in appreciable yields (ca. 33\%$45 \%)$ except in the case of polymer DMC3 (17\%) and DMC4 (14\%). The relatively low yields of these polymers can be ascribed to a possible lower purity of the corresponding diglycidyl ethers since these were used as obtained from the supplier without further purification. All polymer structures were validated by ${ }^{1} \mathrm{H}$ NMR spectroscopy. No residual epoxide signals were observed in all cases. Molecular weights of the polymers were determined through GPC and ranged from $2.5 \mathrm{kDa}$ to $4.2 \mathrm{kDa}$ with polydispersities between 1.5-2.0 (see Table 1).

Table 1. Characteristics of linear bioreducible poly(amino ether)s prepared through reaction of $N, N^{\prime}-$ dimethylcystamine (DMC) with different diglycidyl ethers (1-6).

\begin{tabular}{llllll}
\hline Poly(amino ether)s & $\begin{array}{l}\text { Yield }^{\mathrm{b}} \\
(\%)\end{array}$ & $\begin{array}{l}\mathrm{M}_{\mathrm{w}}{ }^{\mathrm{c}} \\
(\mathrm{kDa})\end{array}$ & PDI $^{\mathrm{c}}$ & $\begin{array}{l}\text { Degree } \\
\text { polymerization }^{\mathrm{c}}\left(\mathrm{X}_{\mathrm{n}}\right)\end{array}$ & $\begin{array}{l}\text { of } \\
\text { capacity }\end{array}$ \\
\hline DMC1 $\%)$
\end{tabular}

\footnotetext{
${ }^{\mathrm{a}}$ Determined by ${ }^{1} \mathrm{H}$ NMR spectroscopy; ${ }^{\mathrm{b}}$ Isolated polymer yield; ${ }^{\mathrm{c}}$ Determined by GPC; ${ }^{\mathrm{d}}$ Determined by titration, $\mathrm{pH}$ range between 5.1 and 7.4.

The obtained PAEs contain tertiary amines in their main chain that are prone to protonation in acidic milieu. Protonation not only provides positive charges to condense DNA into polyplexes, but also endues buffer capacity to facilitate endosomal escape of polyplexes
} 
through the proton sponge effect. ${ }^{62}$ To evaluate the capacity of these polymers to accept protons in the endosomal acidification range $(\mathrm{pH}$ 7.4-5.1), titration experiments were performed. The titration curves for all PAEs are displayed in Figure 1, including the titration of reference compound PEI (25 kDa) and blank $\mathrm{NaCl}$ solution $(0.15 \mathrm{M})$. Plateaus along the titration curves in the $\mathrm{pH}$ 5.1-7.4 region are observed for all PAEs, implying pronounced buffer capacities. These buffer capacities range from $34 \%$ up to $64 \%$, and are superior over PEI (18\%), a commonly employed transfection agent. Since the nitrogens of the DMC units provide the buffer capacity, ${ }^{58}$ it also confirms the successful incorporation of the disulfide units into PAEs. High buffer capacity of polymers is an excellent property to enhance endosomal escape necessary for efficient gene delivery into the cytosol.

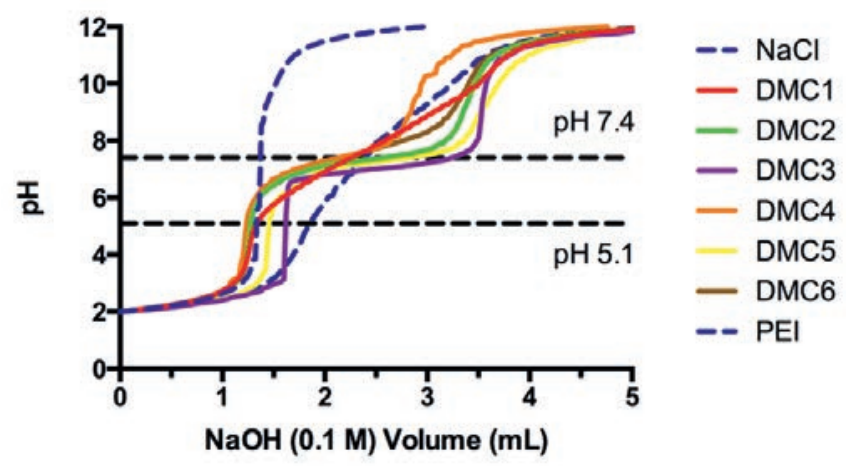

Figure 1. Titration curves of poly(amino ether)s by $\mathrm{NaOH}(0.1 \mathrm{M})$ from $\mathrm{pH} 2-12$. PEI (branched, $25 \mathrm{kDa})$ and $\mathrm{NaCl}(150 \mathrm{mM})$ are included as references.

\section{Polyplex preparation and characterization}

For efficient transfection, naked DNA requires protection by vectors, which can be realized by forming polyplexes through electrostatic interaction between DNA and cationic vectors. ${ }^{63}$ Polyplexes were prepared by combining polymer solutions of DMC1-6 with DNA solutions at mass ratio of $6,12,24$, and 48 . The resulting size and surface charge of the obtained polyplexes at these ratios are displayed in Figure 2. Polyplexes formed at polymer/DNA ratio above 6 possess hydrodynamic sizes from 80 to $200 \mathrm{~nm}$ and surface charge with zetapotentials from +20 to $+40 \mathrm{mV}$. At increasing polymer/DNA mass ratio, the polyplexes become smaller in dimension and carry increased positive charge, corresponding to more cationic PAEs recruited in the formation of these polyplexes. ${ }^{17,20,64}$ Polyplexes formed at a polymer/DNA mass ratio 6 display a relatively large size (over $400 \mathrm{~nm}$ ) and an average surface charges of $+15 \mathrm{mV}$, which is indicative for a rather loose structure. Polyplexes 
prepared from DMC1 and DMC2 have a relatively small size compared to other polymers at the same polymer/DNA ratios. This phenomenon is related to the higher cationic charged density of polymer DMC1 giving increased electrostatic interaction with DNA and the additional disulfide content of polymer DMC2 making this polymer more flexible along the main chain since the disulfide bond has a low rotational barrier. The other four polymers DMC3, DMC4, DMC5 and DMC6 form polyplexes with similar values in size and zetapotential at identical polymer/DNA mass ratios and no clear relation can be drawn between the polymer structure and the characteristics of the polyplexes here.

A

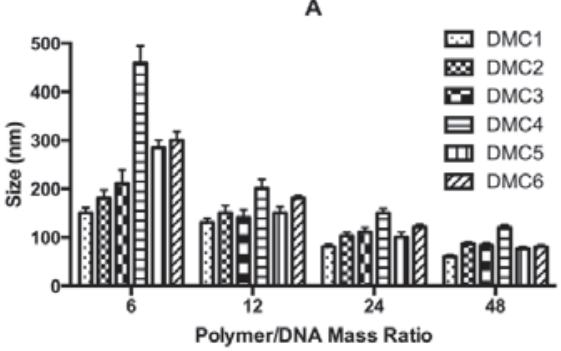

B

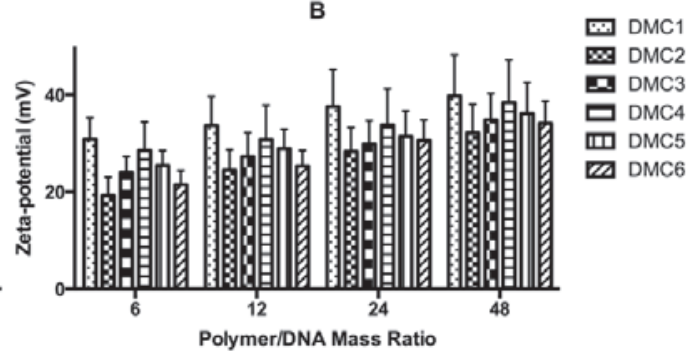

Figure 2. Characteristics of polyplexes prepared from bioreducible poly(amino ether)s and plasmid pCMVGFP under various polymer/DNA mass ratios. (A) Hydrodynamic sizes versus mass ratios; (B) Zeta-potentials versus mass ratios.

The stability of the polyplexes was validated through agarose gel electrophoresis experiments. As illustrated in Figure 3A, DNA bands did not migrate along the electric field in the case of polyplexes based on DMC1-6, indicating that DNA was fully retained by the cationic PAEs through electrostatic interactions. However, it can be expected that due to the relatively high intracellular concentration of glutathione $(\mathrm{GSH}, 2.5-10 \mathrm{mM})$ inside the cell the disulfides in the polymer chain can be cleaved resulting in disassembly of the polyplexes and release the DNA content. This biological reaction was mimicked by incubation of the polyplexes with dithiothreitol (DTT, $2.5 \mathrm{mM}$ ) as a reducing agent for $30 \mathrm{~min}$ under ambient conditions. The resulting mixtures were subsequently subjected to gel electrophoresis (see Figure 3B). These polyplexes display clear bands migrating along the electric force direction, similarly to free DNA, illustrating the release of DNA from the degraded polyplexes. Also in DLS experiments the degradation of the polyplexes under the influence of DTT could be observed. Within less than 5 min after addition of DTT to polyplexes with polymer/DNA mass ratio 48 the size increases to micrometers and the count rate drops to below $<10 \mathrm{kCps}$, which is a clear sign of degradation of the nanoparticles (data not shown). 


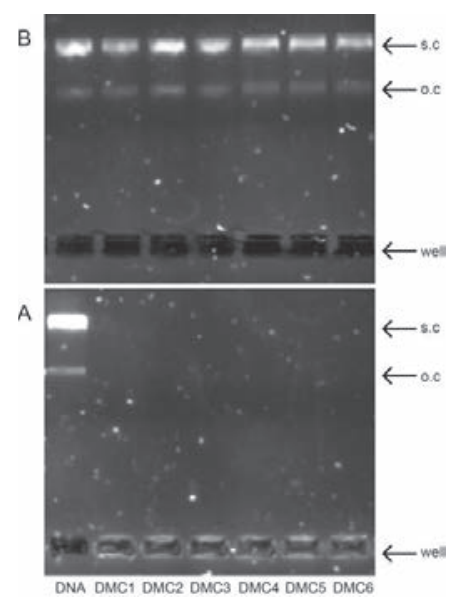

Figure 3. Agarose gel electrophoresis of polyplexes $(\mathrm{w} / \mathrm{w}=48)$ treated without DTT (A) and with DTT (B) (s.c. $=$ supercoiled, o.c. $=$ open circular $)$.

\section{Cytotoxicity of polyplexes of DMC1-6}

As for application in vivo, gene vectors require minimal toxicity and excellent biocompatibility towards cells and tissues. ${ }^{6,65}$ It is therefore important to evaluate cytotoxicity of the polyplexes before exploring their transfection performance. MTT assays were used to study cytotoxicity profiles of the polyplexes towards COS-7 cells under serumfree $(0 \%)$ and serum-present $(10 \%)$ conditions. As shown in Figure 4 , the viability of COS7 cells under serum-free conditions is above $80 \%$ when treated with polyplexes prepared at polymer/DNA ratios of 6, 12, and 24 for all polymers, except DMC1 which has the highest cationic density in the series due to the presence of extra secondary amino groups in the chain. In contrast, PEI $(25 \mathrm{~K})$ is considerably more toxic at the same polymer/DNA ratios, even under its optimal conditions as described by the manufacturer. DMC1 displays acceptable toxicity of polyplexes towards COS-7 cells at polymer/DNA ratios 6 and 12 . However, toxicity becomes more pronounced at polymer/DNA ratios $24(66 \%)$ and 48 (52\%). It is worth noting that polyplexes prepared from DMC2 exhibit even a somewhat higher viability than those prepared from the other polymers in the series. This can be attributed to the beneficial effect of the presence of extra disulfides in the polymers as it is known that the presence of these groups is beneficial for reducing cell toxicity of cationic polymers. ${ }^{36,66-68}$ Under $10 \%$ serum conditions, the cells show an increased viability; significant toxicity is only observed at polymer/DNA mass ratio 48. Importantly, the viability of COS-7 cells treated with polyplexes made of DMC2 at polymer/DNA mass ratio 
48 remains $81 \%$, indicating the promising potential of DMC2 for gene delivery under serum conditions.
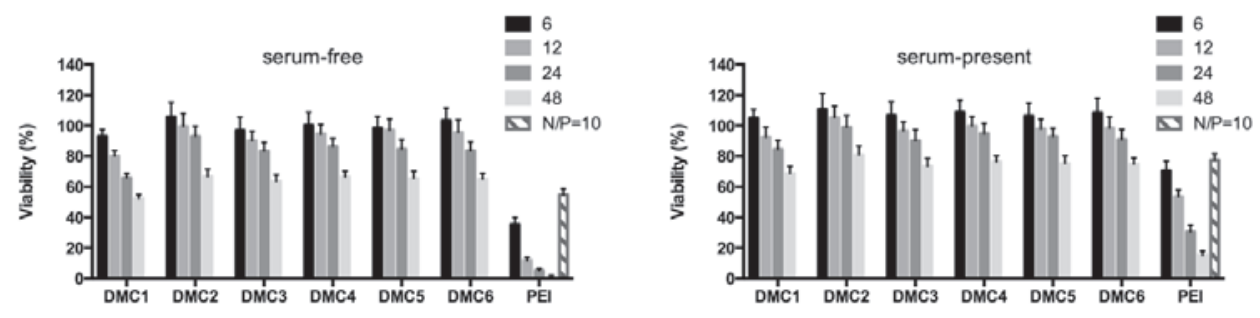

Figure 4. Cell viabilities of COS-7 cells exposed to polyplexes at different polymer/DNA mass ratios, as determined via MTT assays under $0 \%$ serum conditions (A); and $10 \%$ serum conditions (B). (PEI is incorporated for comparison).

\section{Transfection efficiency}

After evaluation of the polyplex toxicity, the transfection performance of the polyplexes at polymer/DNA ratios 6 and 12 was investigated on COS-7 cells using green fluorescent protein (GFP) as the reporter gene. Three different serum conditions $0 \%, 10 \%$, and $25 \%$ were evaluated. In all experiments, PEI was included as a reference both at the same polymer/DNA ratios, as well as at its optimal ratio $(\mathrm{N} / \mathrm{P}=10)$. Transfection efficiency was quantified by flow cytometry, as percentage of GFP-expressing cells of the total population. The results are shown in Figure 5. Under serum-free conditions, the transfection efficiencies of polyplexes prepared from PAEs at a polymer/DNA ratio 6 are similar or enhanced (12$25 \%)$ as compared to PEI (12.1\%). Transfection efficiency increases at polymer/DNA ratio 12, reaching a highest efficiency of 36\% for polyplexes based on DMC2. Relatively low transfection efficiencies are observed for DMC1, DMC4 and DMC6. This is most likely related to their lower buffer capacities as compared to polymers DMC2, DMC3, and DMC5. At polymer/DNA ratio 6, the transfection efficiencies of DMC2, DMC3, and DMC5 are $25 \%, 20 \%$, and $21 \%$, respectively, which increases to $36 \%, 26 \%$, and $29 \%$ respectively at a polymer/DNA ratio of 12 .

As illustrated in Figure 5, PAEs remain efficient in transfecting COS-7 cells with efficiency ranging from $10-32 \%$ at $10 \%$ serum, and $10-28 \%$ at $25 \%$ serum, which is considerably better than that of PEI $(2.5 \%$ at $10 \%$ serum, $1.0 \%$ at $25 \%)$. The better transfection of PAEs in the presence of serum is related to the hydroxyl groups present on the polymers causing a protein repelling effect, similar to polyethylene glycol. ${ }^{69}$ The transfection efficiency of DMC2- 
based polyplexes at polymer/DNA mass ratio 12 in the presence of $25 \%$ serum is $32 \%$ and this is even further enhanced to $50 \%$ for polyplexes with polymer/DNA mass ratio 24 with a cell viability of up to $85 \%$ (data not shown). This underlines the high potential of this disulfide-based PAEs for non-viral gene delivery in vivo.
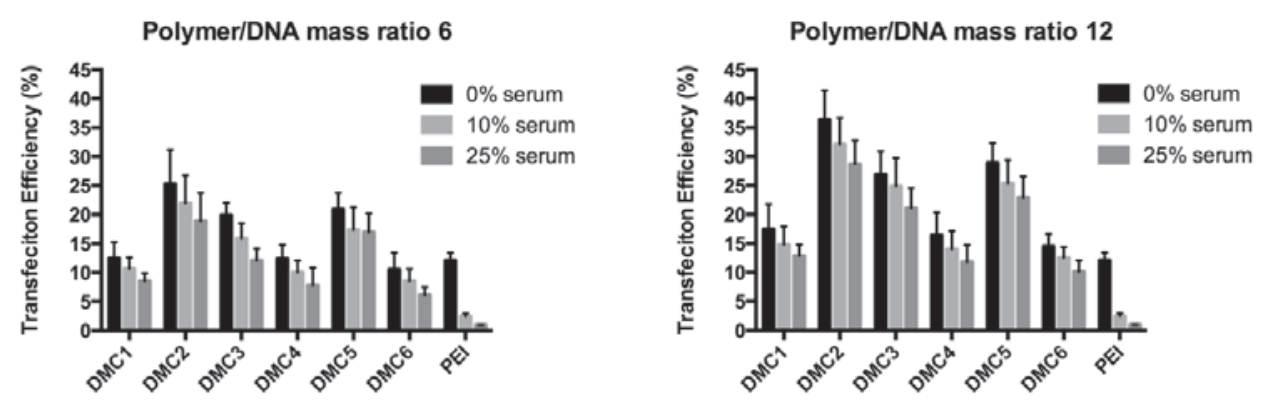

Figure 5. Transfection efficiencies of polyplexes prepared from bioreducible poly(amino ethers)s DMC1-6 and plasmid DNA at polymer/DNA mass ratios of 6 (left) and 12 (right). (PEI as reference)

\section{CONCLUSIONS}

A modular approach towards incorporation of bioreducibility into linear poly(amino ether)s was developed through reaction of $N, N^{\prime}$-dimethylcystamine with various diglycidyl ethers. The obtained PAEs have good to excellent buffer capacities ranging from $40 \%$ to $67 \%$. Upon mixing PAEs with DNA at appropriate mass ratios, polyplexes were formed with hydrodynamic diameters ranging from $80-200 \mathrm{~nm}$ and zeta-potentials of up to $+40 \mathrm{mV}$. The polyplexes displayed no significant toxicity towards COS-7 cells at polymer/DNA ratios up to 24 with transfection of COS-7 cells with notable efficiencies of up to $36 \%$. In addition, the presence of serum does not markedly interfere with transfection efficiency, even at serum concentrations of $10 \%$ and $25 \%$. All transfection efficiencies and biocompatibility profiles of PAE-based polyplexes outpace the common polymeric vector PEI (branched, $25 \mathrm{kDa}$ ). These results present a novel modular approach towards a new generation of easily accessible cationic polymers for gene and drug delivery.

\section{ACKNOWLEDGMENTS}

The work is generously supported by NanoNextNL, a micro and nanotechnology consortium of the Government of the Netherlands and 130 partners. Guoying Si thanks Dr. Karin Roelofs for assistance in cell culture and FACS measurements, and Marc Ankone for his valuable advice regarding the synthesis of DMC. 


\section{REFERENCES}

(1) Mingozzi, F.; High, K. A. Therapeutic in vivo gene transfer for genetic disease using AAV: progress and challenges. Nat. Rev. Genet. 2011, 12, 341-355.

(2) Kay, M. A. State-of-the-art gene-based therapies: the road ahead. Nat. Rev. Genet. 2011, 12, 316-328.

(3) Seow, Y.; Wood, M. J. Biological Gene Delivery Vehicles: Beyond Viral Vectors. Mol. Ther. 2009, 17, 767-777.

(4) Jones, C. H.; Chen, C. K.; Ravikrishnan, A.; Rane, S.; Pfeifer, B. A. Overcoming Nonviral Gene Delivery Barriers: Perspective and Future. Mol. Pharmaceutics 2013, 10, 4082-4098.

(5) Draghici, B.; Ilies, M. A. Synthetic Nucleic Acid Delivery Systems: Present and Perspectives. J. Med. Chem. 2015, 58, 4091-4130.

(6) Davis, M. E. Non-viral gene delivery systems. Curr. Opin. Biotech. 2002, 13, 128131.

(7) Kataoka, K.; Harashima, H. Gene delivery systems: viral vs. non-viral vectors. Adv. Drug Deliv. Rev. 2001, 52, 151-151.

(8) Miyata, K.; Nishiyama, N.; Kataoka, K. Rational design of smart supramolecular assemblies for gene delivery: chemical challenges in the creation of artificial viruses. Chem. Soc. Rev. 2012, 41, 2562-2574.

(9) Yin, H.; Kanasty, R. L.; Eltoukhy, A. A.; Vegas, A. J.; Dorkin, J. R.; Anderson, D. G. Non-viral vectors for gene-based therapy. Nat. Rev. Genet. 2014, 15, 541-555.

(10) Ahmed, M.; Narain, R. Progress of RAFT based polymers in gene delivery. Prog. Polym. Sci. 2013, 38, 767-790.

(11) Pack, D. W.; Hoffman, A. S.; Pun, S.; Stayton, P. S. Design and development of polymers for gene delivery. Nat. Rev. Drug Discov. 2005, 4, 581-593.

(12) Chu, D. S. H.; Schellinger, J. G.; Shi, J. L.; Convertine, A. J.; Stayton, P. S.; Pun, S. H. Application of Living Free Radical Polymerization for Nucleic Acid Delivery. Acc. Chem. Res. 2012, 45, 1089-1099.

(13) Tong, R.; Tang, L.; Ma, L.; Tu, C.; Baumgartner, R.; Cheng, J. Smart chemistry in polymeric nanomedicine. Chem. Soc. Rev. 2014, 43, 6982-7012.

(14) Park, K. Facing the Truth about Nanotechnology in Drug Delivery. ACS Nano 2013, 7, $7442-7447$.

(15) Farokhzad, O. C.; Langer, R. Impact of Nanotechnology on Drug Delivery. Acs Nano 2009, 3, 16-20. 
(16) Chauhan, V. P.; Jain, R. K. Strategies for advancing cancer nanomedicine. Nat. Mater. 2013, 12, 958-962.

(17) Bloomfield, V. A. DNA condensation by multivalent cations. Biopolymers 1997, 44, 269-282.

(18) Perevyazko, I. Y.; Bauer, M.; Pavlov, G. M.; Hoeppener, S.; Schubert, S.; Fischer, D.; Schubert, U. S. Polyelectrolyte Complexes of DNA and Linear PEI: Formation, Composition and Properties. Langmuir 2012, 28, 16167-16176.

(19) Meneksedag-Erol, D.; Tang, T.; Uludağ, H. Molecular modeling of polynucleotide complexes. Biomaterials 2014, 35, 7068-7076.

(20) Schaaf, P.; Schlenoff, J. B. Saloplastics: processing compact polyelectrolyte complexes. Adv. Mater. 2015, 27, 2420-2432.

(21) Midoux, P.; Breuzard, G.; Gomez, J. P.; Pichon, C. Polymer-Based Gene Delivery: A Current Review on the Uptake and Intracellular Trafficking of Polyplexes. Curr. Gene Ther. 2008, 8, 335-352.

(22) Boussif, O.; Lezoualch, F.; Zanta, M. A.; Mergny, M. D.; Scherman, D.; Demeneix, B.; Behr, J. P. A Versatile Vector for Gene and Oligonucleotide Transfer into Cells in Culture and in-Vivo - Polyethylenimine. Proc. Natl. Acad. Sci. U.S.A. 1995, 92, 7297-7301.

(23) Behr, J.-P. The Proton Sponge: a Trick to Enter Cells the Viruses Did Not Exploit. CHIMIA International Journal for Chemistry 1997, 51, 34-36.

(24) Liang, W.; Lam, J. K. W.: Endosomal Escape Pathways for Non-Viral Nucleic Acid Delivery Systems, 2012.

(25) Yu, J.; Chu, X.; Hou, Y. Stimuli-responsive cancer therapy based on nanoparticles. Chem. Commun. 2014, 50, 11614-11630.

(26) Mura, S.; Nicolas, J.; Couvreur, P. Stimuli-responsive nanocarriers for drug delivery. Nat. Mater. 2013, 12, 991-1003.

(27) Liu, Z. Z.; Zheng, M.; Meng, F. H.; Zhong, Z. Y. Non-viral gene transfection in vitro using endosomal pH-sensitive reversibly hydrophobilized polyethylenimine. Biomaterials 2011, 32, 9109-9119.

(28) Knorr, V.; Russ, V.; Allmendinger, L.; Ogris, M.; Wagner, E. Acetal linked oligoethylenimines for use as $\mathrm{pH}$-sensitive gene carriers. Bioconjugate Chem. 2008, $19,1625-1634$. 
(29) Lynn, D. M.; Anderson, D. G.; Putnam, D.; Langer, R. Accelerated discovery of synthetic transfection vectors: parallel synthesis and screening of a degradable polymer library. J. Am. Chem. Soc. 2001, 123, 8155-5156.

(30) Lynn, D. M.; Langer, R. Degradable Poly( $\beta$-amino esters): Synthesis, Characterization, and Self-Assembly with Plasmid DNA. J. Am. Chem. Soc. 2000, 122, 10761-10768.

(31) Law, B.; Tung, C. H. Proteolysis: A Biological Process Adapted in Drug Delivery, Therapy, and Imaging. Bioconjugate Chem. 2009, 20, 1683-1695.

(32) Zhu, L.; Kate, P.; Torchilin, V. P. Matrix Metalloprotease 2-Responsive Multifunctional Liposomal Nanocarrier for Enhanced Tumor Targeting. Acs Nano 2012, 6, 3491-3498.

(33) Zhu, L.; Wang, T.; Perche, F.; Taigind, A.; Torchilin, V. P. Enhanced anticancer activity of nanopreparation containing an MMP2-sensitive PEG-drug conjugate and cell-penetrating moiety. Proc. Natl. Acad. Sci. U.S.A. 2013, 110, 17047-17052.

(34) Zhu, L.; Perche, F.; Wang, T.; Torchilin, V. P. Matrix metalloproteinase 2-sensitive multifunctional polymeric micelles for tumor-specific co-delivery of siRNA and hydrophobic drugs. Biomaterials 2014, 35, 4213-4222.

(35) Stuart, M. A. C.; Huck, W. T. S.; Genzer, J.; Muller, M.; Ober, C.; Stamm, M.; Sukhorukov, G. B.; Szleifer, I.; Tsukruk, V. V.; Urban, M.; Winnik, F.; Zauscher, S.; Luzinov, I.; Minko, S. Emerging applications of stimuli-responsive polymer materials. Nat. Mater. 2010, 9, 101-113.

(36) Bauhuber, S.; Hozsa, C.; Breunig, M.; Gopferich, A. Delivery of Nucleic Acids via Disulfide-Based Carrier Systems. Adv. Mater. 2009, 21, 3286-3306.

(37) Cheng, R.; Feng, F.; Meng, F. H.; Deng, C.; Feijen, J.; Zhong, Z. Y. Glutathioneresponsive nano-vehicles as a promising platform for targeted intracellular drug and gene delivery. J. Controlled Release 2011, 152, 2-12.

(38) Lee, M. H.; Yang, Z.; Lim, C. W.; Lee, Y. H.; Dongbang, S.; Kang, C.; Kim, J. S. Disulfide-Cleavage-Triggered Chemosensors and Their Biological Applications. Chem. Rev. 2013, 113, 5071-5109.

(39) Oupicky, D.; Li, J. Bioreducible polycations in nucleic acid delivery: past, present, and future trends. Macromol. Biosci. 2014, 14, 908-922.

(40) Lin, C.; Engbersen, J. F. J. The role of the disulfide group in disulfide-based polymeric gene carriers. Expert Opin. Drug Delivery 2009, 6, 421-439. 
(41) Gosselin, M. A.; Guo, W. J.; Lee, R. J. Efficient gene transfer using reversibly crosslinked low molecular weight polyethylenimine. Bioconjugate Chem. 2001, 12, 989994.

(42) Wang, Y. X.; Chen, P.; Shen, J. C. The development and characterization of a glutathione-sensitive cross-linked polyethylenimine gene vector. Biomaterials 2006, 27, 5292-5298.

(43) Carlisle, R. C.; Etrych, T.; Briggs, S. S.; Preece, J. A.; Ulbrich, K.; Seymour, L. W. Polymer-coated polyethylenimine/DNA complexes designed for triggered activation by intracellular reduction. J. Gene Med. 2004, 6, 337-344.

(44) Lee, Y.; Mo, H.; Koo, H.; Park, J. Y.; Cho, M. Y.; Jin, G. W.; Park, J. S. Visualization of the degradation of a disulfide polymer, linear poly(ethylenimine sulfide), for gene delivery. Bioconjugate Chem. 2007, 18, 13-18.

(45) Peng, Q.; Zhong, Z. L.; Zhuo, R. X. Disulfide cross-linked polyethylenimines (PEI) prepared via thiolation of low molecular weight PEI as highly efficient gene vectors. Bioconjugate Chem. 2008, 19, 499-506.

(46) Kakizawa, Y.; Harada, A.; Kataoka, K. Environment-sensitive stabilization of coreshell structured polyion complex micelle by reversible cross-linking of the core through disulfide bond. J. Am. Chem. Soc. 1999, 121, 11247-11248.

(47) Miyata, K.; Kakizawa, Y.; Nishiyama, N.; Harada, A.; Yamasaki, Y.; Koyama, H.; Kataoka, K. Block catiomer polyplexes with regulated densities of charge and disulfide cross-linking directed to enhance gene expression. J. Am. Chem. Soc. 2004, $126,2355-2361$.

(48) McKenzie, D. L.; Smiley, E.; Kwok, K. Y.; Rice, K. G. Low molecular weight disulfide cross-linking peptides as nonviral gene delivery carriers. Bioconjugate Chem. 2000, 11, 901-909.

(49) McKenzie, D. L.; Kwok, K. Y.; Rice, K. G. A potent new class of reductively activated peptide gene delivery agents. J. Biol. Chem. 2000, 275, 9970-9977.

(50) Liu, H. M.; Wang, H.; Yang, W. J.; Cheng, Y. Y. Disulfide Cross-Linked Low Generation Dendrimers with High Gene Transfection Efficacy, Low Cytotoxicity, and Low Cost. J. Am. Chem. Soc. 2012, 134, 17680-17687.

(51) Lin, C.; Zhong, Z.; Lok, M. C.; Jiang, X.; Hennink, W. E.; Feijen, J.; Engbersen, J. F. J. Novel Bioreducible Poly(amido amine)s for Highly Efficient Gene Delivery. Bioconjugate Chem. 2007, 18, 138-145. 
(52) Yu, Z. Q.; Yan, J. J.; You, Y. Z. Synthesis of bioreducible and acid labile poly(amido amine)s via Michael-addition reactions and their application in gene delivery. $J$. Controlled Release 2011, 152, E179-E181.

(53) Ou, M.; Xu, R.; Kim, S. H.; Bull, D. A.; Kim, S. W. A family of bioreducible poly(disulfide amine)s for gene delivery. Biomaterials 2009, 30, 5804-5814.

(54) Ferruti, P. Poly(amidoamine)s: Past, present, and perspectives. J. Polym. Sci., Part A: Polym. Chem. 2013, 51, 2319-2353.

(55) Kozielski, K. L.; Tzeng, S. Y.; Green, J. J. A bioreducible linear poly(beta-amino ester) for siRNA delivery. Chem. Commun. 2013, 49, 5319-5321.

(56) Hubbell, J. A.; Langer, R. Translating materials design to the clinic. Nat. Mater. 2013, $12,963-966$.

(57) Hatakeyama, H.; Akita, H.; Harashima, H. A multifunctional envelope type nano device (MEND) for gene delivery to tumours based on the EPR effect: A strategy for overcoming the PEG dilemma. Adv. Drug Deliv. Rev. 2011, 63, 152-160.

(58) Piest, M.; Lin, C.; Mateos-Timoneda, M. A.; Lok, M. C.; Hennink, W. E.; Feijen, J.; Engbersen, J. F. J. Novel poly(amido amine)s with bioreducible disulfide linkages in their diamino-units: Structure effects and in vitro gene transfer properties. $J$. Controlled Release 2008, 130, 38-45.

(59) Zhong, Z.; Feijen, J.; Lok, M. C.; Hennink, W. E.; Christensen, L. V.; Yockman, J. W.; Kim, Y.-H.; Kim, S. W. Low Molecular Weight Linear Polyethylenimine-bpoly(ethylene glycol)-b-polyethylenimine Triblock Copolymers: Synthesis, Characterization, and in Vitro Gene Transfer Properties. Biomacromolecules 2005, 6, 3440-3448.

(60) Ferruti, P.; Marchisio, M. A.; Duncan, R. Poly(amido-amine)s: Biomedical applications. Macromol. Rapid Comm. 2002, 23, 332-355.

(61) Emilitri, E.; Ferruti, P.; Annunziata, R.; Ranucci, E.; Rossi, M.; Falciola, L.; Mussini, P.; Chiellini, F.; Bartoli, C. Novel Amphoteric Cystine-Based Poly(amidoamine)s Responsive to Redox Stimuli. Macromolecules 2007, 40, 4785-4793.

(62) Sonawane, N. D.; Szoka, F. C.; Verkman, A. S. Chloride Accumulation and Swelling in Endosomes Enhances DNA Transfer by Polyamine-DNA Polyplexes. J. Biol. Chem. 2003, 278, 44826-44831.

(63) Nguyen, D. N.; Green, J. J.; Chan, J. M.; Langer, R.; Anderson, D. G. Polymeric Materials for Gene Delivery and DNA Vaccination. Adv. Mater. 2009, 21, 847-867. 
(64) Niebel, Y.; Buschmann, M. D.; Lavertu, M.; De Crescenzo, G. Combined Analysis of Polycation/ODN Polyplexes by Analytical Ultracentrifugation and Dynamic Light Scattering Reveals their Size, Refractive Index Increment, Stoichiometry, Porosity, and Molecular Weight. Biomacromolecules 2014.

(65) Mintzer, M. A.; Simanek, E. E. Nonviral Vectors for Gene Delivery. Chem. Rev. 2009, 109, 259-302.

(66) Lin, C.; Zhong, Z.; Lok, M. C.; Jiang, X.; Hennink, W. E.; Feijen, J.; Engbersen, J. F. J. Linear poly(amido amine)s with secondary and tertiary amino groups and variable amounts of disulfide linkages: Synthesis and in vitro gene transfer properties. J. Controlled Release 2006, 116, 130-137.

(67) Lee, Y. S.; Kim, S. W. Bioreducible polymers for therapeutic gene delivery. J. Controlled Release 2014, 190, 424-439.

(68) Klein, P. M.; Wagner, E. Bioreducible polycations as shuttles for therapeutic nucleic acid and protein transfection. Antioxid. Redox Signal. 2014, 21, 804-817.

(69) Luo, X.; Huang, F.; Qin, S.; Wang, H.; Feng, J.; Zhang, X.; Zhuo, R. A strategy to improve serum-tolerant transfection activity of polycation vectors by surface hydroxylation. Biomaterials 2011, 32, 9925-9939. 


\section{Summary}

As an important element of precision medicine, gene delivery is defined as intracellular delivery of genes into cells to interfere with or promote gene expression with therapeutic or analytic purposes by means of gene carriers. Viral carriers are predominantly used in current clinical trials, owing to their high transgene competencies. However they suffer from high toxicity and immunogenicity risks, have limited gene loading capacity, and pose significant technical difficulties in manufacturing. Non-viral gene vectors, especially polymeric vectors, form a promising alternative to circumvent aforementioned problems with additional beneficiary features, such as possibilities for structural variation and modular functionalization. However, the current polymeric gene vectors are far from ideal due to poor transfection efficiencies and toxicity issues. Optimization of available polymeric vectors and the design of novel polymeric vectors for efficient and safe in vitro and in vivo transgene activities is therefore of great interest, in order to achieve clinical translation.

The background of the work covered in this thesis is presented in Chapter 1. In Chapter 2 an overview of bioreducible polycations with respect to their application in gene delivery is presented. In this chapter the basic knowledge on polycationic gene vectors and the unique features of disulfides in gene delivery is successively addressed. Then, bioreducible polymeric vectors are discussed based on different types of polycations. Finally, the perspectives on bioreducible polymeric vectors are outlined together with remarks on their potential translational capabilities. In Chapter 3 synthesis and characterization of linear disulfide-linked poly(amido amine)s (PAAs) with varying amounts of thiourea-containing flanking groups are evaluated for colloidal stability, transfection performance and cell viability. This study demonstrates that polyplexes prepared from PAAs with $10 \%$ thioureafunctionalities induced higher transfection efficiency on COS-7 cells without bringing in extra cytotoxicities as compared to PAAs without any thiourea groups at the same polymer/DNA mass ratios. Moreover these polyplexes were still able to efficiently transfect COS-7 cells in the presence of $10 \%$ serum owing to increased polyplex stability caused by hydrogen bonding between the thiourea groups of the polymer and phosphate groups in DNA. In Chapter 4, the modification of bioreducible PAAs with fluoroalkyl pendant groups is described, as well as their application as transfection agent for green fluorescent protein (GFP)-encoding gene in COS-7 cells under various serum conditions (up to 50\% serum). It was found that polyplexes of fluoroalkyl-functionalized PAAs exhibited much higher 
transfection efficiency than non-functionalized PAAs without displaying considerable cell toxicity. Significant transfection activities were observed at much lower polymer/DNA mass ratio (as low as 6), which were not dramatically diminished under serum conditions. Transfection activities induced by PAA-based polyplexes under $10 \%$ serum conditions were further improved by polyplexes stabilized via gold nanorods (GNRs) as described in

Chapter 5. Bioreducible PAAs were first coated with GNRs and then associated with DNA into hybrid polyplexes with smaller hydrodynamic diameter and higher surface charge as compared to conventional PAA polyplexes (i.e., GNRs-free polyplexes). Hybrid polyplexes exhibited enhanced colloidal stability through gold-sulfur interaction and are less susceptible to interference by serum proteins, leading to enhanced transfection efficiencies in COS-7 cells. The unique optical properties of GNRs endow hybrid polyplexes with potential in light-triggered traceable gene delivery.

In Chapter 6, the first bioreducible poly(amino ether)s (PAEs) are described as well as their application in gene delivery. PAEs with varying disulfide content were prepared through polyaddition reaction between 1-amino-4-butanol (ABOL) and epoxide mixtures comprising of 2-hydroxyethyl disulfide diglycidyl ether and 1,4-butanediol diglycidyl ether. The obtained PAEs with higher disulfide contents exhibited higher buffer capacity and induced increased transfection on COS-7 cells. The obtained PAEs were essentially non-toxic, and exhibited much higher transfection efficiency than standard PEI (25 kDa). In Chapter 7, bioreducible PAEs with various side groups were prepared through the epoxy-amine reaction. All PAEs showed higher buffer capacities as compared to PEI (25 kDa) and good DNA binding abilities with forming nanosized and positively charged polyplexes. The polyplexes prepared from pABOL, pMPA (2-morpholinoethylamine), and pAPOL (5-amino-1-pentanol) exhibited much higher transfection efficiencies than PEI (25 kDa) without compromising cell viabilities. Moreover, polyplexes of the PAEs showed potent transfection capabilities on COS-7 cells under serum conditions (up to 50\% serum), owing to the presence of abundant hydroxyl groups along the polymer chains. In Chapter 8, an alternative and sophisticated synthesis of bioreducible PAEs was designed by reaction of $N, N^{\prime}$ dimethylcystamine (DMC) with various diglycidyl ethers. The resultant PAEs displayed higher buffer capacities than PEI $(25 \mathrm{kDa})$, and are able to efficiently condense DNA into polyplexes of nanosized dimension (around $200 \mathrm{~nm}$ ). DNA was released through the disassembly of the polyplexes due to disulfide cleavage under reducing conditions, and eventually transcribed in the COS-7 cells with much higher efficiency than PEI (25 kDa). 
In conclusion, transfection efficiency of bioreducible PAAs-based polyplexes was optimized by introducing thiourea groups, fluoroalkyl groups, or GNRs. In addition, a novel class of bioreducible PAEs has been developed that show promising properties as polymeric gene vectors for translational application. The PAEs possess several beneficiary merits, such as good water solubility, possibilities for structural fine-tuning, good DNA binding ability, high buffer capacity, active DNA release by disulfide cleavage, low cytotoxicity and potent transfection capability under serum-free as well as serum-containing conditions. 



\section{Samenvatting}

Genafgifte is een belangrijk onderdeel van experimentele geneeskunde en wordt gedefinieerd als de afgifte van genen in cellen om de expressie van genen te stimuleren of te beïnvloeden met therapeutische of analytische doeleinden door gebruik te maken van gendragermaterialen. Vooral virale gen-dragermaterialen worden toegepast in klinisch onderzoek, vanwege de hoge transfectie efficiëntie. Het gebruik van virale gendragermaterialen brengt echter hoge toxiciteits- en immunogeniciteitsrisico's met zich mee. Bovendien hebben deze dragermaterialen een beperkte gen-beladingscapaciteit en is de productie van deze materialen technisch veeleisend. Niet-virale gen-dragermaterialen, en vooral polymeren, zijn een veelbelovend alternatief om de eerder genoemde problemen op te lossen. Polymeer gen-dragermaterialen bieden daarnaast meer mogelijkheden voor het aanbrengen van structurele variatie en modulaire functionalisaties. De huidige polymeer gen-dragermaterialen zijn echter verre van ideaal vanwege de lage transfectie-efficiëntie en voor sommige materialen de potentiële toxiciteit. Optimalisatie van de beschikbare polymeer gen-dragermaterialen en het ontwerpen van nieuwe materialen voor efficiënte en veilige transfectie in-vitro en in-vivo zijn daarom interessant voor een toekomstige transitie naar de kliniek.

De achtergrond van dit proefschrift wordt behandeld in Hoofdstuk 1. In Hoofdstuk 2 is een overzicht van bioreduceerbare polykationen gegeven in het licht van toepassing voor genafgifte. In dit hoofdstuk worden achtereenvolgens de basisbeginselen van polykationische materialen en de mogelijkheden van disulfidebindingen in de materialen voor genafgifte behandeld. Vervolgens worden bioreduceerbare polymeer vectoren besproken aan de hand van verschillende typen kationen. Als laatste worden de perspectieven van polymeervectoren uiteengezet met betrekking tot de mogelijkheden voor klinische toepassing van deze materialen. Hoofdstuk 3 beschrijft de synthese en karakterisering van lineaire- disulfidebevattende poly(amido amine)s (PAAs) met variërende hoeveelheden thiourea-zijgroepen, en de evaluatie van de kolloidiale stabiliteit, transfectie efficiëntie en de cel toxiciteit. Dit onderzoek toont aan dat polyplexen, gevormd met PAAs met 10\% thiourea zijgroepen, een hogere transfectie efficiëntie hebben dan PAAs zonder thiourea functionaliteit in COS-7 cellen zonder een verhoogde cel toxiciteit bij dezelfde polymeer/DNA verhoudingen. Het was bovendien mogelijk COS-7 cellen te transfecteren bij een serumconcentratie van 10\%. Dit kan worden verklaard door een verhoogde polyplex stabiliteit, veroorzaakt door 
waterstofbruggen tussen de thiourea groepen van het polymeer en de fosfaatgroepen van het DNA. In Hoofdstuk 4 worden de modificatie en toepassing van bioreduceerbare PAAs met fluoralkyl groepen beschreven voor het transfecteren van COS-7 cellen met een voor groen fluorescent proteïne (GFP) coderend gen bij variërende serumconcentraties (tot $50 \%$ ). Bij lage polymeer/massa ratio's (tot 6) werd een hoge transfectieactiviteit waargenomen, welke niet afnam bij een serumconcentratie van $10 \%$. De door PAAs geïnduceerde transfectieactiviteit werd verder verbeterd door polyplexen gestabiliseerd door gouden nanostaafjes (GNSs), zoals beschreven in Hoofdstuk 5. Op de GNSs werd eerst een PAA coating aangebracht en werden vervolgens gecomplexeerd met DNA als hybride polyplexen, welke een lager hydrodynamisch volume en een hogere oppervlaktelading bezaten dan conventionele PAA polyplexen (zonder GNSs). Door de unieke optische eigenschappen van GNSs, bieden deze hybride polyplexen perspectief voor licht-geactiveerde- en door licht detecteerbare genafgifte.

In Hoofdstuk 6 worden voor het eerst bioreduceerbaarde poly(amino ether)s (PAEs) en hun toepassing in genafgifte beschreven. PAEs, met een variërende hoeveelheid disulfidebindingen, werden gemaakt door een polyadditie tussen 1-amino-4-butanol (ABOL) en 1,4-butaandiol diglycidyl ether. De verkregen PEAs met een hoge disulfideinhoud, hadden een hogere buffercapaciteit en gaven hogere transfectiewaarden in COS-7 cellen. De verkregen PAEs waren nagenoeg niet-toxisch en lieten veel hogere transfectiewaarden zien ten opzichte van standaard poly(ethylenimine) (PEI, $25 \mathrm{kDa}$ ). De synthese van bioreduceerbare PAEs, door een epoxy-amine reactie, met verschillende zijgroepen wordt beschreven in Hoofdstuk 7. Alle PAEs bezaten een hogere buffercapaciteit dan PEI (25 kDa) en vertoonden goede bindingseigenschappen met DNA om polyplexen te vormen. Polyplexen gevormd met pABOL, pMPA (2-morpholinoethylamine) en pAPOL (5amino-1-pentanol), bezaten een veel hogere transfectie-efficiëntie dan PEI (25 kDa) en een lage cel toxiciteit. Bovendien gaven PAE polyplexen veelbelovende transfectiewaarden bij COS-7 cellen bij serumconcentraties tot 50\%, wat werd veroorzaakt door de hydroxylgroepen in het polymeer. In Hoofdstuk 8 wordt een alternatieve en verfijnde synthesemethode voor bioreduceerbare PAEs beschreven door de reactie met N,N'dimethylcystamine (DMC) met verschillende diglycidylethers. De resulterende PAEs hadden een hogere buffercapaciteit dan PEI (25 kDa) en konden DNA efficiënt condenseren in polyplexen van ongeveer $200 \mathrm{~nm}$. DNA werd afgegeven door het uiteenvallen van de polyplexen, vanwege het verbreken van de disulfidebindingen onder reducerende 
omstandigheden, en getranscribeerd in COS-7 cellen met een hogere efficiëntie dan PEI (25 $\mathrm{kDa})$.

Concluderend, de transfectie-efficiëntie van op PAA gebaseerde polyplexen is geoptimaliseerd door de introductie van thiourea, fluoralkyl of GNSs. Daarnaast is een nieuw type bioreduceerbare PAEs ontwikkeld met veelbelovende resultaten voor toepassing als vectoren voor genafgifte in translationele applicaties. De PAEs bevatten enkele goede eigenschappen, zoals goede wateroplosbaarheid, mogelijkheden voor structurele aanpassingen, goede binding met DNA, hoge buffercapaciteit, actieve DNA-afgifte bij disulfidereductie, lage cytotoxiciteit en goede transfectie-eigenschappen bij serum-vrije en serum-bevattende condities. 



\section{Acknowledgements}

My Dutch adventure comes to an epilogue, just as every story has an ending. Retrospect back, this adventure is going to be of massive impact on my future, owing to great persons who assist me arrive this exciting harvesting period and frustrating farewell moment. I would like to convey my sincere credits to them.

Johan, it's my great honor have you as my supervisor and promotor for my master and $\mathrm{PhD}$ study. I feel much obligated to your willingness to accept me as international master in your group and further offer me $\mathrm{PhD}$ position with a wonderful project directly after my master. You are always welcome all my questions, supporting my proposals, encouraging me when I was lost, tolerating my mistakes, and improving me. Your scientific insights and fruitful discussions never fail to inspire and refresh me with new ideas and fuels to advance the project. I really appreciated those conversations in your office, at the coffee table, and in your car.

As mentor and friend, Jos, thank you for your wonderful guidance and massive favors in leading me here. It's my greatest time to discuss with you on premature scientific ideas, synthetic routines for different functional molecules, and manuscript reversions. I am grateful to your teaching in how to perform column chromatography and igniting my passion for research. Moreover, your selfless passage of your experiences concerned with research and life is deeply appreciated. Last but not least, I am deeply indebted to your favors for helping moving, for driving together to various meetings.

I would like to credit Prof. dr. Ir. Wim E. Hennink, Prof. dr. Gert Storm, Prof. dr. Kevin Braeckmans, Prof. dr. Ir. J.W.M. Hilgenkamp, Prof. dr. Marcel Karperien, Dr. Sirang Manohar, and Dr. Niels Akeroyd for being members of my committee, for perceptive comments on my thesis, and for sharing their academic insights.

I would like to express my sincere gratitude to Prof. Jan Feijen for his inspiring, humorous, and encouraging conversations from the conference avenues to laboratory hallways. Especially, I am markedly owned to his time spent on my "naive" ideas and his advices on my career development. 
I would like to thank Prof. Dirk Grijpma, Prof. Gert Storm, Prof. Twan Lammers, Prof. Dimistrios Stamatialis, Prof. Joost de Bruijn, Dr. Bart Metselaar, Dr. Andre Poot, and Dr. Jai Prakash for forging and maintaining this burgeoning and viable interdisciplinary biomaterials science and technology (BST) group for me to touch multiple facets of the biomedical realm.

As for Rik Akse, thank you for your efforts to make it possible for me to follow master program of chemical engineering at university of Twente. Especially, I can never appreciate more for the financial aids during my $2^{\text {nd }}$ year in master study resulted from the efforts of you, Johan, and Dr. Ben H.L. Betlem.

I would like to express my appreciation to: Dr. Niels and Dr. Rene for fruitful discussion and conversion inside and outside the lab; Dr. Suvi and Dr. Karin for all the helps in the cell lab and discussion on the cell experiment results; Marc Ankone for the extraordinary efforts on maintaining the chemical labs, the patience for finding right equipment and chemicals, the monomer preparation for the work of Chapter 8 in this thesis, and numerous friendly conversations on culture, science, and life; Hetty for excellent AFM images of my nanoparticles and copious favors of IT support for the whole group; Lyida for your kind cell lab introduction and keeping cell lab running smoothly with full stocks; Zlata for your extensive efforts in ordering every chemical and labware, and your warmhearted familylike conversation; Anita for your supports in maintaining equipment in the chemical labs.

I would like to acknowledge the generous financial support and many valuable courses and workshops from NanoNextNL.

During this adventure, I met a lot of colleagues and students who paved my way to here. Tony, as my officemate during office time and my roommate at conference time, thank you very much for your countless favors in computers, lab administration, group research discussions as well as excellent samenvatting. Iris, your help in TEM measurements and numerous interesting conversations during our business trips concerning NanoNextNL and scientific conferences are highly appreciated. Especially, the two books, my birthday gifts contributed from you, Jos and Tony, will always not only be on the front of my bookshelf but also be cherished from inner heart. Erwin, thank you for your drive for my first scientific conference and my first Sinterklaas poem and gift. Dr. Shahriar and Dr. 
Sebastien, your insightful scientific discussions and selfless scientific experiences are always rewarding and deeply appreciated. Gert Jan, I deeply appreciate our friendship since our master assignment periods and your naming me after "Gijs". Bade, I would like to thank you for your kind accompanying for my late experiments in the evening and many interesting conversations. Wish you all the best in the future. In addition, many sincere thanks go to all my fellow colleagues from BST families, Dr. Hans, Dr. Martin, Dr, Coregory, Dr. Ackati, Dr. Sry Dewi, Pia, Rachel, Dr. Ruchi, Dr. Saleh, Amr, Jonas, Agnieszka, Praneeth, Dwi, Vincent, Karin Postma, Denys, Natalia, Bas, Frits, Mike, Asyun, Nick, Odyl, Ilaria, and Thijs, for copious helps and chats to spicy my research life.

I would like to express my thanks for my students for their exceptional works in the lab and numerous helps outside the lab together with the knowledge I learned from them. Alex, you turn out to be excellent student I came across in UT for your diligence, your talented computer skills, and your willingness to help others at your best. Thank you very much all your wonderful jobs. Christine and Kosta, thank you for have you two around the lab during my most fruitful periods and many nice dinners together. Vincent, Marcel, Anika, and Marion, for your exceptional and astonishing preparation before the practical course and your generation-themed body languages to rekindle my elapsing youth. Thank you for all my students, for the jobs we finished together, for the questions for me to improve self. Wish you all the best, both for your study and future.

As a Cancer, I never feel homesick, because I have met a lot Chinese friends who painted my dutch life. Dr. Rong Jin, Dr. Di Zhou and Xiaolin Zhang, thank you for your all helps during my tough initial period in the Netherlands. The life in Macandra accounts half of my dutch life, when I met many Chinese friends, Ir. Xinfu Xu and Danchao Hu, Yang Cui and Dr. Hanshan Cao, Dr. Tak Shing Chan, Hongxi Guo, Sheng Lv, Ir. Ning Xu, Prof. Zhen Gong, Dr. Li Liu, Dr. Jingang Qin, Dr. Chao Zhou, Dr. Lei Wang, Prof. Jiwu Lu, Changxin Liu, Weijia Li and many others. Thank you very much for all time we spent together and all your kindness. I have relocated to Campus since August 2013, and have many met many new Chinese friends: Qiang Fu, Xiechen Zhu, Yingxin Zhang, Sijia Yan, Meng Li, Jia Liang, Congnan Ye, Jia Song, and so on. It's you who made my life wonderful and colorful. Wishes you all the best for your future. During the my study period, I also pretty appreciated my friends chasing their own research niches, Honglin Chen, Rong Wang, Leilei Zhong, Dr. Hui Nie, Dr. Hairong Wu, Prof. Xiaofeng Sui, 
Kaikuan Zhang, Shanqiu Liu, Yulong Yu, Prof. Yang Shi, Dandan Li, Bo Lou, Prof. Chuanliu Wu, Dr. Mi Liu, and many others. I am deeply indebted with numerous discussions, conversations, and gossips. Wish you all the best in your career, and wish myself can abreast you in the future.

My many thanks go to my friends back home in China, Junyang (君阳), Quanquan (全权), Shixuan (世轩), Xiaojun (晓军), Wen (孙文), Xiaotao (小涛), Bo (崔波), Feng (许峰) and Liming (黎明) for our long friendship that always remains fresh and the same. Wish you all the best, guys! Sorry the absences of your many great moments. Look forwards to seeing you soon!

Last but not least, my thanks go to my all my family for their incredible understanding and supports. I would like to thank Yali Liu and Xiaobai Jiang for their trust, patience, love, inspiration, encouragement and suggestion. To my parents, Fang Zhou and Danian Si, your unconditioned support, sacrifice, tolerance and love is deeply appreciated, and has and will extend me through life's obstacles and victories. Yan, as my soulmate and lover, all my gratitude, affection, and apology is concentrated into the following poem “六月莲叶绿江 南，八月荷藕溢轻舟”. I love you, Yan!

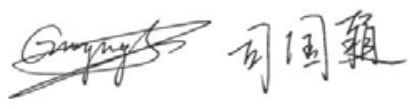

December 2015

Enschede 


\section{Curriculum Vitae}

Guoying Si (司国颖) was born on $28^{\text {th }}$ June, 1986 in Yancheng, Jiangsu province, P.R.China. In July 2005, he entered Soochow University (Suzhou, P.R. China) to study material science and engineering. In June 2009, he earned his Bachelor degree in engineering after accomplishing his bachelor assignment of "design and synthesis of efficient and safe polymeric gene vectors" under the supervision of Prof. Zhiyuan Zhong. Two month later, he came to Department of Biomedical Chemistry in University of Twente (the Netherlands) to start his master education in chemical engineering. In August 2011, he obtained his Master degree in science under supervision of Prof. dr. Johan F.J. Engbersen with the master thesis entitled "fabrication of multilayered thin film of poly(amido amine)s and calf-thymus DNA and their degradation profile in physiological conditions". From September 2011 to August 2015, he remained at the same department to commerce his $\mathrm{PhD}$ research on optimization and development of bioreducible polycations as gene vectors with research results complied in this thesis. 
